\title{
Thinking inside the box
}

Citation for published version (APA):

Deenik, J. (2019). Thinking inside the box: changing lifestyle to improve the health status of inpatients with severe mental illness. [Doctoral Thesis, Maastricht University]. ProefschriftMaken Maastricht. https://doi.org/10.26481/dis.20190522jd

Document status and date:

Published: 01/01/2019

DOI:

10.26481/dis.20190522jd

Document Version:

Publisher's PDF, also known as Version of record

\section{Please check the document version of this publication:}

- A submitted manuscript is the version of the article upon submission and before peer-review. There can be important differences between the submitted version and the official published version of record.

People interested in the research are advised to contact the author for the final version of the publication, or visit the DOI to the publisher's website.

- The final author version and the galley proof are versions of the publication after peer review.

- The final published version features the final layout of the paper including the volume, issue and page numbers.

Link to publication

\footnotetext{
General rights Owners
rights.

- You may freely distribute the URL identifying the publication in the public portal. please follow below link for the End User Agreement:

www.umlib.nl/taverne-license

Take down policy

If you believe that this document breaches copyright please contact us at:

repository@maastrichtuniversity.nl

providing details and we will investigate your claim.
}

Copyright and moral rights for the publications made accessible in the public portal are retained by the authors and/or other copyright owners and it is a condition of accessing publications that users recognise and abide by the legal requirements associated with these

- Users may download and print one copy of any publication from the public portal for the purpose of private study or research.

- You may not further distribute the material or use it for any profit-making activity or commercial gain

If the publication is distributed under the terms of Article $25 \mathrm{fa}$ of the Dutch Copyright Act, indicated by the "Taverne" license above, 
(C) copyright Jeroen Deenik, Maastricht 2019

Printing: ProefschriftMaken || www.proefschriftmaken.nl

ISBN 9789463802970

All rights reserved. No part of this publication may be reproduced, stored in a retrieval system or transmitted, in any form or by any means, electronic, mechanical, photocopying, recording or otherwise, without prior permission of the author or the copyright-owning journals for previous published chapters. 


\title{
Thinking inside the box
}

\section{Changing lifestyle to improve the health status of inpatients with severe mental illness}

\author{
PROEFSCHRIFT \\ ter verkrijging van de graad van doctor aan de Universiteit Maastricht \\ op gezag van de Rector Magnificus Prof. dr. Rianne M. Letschert \\ volgens het besluit van het College van Decanen \\ in het openbaar te verdedigen op woensdag 22 mei 2019 om 12.00 uur \\ door \\ Jeroen Deenik \\ Geboren op 14 februari 1990 te Eindhoven
}




\section{Promotor}

Prof. dr. P.N. van Harten

\section{Copromotores}

Dr. D.E. Tenback (CTP Veldzicht)

Dr. I.J.M. Hendriksen (LivIng Active)

\section{Beoordelingscommissie}

Prof. dr. Ph.A.E.G. Delespaul (voorzitter)

Prof. dr. S.P.J. Kremers

Dr. M.L.F.J. Bak

Prof. dr. W. Cahn (UMC Utrecht)

Prof dr. L. de Haan (Amsterdam UMC) 
To Iris 

and all the people staying at our hospital 


\section{C6}

And it seems ironic that we keep telling ourselves now for twenty years that we have to think outside the box.

It is impossible to think outside the box when our whole life is been boxed. It is time for us to say: 'can we think inside the box, in a different way?'.

(...) we have not gotten accustomed to doing and making changes and thinking inside the box for a change and realising that our freedom is probably already available to us inside the box.

\section{))}

RICARDO SEMLER 


\section{Contents}

Chapter 1 Background and outline of the thesis

Chapter 2 Accelerometer-measured sedentary behaviour and physical activity of inpatients with severe mental illness

Chapter 3 Physical activity and quality of life in long-term hospitalized patients with severe mental illness: a cross-sectional study

Chapter 4 Changes in physical and psychiatric health after a multidisciplinary lifestyle enhancing treatment for inpatients with severe mental illness: the MULTI study I

Chapter 5 Improved psychosocial functioning and quality of life in inpatients with severe mental illness receiving a multidisciplinary lifestyle enhancing treatment. The MULTI study II

Chapter 6 Less medication use in inpatients with severe mental illness receiving a multidisciplinary lifestyle enhancing treatment. The MULTI study III

Chapter 7 Implementation barriers and facilitators of an integrated multidisciplinary lifestyle enhancing treatment for inpatients with severe mental illness. The MULTI study IV

Chapter 8 From impact factors to real impact: translating evidence on lifestyle interventions into routine mental healthcare

Chapter 9 Summary and general discussion

Nederlandse samenvatting / Dutch summary

Valorisation

Dankwoord / Acknowledgements

Curriculum vitae 

Chapter

Background and outline of the thesis 
"If you are looking for your patient, just check the shared living room or his room", a nurse said. Indeed, there he was, sitting in the living room, together with some peers. Sitting, lying and smoking almost the whole day long. Other patients were still in bed. All of them with severe mental illness, but the vast majority of them also suffering from several serious cardiometabolic problems, such as obesity and diabetes. Some of them in direct lifethreatening conditions but, in all cases, leading to premature mortality.

\section{)}

CONVERSATION \& OBSERVATION DURING BASELINE MEASUREMENTS

Unfortunately, this is a typical situation in inpatient mental healthcare facilities for patients with severe mental illness (SMI). Patients with SMI are diagnosed mainly with schizophrenia and other psychotic disorders. Although the worldwide prevalence is low $(<1 \%)$, the burden of schizophrenia is substantial $[1,2]$. The increased risk of premature death in patients with SMI compared to the general population is well-established and reflected in a reduced life expectancy of up to 20 years [3-6], with the highest risk for inpatients [7]. Physical diseases, largely cardiometabolic diseases, account for the majority of this premature mortality [4-6, 8, 9]. Cardiometabolic risk factors are clustered within the socalled metabolic syndrome. According to a harmonized definition [10] - which was also used throughout this thesis - this includes five risk factors (see Table 1).

Table 1. Metabolic syndrome criteria, according to the harmonized definition of Alberti et al. [10]

\begin{tabular}{ll}
\hline Measure & Thresholds \\
\hline Waist circumference & men: $\geq 94 \mathrm{~cm}$; women: $\geq 80 \mathrm{~cm}$ \\
HDL cholesterol $^{a}$ & men: $<1 \mathrm{mmol} / /$; women: $<1.3 \mathrm{mmol} / \mathrm{l}$ \\
Triglycerides $^{\mathrm{a}}$ & $\geq 1.7 \mathrm{mmol} / \mathrm{l}$ \\
Blood pressure $^{a}$ & systolic $\geq 130 \mathrm{mmHg}$ and $/$ or diastolic $\geq 85 \mathrm{mmHg}$ \\
Fasting glucose $^{a}$ & $\geq 5.6 \mathrm{mmol} / \mathrm{l}$ \\
\hline
\end{tabular}

${ }^{a}$ or any drug treatment for this

One must meet at least three of these risk factors to be diagnosed with metabolic syndrome. The syndrome is highly prevalent in patients with SMI and underlies substantially the physical health problems of this population [11, 12]. For instance, based on retrospective data presented in chapter 4,69\% of the inpatients with SMI included in this study met the criteria for metabolic syndrome at baseline. This rate is twice as high as the prevalences in the general population in two Dutch samples, which were found to be $29 \%$ and $36 \%$, respectively $[13,14]$. The emergence of these risk factors in patients with $\mathrm{SMI}$ is most likely a result of a multitude of interacting factors [15]. These include: vulnerability 
in genetics [16, 17], immune-metabolic dysregulations [18]; deficient somatic care (e.g. undertreatment or underdiagnosis and poor access) [19-21]; (in)direct side effects of psychotropic medication (e.g. weight gain, movement disorders, changing food preferences) [22-25], and an unhealthy lifestyle, including smoking, low physical activity, and unhealthy dietary habits [26-31].

\section{Unhealthy lifestyle in patients with SMI}

Within this multitude of interacting factors causing metabolic syndrome and leading to early death, an unhealthy lifestyle plays a major role and yet most likely has the greatest potential to be modified. Patients with SMI do have greater frequencies of heavy smoking and high nicotine dependence than the general population [32]. They lack physical activity and spend the vast majority of their waking hours in sedentary behaviour (defined as any waking behaviour characterised by an energy expenditure $\leq 1.5$ metabolic equivalents while in a sitting, reclining or lying posture) [26-29, 33]. This behaviour was found to be associated independently with all-cause mortality and deleterious health outcomes such as cardiovascular disease and diabetes [34,35]. Also, partly as side effects of medications, there are challenges regarding dietary risks, such as eating too much due to insatiable hunger, alterations in taste and smell, high intake of processed sugary or high-fat foods, and lower resting energy expenditure [30]. In recent decades, there has been an increase in research aimed at addressing this health disparity by improving this lifestyle. Pharmacological smoking-cessation interventions have been shown to be effective, although the overall effectiveness of behavioural interventions alone remains unclear [36]. Regarding increasing physical activity, a variety of improvements were shown. Although interventions have shown to reduce cardiometabolic risk factors in SMI, evidence for the impact on anthropometric measures was inconsistent for the schizophrenia-spectrum disorder, with most effective and engaging interventions including qualified exercise professionals and higher levels of intensity [37]. In addition, improvements in global functioning [38, 39], depressive symptoms [38], psychotic symptoms [38-41], quality of life [38, 40] and cognitive functioning [42] were found. Interventions that (partly) addressed dietary risks yielded improvements in cardiometabolic risk factors, with larger effect sizes for interventions delivered by qualified professionals, as well $[43,44]$.

However, the vast majority of this evidence is based on studies on outpatients or patients undergoing short-term hospitalisations. There is a gap in the literature when it comes to inpatients who are hospitalised for an extended period of time due to the severity of their illness. However, targeting these patients is of clinical importance, as their physical health status is alarming [26, 45-47] and likely worse than that of outpatients, due to the negative associations between duration of illness and physical activity, physical health, and quality of life [29, 48-50]. Also, the hospital setting per se has been considered "obesogenic" [45,51]. A long-term stay, therefore, affects physical activity negatively 
simply by virtue of regulated inactivity. Despite the fact that the inpatient setting probably has the most potential for improving a patient's lifestyle-as the environment, meals, facilities and day-to-day schedule can be controlled-several efforts within studies and daily clinical practices failed to achieve the desired improvements $[52,53]$. Above all, it is not known whether the effects of improving physical activity and dietary habits are the same for inpatients and outpatients. For instance, the few studies on inpatients showed no effect of increased physical activity on psychotic symptoms [54, 55], while other studies showed favourable results in outpatients [38-41]. Therefore, more research on inpatients is needed to close this gap in the literature.

\section{From research to practice}

For healthcare in general, it has been estimated that it takes 17 years, on average, to integrate the results of research into practice fully, and that only $14 \%$ of the original research was translated successfully into day-to-day practice to benefit patients [56]. Although this time lag may have narrowed in recent years, such a timeframe for translating research into practice is generally considered to be too long. In addition to other factors along the so-called "research pipeline", such as transferring completed research to publication, indexing the research on bibliographic databases, inclusion in systematic reviews, and development of evidence-based guidelines, this time lag is attributed partly to challenges in dissemination and implementation [56-58].

Consistent with these findings, when it comes to improving the physical health of patients with SMI, there is much evidence published-apart from the gap regarding inpatients-but yet little change in clinical practice [59]. As Bartels [60] stated, there is currently an implementation gap rather than a knowledge gap in terms of improving the health status of patients with SMI. This implementation gap is most likely present because most of the research so far has focused on the efficacy (does it work in ideal conditions?) within randomised controlled trial designs evaluating relatively short-term goals $(<6$ months). Although such designs are suitable for evaluating efficacy, they are more likely to recruit individuals already in an advanced stage of motivation and readiness to change [60] and to be less focused on the sustainability of changed behaviour. There is currently limited evidence to support the maintenance and long-term health benefits of lifestyle interventions in patients with SMI [43]. Of the studies that have evaluated lifestyle interventions in the longer term ( $>6$ months), the majority have shown no significant effects $[43,52,55,61]$. As there is much evidence regarding the efficacy of lifestyle interventions, there is a need for a shift towards the question of how patients with SMI might include such changes in their day-to-day lives in real-world settings (effectiveness) [43, 62, 63]. This shift would meet the call for more research to identify and manage barriers to and facilitators of implementing lifestyle-related interventions and would help in 
understanding how these interventions can be delivered successfully as part of routine care while taking into consideration associated issues within these settings $[62,64]$.

\section{Outline of the thesis}

This thesis aims to address both gaps - in evidence and in implementation -in changing lifestyle to improve the health status of inpatients with SMI. Using accelerometry, we aimed to obtain reliable and valid data on sedentary behaviour and physical activity in inpatients with SMI, which we then compared with data in people without SMI (chapter 2). We also explored associations between the level of physical activity and patients' quality of life and their attitudes and self-efficacies towards physical activity (chapter 3 ). Subsequently, we evaluated a multidisciplinary lifestyle-enhancing treatment for inpatients with SMI (MULTI). MULTI was developed and implemented in routine healthcare by psychiatrists, nurses, and team leaders in collaboration with activity coordinators and a dietitian, with a focus on decreasing sedentary behaviour, increasing physical activity, and improving dietary habits. By using an observational design, we evaluated changes in sedentary behaviour, physical activity, physical health, and psychotic symptoms after 18 months compared to usual care (chapter 4). In addition to improvements in physical health, we expected that improving lifestyle could prove beneficial for more patient-oriented outcomes, as well, such as well-being. Therefore, we evaluated additionally changes in quality of life and psychosocial functioning (chapter 5). Because the (side) effects of medications - often used longer-term, in high dosage in this population-play a substantial role in physical health problems, we hypothesised that lifestyle changes might cause changes in the medication prescriptions, as well. The medications could include psychoactive medications as well as somatic medications used for co-morbid conditions. In line with this, we analysed changes in the prescribed dosage of both somatic and psychotropic medications (chapter 6 ). To address the implementation gap, we identified barriers to and facilitators of the implementation of MULTI (chapter 7) in order to create leads with which to possibly improve and further disseminate such an integrated approach. Furthermore, we stress the importance of studying the implementation and systematic uptake of effective lifestyle interventions for patients with SMI in real-world settings to improve the translation of evidence to routine clinical practice (chapter 8 ). In the final chapter (chapter 9) findings are summarised and discussed, and the chapter concludes with directions for future steps in research and clinical practice. 


\section{References}

1. Charlson FJ, Ferrari AJ, Santomauro DF, Diminic S, Stockings E, Scott JG, McGrath JJ, Whiteford HA. Global Epidemiology and Burden of Schizophrenia: Findings From the Global Burden of Disease Study 2016. Schizophr Bull. 2018.

2. Moreno-Küstner B, Martín C, Pastor L. Prevalence of psychotic disorders and its association with methodological issues. A systematic review and meta-analyses. PLoS One. 2018;13(4):e0195687.

3. Hjorth $\varnothing \mathrm{j}$ C, Sturup AE, McGrath JJ, Nordentoft M. Years of potential life lost and life expectancy in schizophrenia: a systematic review and meta-analysis. The Lancet Psychiatry. 2017;4(4):295-301.

4. Piotrowski P, Gondek TM, Krolicka-Deregowska A, Misiak B, Adamowski T, Kiejna A. Causes of mortality in schizophrenia: An updated review of European studies. Psychiatr Danub. 2017;29(2):108-120.

5. Tanskanen A, Tiihonen J, Taipale H. Mortality in schizophrenia: 30-year nationwide follow-up study. Acta Psychiatr Scand. 2018.

6. Walker ER, McGee RE, Druss BG. Mortality in Mental Disorders and Global Disease Burden Implications A Systematic Review and Meta-analysis. Jama Psychiatry. 2015;72(4):334-341.

7. John A, McGregor J, Jones I, Lee SC, Walters JTR, Owen MJ, O'Donovan M, DelPozo-Banos M, Berridge D, Lloyd K. Premature mortality among people with severe mental illness - New evidence from linked primary care data. Schizophr Res. 2018;199:154-162.

8. Correll CU, Solmi M, Veronese N, Bortolato B, Rosson S, Santonastaso P, Thapa-Chhetri N, Fornaro M, Gallicchio D, Collantoni E et al. Prevalence, incidence and mortality from cardiovascular disease in patients with pooled and specific severe mental illness: a large-scale meta-analysis of 3,211,768 patients and 113,383,368 controls. World Psychiatry. 2017;16(2):163-180.

9. Laursen TM, Wahlbeck K, Hallgren J, Westman J, Osby U, Alinaghizadeh H, Gissler M, Nordentoft M. Life expectancy and death by diseases of the circulatory system in patients with bipolar disorder or schizophrenia in the Nordic countries. PLoS One. 2013;8(6):e67133.

10. Alberti KGMM, Eckel RH, Grundy SM, Zimmet PZ, Cleeman JI, Donato KA, Fruchart JC, James WPT, Loria CM, Smith SC. Harmonizing the metabolic syndrome: A joint interim statement of the international diabetes federation task force on epidemiology and prevention; National heart, lung, and blood institute; American heart association; World heart federation; International atherosclerosis society; And international association for the study of obesity. Circulation. 2009;120(16):1640-1645.

11. Stubbs B, Vancampfort D, De Hert M, Mitchell AJ. The prevalence and predictors of type two diabetes mellitus in people with schizophrenia: a systematic review and comparative meta-analysis. Acta Psychiatr Scand. 2015;132(2):144-157.

12. Vancampfort D, Stubbs B, Mitchell AJ, De Hert M, Wampers M, Ward PB, Rosenbaum S, Correll CU. Risk of metabolic syndrome and its components in people with schizophrenia and related psychotic disorders, bipolar disorder and major depressive disorder: a systematic review and meta-analysis. World Psychiatry. 2015;14(3):339-347.

13. Agyemang C, Kunst AE, Bhopal R, Zaninotto P, Nazroo J, Unwin N, van Valkengoed I, Redekop WK, Stronks K. A cross-national comparative study of metabolic syndrome among non-diabetic Dutch and English ethnic groups. Eur J Public Health. 2013;23(3):447-452.

14. Agyemang C, van Valkengoed IG, van den Born BJ, Bhopal R, Stronks K. Heterogeneity in sex differences in the metabolic syndrome in Dutch white, Surinamese African and South Asian populations. Diabet Med. 2012;29(9):1159-1164.

15. Penninx BWJH, Lange SMM. Metabolic syndrome in psychiatric patients: overview, mechanisms, and implications. Dialogues Clin Neurosci. 2018;20(1):63-73.

16. Amare AT, Schubert KO, Klingler-Hoffmann M, Cohen-Woods S, Baune BT. The genetic overlap between mood disorders and cardiometabolic diseases: a systematic review of genome wide and candidate gene studies. Translational psychiatry. 2017;7(1):e1007. 
17. Malan-Muller S, Kilian S, van den Heuvel LL, Bardien S, Asmal L, Warnich L, Emsley RA, Hemmings SM, Seedat S. A systematic review of genetic variants associated with metabolic syndrome in patients with schizophrenia. Schizophr Res. 2016;170(1):1-17.

18. Lopresti AL, Drummond PD. Obesity and psychiatric disorders: commonalities in dysregulated biological pathways and their implications for treatment. Prog Neuropsychopharmacol Biol Psychiatry. 2013;45:92-99.

19. Lawrence D, Kisely S. Inequalities in healthcare provision for people with severe mental illness. Journal of Psychopharmacology (Oxford, England). 2010;24(4_supplement):61-68.

20. Mitchell A, Lord O, Malone D. Differences in the prescribing of medication for physical disorders in individuals with v. Without mental illness: meta-analysis. Br J Psychiatry. 2012;201(6):435 - 443.

21. Swildens W, Termorshuizen F, de Ridder A, Smeets H, Engelhard IM. Somatic Care with a Psychotic Disorder. Lower Somatic Health Care Utilization of Patients with a Psychotic Disorder Compared to Other Patient Groups and to Controls Without a Psychiatric Diagnosis. Adm Policy Ment Health. 2016;43(5):650662.

22. Correll CU, Detraux J, De Lepeleire J, De Hert M. Effects of antipsychotics, antidepressants and mood stabilizers on risk for physical diseases in people with schizophrenia, depression and bipolar disorder. World Psychiatry. 2015;14(2):119-136.

23. Kahl KG, Westhoff-Bleck M, Kruger THC. Effects of psychopharmacological treatment with antipsychotic drugs on the vascular system. Vascul Pharmacol. 2017.

24. Solmi M, Murru A, Pacchiarotti I, Undurraga J, Veronese N, Fornaro M, Stubbs B, Monaco F, Vieta E, Seeman MV et al. Safety, tolerability, and risks associated with first- and second-generation antipsychotics: a state-of-the-art clinical review. Ther Clin Risk Manag. 2017;13:757-777.

25. Verhaegen AA, Van Gaal LF. Drug-induced obesity and its metabolic consequences: a review with a focus on mechanisms and possible therapeutic options. J Endocrinol Invest. 2017;40(11):1165-1174.

26. Stubbs B, Chen LJ, Chung MS, Ku PW. Physical activity ameliorates the association between sedentary behavior and cardiometabolic risk among inpatients with schizophrenia: A comparison versus controls using accelerometry. Compr Psychiatry. 2017;74:144-150.

27. Stubbs B, Firth J, Berry A, Schuch FB, Rosenbaum S, Gaughran F, Veronesse N, Williams J, Craig T, Yung AR et al. How much physical activity do people with schizophrenia engage in? A systematic review, comparative meta-analysis and meta-regression. Schizophr Res. 2016;176(2-3):431-440.

28. Stubbs B, Williams JE, Gaughran F, Craig T. How sedentary are people with psychosis? A systematic review and meta-analysis. Schizophr Res. 2016;171(1-3):103-109.

29. Vancampfort D, Probst M, Scheewe T, De Herdt A, Sweers K, Knapen J, van Winkel R, De Hert M. Relationships between physical fitness, physical activity, smoking and metabolic and mental health parameters in people with schizophrenia. Psychiatry Res. 2013;207(1-2):25-32.

30. Teasdale SB, Samaras K, Wade T, Jarman R, Ward PB. A review of the nutritional challenges experienced by people living with severe mental illness: a role for dietitians in addressing physical health gaps. J Hum Nutr Diet. 2017;30(5):545-553.

31. Heald A, Pendlebury J, Anderson S, Narayan V, Guy M, Gibson M, Haddad P, Livingston M. Lifestyle factors and the metabolic syndrome in Schizophrenia: a cross-sectional study. Annals of General Psychiatry. 2017;16:12.

32. de Leon J, Diaz FJ. A meta-analysis of worldwide studies demonstrates an association between schizophrenia and tobacco smoking behaviors. Schizophr Res. 2005;76(2-3):135-157.

33. Tremblay MS, Aubert S, Barnes JD, Saunders TJ, Carson V, Latimer-Cheung AE, Chastin SFM, Altenburg TM, Chinapaw MJM. Sedentary Behavior Research Network (SBRN) - Terminology Consensus Project process and outcome. Int J Behav Nutr Phys Act. 2017;14(1):75.

34. Biswas A, Oh PI, Faulkner GE, Bajaj RR, Silver MA, Mitchell MS, Alter DA. Sedentary Time and Its Association With Risk for Disease Incidence, Mortality, and Hospitalization in Adults A Systematic Review and Metaanalysis. Ann Intern Med. 2015;162(2):123-132.

35. Brocklebank LA, Falconer CL, Page AS, Perry R, Cooper AR. Accelerometer-measured sedentary time and cardiometabolic biomarkers: A systematic review. Prev Med. 2015;76:92-102. 
36. Peckham E, Brabyn S, Cook L, Tew G, Gilbody S. Smoking cessation in severe mental ill health: what works? an updated systematic review and meta-analysis. BMC Psychiatry. 2017;17(1):252.

37. Stubbs B, Vancampfort D, Hallgren M, Firth J, Veronese N, Solmi M, Brand S, Cordes J, Malchow B, Gerber $M$ et al. EPA guidance on physical activity as a treatment for severe mental illness: a meta-review of the evidence and Position Statement from the European Psychiatric Association (EPA), supported by the International Organization of Physical Therapists in Mental Health (IOPTMH). Eur Psychiatry. 2018;54:124144.

38. Dauwan M, Begemann MJH, Heringa SM, Sommer IE. Exercise improves clinical symptoms, quality of life, global functioning, and depression in schizophrenia: A systematic review and meta-analysis. Schizophr Bull. 2016;42(3):588-599.

39. Firth J, Cotter J, Elliott R, French P, Yung AR. A systematic review and meta-analysis of exercise interventions in schizophrenia patients. Psychol Med. 2015;45(7):1343-1361.

40. Rosenbaum S, Tiedemann A, Sherrington C, Curtis J, Ward PB. Physical activity interventions for people with mental illness: a systematic review and meta-analysis. J Clin Psychiatry. 2014;75(9):964-974.

41. Vera-Garcia E, Mayoral-Cleries F, Vancampfort D, Stubbs B, Cuesta-Vargas AI. A systematic review of the benefits of physical therapy within a multidisciplinary care approach for people with schizophrenia: An update. Psychiatry Res. 2015;229(3):828-839.

42. Firth J, Stubbs B, Rosenbaum S, Vancampfort D, Malchow B, Schuch F, Elliott R, Nuechterlein KH, Yung AR. Aerobic Exercise Improves Cognitive Functioning in People With Schizophrenia: A Systematic Review and Meta-Analysis. Schizophr Bull. 2017;43(3):546-556.

43. Naslund JA, Whiteman KL, McHugo GJ, Aschbrenner KA, Marsch LA, Bartels SJ. Lifestyle interventions for weight loss among overweight and obese adults with serious mental illness: A systematic review and metaanalysis. Gen Hosp Psychiatry. 2017;47:83-102.

44. Teasdale SB, Ward PB, Rosenbaum S, Samaras K, Stubbs B. Solving a weighty problem: systematic review and meta-analysis of nutrition interventions in severe mental illness. The British Journal of Psychiatry. 2017;210(2):110-118.

45. Ringen PA, Engh JA, Birkenaes AB, Dieset I, Andreassen OA. Increased mortality in schizophrenia due to cardiovascular disease - a non-systematic review of epidemiology, possible causes, and interventions. Frontiers in psychiatry. 2014;5:137-137.

46. Ringen PA, Faerden A, Antonsen B, Falk RS, Mamen A, Rognli EB, Solberg DK, Andreassen OA, Martinsen EW. Cardiometabolic risk factors, physical activity and psychiatric status in patients in long-term psychiatric inpatient departments. Nordic journal of psychiatry. 2018:1-7.

47. Tenback DE, Van Kessel F, Jessurun J, Pijl YJ, Heerdink ER, Van Harten PN. Risk factors for inactivity in patients in long-term care with severe mental illness. Tijdschrift voor Psychiatrie. 2013;55(2):83-91.

48. Mitchell AJ, Vancampfort D, Sweers K, van Winkel R, Yu W, De Hert M. Prevalence of metabolic syndrome and metabolic abnormalities in schizophrenia and related fisorders - A systematic review and meta-analysis. Schizophr Bull. 2013;39(2):306-318.

49. Vancampfort D, Firth J, Schuch FB, Rosenbaum S, Mugisha J, Hallgren M, Probst M, Ward PB, Gaughran F, De Hert $\mathrm{M}$ et al. Sedentary behavior and physical activity levels in people with schizophrenia, bipolar disorder and major depressive disorder: a global systematic review and meta-analysis. World Psychiatry. 2017;16(3):308-315.

50. Vancampfort D, Guelinckx H, Probst M, Stubbs B, Rosenbaum S, Ward PB, De Hert M. Health-related quality of life and aerobic fitness in people with schizophrenia. Int J Ment Health Nurs. 2015;24(5):394-402.

51. Faulkner GE, Gorczynski PF, Cohn TA. Psychiatric illness and obesity: recognizing the "obesogenic" nature of an inpatient psychiatric setting. Psychiatr Serv. 2009;60(4):538-541.

52. Looijmans A, Stiekema A, Bruggeman R, van der Meer L, Stolk RP, Schoevers RA, Jörg F, Corpeleijn E. Changing the obesogenic environment to improve cardiometabolic health in residential patients with a severe mental IIIness: ELIPS, a randomized controlled trial. Br J Psychiatry. 2017;211(5):296-303.

53. Levitt GA, Shinault K, Patterson S, Otaluka O. Weight Gain in Psychiatric Inpatients: Are Interventions Making a Positive Impact? Prim Care Companion CNS Disord. 2017;19(4):17m02111. 
54. Heggelund J, Nilsberg GE, Hoff J, Morken G, Helgerud J. Effects of high aerobic intensity training in patients with schizophrenia: a controlled trial. Nordic journal of psychiatry. 2011;65(4):269-275.

55. Stiekema APM, Looijmans A, van der Meer L, Bruggeman R, Schoevers RA, Corpeleijn E, Jorg F. Effects of a lifestyle intervention on psychosocial well-being of severe mentally ill residential patients: ELIPS, a cluster randomized controlled pragmatic trial. Schizophr Res. 2018.

56. Balas EA, Boren SA: Managing clinical knowledge for health care improvement. In: Yearbook of medical informatics 2000: patient-centered system. Edited by Bemmel J, McCray AT. Stutgart: Schattauer; 2000 : 65-70.

57. Green LW, Ottoson JM, Garcia C, Hiatt RA. Diffusion theory and knowledge dissemination, utilization, and integration in public health. Annu Rev Public Health. 2009;30:151-174.

58. Trochim W, Kane C, Graham MJ, Pincus HA. Evaluating translational research: a process marker model. Clin TransI Sci. 2011;4(3):153-162.

59. Stewart R. Mental disorders and mortality: so many publications, so little change. Acta Psychiatr Scand. 2015;132(5):410-411.

60. Bartels SJ. Can behavioral health organizations change health behaviors? The STRIDE study and lifestyle interventions for obesity in serious mental illness. Am J Psychiatry. 2015;172(1):9-11.

61. Jakobsen AS, Speyer H, Norgaard HCB, Karlsen M, Birk M, Hjorthoj C, Mors O, Krogh J, Gluud C, Pisinger C et al. Effect of lifestyle coaching versus care coordination versus treatment as usual in people with severe mental illness and overweight: Two-years follow-up of the randomized CHANGE trial. PLoS One. 2017;12(10):e0185881.

62. Liu NH, Daumit GL, Dua T, Aquila R, Charlson F, Cuijpers P, Druss B, Dudek K, Freeman M, Fujii C et al. Excess mortality in persons with severe mental disorders: a multilevel intervention framework and priorities for clinical practice, policy and research agendas. World Psychiatry. 2017;16(1):30-40.

63. Vancampfort D, Stubbs B, Ward PB, Teasdale S, Rosenbaum S. Why moving more should be promoted for severe mental illness. The lancet Psychiatry. 2015;2(4):295.

64. Ward PB, Firth J, Rosenbaum S, Samaras K, Stubbs B, Curtis J. Lifestyle interventions to reduce premature mortality in schizophrenia. The lancet Psychiatry. 2017;4(7):e14. 



\section{Chapter}

\section{Accelerometer-measured sedentary behaviour and physical activity of inpatients with severe mental illness}

Kruisdijk, F.R., Deenik, J., Tenback, D.E., Tak, E.C.P.M., Beekman, A.T.F., van Harten, P.N., Hopman-Rock, M., Hendriksen, I.J.M.

Psychiatry Research 2017; 254: 67-74 doi: 10.1016/j.psychres.2017.04.035 


\section{Abstract}

Sedentary behaviour and lack of physical activity threatens health. Research concerning these behaviours of inpatients with severe mental illness is limited but urgently needed to reveal prevalence and magnitude. In total, 184 inpatients (men $n=108$, women $n=76$, mean age 57,4, 20\% first generation antipsychotics, $40 \%$ second generation antipsychotics, $43 \%$ antidepressants, mean years hospitalisation 13 years), with severe mental illness of a Dutch psychiatric hospital wore an accelerometer for five days to objectively measure total activity counts per hour and percentages in sedentary behaviour, light intensity physical activity and moderate to vigorous physical activity. Accelerometer data were compared with data of 54 healthy ward employees. Patients showed significantly less activity counts per hour compared to employees ( $p=0.02$ ), although the differences were small ( $d=0.32$ ). Patients were sedentary during $84 \%$ of the wear time ( $50 \mathrm{~min} / \mathrm{h}$ ), spend $10 \%$ in light intensity physical activity and $6 \%$ in moderate to vigorous physical activity. Age was the only significant predictor, predicting less total activity counts/h in higher ages. Decreasing sedentary behaviour and improving physical activity in this population should be a high priority in clinical practice. 


\section{Introduction}

Recent epidemiological studies have shown that sedentary behaviour - defined as any waking behaviour in a sitting or reclining posture costing $\leq 1.5$ times the basal metabolic rate [1] - is a major independent lifestyle risk factor for increased mortality and the development of cardiovascular disease, diabetes, obesity and cancer [2,3]. Compared to the general population, patients with severe mental illness have an even higher risk of premature mortality and morbidity caused by cardiovascular disease and diabetes [4]: their life expectancy is 15-30 years lower and their risk of dying is 2.2 times higher. This mortality gap associated with mental illness has widened in recent decades [5]. Risk factors for common health problems that underlie the abovementioned increased mortality are clustered in the metabolic syndrome, which is highly prevalent in this population [6]. In addition to management of weight and dietary habits, the level of physical activity is an important factor for reducing these risk factors [7].

In the Netherlands, an estimated 107.000 patients have severe mental illness, of which 27.000 are permanent residents of a hospital or sheltered living environment [8]. The latter group, but probably even more patients, are likely at risk for the above-mentioned health problems. To develop interventions that may improve health and reduce mortality, insight into the prevalence of sedentary behaviour and physical activity in patients with severe mental illness is essential [9].

More data on the prevalence of physical activity and sedentary behaviour, which is a distinctly different behaviour than physical inactivity [1], is being acquired about patients with severe mental illness [7, 10]. Until 2016, however, most research into sedentary behaviour and physical activity in this population included only outpatients, and the few published studies on inpatients included only patients with a relatively short stay, had a small number of participants, did not use a control group (except for one study), and generally used self-report questionnaires for sedentary behaviour and physical activity [11]. These self-report questionnaires have shown limited reliability and tend to underestimate the amount of sedentary behaviour [12] and overestimate physical activity [13]. In addition, co-morbid cognitive problems in patients with severe mental illness [14] may cause an impairment of memory, influencing reproduction of their activities and thus limiting the self-reported registration of their behaviour.

To overcome the limitations of self-reporting, objective measurement of sedentary behaviour and physical activity by accelerometry offers valid and reliable registration and is now the preferred option $[12,15]$. In the current study, a majority of subjects were inpatients with severe mental illness, mainly schizophrenia, and we measured sedentary behaviour and physical activity objectively by means of accelerometry.

To date, little research has been performed in this population using accelerometry. Data on a comparable inpatient population, published by Chen [16] and Stubbs [17], suggested that higher levels of sedentary behaviour and physical inactivity were independently associated with worse performance across several cognitive domains. Our 
current study, which included a more invalidated and hospitalized population than the abovementioned studies, may enhance the knowledge about activity and inactivity in the inpatient population and can lead to validation of measurement methods.

\section{Methods}

\section{Participants}

All subjects were inpatients on long-term psychiatric wards at a psychiatric hospital in the Netherlands. Patients were eligible if hospitalized for at least one year with a treatment history of at least two years. To ensure that the sample was representative of day-to-day clinical practice, the following exclusion criteria were used: insufficient knowledge of Dutch language, a severe psychiatric or physical condition that prevented accelerometer measurement or being unable to provide informed consent.

A comparison group of employees was formed, because comparing our patient data with published studies was difficult due to a lack of consensus about settings and data processing [18]. We included as many of the 80 available employees of the institution as possible. Exclusion criteria were: working nightshifts or insufficient knowledge of Dutch. The group was mixed in terms of gender, age and profession.

\section{Procedure}

Participants were asked to wear an accelerometer (ActiGraph GT3X+) for five consecutive days (Wednesday morning to Sunday evening), except while sleeping or during water activities. Ward nurses were instructed on registration procedures, on managing the wearing time of the accelerometers and were asked to complete a short questionnaire about the physical inactivity level of each patient (inactivity-subscale of the NOSIE: Nurses' Observation Scale for Inpatient Evaluation) [19]. Patients were instructed verbally per ward by JD ( $N \approx 25$ wards of 10 patients each) and were told about the background of the research, the procedures and the measurement method. Their informed consent was requested, leaving patients free to refuse participation. Employees in the comparison group were instructed individually by JD and also received a written instruction-guide. The comparison group was measured using the same procedures as the patient group. The Netherlands Central Committee on Research Involving Human Subjects (CCMO) stated that no further ethical approval was necessary due to the minimal impact on patients of wearing an accelerometer for five days. 


\section{Measurements}

Demographic variables (gender and age), Body Mass Index (BMI) and disease-characteristics (years of hospitalisation, diagnosis, illness severity and use of antipsychotics and antidepressants) were derived retrospectively from electronic patient records. Diagnoses were classified according to the DSM-IV-TR into three main groups: schizophrenia/other psychotic disorders, personality disorders and affective disorders. Incidental diagnoses were categorized as 'other disorders', such as substance-related diagnosis. Mood disorders were split into depression and bipolar, assuming more physical activity in (hypo)manic state. Antipsychotics were split into first generation, second generation or both. This is due to the differing effects these medications may have on physical activity: movement disorders are generally associated with first-generation antipsychotics, while metabolic side effects are associated with the second-generation [20].

Severity of illness was measured by the Dutch version of the severity scale from the Clinical Global Impression Scale [CGI, 21], consisting of one item (global severity of disease), rated by the psychiatrist from 1 (not at all ill) to 7 (extremely ill) [22]. In the comparison group, only data on gender and age were collected. Sedentary behaviour and physical activity were measured by ActiGraph GT3X+ accelerometers (ActiGraph, Pensacola, Florida, VS) and analysed with ActiLife 6.8.0 software (same manufacturer). The accelerometers were worn on the right hip, and were held in place with an elastic strap between two belt loops or were placed in a small pouch that was pinned up on the same place. The ActiGraphs used firmware version 3.2.1, and accelerometer data were sampled at $100 \mathrm{~Hz}$ in order to obtain detailed data and prevent vigorous activity to be eliminated in data-processing, which may happen at lower sampling frequencies [23]. Data were downloaded at a user-specified time interval (epoch) of 1 second (1s) [24]. To avoid major data drop out, a wear time of more than six hours/day for at least three days was used as the criterion for a valid measurement. Periods with zero counts of 90 minutes or more, were defined as non-wear time [25].

We used the data of the Vector Magnitude variable, combining the data from all three axes, which appears to be more accurate than data from the vertical axis only [26]. Due to the previously mentioned lack of consensus about settings and data-processing in accelerometry measurement, we decided to use total activity counts per day, which had been suggested as a complementary outcome and potential standard for better comparability [15]. Patients' irregular daily rhythm and expected variance in wear time complicated the definition of a 'day'. Therefore, total activity counts/hour were calculated and percentage of valid wear time in sedentary behaviour (< 150 counts/min), light intensity physical activity (151 - 3207 counts/min) and moderate to vigorous physical activity ( $\geq$ 3208 counts/min) were reported [26]. For patients older than 65 years, the cut-off point for moderate to vigorous physical activity was fixed at $\geq 2751$ counts/min. Total activity counts/hour was used in the statistical analysis as continuous variable representing total activity. To compare patients' data, the same timeframe was used for each dataset: 09.00 
a.m. till 10.00 p.m. Data from the comparison group was processed with the same settings and criteria. The GT3X+ has a high inter- and intra-instrumental reliability and validity [27-29]. The inactivity-subscale of the Nurse Observation Scale for Inpatient Evaluation, Dutch version [NOSIE; 19] reflects the nurse's opinion about the level of physical inactivity of each patient, scoring inactivity behaviours and motor retardation in four items, on a scale from 0 (never) to 4 (always). The summed score of the four items is the main variable, with a range from 0 (no inactivity) to 16 (severe). The NOSIE shows a good inter-rater reliability [30] and a Cronbach's alpha of .64 in the present study.

\section{Data analysis}

All statistical tests were conducted using SPSS version 21.0 [31] and interpreted at 0.05 two-tailed significance level, unless noted otherwise. Continuous variables were examined for normality and homogeneity by comparing means with medians and standard deviations and by analysing frequency histograms and normality plots. If the assumption of normal distribution was violated, data was bootstrapped using 1000 samples with $95 \%$ confidence intervals, bias-corrected and accelerated [32]. Descriptive analyses were performed on each of the study variables. To check for differences between groups (participants/dropouts, attachment of accelerometers, men/women and patients/comparisons), independent t-tests and chi-square tests were conducted on continuous and categorical variables. For further analysis with categorical variables (diagnosis and medication), dummy variables were used. Therefore, the variables 'other diagnosis' and 'both generations antipsychotics' were the reference groups for diagnoses and medication types, respectively. Analysis of covariance (ANCOVA) was conducted to control for gender and age between patients and comparisons. Pearson correlations were calculated to assess bivariate associations between sedentary behaviour, physical activity and demographic and disease characteristics, and between sedentary behaviour, physical activity and the nurse-rated inactivity scores (0.05 two-tailed significance level). Hierarchical regression analyses (method Enter) were used to assess the degree to which demographic and disease characteristics could explain the variance in total activity counts/hour. In order to control for the method of attachment of the accelerometers, this was entered in the model first.

Demographic and disease characteristics were added into the second model. In the regression analysis, homogeneity and linearity were examined by scatterplots. Multicollinearity was examined by correlation coefficients and collinearity statistics (tolerance and VIF values). 


\section{Results}

\section{Sample}

A total of 251 patients were eligible for the study, of which 16 were excluded because they were unable to give informed consent due to severe psychosis. Of the remaining 235 patients, 26 patients were not included for various reasons: refusal to sign informed consent $(n=24)$, removal $(n=1)$, bedridden patient $(n=1)$. This left 209 patients who were accelerometer registered. Of this group 23 were excluded from analysis due to incomplete data $(n=4)$ and inadequate wearing time $(n=19)$. The 184 remaining patients (response rate $=73 \%$ ) were included in the analysis. This group had a higher proportion of men (59\%) compared to the group that was excluded from the analysis (43\%), $X^{2}(1, N=$ $251)=4.71, p=0.03$. The participant group and the excluded group did not differ in terms of age, diagnosis, years of hospitalization, disease-severity, BMI and medication. Of all available employees ( $n=80$ ), 26 were excluded because they had to work nightshifts. The remaining 54 employees were all measured during a three-week-period; all of them complied with the required wearing time.

\section{Participant characteristics}

Table 1 shows the patient characteristics. Men were between 25 and 89 years old and women between 28 and 91 . Men were hospitalized for a minimum of one year and a maximum of 58 years, which was substantially longer than the female patients ( 1 - 41 years). The comparison group $(n=54)$ consisted of 16 men and 38 women. Men were between 23 and 61 years old and women between 38 and 63 years, with significantly fewer men in the comparison group (30\%), than in the patient group (59\%), $X^{2}(1, N=238)$ $=14.13, p<0.001$ and with significantly younger age than the patient group, $t(236)=$ $6.45, p<0.001$. We controlled for age and sex in further analysis. 
Table 1. Demographics, disease characteristics and BMI of all patients, and for men and women separately

\begin{tabular}{|c|c|c|c|c|c|c|c|}
\hline \multirow{2}{*}{$\frac{\text { Variable (scale) }}{\text { Age in years }}$} & \multicolumn{2}{|c|}{ Total $(n=184)$} & \multicolumn{2}{|c|}{ Men $(n=108)$} & \multicolumn{2}{|c|}{ Women $(n=76)$} & \multirow{2}{*}{$\frac{p}{0.20}$} \\
\hline & 57.4 & $(12.8)$ & 56.5 & $(12.1)$ & 58.9 & $(13.6)$ & \\
\hline Diagnosis, $n(\%)$ & & & & & & & 0.72 \\
\hline Schizophrenia and otherwise psychotic & 142 & $(77.2)$ & 82 & $(75.9)$ & 60 & (78.9) & \\
\hline Personality disorder & 17 & $(9.2)$ & 12 & $(11.1)$ & 5 & (6.6) & \\
\hline \multicolumn{8}{|l|}{ Mood disorder } \\
\hline Depressive & 6 & (3.3) & 3 & $(2.8)$ & 3 & (3.9) & \\
\hline Bipolar & 7 & $(3.8)$ & 5 & $(4.6)$ & 2 & $(2.6)$ & \\
\hline Others $^{\mathrm{a}}$ & 12 & $(6.5)$ & 6 & $(5.6)$ & 6 & $(7.9)$ & \\
\hline Years of hospitalisation ${ }^{b}$ & 13.0 & $(12.3)$ & 14.8 & $(13.2)$ & 10.7 & $(10.7)$ & 0.02 \\
\hline Severity of illness (scale 1-6) ${ }^{c}$ & 4.67 & $(1.36)$ & 4.51 & $(1.39)$ & 4.89 & $(1.26)$ & 0.06 \\
\hline Body Mass Index (BMI) & 27.8 & $(6.2)$ & 27.7 & $(5.4)$ & 28.8 & $(7.0)$ & 0.05 \\
\hline \multicolumn{8}{|l|}{ Medication, $n(\%)$} \\
\hline Antipsychotics & & & & & & & 0.55 \\
\hline First generation & 36 & $(19.6)$ & 21 & $(19.4)$ & 15 & $(19.7)$ & \\
\hline Second generation & 70 & $(38.0)$ & 45 & $(41.7)$ & 25 & (32.9) & \\
\hline Both & 73 & $(39.7)$ & 40 & $(37.0)$ & 33 & $(43.4)$ & \\
\hline Antidepressants & 82 & $(44.6)$ & 46 & $(42.6)$ & 36 & $(47.4)$ & 0.52 \\
\hline
\end{tabular}

Mean (SD) unless otherwise noted.

Note. significant $p$-values $(p<0.05)$ are bold.

a Substance-related disorders ( $n=3)$; delirium, dementia, and amnestic and other cognitive disorders $(n=3)$; somatoform disorders $(n=2)$; mental disorder not otherwise specified $(n=2)$; anxiety disorder $(n=1)$ and developmental disorder $(n=1)$.

${ }^{b}$ Skewed distribution, bootstrapped (1000 samples, 95\% confidence intervals BCa).

${ }^{c}$ Higher scores mean higher severity of illness.

\section{Sedentary behaviour and physical activity}

As shown in Table 2, the patient group had significantly fewer total activity counts/hr than the comparison group. Although the accelerometers were more frequently attached to patients using a pouch, $\left.X^{2}(1, N=238)=11.93, p=0.001\right)$, after controlling for the known differences in sex, age and attachment method, the difference in total activity counts/hr remained highly significant, $F(1, N=238)=5.82, p=0.02$. However, the absolute differences were small $(d=0.32)$. Patients were predominantly sedentary. Although the comparison group scored about 1.5 times higher in light physical activity and moderate-tovigorous physical activity than the patients, the comparison group also showed a high percentage of sedentary behaviour. 
Table 2. Objectively measured sedentary behaviour and physical activity compared between patients and comparisons

\begin{tabular}{|c|c|c|c|c|c|}
\hline \multirow{2}{*}{$\begin{array}{l}\text { Variable (scale) } \\
\text { Wear time during measurement (hours) }\end{array}$} & \multicolumn{2}{|c|}{ Patients $(n=184)$} & \multicolumn{2}{|c|}{ Comparisons $(n=54)$} & \multirow{2}{*}{$\frac{p}{0.004}$} \\
\hline & 54.6 & $(9.6)$ & 58.3 & $(7.80)$ & \\
\hline Total activity counts per hour ${ }^{a}$ & 24527 & $(14822)$ & 35564 & $(10778)$ & 0.001 \\
\hline \multicolumn{6}{|l|}{ Intensity during wear time } \\
\hline Sedentary behaviour (\%) & 83.6 & $(8.0)$ & 76.0 & $(4.6)$ & $<0.001$ \\
\hline Light physical activity (\%) ${ }^{a}$ & 10.5 & $(6.0)$ & 15.3 & $(3.0)$ & 0.001 \\
\hline Moderate to vigorous physical activity (\%) ${ }^{a}$ & 5.9 & $(4.3)$ & 8.8 & $(3.0)$ & 0.001 \\
\hline
\end{tabular}

Mean (SD).

Note. significant $p$-values $(p<0.05)$ are bold.

a Skewed distribution, bootstrapped (1000 samples, 95\% confidence intervals BCa).

We initially found a sex difference in patients for both total activity counts/hr and moderate-to-vigorous physical activity, with women showing lower values than men (Table 3). However, after controlling for wearing method (women wore a pouch more frequently than men $\left(X^{2}(1, N=184)=22.21, p<0.001\right)$ and the fact that patients who wore a pouch $(40 \%)$ scored significantly lower in total activity counts/h, $(t(182)=2.96$ (bootstrapped $\mathrm{Cl}=2170.95-10265.25), p=0.003)$, no sex difference was found in total activity counts/hr $(F(1, N=184)=1.21, p=0.27)$ and moderate-to-vigorous physical activity $(F(1, N=184)=3.41, p=0.07)$.

Because comparing accelerometer data between studies is difficult, for comparison purposes we used data from several recent studies with similar methods in populations of elderly people: the same accelerometer, length of time sampling interval (epoch) and wear-time validation settings. We recalculated our data using the same cut-off points as these studies, based on vertical axis counts (Table 4). Even compared to these data from mobility-limited older adults (without a current diagnosis of schizophrenia or other psychotic disorder) [33] and elderly people with mild-to-moderate Parkinson disease [34], our patients were much more sedentary, although they spent more time in moderate-tovigorous physical activity 


\section{Chapter 2}

Table 3. Sedentary behaviour and physical activity scores of patients and comparisons for men and women

\begin{tabular}{|c|c|c|c|c|c|}
\hline \multirow{2}{*}{$\begin{array}{l}\text { Variable (scale) } \\
\text { Patients }\end{array}$} & \multicolumn{2}{|c|}{ Men } & \multicolumn{2}{|c|}{ Women } & \multirow[t]{2}{*}{$p$} \\
\hline & & & & & \\
\hline $\mathrm{N}$ & \multicolumn{2}{|c|}{108} & \multicolumn{2}{|r|}{76} & \\
\hline Subjectively rated inactivity $(0-16)^{a}$ & 4.53 & $(2.75)$ & 4.78 & $(3.18)$ & 0.57 \\
\hline \multicolumn{6}{|c|}{ Objectively measured sedentary behaviour and physical activity } \\
\hline Wear time during measurement (hours) ${ }^{b}$ & 56.2 & $(7.8)$ & 52.3 & $(11.3)$ & 0.02 \\
\hline Total activity counts per hour ${ }^{b}$ & 26377 & $(16597)$ & 21899 & $(11451)$ & $0.04^{\circ}$ \\
\hline \multicolumn{6}{|l|}{ Intensity during wear time } \\
\hline Sedentary behaviour (\%) & 82.9 & $(8.3)$ & 84.7 & $(7.5)$ & 0.15 \\
\hline Light physical activity $(\%)^{b}$ & 10.5 & $(6.0)$ & 10.5 & $(6.0)$ & 0.97 \\
\hline Moderate to vigorous physical activity $(\%)^{b}$ & 6.6 & $(4.9)$ & 4.9 & $(3.1)$ & $0.01^{\circ}$ \\
\hline \multicolumn{6}{|l|}{ Comparison group } \\
\hline $\mathrm{N}$ & & 16 & & 38 & \\
\hline \multicolumn{6}{|c|}{ Objectively measured sedentary behaviour and physical activity } \\
\hline Wear time during measurement (hours) ${ }^{\mathrm{b}}$ & 60.34 & $(4.63)$ & 57.49 & $(8.71)$ & 0.12 \\
\hline Total activity counts per hour ${ }^{b}$ & 34234 & (9082) & 36124 & $(11483)$ & 0.50 \\
\hline \multicolumn{6}{|l|}{ Intensity during wear time } \\
\hline Sedentary behaviour (\%) & 76.2 & (4.9) & 75.9 & $(4.6)$ & 0.83 \\
\hline Light physical activity $(\%)^{b}$ & 15.6 & $(3.4)$ & 15.9 & $(2.9)$ & 0.55 \\
\hline Moderate to vigorous physical activity (\%) & 8.2 & $(2.2)$ & 9.0 & (3.3) & 0.29 \\
\hline
\end{tabular}

Mean (SD).

Note. significant $p$-values $(p<0.05)$ are bold.

${ }^{a}$ Higher scores = more inactivity. ${ }^{b}$ Skewed distribution, bootstrapped (1000 samples, 95\% confidence intervals $\mathrm{BCa}$. ${ }^{\mathrm{c}}$ After analysis of covariance with the way of attachment, men were no longer more active than women. 
Table 4. Comparison of ActiGraph GT3X(+) vertical axis data of the present study with two other studies, based on 1s epochs and using wear time validation of Choi et al. [25]

\begin{tabular}{|c|c|c|}
\hline Variable & Fitzgerald et al. [33] & Benka Wallen et al. [34] \\
\hline Population & $\begin{array}{l}\text { Mobility-limited older } \\
\text { adults }\end{array}$ & $\begin{array}{l}\text { Elderly people with mild to } \\
\text { moderate Parkinson disease }\end{array}$ \\
\hline $\mathrm{N}$ & 1170 & 79 \\
\hline$\%$ women & 66 & 47 \\
\hline Age, mean (SD) & $78.8 \quad(5.3)$ & $73.2 \quad(5.7)$ \\
\hline \multicolumn{3}{|l|}{ Used cut-off points (counts per minute) } \\
\hline Sedentary behaviour & $0-99$ & $0-99$ \\
\hline Light physical activity & $100-499$ & $100-759$ \\
\hline Moderate to vigorous physical activity & $>500$ & $\geq 760$ \\
\hline \multicolumn{3}{|l|}{$\%$ of time in } \\
\hline Sedentary behaviour & 77.0 & 75.9 \\
\hline Light physical activity & 16.6 & 18.1 \\
\hline Moderate to vigorous physical activity & 6.4 & 6.0 \\
\hline \multicolumn{3}{|l|}{ Recalculated outcomes present study } \\
\hline \multicolumn{3}{|l|}{ Patients, $\%$ of time in } \\
\hline Sedentary behaviour & 88.4 & 88.4 \\
\hline Light physical activity & 2.4 & 3.4 \\
\hline Moderate to vigorous physical activity & 9.2 & 8.2 \\
\hline \multicolumn{3}{|l|}{ Comparison group, \% of time in } \\
\hline Sedentary behaviour & 84.3 & 84.3 \\
\hline Light physical activity & 3.4 & 4.9 \\
\hline Moderate to vigorous physical activity & 12.3 & 10.8 \\
\hline
\end{tabular}

\section{Associations with background characteristics}

Pearson correlations showed significant associations between sedentary behaviour, physical activity and background characteristics. Younger age was moderately associated with less sedentary behaviour $(r=.38, p<0.001)$, and more moderate-to-vigorous physical activity $(r=-0.51, p<0.001)$ and total activity counts/hr $(r=-0.53, p<0.001)$. Years of hospitalisation, a diagnosis of schizophrenia, personality disorder and 'other' showed weaker associations with various sedentary behaviour and physical activity variables, reflected in associations with total activity counts/hr $(r=-0.16, p<0.05 ; r=0.27, p<0.001$; $r=-0.18, p<0.05 ; r=-0.22, p<0.01$, respectively). However, all these variables were also significantly associated with age; after performing the hierarchical regression, age remained the only significant predictor (Table 5). The model also showed that, after controlling for these patient characteristics, the wearing method was not a significant predictor of the measured total activity counts/hr. The resulting total model was significant, with a substantial explained variance. Finally, lower nurse-rated inactivity scores showed 
medium-to-strong correlations with lower total activity counts/hr $(r=-0.35, p<0.001)$, more sedentary behaviour $(r=0.39, p<0.001)$, less light physical activity $(r=-0.31, p$ $<0.001)$ and less moderate-to-vigorous physical activity $(r=-0.30, p<0.001)$.

Table 5. Hierarchical regression for the total activity counts per hour (bias-corrected and accelerated bootstrap, 1000 samples; $N=184$ ).

\begin{tabular}{|c|c|c|c|c|c|c|c|c|}
\hline \multirow{3}{*}{ Variable } & \multicolumn{4}{|l|}{ Model 1} & \multicolumn{4}{|l|}{ Model 2} \\
\hline & \multirow[t]{2}{*}{$B$} & \multirow[t]{2}{*}{ SE B } & \multicolumn{2}{|l|}{$95 \% \mathrm{Cl}$} & \multirow[t]{2}{*}{$B$} & \multirow[t]{2}{*}{$S E B$} & \multicolumn{2}{|l|}{$95 \% \mathrm{Cl}$} \\
\hline & & & Min & Max & & & Min & Max \\
\hline $\begin{array}{l}\text { Way of } \\
\text { attachment }^{\text {a }}\end{array}$ & $-6464.55^{* *}$ & 2167.77 & -10487.83 & -2213.72 & -2995.26 & 1982.90 & -6738.30 & 1060.34 \\
\hline Gender $^{b}$ & & & & & -1382.26 & 1961.87 & -5242.74 & 2256.41 \\
\hline Age & & & & & $-531.24 * *$ & 95.67 & -718.73 & -346.54 \\
\hline \multicolumn{9}{|l|}{ Diagnosis $^{c}$} \\
\hline Schizophrenia & & & & & 4223.27 & 2508.24 & -341.26 & 9043.94 \\
\hline $\begin{array}{l}\text { Personality } \\
\text { disorder }\end{array}$ & & & & & -7.83 & 2738.48 & -5154.41 & 5306.02 \\
\hline $\begin{array}{l}\text { Depressive } \\
\text { disorder }\end{array}$ & & & & & 1746.34 & 6109.31 & -9347.07 & 13279.47 \\
\hline Bipolar disorder & & & & & 5319.01 & 5720.52 & -4635.89 & 15853.59 \\
\hline $\begin{array}{l}\text { Years of } \\
\text { hospitalisation }\end{array}$ & & & & & 12.09 & 78.85 & -132.52 & 148.64 \\
\hline Severity of illness & & & & & -1165.54 & 818.13 & -2742.86 & 563.31 \\
\hline Body Mass Index & & & & & -85.16 & 144.60 & -385.67 & 182.60 \\
\hline \multicolumn{9}{|l|}{ Antipsychotics $^{d}$} \\
\hline First generation & & & & & -2984.31 & 2027.87 & -6842.74 & 1250.14 \\
\hline $\begin{array}{l}\text { Second } \\
\text { generation }\end{array}$ & & & & & -1289.85 & 1992.05 & -4990.78 & 2566.89 \\
\hline Antidepressants & & & & & 717.59 & 1945.29 & -2935.69 & 4290.83 \\
\hline$R^{2}$ & .05 & & & & .33 & & & \\
\hline$R^{2}$ Adj. & .04 & & & & .28 & & & \\
\hline$F$ & $8.77^{*}$ & & & & $6.33 * *$ & & & \\
\hline
\end{tabular}

Note. significant coefficients are bold.

${ }^{a}$ strap between belt loops $=0$, pouch $=1 .{ }^{b}$ men $=0$, women $=1 .{ }^{c}$ reference group: 'other diagnosis'. ${ }^{d}$ reference group: 'both generation antipsychotics'.

${ }^{*} p<0.01 .{ }^{* *} p \leq 0.001$.

\section{Discussion}

To our knowledge, this is one of the first studies measuring sedentary behaviour and physical activity using accelerometry in a large group of hospitalised patients with severe mental illness. These measurements showed significantly lower total activity counts per hour in patients than in the comparison group. Moreover, the patients were sedentary 
on average $84 \%$ of their awake time. These findings are in line with other studies in this population which used self-reports to measure physical activity [10, 35, 36]. However, only one accelerometer study with inpatients was included in the meta-analysis of Stubbs. That study [37] was based on a relatively small group of 30 participants with schizophrenia, with an unknown proportion of them being outpatients in a day hospital programme. Razavi et al. [38] also used actigraphy in a population with psychiatric inpatients suffering from major depression in a first or recurrent episode. They showed that actigraphy was more precise in reflecting the motor activity parameters of the Hamilton Depression Rating Scale than the score of experts. However, comparison with our study is limited due to the actigraph type, method of registration and wear-time. It is noteworthy that in our study not only participants with schizophrenia were included but also a minority with other diagnoses, for instance major depression, as a result of a broad definition of a patient with severe mental illness [5].

Consequently, our accelerometer study contributes to the field, not only due to our relatively large group of inpatient participants with severe mental illness, but also due to our relatively precise accelerometry measurements of sedentary behaviour and physical activity. As mentioned by Bassett et al. [15], registration with an accelerometer gives a more reliable and detailed representation of the activity levels in a variety of domains and more accurate registration of sedentary behaviour and random physical activity in the lower spectrum of intensity. The recent accelerometer studies of Chen and Stubbs $[16,17]$ also showed that inpatients with schizophrenia in Taiwan spend significantly less time in light physical activity and moderate-to-vigorous physical activity than a comparison group without the disease. However, data from that study are difficult to compare with those from our study. Not only did they use wrist-worn and hip-worn accelerometers [39], but also a binary split into low (<581.1 min per day) and high sedentary behaviour (>581.1 min per day) instead of the three intensities sedentary, light physical activity and moderate-to-vigorous physical activity used in our study. Although the authors emphasized the importance of separating sedentary behaviour from light physical activity, no similar data on sedentary behaviour are available. Moreover, severity of illness has not been standardized internationally, which also results in poor comparability between patient samples. Finally, their patients were younger (mean age of 44 compared to 57.4 in our study), had a lower BMI (24.3 compared to 27.8), and had fewer years of hospitalisation (14.2 months compared to 13 years). However, the direction of the findings is comparable with our study. Their advice was also to engage patients in more light activity instead of sedentary behaviour. No guidelines are currently available for sedentary behaviour, but relative to other accelerometry data we can conclude that the percentage of sedentary time is very high in this population. Based on these findings, we suggest making it priority to reduce sedentary behaviour in this population in favour of light physical activity. The shift from sedentary behaviour to light physical activity implies a relatively moderate increase in activity. In clinical practice this can be accomplished by a broad multidisciplinary lifestyle intervention programme. 
Several of our outcomes were unexpected. First, we found an association only between sedentary behaviour and age, and no association with antipsychotic medication regarding the sedative and metabolic side-effects of this medication. Chen et al. [16] and Stubbs et al. [17] also found no association between physical activity and chlorpromazine equivalents. Future intervention studies that aim to decrease sedentary behaviour could look for possible associations with changes in clinical variables. In particular, further study of the effect of psychotropic medication on sedentary behaviour is necessary [40].

A second unexpected outcome was that we found no differences in sedentary behaviour and physical activity between men and women. This differs from findings in previous studies with less severely mentally ill populations, such as outpatients in regular health care [41] and outpatients with severe mental illness [42], but is in line with the findings of the above-mentioned studies of Chen et al. [17] and Stubbs et al. [17] in an inpatient population. It is possible that gender has less association with activity levels in patients who are hospitalized for a long time. However, because of the significant difference in gender between our participant group, the group excluded from the analysis and the comparison group (both included predominantly women), studies with more patients are necessary to make stronger statements about this finding.

A third unexpected outcome concerns sedentary behaviour of the comparison group of employees. Even the adjusted data based on the vertical axis showed that they spent more time in sedentary behaviour (84.3\%) than older adults with mobility issues (78.5\%) [33] and elderly patients with mild-to-moderate Parkinson disease (75.9\%) [34]. These studies provided reliable data for comparison concerning the transparency in the settings of handling and processing accelerometer data. Nevertheless, the exclusion of hours with less than 54 minutes of data registration in the study of Benka Wallen et al. [34] and our choice of using a sampling frequency of $100 \mathrm{~Hz}$ instead of $30 \mathrm{~Hz}$ in both comparison studies may have resulted in more sedentary behaviour counts in our study. Other possible differences in these studies (e.g. attachment methods, time standardisation, environment and culture) could also have caused bias. In addition, using only the vertical axis may not be the most suitable measurement to compare the activity intensities of these different groups. However, our data still strongly support the initiatives that involve staff in lifestyle interventions in mental health care.

Our study has several limitations concerning study design, methodological considerations, data comparison and disease characteristics of the population. First, the cross-sectional design offers valuable information about associations between the various parameters, but does not allow any interpretations about potential causal relationships.

Second, methodological and technical limitations are due to the lack of literature on accelerometer-based data in this specific inpatient population for physical activity and sedentary behaviour. As a result, no validated settings are available for collecting and processing the accelerometer data of these patients, such as sampling frequency, wear time, time intervals (epochs) and cut-points. Although we used a high sampling frequency of $100 \mathrm{~Hz}$ to obtain detailed data to prevent the loss of vigorous acceleration in data processing 
that occurs with lower frequencies (e.g. the default $30 \mathrm{~Hz}$ ), the high frequency can cause bias by additional activity counts that escaped the band-pass filter while processing data. Consequently, we may have overestimated the percentage of vigorous activity. This could mean that physical activity among our participants was even worse than reported.

Third, our minimum wear time for accelerometer data (six hours for at least three days) was less than the advised $10 \mathrm{~h}$ a day [43]. However, many patients have irregular circadian rhythms, resulting in fewer hours of valid wear time. Therefore, we followed the daily schedule on most wards to determine the minimum wear time per day and the specified timeframe (09:00 a.m. - 10:00 p.m.), to be able to compare data between patients.

Concerning time intervals, 1-second epochs were chosen because longer time intervals result in a higher likelihood of misclassifying daily activity [24]. To determine wear time, we followed the guidelines of Choi et al. [25], which stated that 1-second epochs result in the fewest misclassifications.

A fourth limitation consisted of the choice of cut-off points, because this differs according to the accelerometer model, firmware version, settings and the age of the subjects (due to differing energy expenditure) [44-47]. Moreover, existing cut-off points are mostly based on uni-axial measurement, while recent research states that a combination of three axis (Vector Magnitude) produces more accurate results [26]. We used the cut-off points based on the vector magnitude values of an almost identical accelerometer (ActiGraph GT3X), and we made a distinction in cut-off points between adults and elderly people, which turned out to be the best way to define sedentary behaviour [48, 49].

As mentioned above, a variety of accelerometers and preferred settings are available for data collection and processing (e.g. sampling frequency, epoch length, use of uni-axial or tri-axial data, wear-time validation and cut-off points). However, standardisation and consensus is urgently needed to improve comparability because studies use different methods which are often poorly reported, making comparison difficult. By using total activity counts, which was recently suggested to reach a better standard for comparability between studies [15], we took initial steps towards more comparable accelerometer data. Although we had to use total activity counts/hr instead of total activity counts/day as a result of the limited wear time, studies in which it is possible to measure 'a day' can translate their total activity counts per day into hours to compare their results with ours. In addition, due to the severity of mental illness in this population, we had to develop new ways to attach the accelerometers in order to minimize discomfort. It is possible this might have caused not fully comparable data, because we did not validate these methods.

A final limitation concerns our decision to not use self-reporting in our study, which prevents comparability with accelerometry data. We did this because self-reports are not reliable measuring instruments in this population [12] due to illness severity and cognitive deficits. Also, because the burden of wearing an accelerometer for this population was already high, we decided to use the nurse observation scale (NOSIE; Dingemans et al. [19]) instead. 


\section{Conclusion}

This accelerometer study has shown that hospitalized patients with severe mental illness are very sedentary and physically inactive. In this population, registration of sedentary behaviour and physical activity with accelerometers is probably more accurate and reliable than self-reporting and is therefore preferable. In addition, this approach enables the standardization of settings, which is required to provide future research in a comparable population with an accurate method to measure sedentary behaviour and physical activity. Standardized and longitudinal objective measurement of sedentary behaviour and physical activity in this patient group is needed to confirm the current prevalence data, combined with a suitable control group, to study potential causal relationships. Considering the well-known comorbidities in this population, resulting in greatly decreased life expectancy, reducing sedentary behaviour and improving physical activity should be a high priority.

\section{Funding}

None

\section{Conflict of interest}

AJB received honorarium as a speaker from Lundbeck (no relation with this study). Other authors: no conflicts of interest.

\section{Acknowledgements}

The authors wish to thank the staff, nurses and patients for their efforts and participation in the study, and the University of Twente for participating in the study design. 


\section{References}

1. Sedentary Behaviour Research Network. Standardized use of the terms "sedentary" and "sedentary behaviours". Mental Health and Physical Activity. 2013;6(1):55-56.

2. Biswas A, Oh PI, Faulkner GE, Bajaj RR, Silver MA, Mitchell MS, Alter DA. Sedentary Time and Its Association With Risk for Disease Incidence, Mortality, and Hospitalization in Adults A Systematic Review and Metaanalysis. Ann Intern Med. 2015;162(2):123-132.

3. Brocklebank LA, Falconer CL, Page AS, Perry R, Cooper AR. Accelerometer-measured sedentary time and cardiometabolic biomarkers: A systematic review. Prev Med. 2015;76:92-102.

4. Vancampfort D, Correll CU, Galling B, Probst M, De Hert M, Ward PB, Rosenbaum S, Gaughran F, Lally J, Stubbs B. Diabetes mellitus in people with schizophrenia, bipolar disorder and major depressive disorder: a systematic review and large scale meta-analysis. World Psychiatry. 2016;15(2):166-174.

5. Walker ER, McGee RE, Druss BG. Mortality in mental disorders and global disease burden implications: a systematic review and meta-analysis. JAMA Psychiatry. 2015;72(4):334-341.

6. Vancampfort D, Stubbs B, Mitchell AJ, De Hert M, Wampers M, Ward PB, Rosenbaum S, Correll CU. Risk of metabolic syndrome and its components in people with schizophrenia and related psychotic disorders, bipolar disorder and major depressive disorder: a systematic review and meta-analysis. World Psychiatry. 2015;14(3):339-347.

7. Stubbs B, Firth J, Berry A, Schuch FB, Rosenbaum S, Gaughran F, Veronesse N, Williams J, Craig T, Yung AR et al. How much physical activity do people with schizophrenia engage in? A systematic review, comparative meta-analysis and meta-regression. Schizophr Res. 2016;176(2-3):431-440.

8. Goossens PJJ, Wesselink W, Janssen WFA: Palliatieve zorg bij mensen met een psychiatrische stoornis. In: Palliatieve geneeskunde. Edited by Wanrooij BS. Houten: Bohn Stafleu van Loghum; 2010: 309.

9. Firth J, Rosenbaum S, Stubbs B, Gorczynski P, Yung AR, Vancampfort D. Motivating factors and barriers towards exercise in severe mental illness: a systematic review and meta-analysis. Psychol Med. 2016;46(14):2869-2881.

10. Stubbs B, Williams J, Gaughran F, Craig T. How sedentary are people with psychosis? A systematic review and meta-analysis. Schizophr Res. 2016;171(1-3):103-109.

11. Lindamer LA, McKibbin C, Norman GJ, Jordan L, Harrison K, Abeyesinhe S, Patrick K. Assessment of physical activity in middle-aged and older adults with schizophrenia. Schizophr Res. 2008;104(1-3):294-301.

12. Soundy A, Roskell C, Stubbs B, Vancampfort D. Selection, Use and Psychometric Properties of Physical Activity Measures to Assess Individuals with Severe Mental Illness: A Narrative Synthesis. Archives of Psychiatric Nursing. 2014;28(2):135-151.

13. Dyrstad SM, Hansen. B.H., Holme, I.M. , Anderssen, S.A. Comparison of self-reported versus accelerometer-measured physical activity. Med Sci Sports Exerc. 2014;46(1)(January 2014):99-106.

14. Aleman A, Hijman R, De Haan EHF, Kahn RS. Memory impairment in schizophrenia: A meta-analysis. Am J Psychiatry. 1999;156(9):1358-1366.

15. Bassett DR, Troiano RP, McClain JJ, Wolff DL. Accelerometer-based physical activity: total volume per day and standardized measures. Med Sci Sports Exerc. 2015;47(4):833-838.

16. Chen LJ, Steptoe A, Chung MS, Ku PW. Association between actigraphy-derived physical activity and cognitive performance in patients with schizophrenia. Psychol Med. 2016;46(11):2375-2384.

17. Stubbs B, Ku PW, Chung MS, Chen LJ. Relationship Between Objectively Measured Sedentary Behavior and Cognitive Performance in Patients With Schizophrenia Vs Controls. Schizophr Bull. 2016.

18. Kozey-Keadle S, Shiroma EJ, Freedson PS, Lee IM. Impact of accelerometer data processing decisions on the sample size, wear time and physical activity level of a large cohort study. BMC Public Health. 2014;14(1):1210.

19. Dingemans PM, Bleeker JAC, Frohn-De Winter ML. A cross-cultural study of the reliability and factorial dimensions of the nurses' observation scale for inpatient evaluation (NOSIE). J Clin Psychol. 1984;40(1):169-172. 
20. Owen RR, Drummond KL, Viverito KM, Marchant K, Pope SK, Smith JL, Landes RD. Monitoring and managing metabolic effects of antipsychotics: a cluster randomized trial of an intervention combining evidencebased quality improvement and external facilitation. Implement Sci. 2013;8:120.

21. Nolen WA. Globale Klinische Beoordeling (Clinical Global Impression: CGI). Groningen: UMC; 1990.

22. Busner J, Targum SD. The clinical global impressions scale: applying a research tool in clinical practice. Psychiatry (Edgmont (Pa : Township)). 2007;4(7):28-37.

23. Brond JC, Arvidsson D. Sampling frequency affects the processing of Actigraph raw acceleration data to activity counts. J Appl Physiol (1985). 2016;120(3):362-369.

24. Matthews CE, Hagströmer M, Pober DM, Bowles HR. Best practices for using physical activity monitors in population-based research. Med Sci Sports Exerc. 2012;44:S68-S76.

25. Choi L, Liu Z, Matthews CE, Buchowski MS. Validation of accelerometer wear and nonwear time classification algorithm. Med Sci Sports Exerc. 2011;43(2):357-364.

26. Santos-Lozano A, Santin-Medeiros F, Cardon G, Torres-Luque G, Bailon R, Bergmeir C, Ruiz JR, Lucia A, Garatachea N. Actigraph GT3X: validation and determination of physical activity intensity cut points. Int J Sports Med. 2013;34(11):975-982.

27. Gatti AA, Stratford PW, Brenneman EC, Maly MR. GT3X+ accelerometer placement affects the reliability of step-counts measured during running and pedal-revolution counts measured during bicycling. J Sports Sci. 2015;34(12):1-8.

28. Jarrett H, Fitzgerald L, Routen AC. Interinstrument reliability of the ActiGraph GT3X+ambulatory activity monitor during free-living conditions in adults. Journal of Physical Activity and Health. 2015;12(3):382-387.

29. McMinn D, Acharya R, Rowe DA, Gray SRA, Allan JLA. Measuring activity energy expenditure: accuracy of the GT3X+ and actiheart monitors. International Journal of Exercise Science. 2013;6(3):217-229.

30. Hafkenscheid A. Psychometric evaluation of the Nurses Observation Scale for Inpatient Evaluation in the Netherlands. Acta Psychiatr Scand. 1991;83(1):46-52.

31. IBM SPSS Inc. Statistical Package for the Social Sciences (SPSS) 21.0 for Windows. Chicago, IL: IBM SPSS Incorporated; 2012.

32. Wright DB, London K, Field AP. Using Bootstrap Estimation and the Plug-in Principle for Clinical Psychology Data. Journal of Experimental Psychopathology. 2011;2:252-270.

33. Fitzgerald JD, Johnson L, Hire DG, Ambrosius WT, Anton SD, Dodson JA, Marsh AP, McDermott MM, Nocera $J R$, Tudor-Locke $C$ et al. Association of objectively measured physical activity with cardiovascular risk in mobility-limited older adults. Journal of the American Heart Association. 2015;4(2).

34. Benka Wallen M, Franzen E, Nero H, Hagstromer M. Levels and Patterns of Physical Activity and Sedentary Behavior in Elderly People With Mild to Moderate Parkinson Disease. Phys Ther. 2015;95(8):1135-1141.

35. Ussher M, Stanbury L, Cheeseman V, Faulkner G. Physical activity preferences and perceived barriers to activity among persons with severe mental illness in the United Kingdom. Psychiatr Serv. 2007;58(3):405-408.

36. Vancampfort D, Probst M, Scheewe T, De Herdt A, Sweers K, Knapen J, van Winkel R, De Hert M. Relationships between physical fitness, physical activity, smoking and metabolic and mental health parameters in people with schizophrenia. Psychiatry Research. 2012.

37. Snethen GA, McCormick BP, Lysaker PH. Physical activity and psychiatric symptoms in adults with schizophrenia spectrum disorders. J Nerv Ment Dis. 2014;202(12):845-852.

38. Razavi N, Horn H, Koschorke P, Hugli S, Hofle O, Muller T, Strik W, Walther S. Measuring motor activity in major depression: the association between the Hamilton Depression Rating Scale and actigraphy. Psychiatry Res. 2011;190(2-3):212-216.

39. Shiroma EJ, Schepps MA, Harezlak J, Chen KY, Matthews CE, Koster A, Caserotti P, Glynn NW, Harris TB. Daily physical activity patterns from hip- and wrist-worn accelerometers. Physiol Meas. 2016;37(10):18521861.

40. Stubbs B, Vancampfort D, Manty M, Svard A, Rahkonen O, Lahti J. Bidirectional longitudinal relationship between leisure-time physical activity and psychotropic medication usage: A register linked follow-up study. Psychiatry Res. 2016;247:208-213. 
41. Janney CA, Richardson CR, Holleman RG, Glasheen C, Strath SJ, Conroy MB, Kriska AM. Gender, mental health service use and objectively measured physical activity: Data from the National Health and Nutrition Examination Survey (NHANES 2003-2004). Mental Health and Physical Activity. 2008;1(1):9-16.

42. Daumit GL, Goldberg RW, Anthony C, Dickerson F, Brown CH, Kreyenbuhl J, Wohlheiter K, Dixon LB. Physical activity patterns in adults with severe mental illness. J Nerv Ment Dis. 2005;193(10):641-646.

43. Troiano RP, Berrigan D, Dodd KW, Masse LC, Tilert T, McDowell M. Physical activity in the United States measured by accelerometer. Med Sci Sports Exerc. 2008;40(1):181-188.

44. Colley RC, Tremblay MS. Moderate and vigorous physical activity intensity cut-points for the Actical accelerometer. J Sports Sci. 2011;29(8):783-789.

45. Freedson PS, Bowles HR, Troiano R, Haskell W. Assessment of physical activity using wearable monitors: Recommendations for monitor calibration and use in the field. Med Sci Sports Exerc. 2012;44 (SUPPL. 1):S1-S4.

46. Hooker SP, Feeney A, Hutto B, Pfeiffer KA, Mclver K, Heil DP, Vena JE, LaMonte MJ, Blair SN. Validation of the actical activity monitor in middle-aged and older adults. Journal of Physical Activity and Health. 2011;8(3):372-381.

47. Trost SG, Loprinzi PD, Moore R, Pfeiffer KA. Comparison of accelerometer cut points for predicting activity intensity in youth. Med Sci Sports Exerc. 2011;43(7):1360-1368.

48. Carr $\amalg$, Mahar MT. Accuracy of intensity and inclinometer output of three activity monitors for identification of sedentary behavior and light-intensity activity. J Obes. 2012;2012.

49. Kozey-Keadle S, Libertine A, Lyden K, Staudenmayer J, Freedson P. Validation of wearable monitors for assessing sedentary behavior. Med Sci Sports Exerc. 2011;43(8):1561 - 1567 



\section{Chapter}

\section{Physical activity and quality of life in long- term hospitalized patients with severe mental illness: a cross-sectional study}

Deenik, J., Kruisdijk, F.R., Tenback, D.E., Braakman-Jansen, L.M.A., Taal, E., HopmanRock, M., Beekman, A.T.F., Tak, E.C.P.M., Hendriksen, I.J.M., van Harten, P.N.

BMC Psychiatry 2017; 17: 298 doi: 10.1186/s12888-017-1466-0 


\section{Abstract}

\section{Background:}

Increasing physical activity in patients with severe mental illness is believed to have positive effects on physical health, psychiatric symptoms and as well quality of life. Till now, little is known about the relationship between physical activity and quality of life in longterm hospitalized patients with severe mental illness and knowledge of the determinants of behavioural change is lacking. The purpose of this study was to elucidate the relationship between objectively measured physical activity and quality of life, and explore modifiable psychological determinants of change in physical activity in long-term hospitalized patients with severe mental illness.

\section{Methods:}

In 184 inpatients, physical activity was measured using an accelerometer (ActiGraph GTX+). Quality of life was assessed by EuroQol-5D and WHOQol-Bref. Attitude and perceived selfefficacy towards physical activity were collected using the Physical Activity Enjoyment Scale and the Multidimensional Self Efficacy Questionnaire, respectively. Patient and disease characteristics were derived retrospectively from electronic patient records. Associations and potential predictors were analysed using hierarchical regression.

\section{Results:}

Physical activity was positively related with and a predictor of all quality of life outcomes except on the environmental domain, independent of patient and disease characteristics. However, non-linear relationships showed that most improvement in quality of life lies in the change from sedentary to light activity. Attitude and self-efficacy were not related to physical activity.

\section{Conclusions:}

Physical activity is positively associated with quality of life, especially for patients in the lower spectrum of physical activity. An association between attitude and self-efficacy and physical activity was absent. Therefore, results suggest the need of alternative, more integrated and (peer-)supported interventions to structurally improve physical activity in this inpatient population. Slight changes from sedentary behaviour to physical activity may be enough to improve quality of life. 


\section{Background}

Research into lifestyle-related factors in patients with Severe Mental Illness (SMI) is increasing. Efforts often focus on physical health, consistent with the highly prevalent metabolic risk factors [1] that underlie the well-known poor cardiovascular health and premature mortality gap of at least 10-20 years compared to the general population $[2,3]$. Recent systematic reviews and meta-analyses showed beneficial effects of increasing physical activity (PA) on physical health, psychiatric symptoms, global functioning, and quality of life (QoL) [4-7]. These are relevant findings, especially for long-term hospitalized patients with SMI, given the combination of a strong negative relationship between illness duration and QoL [8] and a high level of sedentariness in this population [9].

Although QoL is a complex construct influenced by multiple factors [10], these recent findings positively support PA as an important modifiable factor affecting patients' QoL.

However, until now little is known about the relationship between objective measured PA and QoL in long-term hospitalized patients with SMI and most of the studies in the referred systematic reviews and meta-analyses involved outpatient- or short term hospitalized populations. Objective PA measurement of patients with long-term hospitalization due to their illness severity remains a challenge and just a few studies succeeded in such measurements at larger scale $[9,11,12]$.

Also, despite growing awareness of the positive effects of increasing PA in patients with SMI, no clear answer exists on how to motivate patients with SMI to structurally engage in PA [13]. In addition, the hospital setting has been considered 'obesogenic' and a cause of inactivity itself $[14,15]$. A long term stay therefore negatively affects PA due to regulated inactivity. More knowledge of determinants of change in PA in this population is needed. The Theory of Planned Behaviour [16], a basic social-cognitive model, provides insight into such determinants. It distinguishes attitudes towards the desired behaviour and its outcomes, subjective norms (perceived social pressure and (dis)approval of certain behaviours) and perceived behavioural control [16], also defined as self-efficacy [17]. These determinants are assumed to affect one's intention to perform the given behaviour, which is hypothesized to be the immediate antecedent of the actual behaviour (e.g. being more physically active). Especially in long-term mental healthcare, it is important to gain more insight into psychiatric and psychological determinants of PA to guide activation [18]. However, in SMI patients the abovementioned subjective norms and the ability to consciously establish intentions towards behaviour are affected by a lack of insight into their condition, poor skills in cognitive empathy and planning deficits [19-21]. Therefore, we decided to explore attitude and self-efficacy as determinants with the greatest potential to influence the result of treatment. To our knowledge, these determinants are rarely studied in a SMI population and have never been associated with objectively measured PA. 
The aim of our study was to (A) analyse the relationship between objectively measured PA and QoL in long-term hospitalized patients with severe mental illness and (B) explore to what extent attitude and self-efficacy are related to the level of PA in this population.

\section{Methods}

\section{Participants}

Subjects were long-term hospitalized patients with SMI of a psychiatric hospital in The Netherlands for whom we provide mental healthcare and residence if they are unable to live independently or in sheltered homes. Inclusion criteria were age $\geq 18$, hospitalized $\geq 1$ year and treatment history $\geq 2$ years. For the current study, we used accelerometer data previously reported by Kruisdijk et al [9]. In this relevant study, forty-four patients were excluded because of no informed consent $(n=26)$, unstable psychiatric or physical conditions ( $n=17$ ) or relocation ( $n=1$ ). Of the 207 included patients, 23 dropped out because of a lack of required wear time $(n=19)$, losing their accelerometer $(n=2)$, discharge during the study period $(n=1)$ or an acute episode of illness $(n=1)$. In total 184 patients were included with sufficient accelerometer data, that we used in analysis in the current study, which was approved by the Central Committee on Research Involving Human Subjects (CCMO). After extensive verbal explanation per ward, taking understandable comments due to the mental illness into account (e.g. fear, suspicion and psychotic thoughts), written informed consent was obtained from all subjects who understood the intent of the study and were willing to participate.

\section{Procedures}

To measure PA, subjects wore an accelerometer (ActiGraph GT3X+) for five consecutive days (Wednesday morning to Sunday evening) except while sleeping or during water related activities [9]. Questionnaires for QoL and attitude and self-efficacy as determinants of change in PA were added to the routine health screening and conducted by a trained research assistant in a semi-structured interview. The average duration of a screening was 20-30 minutes, depending on the specific patient. If needed, the screening was split up into two appointments (e.g. due to a limited attention span).

\section{Measurements}

Patient- and disease-specific characteristics

Gender, age, years of hospitalization, diagnosis, illness severity and use of medication were derived retrospectively from electronic patient records. Primary diagnoses were classified following the DSM-IV-TR in main groups of the most frequent diagnoses: schizophrenia and other psychotic disorders, personality disorders and affective disorders. 
Less frequent diagnoses were merged in 'others'. Furthermore, affective disorders were split into depression and bipolar disorder. Use of antipsychotics was split into first, second or both generations, because the difference in side-effects (movement disorders and metabolic side-effects, respectively) may have an effect on the activity level. Severity of illness was measured by the Dutch translation of the severity-scale of the Clinical Global Impression Scale [CGI, 22], rating from 1 (normal, not at all ill) to 7 (among the most extremely ill patients).

\section{Physical activity}

The ActiGraph GT3X+ (ActiGraph, Pensacola, Florida, VS) was used to measure PA. The accelerometers were worn on the right hip with an elastic strap between two belt loops. Patients without belt loops used a pouch pinned at the same place. A wear time of $\geq 6$ hours/day for $\geq 3$ days was used as the criterion for sufficient measurement. To be able to compare individual data, the same timeframe was used for each dataset: $09.00 \mathrm{am}$ till 10.00 pm. Data were analysed using the ActiGraph software ActiLife 6.8.0 and calculated into average total activity counts per hour (TAC/h) as a continuous and detailed outcome variable of PA, where more counts indicate a higher level of PA. For detailed information on used settings and criteria, see Kruisdijk et al [9]. The GT3X+ has a high inter- and intrainstrumental reliability and validity [23-25].

\section{Quality of life}

The Dutch versions of the EuroQol 5D (EQ-5D) and brief World Health Organization Quality of Life Assessment scale (WHOQoL-Bref) were used to assess QoL. As a generic instrument, the EQ-5D measures five dimensions of health (one item each): mobility, self-care, usual activities, pain/discomfort and anxiety/depression, rated from 1 (no problems) to 3 (many problems). The added value of the EQ-5D is the calculation of an index score ranging from 0 (worst QoL) to 1 (perfect $Q \mathrm{OL}$ ) using the Dutch value-set based on time-tradeoff weightings of a representative Dutch sample [26]. The EQ-5D is a valid instrument to measure QoL in patients with a diagnosis of schizophrenia [27].

Because the EQ-5D is recommended to be used complementary to other instruments [28] and physical disability and poor daily functioning not necessarily mean that the particular patient has a poor QoL [29], we added the WHOQoL-Bref. This questionnaire focuses on ones' perceived QoL, including 24 items divided in four domains: physical (7 items), psychological (6 items), social (3 items) and environmental (8 items). In addition, there are two items that individually score one's overall perception of QoL and satisfaction with his/her health. Items are scored on a five-point Likert scale (1 to 5; e.g. from 'very dissatisfied' to 'very satisfied'). Scores were transformed into domain scores ranging from 4 to 20 , according to the WHO guidelines. The WHOQoL-Bref is the most often used QoLinstrument in studies investigating patients with a diagnosis of schizophrenia [30] and showed good to excellent reliability and validity in these patients in long-term mental healthcare [31] and in Dutch outpatients with psychiatric disorders [32]. In the present 
study, we found a sufficient internal consistency in the separate domains: physical ( $\alpha=$ $0.74)$, psychological ( $\alpha=0.82)$, social $(\alpha=0.63)$ and environmental $(\alpha=0.72)$.

\section{Attitude \& self-efficacy towards physical activity}

For these measures, no validated Dutch questionnaires were available for this population. Therefore, attitude was measured using the Dutch version of the Physical Activity Enjoyment Scale [PACES; 33], previously used in the general population [34]. It includes 18 dichotomous statements regarding the participants' thoughts about physical activities they do (or used to do). Items are scored at a Likert-scale from 1 to 7 whereby participants choose the number that most closely corresponds to the way they feel (e.g. 'I feel bored' vs. 'I feel interested'). Eleven items are formulated negatively. After recoding these items, a sum-score was calculated, with a higher score representing a more positive attitude towards PA (range 18-126). In the present study, the questionnaire showed a high internal consistency $(\alpha=.97)$.

Self-efficacy was measured with a questionnaire based on the Multidimensional Self Efficacy Questionnaire [MSEQ; 35]. Originally, this questionnaire comprised 18 items measuring the extent to which a patient feels able to be physically active (e.g. 'I am confident in my ability to exercise when I am under a lot of stress'). Items are scored on a Likert-scale from 1 (totally unable) to 5 (totally able). For use in the present study, the questionnaire was translated (once forwards) into Dutch. To avoid unduly burdening patients with irrelevant questions and to have a questionnaire in line with the treatment conditions, some adjustments were made. First, using understandable terminology towards patients, we replaced the word 'exercise' by 'be physically active'. Secondly, due to the inpatient setting, the item regarding PA when traveling became unnecessary and was deleted, and items referring to several social situations were reduced to one item focusing on the situation at the treatment group (I am confident in my ability to be in PA when my fellow group members don't want me to go to physical activities). Finally, one of the three items regarding cold weather conditions was adjusted into an item on hot weather, in order to involve summer conditions. A sum score was used with a higher score representing a higher self-efficacy towards PA (range 15-75). In the present study, the adjusted questionnaire showed a high internal consistency $(\alpha=0.92)$.

\section{Statistical analysis}

Data analyses were performed using SPSS 22.0. Continuous variables were examined for normality and homogeneity by comparing means with medians and standard deviations, and by analysing frequency histograms and normality plots. Linearity was examined by scatterplots and analysing the variables in quartiles. If variables were not distributed linearly with respect to the dependent variables, they were added as quartiles in the analysis, with the first quartile as reference-category. Categorical variables (diagnosis and types of antipsychotics) were transformed into dummy variables. 'Schizophrenia and 
other psychotic disorders' and 'first generation antipsychotics' were the reference groups for diagnosis and antipsychotics, respectively.

Relationships between the independent (PA, attitude or self-efficacy) and dependent variable (QoL outcomes or PA) were analysed using linear regression. First, analyses focused on these associations specifically. To estimate these associations as accurately as possible, it was checked whether patient and disease characteristics affected the relationship. This confounding was defined as a change of $\geq 10 \%$ in the regression coefficient of the particular independent variable (e.g. PA) when adding a patient or disease characteristic. The strongest confounder was added to the model to control for, until there were no variables left causing $\geq 10 \%$ change in the regression coefficient. For the analysis of PA, we also controlled for the way of attachment of the accelerometer. Associations were considered significant at a 0.05 two tailed significance level. Then, regardless of any specific association, significant predictors of QoL and PA were analysed using multiple regression with manual backward elimination retaining only the strongest predictors $(p<$ 0.10). Proportions of explained variance were reported to give an indication of the predictive power of these models. Multicollinearity was examined by observing regression coefficients (e.g. change of direction when adding variables) and collinearity statistics (VIF $>10$ and tolerance $<0.2$ ). Because PA is represented in large numbers by total activity counts per hour, the variable was standardized (each value subtracted by the mean total activity counts per hour and divided by its SD) to use as independent variable in analysis towards QoL, in order to optimize readability.

\section{Results}

Table 1 shows the characteristics of the 184 participants. They were between 25 and 91 years old and hospitalized with a minimum of one and a maximum of 58 years. 


\section{Chapter 3}

Table 1. Patient and disease characteristics, physical activity, quality of life, attitude and self-efficacy $(N=184)$

\begin{tabular}{lcc}
\hline Variable (scale) & Mean (SD) & N (\%) \\
\hline Gender (men) & & 108 (58.7) \\
Age (years) & $57.4 \quad(12.8)$ &
\end{tabular}

Diagnosis

Schizophrenia and other psychotic disorders

$142(77.2)$

Personality disorder

Mood disorder

Depressive

Bipolar

Others ${ }^{\mathrm{a}}$

$12(6.5)$

Years of hospitalization, median (25 - 75 percentile $)^{b}$

$6.0(4.0-21.8)$

Severity of illness (range 1-6)

$4.7 \quad(1.4)$

Medication

Antipsychotics

First generation

36 (19.6)

Second generation

$70 \quad(38.0)$

Both

Antidepressants

82 (44.6)

$\mathrm{TAC} / \mathrm{h}$

24527 (14821)

EQ-5D index score (0-1)

$0.6 \quad(0.3)$

WHOQoL-Bref

Overall QoL rating (1-5)

$3.5(0.9)$

Health satisfaction rating (1-5)

3.4 (1.1)

Physical domain (4-20)

$13.6 \quad(2.7)$

Psychological domain (4-20)

Social domain (4-20)

13.1 (2.9)

Environmental domain (4-20)

$14.9(2.1)$

Attitude towards PA (18-126)

76.6 (26.8)

Self-efficacy towards PA (15-75)

41.2 (14.6)

$\mathrm{TAC} / \mathrm{h}$ = average Total Activity Counts per hour; QoL = Quality of life; EQ-5D = EuroQol five-dimension questionnaire; WHOQoL-Bref = World Health Organization Quality of Life questionnaire, brief version.

a Delirium, dementia, and amnestic and other cognitive disorders $(n=3)$; substance-related disorders $(n=3)$, somatoform disorders $(n=2)$; mental disorder not otherwise specified $(n=2)$; anxiety disorder $(n=1)$; developmental disorder $(n=1)$

b Positively skewed distribution. 


\section{Physical activity and quality of life}

When examining scatterplots, we found that PA was non-linearly distributed towards QoL. Although there was no obvious alternative shape of the distribution (e.g. quadratic), smoothing a line using Locally Estimated Scatterplot Smoothing (LOESS) [36] clearly visualized that QoL did not constantly increase with more PA (Figure 1). Coefficients of PA quartiles confirmed this finding (Table 3). Because of this non-linearity, quartiles were used in the regression analysis, with the lowest quartile (Q1) as reference group. To support interpretation of the results, Table 2 provides insight into means of activity counts and corresponding intensities within the quartiles, according to age-specific cut-off points for tri-axial measurement [37-39].

Table 2. Average total activity counts per hour and proportions of wear time in intensities within quartiles

\begin{tabular}{|c|c|c|c|c|c|c|}
\hline \multirow[t]{2}{*}{ Quartile } & \multicolumn{3}{|c|}{$\mathrm{TAC} / \mathrm{h}$} & \multicolumn{3}{|c|}{ Intensities ${ }^{c}$} \\
\hline & Mean (SD) & $\min ^{b}$ & $\max ^{b}$ & $\% \mathrm{SB}$ & $\%$ LPA & $\%$ MVPA \\
\hline $\mathrm{Q} 1^{\mathrm{a}}$ & 8260 (2938) & 2518 & 12840 & 92.2 & 6.2 & 1.6 \\
\hline Q2 & 18136 (2973) & 13350 & 22317 & 86.0 & 10.1 & 3.9 \\
\hline Q3 & 27160 & 22566 & 31469 & 81.9 & 11.7 & 6.4 \\
\hline Q4 & 44553 (11814) & 31702 & 83698 & 74.4 & 14.0 & 11.6 \\
\hline
\end{tabular}

$\mathrm{Q}=$ Quartile $(\mathrm{n}=46) ; \mathrm{TAC} / \mathrm{h}=$ average Total Activity Counts per hour; SB = Sedentary Behaviour; LPA = Light Physical Activity; MVPA = Moderate to Vigorous Physical Activity.

a reference group in analysis.

${ }^{b}$ minimum and maximum average $\mathrm{TAC} / \mathrm{h}$ (patient) within the quartile.

${ }^{c}$ mean percentage of wear time that patients within the quartile spend in: SB [<150], LPA [151-3207], MVPA [ $\geq 3208$; but $\geq 2751$ for 65 years or older] [37-39]. Thresholds in counts per minute. 

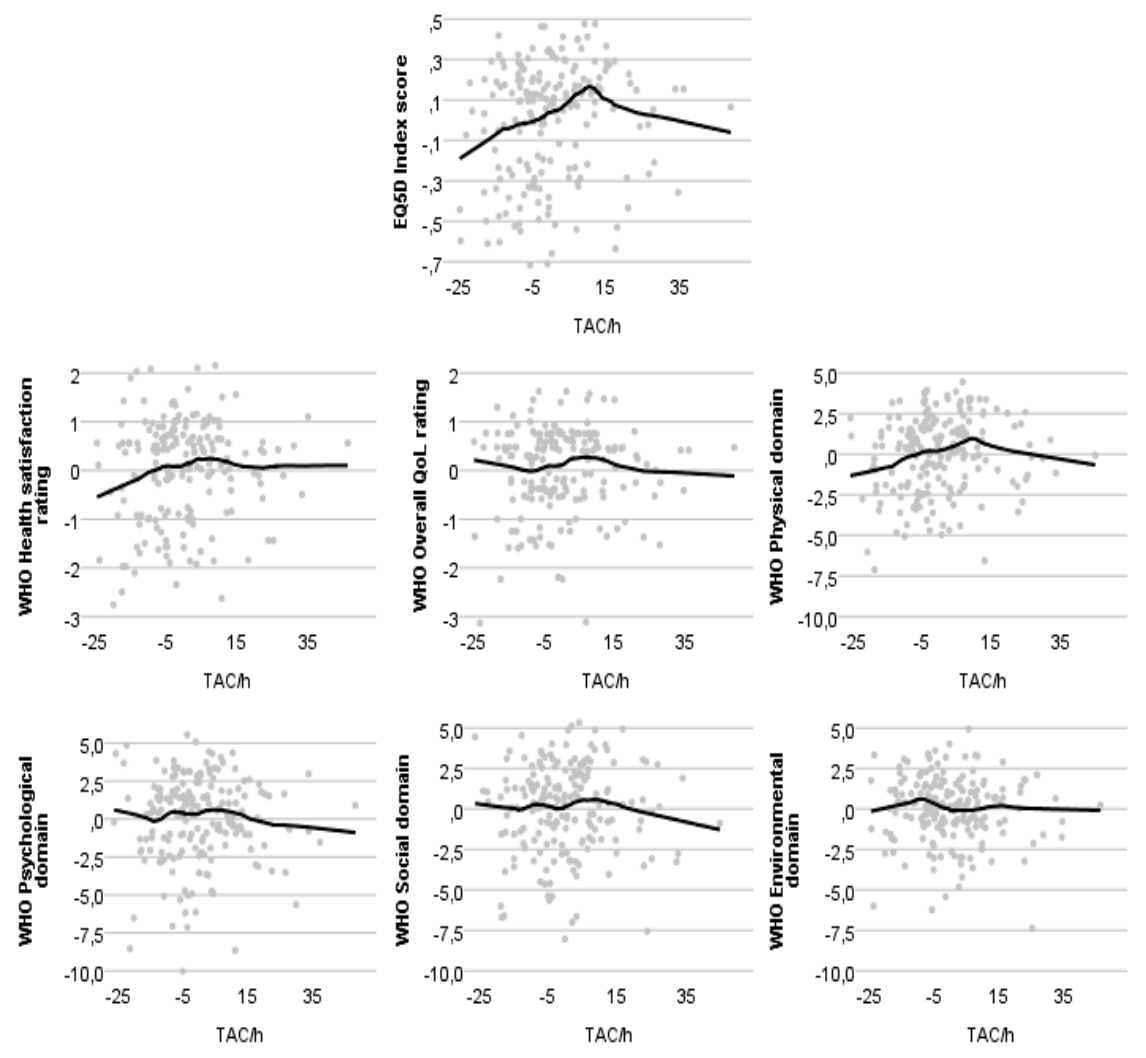

Fig. 1. Non-linear distributions between physical activity (TAC/h) and Quality of Life (QoL) variables Explored using scatterplots and LOESS Curves (Kernel: Epanechnikov, $=0.5$ ) on standardized axis. TAC/h x1000. $\mathrm{TAC} / \mathrm{h}$ = average Total Activity Counts per hour; QoL = Quality of Life; LOESS = Locally Estimated Scatterplot Smoothing; EQ5D = EuroQol-5D; WHO = World Health Organization

Table 3 shows the associations between PA (total activity counts per hour) and QoL with the corresponding confounders, reflected in regression coefficients for the particular associations and $F$-values for the models as a whole. There were significant positive associations between PA and the EQ-5D index score and WHO overall, physical, psychological and social QoL. For overall QoL and the psychological and social domains, patients with PA levels in the lower spectrum (Q2) had the best QoL and the QoL of the most active patients (Q4) differed less from the least active patients (Q1, reference group). This corresponds to the shapes of distribution in the uncorrected data, showing a (small) increase which then runs off. There were no significant associations with health satisfaction and environmental QoL. 
Physical activity and quality of life in long-term hospitalized patients

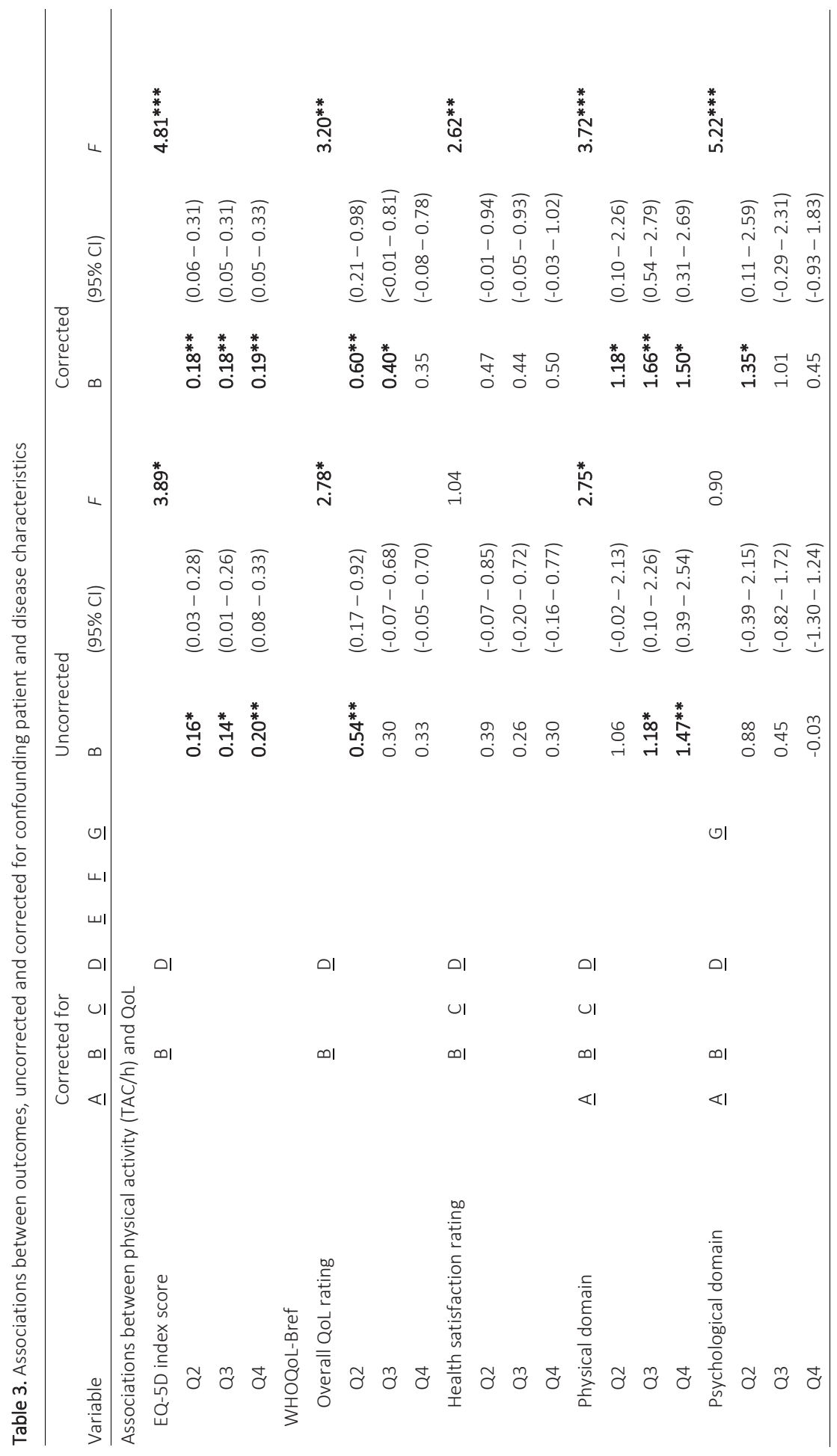


Chapter 3

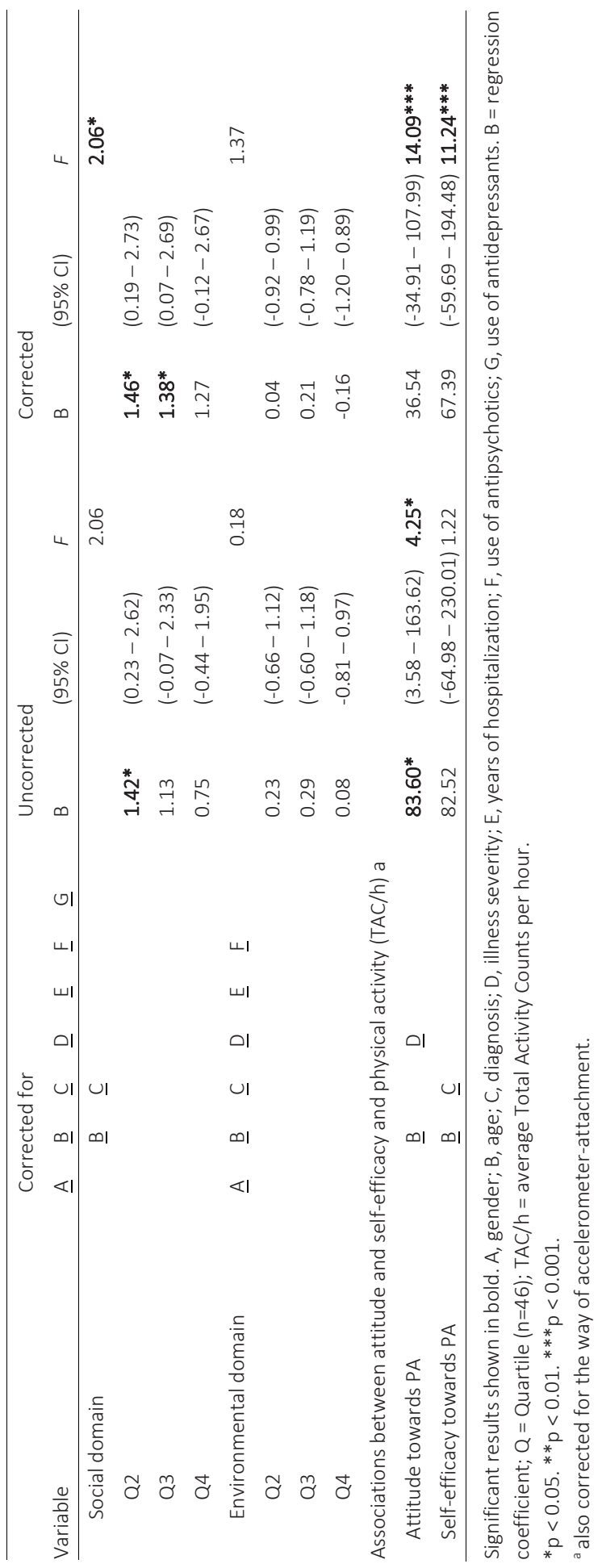


The multiple regression with backward elimination showed PA to be a significant predictor for the EQ-5D, WHO overall QoL, health satisfaction and the physical, psychological and social domains (Table 4). Regression coefficients for the prediction of the WHO overall, psychological and social QoL showed the strongest relationships for the lower spectrum of activity (Q2). This confirmed the distributions we found earlier (Figure 1). Explained variance $\left(R^{2}{ }_{A d j}\right)$ of the models of these significant predictors ranged between $8 \%$ and $17 \%$. The level of PA was no significant predictor for environmental QoL, which was predicted by years of hospitalization, illness severity and use of antipsychotics ( $F=3.91$, $p<0.01, R^{2}{ }_{A d j}=0.06$ ).

Table 4. Multiple regression models with significant predictors of quality of life $(p<0.10)$, using backwardselection

\begin{tabular}{|c|c|c|c|c|c|}
\hline Measure & $\mathrm{B}$ & $95 \% \mathrm{Cl}$ & $F$ & $R^{2}$ & $R^{2}{ }_{A d j}$ \\
\hline \multicolumn{6}{|c|}{ Predicting EQ-5D index score } \\
\hline Overall model & & & $6.76 * * * *$ & 0.16 & 0.14 \\
\hline \multicolumn{6}{|l|}{$\mathrm{TAC} / \mathrm{h}$} \\
\hline Q2 & $0.16^{* * *}$ & $(0.05-0.28)$ & & & \\
\hline Q3 & $0.15^{* *}$ & $(0.04-0.27)$ & & & \\
\hline Q4 & $0.17^{* * *}$ & $(0.05-0.28)$ & & & \\
\hline \multicolumn{6}{|l|}{ Gender } \\
\hline \multicolumn{6}{|l|}{ Illness severity } \\
\hline \multicolumn{6}{|c|}{ Predicting WHO overall QoL rating } \\
\hline Overall model & & & $5.18 * * * *$ & 0.13 & 0.10 \\
\hline \multicolumn{6}{|l|}{$\mathrm{TAC} / \mathrm{h}$} \\
\hline Q2 & $0.56^{* * *}$ & $(0.20-0.92)$ & & & \\
\hline Q3 & $0.35^{*}$ & $(-0.01-0.71)$ & & & \\
\hline Q4 & 0.22 & $(-0.14-0.59)$ & & & \\
\hline \multicolumn{6}{|l|}{ Gender } \\
\hline \multicolumn{6}{|l|}{ Illness severity } \\
\hline \multicolumn{6}{|c|}{ Predicting WHO health satisfaction rating } \\
\hline Overall model & & & $2.74 * * *$ & 0.19 & 0.12 \\
\hline \multicolumn{6}{|l|}{$\mathrm{TAC} / \mathrm{h}$} \\
\hline Q2 & $0.48 * *$ & $(0.01-0.95)$ & & & \\
\hline Q3 & 0.41 & $(-0.08-0.90)$ & & & \\
\hline Q4 & $0.50^{*}$ & $(-0.02-1.01)$ & & & \\
\hline \multicolumn{6}{|l|}{$\mathrm{Age}^{\mathrm{a}}$} \\
\hline \multicolumn{6}{|l|}{ Diagnosis } \\
\hline \multicolumn{6}{|l|}{ Illness severity ${ }^{\mathrm{a}}$} \\
\hline \multicolumn{6}{|l|}{ Antidepressants } \\
\hline \multicolumn{6}{|c|}{ Predicting WHO physical QoL domain } \\
\hline Overall model & & & $3.72 * * * *$ & 0.24 & 0.17 \\
\hline \multicolumn{6}{|l|}{$\mathrm{TAC} / \mathrm{h}$} \\
\hline Q2 & $1.18^{* *}$ & $(0.10-2.26)$ & & & \\
\hline
\end{tabular}




\begin{tabular}{|c|c|c|c|c|c|}
\hline Measure & B & $95 \% \mathrm{Cl}$ & $F$ & $R^{2}$ & $R^{2} A d j$ \\
\hline Q3 & $1.66 * * *$ & $(0.54-2.79)$ & & & \\
\hline Q4 & $1.50^{* *}$ & $(0.31-2.69)$ & & & \\
\hline \multicolumn{6}{|l|}{$\mathrm{Age}^{\mathrm{a}}$} \\
\hline \multicolumn{6}{|l|}{ Gender } \\
\hline \multicolumn{6}{|l|}{ Diagnosis } \\
\hline \multicolumn{6}{|l|}{ Illness severity ${ }^{a}$} \\
\hline \multicolumn{6}{|c|}{ Predicting WHO psychological QoL domain } \\
\hline Overall model & & & $3.85 * * * *$ & 0.23 & 0.17 \\
\hline \multicolumn{6}{|l|}{$\mathrm{TAC} / \mathrm{h}$} \\
\hline Q2 & $1.09 *$ & $(-0.16-2.35)$ & & & \\
\hline Q3 & 0.90 & $(-0.39-2.20)$ & & & \\
\hline Q4 & 0.30 & $(-1.07-1.68)$ & & & \\
\hline \multicolumn{6}{|l|}{ Age } \\
\hline \multicolumn{6}{|l|}{ Gender } \\
\hline \multicolumn{6}{|l|}{ Diagnosis } \\
\hline \multicolumn{6}{|l|}{ Illness severity } \\
\hline \multicolumn{6}{|l|}{ Use of antipsychotics } \\
\hline \multicolumn{6}{|l|}{ Use of antidepressants } \\
\hline \multicolumn{6}{|c|}{ Predicting WHO social QoL domain } \\
\hline Overall model & & & $2.33^{* * *}$ & 0.14 & 0.08 \\
\hline \multicolumn{6}{|l|}{$\mathrm{TAC} / \mathrm{h}$} \\
\hline Q2 & $1.49 * *$ & $(0.27-2.72)$ & & & \\
\hline Q3 & $1.19 *$ & $(-0.03-2.42)$ & & & \\
\hline Q4 & 0.97 & $(-0.30-2.23)$ & & & \\
\hline \multicolumn{6}{|l|}{ Years of hospitalization } \\
\hline \multicolumn{6}{|l|}{ Diagnosis } \\
\hline \multicolumn{6}{|l|}{ IIIness severity ${ }^{a}$} \\
\hline Use of antidepressants & & & & & \\
\hline
\end{tabular}

Significant results shown in bold. $\mathrm{TAC} / \mathrm{h}=$ average Total Activity Counts per hour; $\mathrm{Q}=$ Quartile $(\mathrm{n}=46)$.

${ }^{*} p<0.10$. ** $p<0.05$. *** $p<0.01 .{ }^{* * *} p<0.001$.

a In quartiles.

\section{Attitude and self-efficacy and physical activity}

Table 3 shows the associations between attitude and self-efficacy and PA, reflected in regression coefficients for the particular associations and $F$-values for the models as a whole. After correction, there were no significant associations. In parallel, attitude and self-efficacy were not significant predictors of PA in multiple regression. Of all patient and disease characteristics, only age was a significant predictor $\left(F=38.66, p<0.001, R^{2}{ }_{A d j}=\right.$ 0.29). 


\section{Discussion}

This study clearly showed that (A) PA was positively associated with QoL and a significant predictor of overall, physical, psychological and social QoL, and (B) there was no association between attitude and self-efficacy and PA, contrary to what we expected. These findings are summarized in Figure 2.

(A)

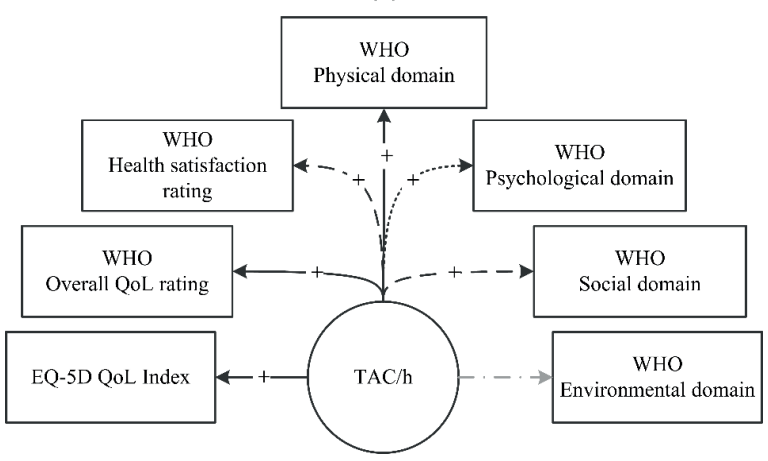

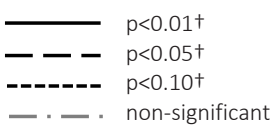

(B)



Fig. 2. Summary of the relationships found, controlled for patient and disease characteristics"

(A): between physical activity and quality of life. (B): between attitude/self-efficacy and physical activity. TAC/h = average Total Activity Counts per hour; QoL = Quality of Life; EQ5D = EuroQol-5D; WHO = World Health Organization.

*corrected for any added value to the prediction by gender, age, diagnosis, years of hospitalization, illness severity and use of antipsychotics and antidepressants.

tFor at least one of the quartiles of TAC/h.

\section{Associations with QoL}

The positive association with QoL needs to be discussed in more detail, as for overall, psychological and social QoL, relationships with PA were strongest for the patients classified in the second quartile. QoL of the most active patients was not significantly different from the QoL of the least active patients (reference group). As there were no big differences in day-to-day programs during the week, weekend activities and approaching patients between wards, it is unlikely that this has affected results. Restlessness (caused by e.g. akathisia, which is well-known in this population [40], anxiety or agitated depression) could however be a reason for high activity scores, while having a QoL below average. Nevertheless, adding presence of akathisia (which was available in the database and diagnosed by using the St. Hans Rating Scale [41]) to the models did not change the shape of the relations. Despite that an anxiety disorder was diagnosed only once and a diagnosis of agitated depression is also rare in this population, anxious and agitated feelings are common within psychiatric patients. Especially these feelings can be reflected in perceived psychological and social QoL, which may have been more common in patients with relatively high PA scores within the current study. However, it seems that relevant 
improvement in QoL can be achieved by activating the most sedentary patients to do/perform more light intensity PA. Intervention studies are needed to analyse such possible causal relationships. Noteworthy are the relatively low levels of explained variance of the models of the significant predictors ( $8 \%-17 \%)$. This reflects the complexity of QoL, whereby - apart from patient and disease characteristics and PA - many more factors may play a role. In the QoL analysis, PA was not related to environmental QoL, in both association and prediction models. Years of hospitalization, illness severity and use of antipsychotics were the only significant predictors of environmental QoL. This could be a plausible finding for this population, since the hospitalized setting is a regulated environment itself, which is strongly related to one's pathology and hardly affected by the individual level of physical activity.

These findings show only limited agreement with earlier cross-sectional research on the relationship between PA and QoL in inpatients with SMI. Two studies showed selfreported PA to be (positively) associated only with physical QoL $[42,43]$, while two others found no significant associations with any QoL variable $[8,18]$. These differences may have to do with the power in these studies ( $N=18$ to 60 ) and the use of self-reports instead of objective measurement of PA.

It is important to perform research in specific SMI groups such as long-term hospitalized patients. Namely, the WHO QoL domain scores were on average 1.5 points higher compared to Dutch psychiatric outpatients and (just) 1.5 points lower than the general Dutch population (on a scale from 4 to 20) [44]. Because the QoL is not as low as we sometimes may assume in clinical practice and the non-linear relationships we found, the question is to what extend more PA can positively influence QoL in this hospitalized population. Current data suggests that slight increases in PA may be enough to improve QoL.

\section{Attitude/self-efficacy and physical activity}

Results showed that SMI inpatients who have a positive attitude towards being physically active and feel able to do so, are not more active than SMI inpatients with a less positive attitude and lower self-efficacy. This might play a role in difficulties activating patients in clinical practice, taking into account that attempts to activate people often involve increasing attitude (e.g. telling them the importance and advantages of PA) and supporting self-efficacy (e.g. by facilitating them with home-trainers at the ward). A previous study showed similar results for self-efficacy, finding no association with exercise attendance in outpatients with SMI [45]. The idea that having a positive attitude and high self-efficacy towards PA not necessarily leads to increased PA, is described as the intention-behaviour gap [46]. In this population, a possible explanation for this gap could be a lack of competences to plan the actual activity, due to poor skills in cognitive abilities and systematic thinking $[20,21]$. Also, based on clinical practice, other attitudes may play a role that compete with healthy behaviour (e.g. if a patient intended to take a walk but ends up with a fellow patient to smoke a cigarette). Nevertheless, although these factors may 
explain the lack of a relationship between attitude and self-efficacy and PA, this finding guides the way in which we should activate this population. Implementation intentions whereby a person plans when, where and how to act in an if-then format [47] are assumed to improve the translation of one's intention to actual behaviour. However, due to the planning deficits [21], this could be less applicable in this population and a more intensive and guided approach might help to overcome this gap. Support by positive staff attitudes, staff participation (modelling) and peer support are determined as essential factors to affect ones' behaviour to achieve a maximum result with a lifestyle intervention in patients with SMI [48]. Recent systematic reviews on this subject encourage structural physical activities integrated in a multidisciplinary treatment $[6,13,49]$. Moreover, provided that the obesogenic environment will be changed using such an activating strategy, especially inpatient healthcare offers a lot of opportunities. The inpatient setting has the abilities to structurally activate patients to engage in PA and pay attention to the development of habits they can maintain when discharged from the hospital [49].

\section{Strengths and limitations}

So far, little is known about the level of PA of long-term hospitalized patients with SMI. The main strength of the present study is the use of objective measurement of PA in a relatively large group of long-term hospitalized patients with SMI [9] and involving modifiable psychological determinants. This leads to more reliable conclusions, independent of patient and disease characteristics. Accelerometer data are more reliable than self-reports due to psychopathology and impaired cognitive abilities of patients [50] and better registration of the lower spectrum of PA intensity [51]. Besides, by measuring PA in daily clinical practice and by involving modifiable psychological determinants such as attitude and self-efficacy, results are very relevant for clinical practice. Especially, research towards specific groups can contribute to better treatment, such as in long-term hospitalized population with SMI. Findings, such as the QoL scores compared to outpatients and non-linear distributions, show us that patients with SMI in different settings also differ in relationships between PA and QoL and therefore need a different approach.

The cross-sectional design of the present study does not allow the drawing of any conclusions about causality of the relationships. Another limitation is that there is no international consensus on how to set up and process accelerometer data. Besides, validated instruments to assess attitude and self-efficacy are not available in this population, because so far little research on this topic has been done in long-term hospitalized patients with SMI. The self-efficacy questionnaire was slightly adjusted and translated to Dutch by people with excellent command of English, but we did not perform an extensive back and forth translation-procedure. However, as shown in the method section, internal consistencies of the questionnaires were high. Moreover, the levels of explained variance of the models confirm the complex constructs of QoL, in which many individual aspects may play a role. Furthermore, in step-wise regression choices of elimination are based on 
the current data-set, which means that this procedure possibly reduced generalizability of the results. However, in our opinion this was the best way to achieve the maximum power of models to estimate and predict the relationships as accurately as possible, taking our sample-size into account.

We encourage further research on this topic within hospitalized SMI patients, especially regarding the non-linear relationship between TAC/h and QoL. For example, it would be very relevant for clinical practice to know whether there is a causal relationship between high levels of PA and lower QoL. If this is the case, it must be taken into account in future interventions aiming to improve the poor health status of this population by increasing PA. For such interventions, the lack of association between attitude and selfefficacy and PA suggests the need of a more intensive and guided approach. Therefore, we think that long-term hospitalized patients with SMI will benefit from an integrated, multidisciplinary and peer supported approach focusing on a shift from sedentary behaviour to light intensity PA.

\section{Conclusions}

In summary, the current study showed a positive relationship between PA and QoL, especially for patients in the lower spectrum of PA. Although no causal relationship can be drawn, the data suggests that in long-term hospitalized patients with SMI slight increases in PA may be enough to improve QoL. The lack of association between attitude and selfefficacy and PA suggests the need of a more intensive and guided approach. We encourage further (longitudinal) research to obtain more accurate insights on this topic, which remains priority in this population. 
List of abbreviations

SMI

PA

QoL

$\mathrm{TAC} / \mathrm{h}$

EQ-5D

WHOQoL-Bref

Q

LOESS

SB

LPA

MVPA
Severe Mental IIIness

Physical Activity

Quality of Life

average Total Activity Counts per hour

EuroQol five-dimension questionnaire

World Health Organization Quality of Life questionnaire, brief version.

Quartile

Locally Estimated Scatterplot Smoothing

Sedentary Behaviour

Light Physical Activity

Moderate to Vigorous Physical Activity

\section{Declarations}

\section{Ethics approval and consent to participate}

After extensive verbal explanation per ward, taking understandable comments due to the mental illness into account (e.g. fear, suspicion and psychotic thoughts), written informed consent was obtained from all subjects who understood the intent of the study and were willing to participate. All participants were able to decide this by themselves, as reviewed by their attending psychiatrist. The study protocol was approved by the Central Committee on Research Involving Human Subjects (CCMO) before measurements were started.

\section{Consent for publication}

Not applicable.

\section{Availability of data and materials}

The data that support the findings of this study are not publicly available because it is inconsistent with the informed consent. Data are however available from the corresponding author on reasonable request and with permission of GGz Centraal. 


\section{Competing interests}

The authors declare that they have no competing interests.

\section{Funding}

Not applicable.

\section{Authors' contributions}

JD: study design, collection and analysis of data, drafting and revising the manuscript. FK: study design, drafting and revising the manuscript. DT: study design, supporting collection and analysis of data, revising the manuscript. ABJ and ET1: study design, supporting quality of life, attitude and self-efficacy measurements, revising the manuscript. $\mathrm{MH}$ : revising the manuscript. AB: supporting data analysis, revising the manuscript. ET2: revising the manuscript. IH: study design, supporting accelerometer measurement and data analysis, revising the manuscript. PH: revising the manuscript. All authors contributed and approved the manuscript.

\section{Acknowledgements}

The authors would like to acknowledge, with thanks, all patients and mental healthcare professionals of GGz Centraal who have made efforts to collect all the data, which formed the basis for this publication. 


\section{References}

1. Vancampfort D, Stubbs B, Mitchell AJ, De Hert M, Wampers M, Ward PB, Rosenbaum S, Correll CU. Risk of metabolic syndrome and its components in people with schizophrenia and related psychotic disorders, bipolar disorder and major depressive disorder: a systematic review and meta-analysis. World Psychiatry. 2015;14(3):339-347.

2. Walker ER, McGee RE, Druss BG. Mortality in Mental Disorders and Global Disease Burden Implications A Systematic Review and Meta-analysis. Jama Psychiatry. 2015;72(4):334-341.

3. Laursen TM, Wahlbeck K, Hallgren J, Westman J, Osby U, Alinaghizadeh H, Gissler M, Nordentoft M. Life Expectancy and Death by Diseases of the Circulatory System in Patients with Bipolar Disorder or Schizophrenia in the Nordic Countries. PLoS One. 2013;8(6).

4. Dauwan M, Begemann MJH, Heringa SM, Sommer IE. Exercise Improves Clinical Symptoms, Quality of Life, Global Functioning, and Depression in Schizophrenia: A Systematic Review and Meta-analysis. Schizophr Bull. 2016;42(3):588-599.

5. Rosenbaum S, Tiedemann A, Sherrington C, Curtis J, Ward PB. Physical activity interventions for people with mental illness: a systematic review and meta-analysis. J Clin Psychiatry. 2014;75(9):964-974.

6. Vera-Garcia E, Mayoral-Cleries F, Vancampfort D, Stubbs B, Cuesta-Vargas AI. A systematic review of the benefits of physical therapy within a multidisciplinary care approach for people with schizophrenia: An update. Psychiatry Res. 2015;229(3):828-839.

7. Stubbs B, Williams JE, Gaughran F, Craig T. How sedentary are people with psychosis? A systematic review and meta-analysis. Schizophr Res. 2016;171(1-3):103-109.

8. Vancampfort D, Guelinckx H, Probst M, Stubbs B, Rosenbaum S, Ward PB, De Hert M. Health-related quality of life and aerobic fitness in people with schizophrenia. Int J Ment Health Nurs. 2015;24(5):394-402.

9. Kruisdijk F, Deenik J, Tenback D, Tak E, Beekman A-J, van Harten P, Hopman-Rock M, Hendriksen I. Accelerometer-measured sedentary behaviour and physical activity of inpatients with severe mental illness. Psychiatry Res. 2017;254:67-74.

10. Awad AG, Voruganti LNP. Measuring Quality of Life in Patients with Schizophrenia. Pharmacoeconomics. 2012;30(3):183-195.

11. Chen LJ, Steptoe A, Chung MS, Ku PW. Association between actigraphy-derived physical activity and cognitive performance in patients with schizophrenia. Psychol Med. 2016;46(11):2375-2384.

12. Stubbs B, Ku PW, Chung MS, Chen LJ. Relationship Between Objectively Measured Sedentary Behavior and Cognitive Performance in Patients With Schizophrenia Vs Controls. Schizophr Bull. 2016; doi: 10.1093/schbul/sbw126.

13. Farholm A, Sørensen M. Motivation for physical activity and exercise in severe mental illness: A systematic review of intervention studies. Int J Ment Health Nurs. 2016;25(3):194-205.

14. Ringen PA, Engh JA, Birkenaes AB, Dieset I, Andreassen OA. Increased mortality in schizophrenia due to cardiovascular disease - a non-systematic review of epidemiology, possible causes, and interventions. Frontiers in psychiatry. 2014;5:137-137.

15. Faulkner GE, Gorczynski PF, Cohn TA. Psychiatric illness and obesity: recognizing the "obesogenic" nature of an inpatient psychiatric setting. Psychiatr Serv. 2009;60(4):538-541.

16. Ajzen I, Madden TJ. Prediction of goal-directed behavior: Attitudes, intentions, and perceived behavioral control. J Exp Soc Psychol. 1986;22(5):453-474.

17. Fishbein M, Cappella JN. The role of theory in developing effective health communications. J Commun. 2006;56:S1-S17.

18. Bonsaksen $\mathrm{T}$, Lerdal A. Relationships between physical activity, symptoms and quality of life among inpatients with severe mental illness. Br J Occup Ther. 2012;75(2):69-75.

19. Brüne M. "Theory of mind" in schizophrenia: A review of the literature. Schizophr Bull. 2005;31(1):21-42.

20. Dam J. Insight in schizophrenia: A review. Nordic journal of psychiatry. 2006;60(2):114-120.

21. Holt DV, Wolf J, Funke J, Weisbrod M, Kaiser S. Planning impairments in schizophrenia: Specificity, task independence and functional relevance. Schizophr Res. 2013;149(1-3):174-179. 
22. Nolen WA. Globale Klinische Beoordeling (Clinical Global Impression: CGI). Groningen: UMC; 1990.

23. Jarrett H, Fitzgerald L, Routen AC. Interinstrument Reliability of the ActiGraph GT3X+Ambulatory Activity Monitor During Free-Living Conditions in Adults. Journal of Physical Activity \& Health. 2015;12(3):382-387.

24. Gatti AA, Stratford PW, Brenneman EC, Maly MR. GT3X+ accelerometer placement affects the reliability of step-counts measured during running and pedal-revolution counts measured during bicycling. J Sports Sci. 2015;34(12):1-8.

25. McMinn D, Acharya R, Rowe DA, Gray SRA, Allan JLA. Measuring activity energy expenditure: accuracy of the GT3X+ and actiheart monitors. International Journal of Exercise Science. 2013;3:217-229.

26. Lamers LM, McDonnell J, Stalmeier PFM, Krabbe PFM, Busschbach JJV. The Dutch tariff: Results and arguments for an effective design for national EQ-5D valuation studies. Health Econ. 2006;15(10):1121-1132.

27. Prieto L, Sacristan JA, Hormaechea JA, Casado A, Badia X, Gomez JC. Psychometric validation of a generic health-related quality of life measure (EQ-5D) in a sample of schizophrenic patients. Curr Med Res Opin. 2004;20(6):827-835.

28. Brooks R, De Charro F. EuroQol: The current state of play. Health Policy. 1996;37(1):53-72.

29. Breek JC, De Vries J, Van Heck GL, Van Berge Henegouwen DP, Hamming JF. Assessment of disease impact in patients with intermittent claudication: Discrepancy between health status and quality of life. J Vasc Surg. 2005;41(3):443-450.

30. Karow A, Wittmann L, Schottle D, Schafer I, Lambert M. The assessment of quality of life in clinical practice in patients with schizophrenia. Dialogues Clin Neurosci. 2014;16(2):185-195.

31. Mas-Expósito L, Amador-Campos JA, Gómez-Benito J, Lalucat-Jo L. The World Health Organization Quality of Life Scale Brief Version: A validation study in patients with schizophrenia. Qual Life Res. 2011;20(7):1079-1089.

32. Trompenaars FJ, Masthoff ED, Van Heck GL, Hodiamont PP, De Vries J. Content validity, construct validity, and reliability of the WHOQOL-Bref in a population of Dutch adult psychiatric outpatients. Qual Life Res. 2005;14(1):151-160.

33. Kendzierski D, DeCarlo KJ. Physical activity enjoyment scale: Two validation studies. Journal of Sport and Exercise Psychology. 1991;13(1):50-64.

34. van Sluijs EMF, van Poppel MNM, Twisk JWR, Brug J, van Mechelen W. The positive effect on determinants of physical activity of a tailored, general practice-based physical activity intervention. Health Educ Res. 2005;20(3):345-356.

35. Benisovich SV, Rossi JS, Norman GJ, Nigg CR. Development of a multidimensional measure of exercise selfefficacy. Ann Behav Med. 1998;20(S190).

36. Jacoby WG. Loess: A nonparametric, graphical tool for depicting relationships between variables. Electoral Studies. 2000;19(4):577-613.

37. Carr LJ, Mahar MT. Accuracy of intensity and inclinometer output of three activity monitors for identification of sedentary behavior and light-intensity activity. J Obes. 2012;2012; doi: 10.1155/2012/460271.

38. Kozey-Keadle S, Libertine A, Lyden K, Staudenmayer J, Freedson PS. Validation of wearable monitors for assessing sedentary behavior. Med Sci Sports Exerc. 2011;43(8):1561-1567.

39. Santos-Lozano A, Santín-Medeiros F, Cardon G, Torres-Luque G, Bailón R, Bergmeir C, Ruiz JR, Lucia A, Garatachea N. Actigraph GT3X: Validation and Determination of Physical Activity Intensity Cut Points. Int J Sports Med. 2013;34(11):975-982.

40. van Harten PN, Bakker PR, Mentzel CL, Tijssen MA, Tenback DE. Movement Disorders and Psychosis, a Complex Marriage. Frontiers in Psychiatry. 2015;5(190); doi: 10.3389/fpsyt.2014.00190.

41. Gerlach J, Korsgaard S, Clemmesen P, Lauersen AML, Magelund G, Noring U, Povlsen UJ, Bech P, Casey DE. The St. Hans Rating Scale for extrapyramidal syndromes: reliability and validity. Acta Psychiatr Scand. 1993;87(4):244-252.

42. Pesek MB, Mihoci J, Medved K, Šolinc NP. Long Term Groups of Patients With Psychosis: Physical Activity and Medical Treatment. Psychiatria Danubina. 2011;23:149-154.

43. Vancampfort D, Probst M, Scheewe T, Maurissen K, Sweers K, Knapen J, De Hert M. Lack of physical activity during leisure time contributes to an impaired health related quality of life in patients with schizophrenia. Schizophr Res. 2011;129(2-3):122-127. 
44. Masthoff ED, Trompenaars FJ, Van Heck GL, Hodiamont PP, De Vries J. Quality of life and psychopathology: investigations into their relationship. Aust N Z J Psychiatry. 2006;40(4):333-340.

45. Daumit GL, Dalcin AT, Jerome GJ, Young DR, Charleston J, Crum RM, Anthony C, Hayes JH, McCarron PB, Khaykin E et al. A behavioral weight loss intervention for persons with serious mental illness in psychiatric rehabilitation centers. Int J Obes (Lond). 2011;35(8):1114-1123.

46. Sniehotta FF, Schwarzer R, Scholz U, Schüz B. Action planning and coping planning for long-term lifestyle change: theory and assessment. Eur J Soc Psychol. 2005;35(4):565-576.

47. Gollwitzer PM. Implementation Intentions: Strong Effects of Simple Plans. The American Psychologist. 1999;54(7):493-503.

48. Roberts SH, Bailey JE. Incentives and barriers to lifestyle interventions for people with severe mental illness: a narrative synthesis of quantitative, qualitative and mixed methods studies. J Adv Nurs. 2011;67(4):690-708.

49. Stanton R, Happell B. Exercise for mental illness: A systematic review of inpatient studies. Int J Ment Health Nurs. 2014;23(3):232-242.

50. Aleman A, Hijman R, De Haan EHF, Kahn RS. Memory impairment in schizophrenia: A meta-analysis. Am J Psychiatry. 1999;156(9):1358-1366.

51. Bassett DR, Troiano RP, McClain JJ, Wolff DL. Accelerometer-based Physical Activity: Total Volume per Day and Standardized Measures. Med Sci Sports Exerc. 2015;47(4):833-838. 


\section{6}

\section{If such a disparity in mortality}

rates were to affect a large segment of

the population with a less

stigmatised characteristic, then we

would witness an outcry against

a socially unacceptable decimation

of this group.

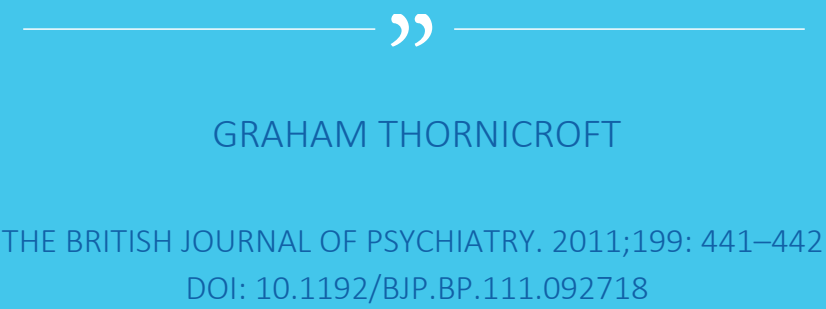




\section{Chapter}

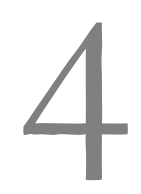

Changes in physical and psychiatric health after a multidisciplinary lifestyle enhancing treatment for inpatients with severe mental illness: the MULTI study I

Deenik, J., Tenback, D.E., Tak, E.C.P.M., Rutters, F., Hendriksen, I.J.M., van Harten, P.N. 


\section{Abstract}

Patients hospitalized with severe mental illness (SMI) often have an unhealthy lifestyle. Changing their sedentary behavior and deficiency in physical activity is challenging and effective interventions are lacking. We evaluated changes in sedentary behavior, physical activity, metabolic health and psychotic symptoms after 18 months of MUltidisciplinary Lifestyle enhancing Treatment for Inpatients with SMI (MULTI) compared to treatment as usual (TAU) and explored mediation by change in total activity. We measured sedentary behavior and physical activity using accelerometry (ActiGraph GT3X+), reflected in total activity counts. Data on metabolic health and psychotic symptoms were retrieved from routine screening data within our cohort of inpatients with SMI. Of 65 patients receiving MULTI versus 43 receiving TAU, data were analyzed using linear and logistic multilevel regression, adjusting for baseline values of outcome and differences between groups. Compared to TAU, in which no improvements were observed, we found significantly $(\mathrm{p}<$ 0.05 ) improved total activity ( $B=0.5$ standardized total activity counts per hour), moderate-to-vigorous physical activity $(B=1.8 \%)$, weight $(B=-4.2 \mathrm{~kg})$, abdominal girth $(B=-3.5$ $\mathrm{cm})$, systolic blood pressure $(B=-8.0 \mathrm{mmHg})$ and $\mathrm{HDL}$ cholesterol $(B=0.1 \mathrm{mmol} / \mathrm{l})$. No changes in psychotic symptoms were observed. Changes in total activity did not mediate metabolic improvements, suggesting that multiple components of MULTI contribute to these improvements. In contrast to previously unsuccessful attempts to change lifestyle behavior in inpatients with SMI in the longer term, MULTI showed to be a feasible treatment to sustainably improve PA and metabolic health. 


\section{Introduction}

It is well known that the physical condition of patients with Severe Mental Illness (SMI) is a cause for concern in the daily practice of mental healthcare. Compared to the general population, the mortality rate of these patients is two- to three times higher and their life expectancy is 10-20 years less, mainly due to cardiovascular disease [1-3]. Metabolic syndrome (MetS), which clusters risk factors of cardiovascular health problems and type 2 diabetes, is highly prevalent in patients with SMI [4, 5] and - despite several guidelines still seriously undertreated $[6,7]$. Sedentary behavior (SB), defined as any waking behavior in a sitting or reclining posture costing $\leq 1.5$ times the basal metabolic rate [8], has been found to be independently associated with developing the abovementioned health problems and increased mortality $[9,10]$. Physical activity (PA) is an important intervenable factor in reducing these risks [11]. Recent systematic reviews and meta-analyses showed that patients with SMI are very sedentary and are deficient in PA [12, 13]. Previous research in this area has focused mainly on outpatients or short-term inpatients and in many cases on self-reports, which may underestimate SB [14]. However, recent objective measurements have also confirmed these findings in long-term hospitalized patients $[15,16]$. Especially for these inpatients, whose metabolic health and physical fitness are generally worse compared to patients with a shorter duration of illness [17, 18], it is important to increase PA. Recent systematic reviews and meta-analyses have shown that increased PA is associated with lower metabolic risk and weight in both inpatients and outpatients with SMI [19-22] as well with beneficial changes in psychotic symptoms [19, 20]. The improvement in both physical and psychiatric health is very relevant for long-term hospitalized patients with SMI, especially considering their often poor physical health status and severe psychiatric health problems.

However, currently there is no clear answer on how we can sustainably increase the PA levels of inpatients with SMI. Studies to improve the lifestyle of inpatients with SMI, especially over the longer term, are lacking [23-25] and behavioral change is very challenging in this inpatient population. Previous research has indicated that only verbally motivating patients and facilitating them to improve self-efficacy, may be insufficient to sustainably increase the level of activity [26]. Additionally, studies focusing on factors in lifestyle interventions for effectively increasing PA indicate that such interventions should include multiple components (e.g. diet and psycho-education in addition to increasing $\mathrm{PA})$, personalization/tailoring, qualified professionals, a duration of at least four months of active intervention [27-29] and, above all, a culture change driven at management level $[25,29,30]$. However, previous intervention studies on lifestyle improvements in patients with SMI often failed to employ multiple components and their methodological quality was highly variable $[23,29,31]$.

In order to find a way to address this situation and based on previous cross-sectional research $[15,26]$, a Multidisciplinary Lifestyle Enhancing Treatment for Inpatients (MULTI) with SMI was pragmatically implemented within long-term mental healthcare of 
the psychiatric hospital GGz Centraal in the Netherlands. The purpose of MULTI was overall lifestyle change with a focus on decreasing SB and increasing PA and improving dietary habits. In this first study regarding the evaluation of MULTI, we aimed to evaluate changes in SB/PA, metabolic health and psychotic symptoms after 18 months of MULTI compared to treatment as usual (TAU) and explored whether effects were mediated by change in total activity.

\section{Materials and methods}

\section{Study design}

This cohort study was conducted at wards for long-term inpatient mental healthcare within a psychiatric hospital of GGz Centraal (The Netherlands). The current study is part of a comprehensive evaluation of MULTI, a new treatment method that was implemented pragmatically in February 2014 at three wards irrespective of any study protocol. To evaluate changes in physical health 18 months after implementation, we used routine screening data which were collected yearly in the context of the treatment and compared it to three wards that continued TAU. For baseline, we used the screening data prior to implementation of MULTI (August-December 2013), supplemented by data from previous cross-sectional research on physical activity [15], collected in the same period. Data from screening 18 months after implementation (August-December 2015) was used as follow-up, supplemented by a repeated physical activity measurement. The study protocol was approved by Medical Ethical Committee of the Isala Academy (case 14.0678). All subjects gave written informed consent in accordance with the Declaration of Helsinki.

\section{Study population}

The cohort consisted of patients with SMI who were hospitalized for at least one year. Patients were included if baseline accelerometer data were available and excluded if they (1) moved or were discharged from the hospital, (2) were deceased or (3) received another intervention related to lifestyle within 18 months after the start of MULTI. Patients who were included for follow-up, were excluded from further analysis if they refused repeated accelerometer measurement, had insufficient accelerometer data (see 2.5.1) or if we had no or hardly any baseline or follow-up data on them, defined as at least two out of the three screening measurements (somatic, blood test and psychotic symptoms) missing.

\section{Randomization and blinding}

Due to the observational nature of this study, whereby MULTI was already implemented pragmatically at three wards before the start of this study, no randomization took place. 
Therefore, we analyzed potential differences between groups at baseline and corrected for these differences in analyses if significant. Screening data were collected by research assistants, who -although not actively informed about the treatment condition- were not blinded due to visible differences regarding day-to-day program.

\section{Treatment}

We evaluated MULTI 18 months after its implementation. The purpose of this treatment method was overall lifestyle change with a focus on decreasing SB and increasing PA, and improving dietary habits. The treatment was based on improving day-to-day structure, by starting each day with getting up on time, having three joint meals per day and an active day program consisting of sports-related activities (e.g. walking, running, yoga, biking, indoor team sports), work-related activities (e.g. gardening and working in services within the hospital such as a copy shop or lunchroom), psycho-education (e.g. about side effects, dietary habits) and daily living skills training (e.g. making a grocery list, shopping, cooking). In addition, existing policies were reviewed critically - such as limiting the use of personal transport within walking distance around the hospital area for every patient. Based on heterogeneity in illness severity and different capabilities and interests, the content and intensity of the day to day program was tailored to the particular ward and individual patients in order to intend sustainable change. Although the actual frequency, intensity, kind of activities and format (e.g. group or alone) could therefore vary per patient, it was expected that all patients were doing any of the possible activities in the morning and afternoon, instead of lying in bed or sitting at the ward. A final essential element concerned the participation of the nurses in the day to day program, which contributed to the culture change and support of patients. MULTI was based on a 'change from within-principle', using current resources and staff, including supervision by psychiatrists, activity coordinators, nurse practitioners, a dietician and nurses. Adherence to and compliance with treatment was registered by the nurses in the electronic patient records and discussed in weekly multidisciplinary consultation. If needed, it was agreed that specific action would be taken to physically activate the particular patient, using motivational counselling by their mentor (one of the nurses) or psychiatrist.

Patients who received TAU continued their treatment, which mainly consisted of pharmacological treatment and a less structured day program, excluding any supported lifestyle interventions or adjustments.

\section{Measurements}

\section{Sedentary behavior and physical activity}

The ActiGraph GT3X+ (ActiGraph, Pensacola, Florida, VS) was used to measure SB and PA. The specific procedures and settings were similar to the baseline-measurement and are described elsewhere [15]. Accelerometers were worn on the right hip with an elastic 
strap between two belt loops. Patients without belt loops, used a pouch pinned on the right hip. Wear time of $\geq 6$ hours/day for $\geq 3$ days was used as the criterion for sufficient measurement. To compare individual data, the same timeframe was used for each dataset: 09.00am till 10.00pm. Data were analyzed using the ActiLife 6.8.0 software and converted into average total activity counts per hour (TAC/h) as a continuous and detailed outcome variable, where more counts indicate a higher level of activity. For regression analysis, $\mathrm{TAC} / \mathrm{h}$ was standardized to facilitate interpretation by subtracting individual values by the mean and divide it by its standard deviation. Therefore, B can be interpreted as Cohen's $d$. To differentiate activity intensities, percentage of valid wear time in SB ( $<150$ counts/min), light intensity physical activity (LPA; $151-3207$ counts/min) and moderate to vigorous physical activity (MVPA; $\geq 3208$ counts/min) were reported [32]. For patients $>65$ years old, the MVPA-threshold was fixed at $\geq 2751$ counts/min. The GT3X+ has a high inter- and intrainstrumental reliability and validity [33-35].

\section{Metabolic health}

Data on metabolic health - weight, abdominal girth, blood pressure, fasting glucose, triglycerides and total and HDL-cholesterol - were screened routinely by trained nurses in the context of prevention and treatment of somatic complications associated with the use of antipsychotics [36]. Weight was measured to the nearest $0.1 \mathrm{~kg}$ without clothes on. Abdominal girth was measured to the nearest $0.1 \mathrm{~cm}$, under the clothes at the level of the umbiculus (with the patient standing). We used the harmonized definition to determine whether patients had MetS, which requires the presence of any three of the following: increased waist circumference (men: $\geq 94 \mathrm{~cm}$, women: $\geq 80 \mathrm{~cm}$ ), low HDL cholesterol (men: $<1 \mathrm{mmol} / \mathrm{l}$, women: $<1.3 \mathrm{mmol} / \mathrm{l}$ ), hypertriglyceridemia( $\geq 1.7 \mathrm{mmol} / \mathrm{l})$, elevated blood pressure (systolic $\geq 130 \mathrm{mmHg}$ and/or diastolic $\geq 85 \mathrm{mmHg}$ ), elevated fasting glucose ( $\geq 5.6 \mathrm{mmol} / \mathrm{l})$ or any drug treatment regarding those last four [37].

\section{Psychotic symptoms}

Psychotic symptoms were screened routinely parallel to the somatic screening using the Dutch version of the Positive and Negative Syndrome Scale Remission tool (PANSS-r) within a semi-structured interview. It includes eight core symptoms of the diagnosis schizophrenia (two general psychopathology items and three items of both positive and negative symptoms), scored from 1 (absent) to 7 (extreme) [38, 39]. Separate item scores were used for analysis. The instrument was validated for clinical research within health services [40,41] and can be used in both outpatients and inpatients [40]. Unfortunately, the item 'unusual thought content' was not measured at baseline and was therefore excluded for the current analyses. 


\section{Statistical analysis}

Data analyses were performed using SPSS 22.0 and MLwiN 2.22 and interpreted at twotailed significance level of $p<0.05$. Potential differences in patient and disease characteristics between patients receiving MULTI and TAU were analyzed using t-tests and chisquare statistics. Patients for whom a change score for one measurement was missing were excluded from analysis for this particular variable ( $n=1$ for abdominal girth, $n=1$ for blood pressure, $n=2$ for blood levels and $n=12$ for PANSS-r). Continuous variables were examined for normality and homogeneity by comparing means with medians and analyzing frequency histograms and normality plots. Linearity was determined by analyzing scatterplots and plots of residual versus predicted values. If variables were not distributed linearly towards the dependent variables, they were added as tertiles in the analysis, with the first tertile as reference category.

We used linear multilevel regression to evaluate the treatment effects. Possible clustering of data within wards was taken into account, using a two-level structure with the wards as the first level and the participants as the second. The treatment variable was regressed on the change scores of the different outcome variables and adjusted for the baseline value to prevent potential regression to the mean (crude, model 1). We added patient and disease characteristics, which significantly differed between patients receiving MULTI and TAU as covariates in models 2 and 3, respectively. To evaluate recovery of MetS (yes/no, meaning that a patient no longer meets these criteria) we performed logistic multilevel regression, using the same covariates. Additionally, to gain more insight into the contribution of different elements of MULTI in the total outcome effect, final significant models were analyzed in SPSS using the PROCESS tool [42] to calculate the mediating effect of changes in TAC/h on the association between the treatment condition and the particular outcome. Therefore, we used the product of the coefficient method (Figure 1) in which associations were calculated using linear regression models. The mediation effect is the product of the a- and b-coefficient ( $a b$, not shown within models) and was considered significant if the bias-corrected and accelerated (BCa) bootstrapped confidence intervals did not include zero.

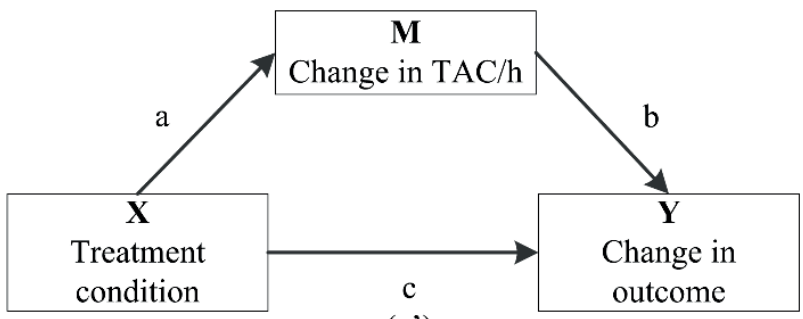

(c')

Fig. 1. Model summarizing how the role of change in average total activity counts per hour (TAC/h) as potential mediator $(M)$ in the association between treatment condition $(X)$ and significant change in measures for metabolic health or psychotic symptoms $(Y)$ is quantified in mediation analysis. It includes the associations between 
treatment condition and TAC/h (a), TAC/h and the particular outcome variable (b) and treatment condition on the particular outcome variable (c). Mediation is only possible if (a) and (b) are significant. The coefficient between the latter two, controlling for change in TAC/h, is in parentheses $\left(c^{\prime}\right)$.

\section{Results}

Of the eligible patients, 108 were included for analyses and 15 dropped out (Figure 2). Table 1 shows the baseline characteristics of patients receiving MULTI and TAU. On average, patients receiving MULTI were younger $(t=3.22, p=0.002)$, had a higher baseline illness severity $(t=-3.18, p=0.002)$ and were more frequently diagnosed with schizophrenia or other psychotic disorders $\left(X^{2}=18.41, p<0.001\right)$ compared to patients receiving TAU.

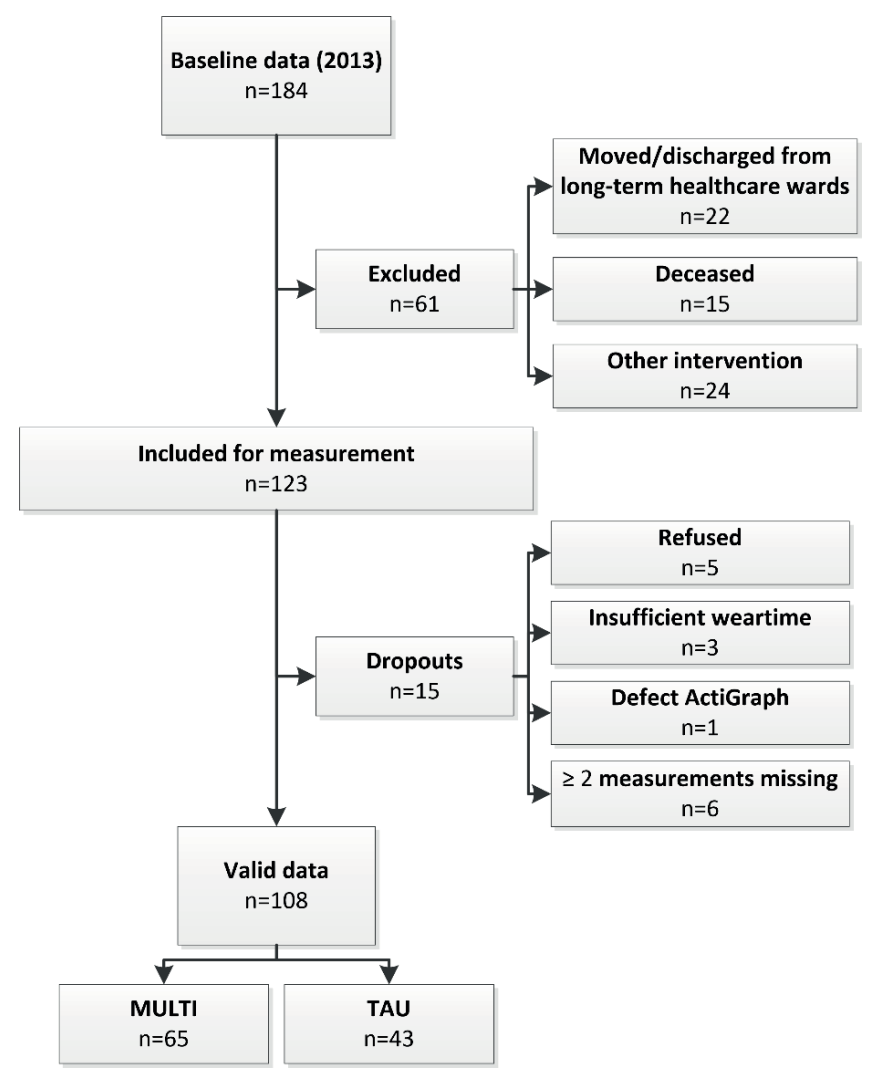

Fig. 2. Flowchart of the study population. MULTI, Multidisciplinary Lifestyle-enhancing Treatment for Inpatients with severe mental illness; TAU, Treatment As Usual. Baseline data reported in Kruisdijk et al. [15] 


\section{Sedentary behavior and physical activity}

Table 1 shows that TAC/h increased with 3918 counts per hour (13.5\%) in the patients receiving MULTI and decreased with 330 counts per hour $(-1.4 \%)$ in TAU. The final adjusted model (Table 2) confirms this observation, showing a significant effect on TAC/h in patients receiving $\mathrm{MULTI}$, compared to TAU ( $B=0.46$ standardized TAC/h, $p=0.02)$. This effect was mainly reflected in a non-significant decrease of SB $(B=-2.15 \%, p=0.07)$ and a significant increase in MVPA ( $B=1.78 \%, p=0.03)$.

\section{Metabolic health}

We observed several significant changes in metabolic health after adjustment for age, diagnosis and baseline illness severity. When compared to TAU, we observed significantly greater changes in weight $(B=-4.18 \mathrm{~kg}, p=0.04)$, abdominal girth $(B=-3.48 \mathrm{~cm}, p=0.04)$, systolic blood pressure $(B=-8.03 \mathrm{mmHg}, p=0.02)$ and $\mathrm{HDL}$ cholesterol $(B=0.10 \mathrm{mmol} / \mathrm{l}$, $\mathrm{p}=0.03$ ) in the group receiving MULTI.

Weight loss in patients receiving MULTI corresponded to an average of $4.2 \%$ reduction in the initial weight. Regarding change in MetS status, too few patients recovered from MetS as a whole to make a valid corrected analysis [43]. Therefore, we analyzed recovery of at least one MetS criterion, which was the case in 24 (36.9\%) patients receiving MULTI and in 10 (23.3\%) patients receiving TAU, compared to no change and deterioration. Corrected for criteria met at baseline, age, diagnosis and baseline illness severity, analysis showed a non-significant effect in favor of MULTI (OR $=2.06, p=0.22$ ).

\section{Psychotic symptoms}

As shown in Table 1, we observed a decrease in negative symptoms in patients receiving MULTI, indicated by blunted affect ( $M=-1.34, S D=2.43)$, passive/apathetic social withdrawal $(M=-0.61, S D=2.28)$ and lack of spontaneity and flow of conversation $(M=-0.49$, $S D=2.18)$. These symptoms increased in TAU. Although coefficients in the regression models confirm these directions, effects were not significant. 


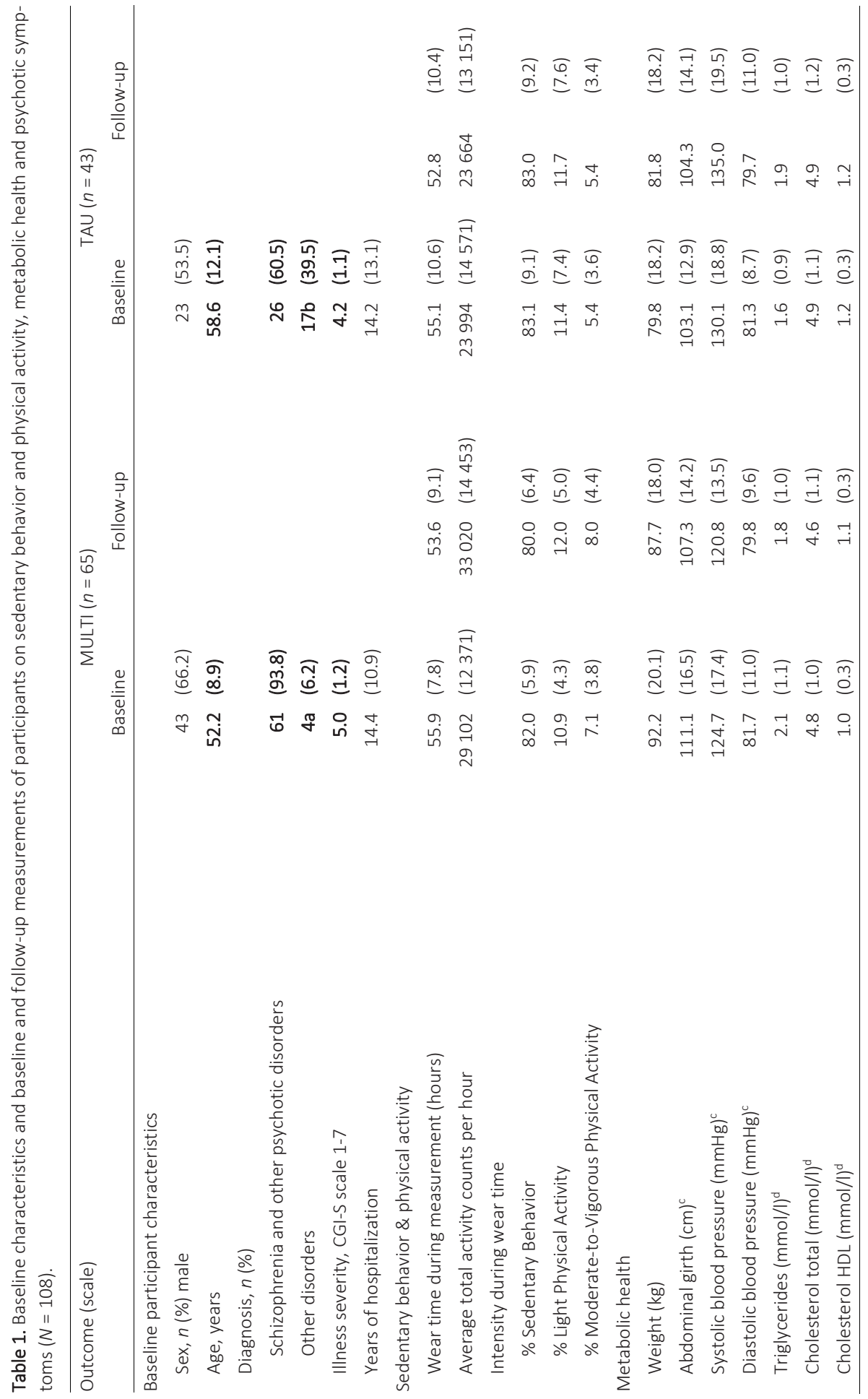


The MULTI study I: physical and psychiatric health

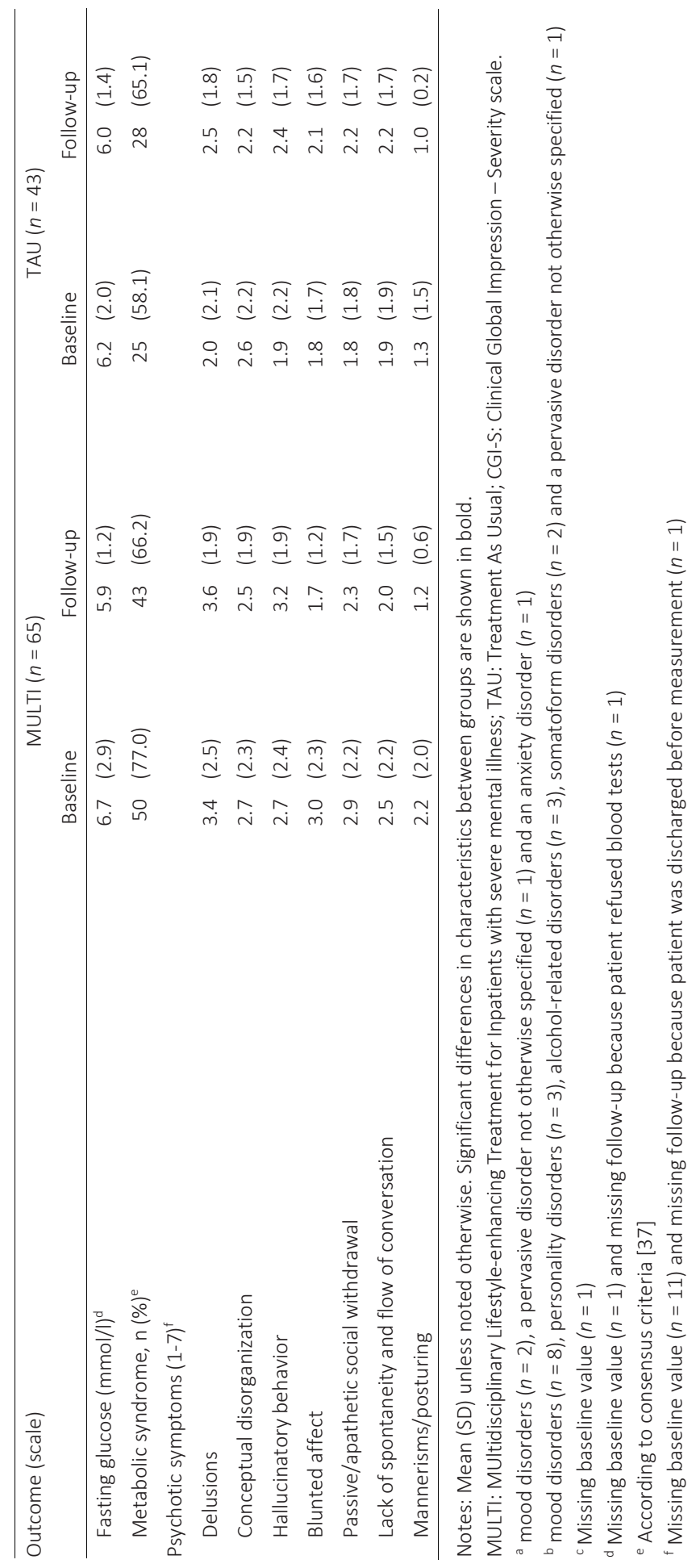




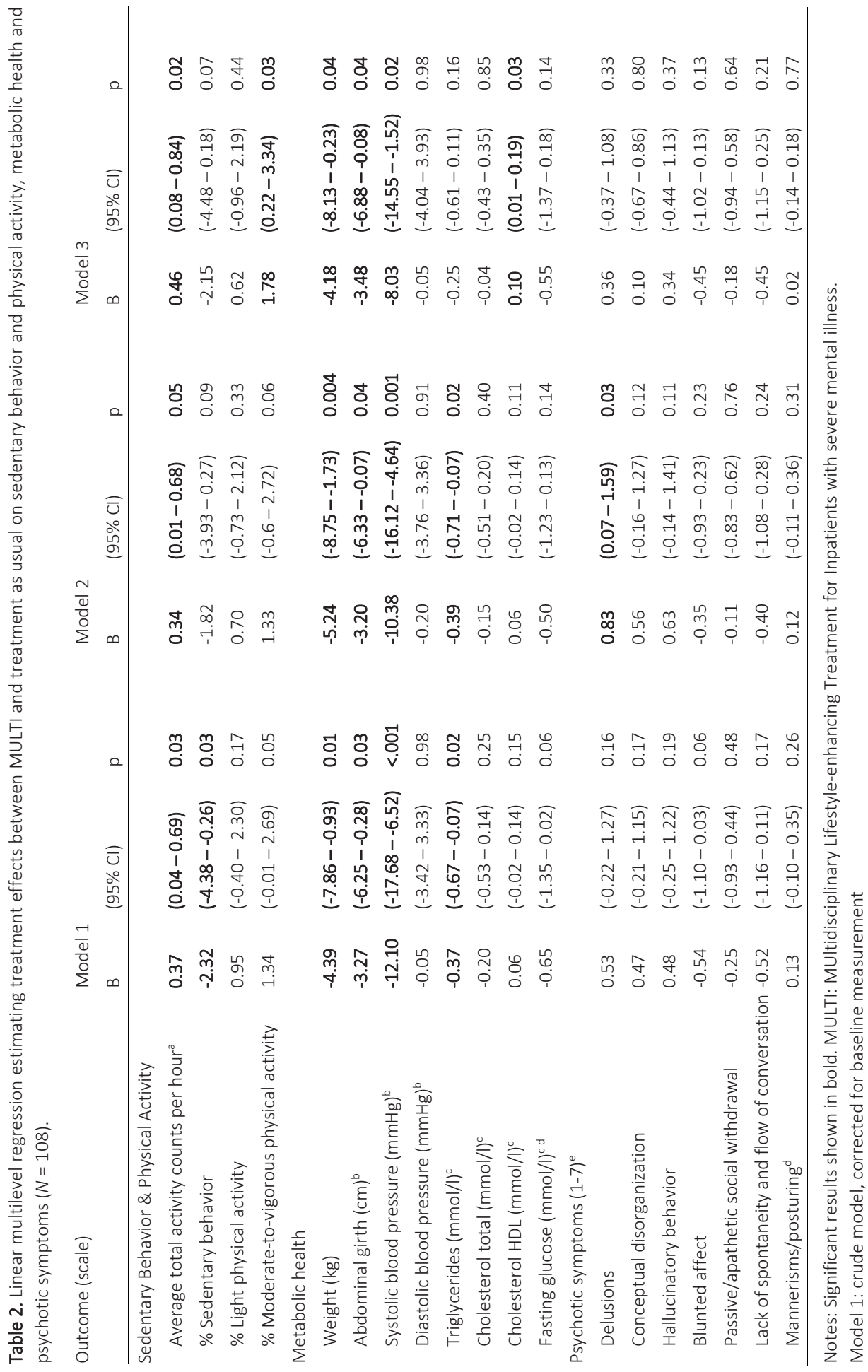


The MULTI study I: physical and psychiatric health






\section{Mediation by change in average total activity counts}

With regard to the mediation analysis (Figure 3), except for systolic blood pressure, none of the mediation models showed statistically significant standardized regression coefficients between treatment condition and change in TAC/h (a). All models showed nonsignificant coefficients between change in TAC/h and the specific outcome measure (b). In line with these findings, mediation analyses showed that change in TAC/h did not mediate the effect of MULTI on weight ( $a b=-0.38 ; 95 \% \mathrm{BCa} C l:-2.24-0.17)$, abdominal girth ( $\mathrm{ab}=-0.51 ; 95 \% \mathrm{BCa} \mathrm{Cl}:-2.01-0.06)$, systolic blood pressure $(\mathrm{ab}=0.74 ; 95 \% \mathrm{BCa} \mathrm{Cl}$ : 0.49-3.56) and HDL cholesterol ( $\mathrm{ab}=-0.001 ; 95 \% \mathrm{BCa} \mathrm{Cl}:-0.03-0.01)$.

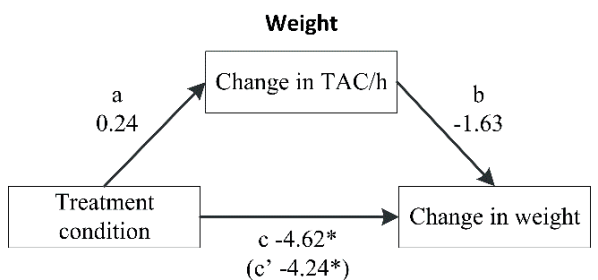

Systolic blood pressure



$\left(c^{\prime}-10.11^{*}\right)$

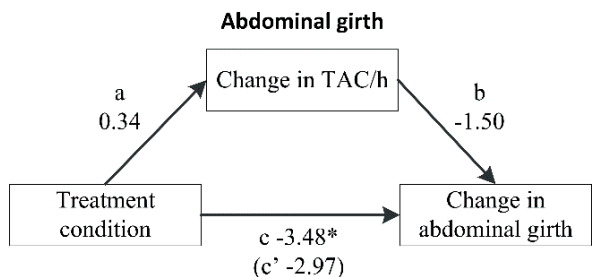

HDL cholesterol



(c' $\left.0.10^{*}\right)$

Fig. 3. Regression coefficients for significant changes on weight, abdominal girth, systolic blood pressure and HDL cholesterol, analyzed for mediation by change in average total activity counts per hour (TAC/h). The association between treatment condition and specific outcome, controlling for change in $\mathrm{TAC} / \mathrm{h}$, is in parentheses. Models were corrected for baseline measurement, age, diagnosis (schizophrenia/other psychotic disorders, yes/no) and illness severity at baseline. ${ }^{*} p<0.05$

\section{Discussion}

MULTI showed to be an effective treatment resulting in sustainable and significant improvements in PA and metabolic health in inpatients with SMI. In addition -although it was not a specific research question- this study showed no substantial change within the treatment as usual group.

Overall, we observed a $13.5 \%$ increase in total activity, showing a significant treatment effect. Although modest, the non-significant decrease in SB and the significant 1.8\% increase of MVPA compared to TAU correspond to recommendations to replace SB by PA in patients with SMI $[12,44]$. To our knowledge, no intervention studies have been 
conducted in a comparable population presenting follow-up data on objectively measured activity counts. Improvements in PA, however, correspond to findings in small exercise-focused outpatient studies [45] and outpatients with psychotic and bipolar disorder after receiving group PA and education on diet [46]. Taking the substantial effects on metabolic health into account, it seems that these relatively small changes in SB and PA after 18 months of MULTI could be of value as part of such an integrated lifestyle approach.

Given the fact that the MetS is still highly prevalent and undertreated in patients with SMI [4-7], the finding that patients receiving MULTI had two times higher odds to recover from at least one MetS criterion compared to TAU is clinically relevant. Changes in individual MetS criteria included significant improvements in weight, abdominal girth and systolic blood pressure and HDL cholesterol. The $4.2 \%$ reduction of the initial weight in patients receiving MULTI approaches the clinically significant marker of $5 \%$ weight loss, associated with reduced cardiovascular risk among overweight and obese individuals [47]. A meta-analytic review of previous intervention studies in adults with a serious mental illness reported a much smaller weight loss of $2 \%$ [48]. This disparity may be explained by the different setting - primarily outpatients - and less comprehensive add-on interventions, as about half of them focused on education instead of an integrated supported approach. Although our findings correspond with small to medium effects after PA and nutrition interventions on anthropometric measures in patients with SMI [20,49], they are inconsistent with a recent study which included Dutch inpatients with SMI - a population quite similar to ours - as they found no effect on waist circumference and metabolic health after twelve months [50]. This difference could be explained by the use of another intervention design, in which lifestyle coaches from outside the organization were used instead of an integrated 'change from within' approach. A systematic review of studies on blood pressure, triglycerides, fasting glucose and cholesterol reported inconsistent findings [51], which may be explained by the high heterogeneity of interventions and methodological quality (e.g. small sample sizes) of the included studies.

We observed no significant improvements in psychotic symptoms, which is inconsistent with recent reviews and meta-analysis that reported significant improvements as a result of increased PA [19-21, 51] in patients with SMI. However, the majority of their included studies concerned outpatients, who may be more likely to achieve reduction of symptom severity compared to inpatients with a higher and prolonged illness severity. Our findings did correspond to a previous study evaluating high aerobic intensity training in inpatients with schizophrenia and a recent RCT in residential and clinical teams treating patients with SMI with a combined diet- and exercise lifestyle intervention, both finding no effects on PANSS $[52,53]$. Mediation by change in total activity was absent, indicating that the improvements we found were not just because of increased physical activity. It suggests that improvements are a result of a combination of components of MULTI. We speculate that the organizational culture change is the main factor, with multiple components complementing PA, including a focus on dietary habits, psycho-education, personal tailoring, 
support by peers and qualified participating staff. This corresponds to results of recent studies, which advocated the use of such elements [28-30, 49, 54].

Some limitations of our study should be discussed. Firstly, because we evaluated a treatment that was already implemented, we were not able to randomize the wards. By using multilevel regression correcting for differences between MULTI and TAU, we aimed to minimize bias and obtain robust results. Secondly, our analyses were largely dependent on the number of patients and available data within the cohort. As a result, our analysis on the recovery of the MetS was affected by the limited group size and should be interpreted with caution [43]. Thirdly, we had a relatively large amount of missings of baseline PANSS-r scores. However, it is likely that these scores were missing due the greater difficulty of obtaining measurements from patients with severe illness. Consequently, we could presume that this understated rather than overstated the impact of the intervention. Fourthly, no international consensus exists on how to set up and process accelerometer data and on the heterogeneity of chosen thresholds, which can hinder comparisons between studies, especially percentages of SB, light PA and MVPA. By using average total activity counts, which was suggested to reach a better standard for comparability [55], we took initial steps to improve comparability of accelerometer data. Lastly, as MULTI was based on prolonged hospital stay, such an approach may be less feasible for other healthcare settings. However, previously mentioned important elements of the treatment that are supported by literature such as multidisciplinary cooperation, combining multiple components (e.g. instead of PA and diet separately) and support of peers and qualified staff should be possible to implement in other settings, such as sheltered housing or outpatient facilities, as well.

Compared to previous research, our study has several advantages. Firstly, because of the observational design and a treatment developed within the current clinical practice and resources of inpatient mental healthcare, our data support the generalizability of our findings and the feasibility of MULTI, which is very relevant for clinical practice [22]. Secondly, we used a follow-up period of 18 months in this study, compared to the majority of previous studies which followed patients for $\leq 6$ months $[22,23,25,31]$. Another strength is the use of accelerometers instead of self-reports to measure SB and PA $[12,56]$, which greatly improved the reliability of the data, especially in this population. Furthermore, in the multilevel analysis, we corrected for possible clustering within wards (e.g. patients or the way staff works within a ward might differ between wards, influencing results), regression to the mean (e.g. overweight patients are more likely to lose weight) and differences between MULTI and TAU, as randomization was not possible. Finally, by analyzing possible mediation by total activity, we took a first step to gain more insight into the contribution of different elements of MULTI to the observed improvements.

Before this intervention can be widely implemented in inpatient mental healthcare, replication of MULTI including the measurements at other sites is needed. Nevertheless, the findings provide important implications for clinical practice. Previous interventions involving inpatients with SMI failed to achieve desired improvements $[24,50]$ and often 
lack an integrated approach and culture change. After maintaining such promising results over the longer term, with a treatment developed within the current clinical practice and resources of inpatient mental healthcare, our study suggests that a sustainable solution towards a healthier lifestyle is already at our fingertips. This could have an even bigger impact if transferred into standard care, where MULTI could be an essential part of a treatment strategy to interrupt the deterioration of physical health usually seen within this population and to improve PA and metabolic health in the longer term. Although this is a hopeful message, an integrated multi-component treatment requires a culture change driven by multidisciplinary cooperation and staff participation, supported at management level. Future implementation-evaluation identifying barriers and facilitators towards implementation are therefore critical for clinical practice. Additionally, since especially SMI starts at early age [57] and somatic comorbidities are associated with more frequent rehospitalization [58], an integrated and culture changing approach can provide lifelong improvements and prevent major health issues that are currently seen these days in patients with a long history of SMI.

In summary, this 18 months follow-up study shows that an integrated multi-component and multidisciplinary lifestyle enhancing treatment can improve PA and metabolic health substantially compared to treatment as usual. We urge long-term follow-up studies on multi-component lifestyle enhancing interventions to improve the disproportional metabolic health problems in SMI patients. 


\section{References}

1. Walker ER, McGee RE, Druss BG. Mortality in Mental Disorders and Global Disease Burden Implications A Systematic Review and Meta-analysis. Jama Psychiatry. 2015;72(4):334-341.

2. Laursen TM, Wahlbeck K, Hallgren J, Westman J, Osby U, Alinaghizadeh H, Gissler M, Nordentoft M. Life expectancy and death by diseases of the circulatory system in patients with bipolar disorder or schizophrenia in the Nordic countries. PLoS One. 2013;8(6):e67133.

3. Lawrence D, Hancock KJ, Kisely S. The gap in life expectancy from preventable physical illness in psychiatric patients in Western Australia: retrospective analysis of population based registers. $\mathrm{Br}$ Med J. 2013;346:f2539.

4. Stubbs B, Vancampfort D, De Hert M, Mitchell AJ. The prevalence and predictors of type two diabetes mellitus in people with schizophrenia: a systematic review and comparative meta-analysis. Acta Psychiatr Scand. 2015;132(2):144-157.

5. Vancampfort D, Stubbs B, Mitchell AJ, De Hert M, Wampers M, Ward PB, Rosenbaum S, Correll CU. Risk of metabolic syndrome and its components in people with schizophrenia and related psychotic disorders, bipolar disorder and major depressive disorder: a systematic review and meta-analysis. World Psychiatry. 2015;14(3):339-347.

6. Bruins J, Pijnenborg GH, van den Heuvel ER, Visser E, Corpeleijn E, Bartels-Velthuis AA, Bruggeman R, Jorg F. Persistent Low Rates of Treatment of Metabolic Risk Factors in People With Psychotic Disorders: A PHAMOUS Study. J Clin Psychiatry. 2017;78(8):1117-1125.

7. Swaby L, Hind D, Gossage-Worrall R, Shiers D, Mitchell J, Holt RIG. Adherence to NICE guidance on lifestyle advice for people with schizophrenia: a survey. BJPsych bulletin. 2017;41(3):137-144.

8. Sedentary Behaviour Research Network. Letter to the editor: standardized use of the terms "sedentary" and "sedentary behaviours". Applied Physiology, Nutrition, and Metabolism. 2012;37(3):540-542.

9. Biswas A, Oh PI, Faulkner GE, Bajaj RR, Silver MA, Mitchell MS, Alter DA. Sedentary Time and Its Association With Risk for Disease Incidence, Mortality, and Hospitalization in Adults A Systematic Review and Metaanalysis. Ann Intern Med. 2015;162(2):123-132.

10. Brocklebank LA, Falconer CL, Page AS, Perry R, Cooper AR. Accelerometer-measured sedentary time and cardiometabolic biomarkers: A systematic review. Prev Med. 2015;76:92-102.

11. Cabassa L, Ezell JM, Lewis-Fernández R. Lifestyle interventions for adults with serious mental illness: A systematic literature review. Psychiatr Serv. 2010;61(8):774-782.

12. Stubbs B, Williams JE, Gaughran F, Craig T. How sedentary are people with psychosis? A systematic review and meta-analysis. Schizophr Res. 2016;171(1-3):103-109.

13. Vancampfort D, Firth J, Schuch FB, Rosenbaum S, Mugisha J, Hallgren M, Probst M, Ward PB, Gaughran F, De Hert M et al. Sedentary behavior and physical activity levels in people with schizophrenia, bipolar disorder and major depressive disorder: a global systematic review and meta-analysis. World Psychiatry. 2017;16(3):308-315.

14. Firth J, Stubbs B, Vancampfort D, Schuch FB, Rosenbaum S, Ward PB, Firth JA, Sarris J, Yung AR. The Validity and Value of Self-reported Physical Activity and Accelerometry in People With Schizophrenia: A Population-Scale Study of the UK Biobank. Schizophr Bull. 2017.

15. Kruisdijk F, Deenik J, Tenback D, Tak E, Beekman A, van Harten P, Hopman-Rock M, Hendriksen I. Accelerometer-measured sedentary behaviour and physical activity of inpatients with severe mental illness. Psychiatry Res. 2017;254:67-74.

16. Stubbs B, Chen LJ, Chung MS, Ku PW. Physical activity ameliorates the association between sedentary behavior and cardiometabolic risk among inpatients with schizophrenia: A comparison versus controls using accelerometry. Compr Psychiatry. 2017;74:144-150.

17. Mitchell AJ, Vancampfort D, Sweers K, van Winkel R, Yu W, De Hert M. Prevalence of metabolic syndrome and metabolic abnormalities in schizophrenia and related fisorders - A systematic review and meta-analysis. Schizophr Bull. 2013;39(2):306-318. 
18. Vancampfort D, Probst M, Scheewe T, De Herdt A, Sweers K, Knapen J, van Winkel R, De Hert M. Relationships between physical fitness, physical activity, smoking and metabolic and mental health parameters in people with schizophrenia. Psychiatry Res. 2013;207(1-2):25-32.

19. Dauwan M, Begemann MJH, Heringa SM, Sommer IE. Exercise improves clinical symptoms, quality of life, global functioning, and depression in schizophrenia: A systematic review and meta-analysis. Schizophr Bull. 2016;42(3):588-599.

20. Rosenbaum S, Tiedemann A, Sherrington C, Curtis J, Ward PB. Physical activity interventions for people with mental illness: a systematic review and meta-analysis. J Clin Psychiatry. 2014;75(9):964-974.

21. Vera-Garcia E, Mayoral-Cleries F, Vancampfort D, Stubbs B, Cuesta-Vargas AI. A systematic review of the benefits of physical therapy within a multidisciplinary care approach for people with schizophrenia: An update. Psychiatry Res. 2015;229(3):828-839.

22. Naslund JA, Whiteman KL, McHugo GJ, Aschbrenner KA, Marsch LA, Bartels SJ. Lifestyle interventions for weight loss among overweight and obese adults with serious mental illness: A systematic review and metaanalysis. Gen Hosp Psychiatry. 2017;47:83-102.

23. Stanton R, Happell B. Exercise for mental illness: A systematic review of inpatient studies. Int J Ment Health Nurs. 2014;23(3):232-242.

24. Levitt GA, Shinault K, Patterson S, Otaluka O. Weight Gain in Psychiatric Inpatients: Are Interventions Making a Positive Impact? Prim Care Companion CNS Disord. 2017;19(4):17m02111.

25. Vancampfort D, Stubbs B, Ward PB, Teasdale S, Rosenbaum S. Integrating physical activity as medicine in the care of people with severe mental illness. Aust N Z J Psychiatry. 2015;49(8):681-682.

26. Deenik J, Kruisdijk F, Tenback D, Braakman-Jansen A, Taal E, Hopman-Rock M, Beekman A, Tak E, Hendriksen I, van Harten P. Physical activity and quality of life in long-term hospitalized patients with severe mental illness: a cross-sectional study. BMC Psychiatry. 2017;17:298.

27. Bonfioli E, Berti L, Goss C, Muraro F, Burti L. Health promotion lifestyle interventions for weight management in psychosis: a systematic review and meta-analysis of randomised controlled trials. BMC Psychiatry. 2012;12(1):1-12.

28. Vancampfort D, Rosenbaum S, Schuch F, Ward PB, Richards J, Mugisha J, Probst M, Stubbs B. Cardiorespiratory fitness in severe mental illness: A systematic review and meta-analysis. Sports Med. 2017;47(2):343352.

29. Ward MC, White DT, Druss BG. A meta-review of lifestyle interventions for cardiovascular risk factors in the general medical population: lessons for individuals with serious mental illness. J Clin Psychiatry. 2015;76(4):e477-486.

30. Long C, Rowell A, Rigg S, Livesey F, McAllister P. What is effective in promoting a healthy lifestyle in secure psychiatric settings? A review of the evidence for an integrated programme that targets modifiable health risk behaviours. The Journal of Forensic Practice. 2016;18(3):204-215.

31. Chalfoun C, Karelis AD, Stip E, Abdel-Baki A. Running for your life: A review of physical activity and cardiovascular disease risk reduction in individuals with schizophrenia. J Sports Sci. 2016;34(16):1500-1515.

32. Santos-Lozano A, Santin-Medeiros F, Cardon G, Torres-Luque G, Bailon R, Bergmeir C, Ruiz JR, Lucia A, Garatachea N. Actigraph GT3X: validation and determination of physical activity intensity cut points. Int J Sports Med. 2013;34(11):975-982.

33. Jarrett $H$, Fitzgerald L, Routen AC. Interinstrument reliability of the ActiGraph GT3X+ambulatory activity monitor during free-living conditions in adults. Journal of Physical Activity and Health. 2015;12(3):382-387.

34. Gatti AA, Stratford PW, Brenneman EC, Maly MR. GT3X+ accelerometer placement affects the reliability of step-counts measured during running and pedal-revolution counts measured during bicycling. J Sports Sci. 2015;34(12):1-8.

35. McMinn D, Acharya R, Rowe DA, Gray SRA, Allan JLA. Measuring activity energy expenditure: accuracy of the GT3X+ and actiheart monitors. International Journal of Exercise Science. 2013;6(3):217-229.

36. Cahn W, Ramlal D, Bruggeman R, de Haan L, Scheepers FE, van Soest MM, Assies J, Slooff CJ. [Prevention and treatment of somatic complications arising from the use of antipsychotics]. Tijdschr Psychiatr. 2008;50(9):579-591. 
37. Alberti KGMM, Eckel RH, Grundy SM, Zimmet PZ, Cleeman JI, Donato KA, Fruchart JC, James WPT, Loria CM, Smith SC. Harmonizing the metabolic syndrome: A joint interim statement of the international diabetes federation task force on epidemiology and prevention; National heart, lung, and blood institute; American heart association; World heart federation; International atherosclerosis society; And international association for the study of obesity. Circulation. 2009;120(16):1640-1645.

38. Kay SR, Fiszbein A, Opler LA. The positive and negative syndrome scale (PANSS) for schizophrenia. Schizophr Bull. 1987;13(2):261-276.

39. van Os J, Burns T, Cavallaro R, Leucht S, Peuskens J, Helldin L, Bernardo M, Arango C, Fleischhacker W, Lachaux B et al. Standardized remission criteria in schizophrenia. Acta Psychiatr Scand. 2006;113(2):91-95.

40. Linden M, Scheel T, Rettig K. Validation of the factorial structure of the Positive and Negative Syndrome Scale in use by untrained psychiatrists in routine care. Int J Psychiatry Clin Pract. 2007;11(1):53-60.

41. van Os J, Drukker M, a Campo J, Meijer J, Bak M, Delespaul P. Validation of remission criteria for schizophrenia. Am J Psychiatry. 2006;163(11):2000-2002.

42. PROCESS: A versatile computational tool for observed variable mediation, mod-eration, and conditionalprocess modeling [White paper] [http://www.afhayes.com/public/process2012.pdf]

43. Vittinghoff $E$, McCulloch CE. Relaxing the rule of ten events per variable in logistic and Cox regression. Am J Epidemiol. 2007;165(6):710-718.

44. Stubbs B, Firth J, Berry A, Schuch FB, Rosenbaum S, Gaughran F, Veronesse N, Williams J, Craig T, Yung AR et al. How much physical activity do people with schizophrenia engage in? A systematic review, comparative meta-analysis and meta-regression. Schizophr Res. 2016;176(2-3):431-440.

45. Pearsall R, Hughes S, Geddes J, Pelosi A. Understanding the problems developing a healthy living programme in patients with serious mental illness: A qualitative study. BMC Psychiatry. 2014;14(1):38.

46. Masa-Font R, Fernandez-San-Martin MI, Martin Lopez LM, Alba Munoz AM, Oller Canet S, Martin Royo J, San Emeterio Echevarria L, Olona Tabuena N, Ibarra Jato M, Barroso Garcia A et al. The effectiveness of a program of physical activity and diet to modify cardiovascular risk factors in patients with severe mental illness after 3-month follow-up: CAPiCOR randomized clinical trial. Eur Psychiatry. 2015;30(8):1028-1036.

47. Brown JD, Buscemi J, Milsom V, Malcolm R, O'Neil PM. Effects on cardiovascular risk factors of weight losses limited to 5-10\%. Transl Behav Med. 2016;6(3):339-346.

48. Olker SJ, Parrott JS, Swarbrick MA, Spagnolo AB. Weight management interventions in adults with a serious mental illness: A meta-analytic review. American Journal of Psychiatric Rehabilitation. 2016;19(4):370-393.

49. Teasdale SB, Ward PB, Rosenbaum S, Samaras K, Stubbs B. Solving a weighty problem: systematic review and meta-analysis of nutrition interventions in severe mental illness. The British Journal of Psychiatry. 2017;210(2):110-118

50. Looijmans A, Stiekema A, Bruggeman R, van der Meer L, Stolk RP, Schoevers RA, Jörg F, Corpeleijn E. Changing the obesogenic environment to improve cardiometabolic health in residential patients with a severe mental Illness: ELIPS, a randomized controlled trial. Br J Psychiatry. 2017;211(5):296-303.

51. Firth J, Cotter J, Elliott R, French P, Yung AR. A systematic review and meta-analysis of exercise interventions in schizophrenia patients. Psychol Med. 2015;45(7):1343-1361.

52. Heggelund J, Nilsberg GE, Hoff J, Morken G, Helgerud J. Effects of high aerobic intensity training in patients with schizophrenia: a controlled trial. Nordic journal of psychiatry. 2011;65(4):269-275.

53. Stiekema APM, Looijmans A, van der Meer L, Bruggeman R, Schoevers RA, Corpeleijn E, Jorg F. Effects of a lifestyle intervention on psychosocial well-being of severe mentally ill residential patients: ELIPS, a cluster randomized controlled pragmatic trial. Schizophr Res. 2018.

54. Roberts SH, Bailey JE. Incentives and barriers to lifestyle interventions for people with severe mental illness: a narrative synthesis of quantitative, qualitative and mixed methods studies. J Adv Nurs. 2011;67(4):690-708.

55. Bassett DR, Troiano RP, McClain JJ, Wolff DL. Accelerometer-based physical activity: total volume per day and standardized measures. Med Sci Sports Exerc. 2015;47(4):833-838.

56. Soundy A, Roskell C, Stubbs B, Vancampfort D. Selection, use and psychometric properties of physical activity measures to assess individuals with severe mental illness: a narrative synthesis. Arch Psychiatr Nurs. 2014;28(2):135-151. 
57. Kessler RC, Amminger GP, Aguilar-Gaxiola S, Alonso J, Lee S, Ustun TB. Age of onset of mental disorders: a review of recent literature. Current opinion in psychiatry. 2007;20(4):359-364.

58. Filipcic I, Simunovic Filipcic I, Ivezic E, Matic K, Tunjic Vukadinovic N, Vuk Pisk S, Bodor D, Bajic Z, Jakovljevic M, Sartorius N. Chronic physical illnesses in patients with schizophrenia spectrum disorders are independently associated with higher rates of psychiatric rehospitalization; a cross-sectional study in Croatia. Eur Psychiatry. 2017;43:73-80. 



\title{
Chapter
}

\author{
Improved psychosocial functioning and \\ quality of life in inpatients with severe \\ mental illness receiving a multidisciplinary \\ lifestyle enhancing treatment. The MULTI \\ study II
}

Deenik, J., Tenback, D.E., Tak, E.C.P.M., Hendriksen, I.J.M., van Harten, P.N.

Mental Health and Physical Activity 2018; 15: 145-152

doi: 10.1016/j.mhpa.2018.10.004 


\section{Abstract}

Patients hospitalised with severe mental illness (SMI) have poor physical health. Recently, a multidisciplinary lifestyle enhancing treatment for inpatients with SMI (MULTI) was implemented after which improvements of physical health were observed in the longer term. As part of a comprehensive evaluation of MULTI, we aimed to additionally analyse changes in perceived psychosocial functioning and quality of life after 18 months of MULTI compared to treatment as usual (TAU). Furthermore, we explored whether increased physical activity mediated significant changes. In this observational study, we collected data on psychosocial functioning (HoNOS) and quality of life (EQ-5D and WHOQoL-Bref) within our cohort of inpatients with SMI. This was supplemented by repeated physical activity measurement (ActiGraph GT3X+). Data were analysed using linear multilevel regression, adjusting for baseline values of outcome and differences between groups. Patients receiving MULTI $(n=65)$ showed significantly improved functioning on sum score and subscales for impairment and social functioning compared to TAU $(n=47)$. Quality of life improved within MULTI but did not differ significantly from TAU. Changes in total activity did not mediate improvements in psychosocial functioning, suggesting that multiple components of MULTI contribute to these improvements. In addition to previously observed improvement of physical health, MULTI showed to be a feasible treatment to sustainably improve psychosocial functioning compared to TAU and increase the quality of life in inpatients with SMI. 


\section{Introduction}

The poor physical health of patients with severe mental illness (SMI) has been well-studied. Metabolic risk factors are highly prevalent in this population [1-3], contributing to poor cardiovascular health, one of the main causes of premature mortality of at least 720 years compared to the general population [4-10]. An increasing number of studies focused on improving lifestyle as an essential factor in this context, and they showed positive effects on physical health by addressing the lack of physical activity and/or poor dietary habits [11-14]. Additionally, improvements in global functioning and quality of life (QoL) have been found $[11,15]$. These findings are especially relevant for long-term hospitalized patients, given the negative associations between illness duration and physical activity, physical health and QoL [16-19], combined with their high level of sedentary behaviour $[20,21]$.

However, the majority of these studies focused on outpatients. Studies on how to improve the lifestyle of inpatients with SMI, notably over the longer term, are lacking [2224]. Recently, an integrated lifestyle approach was applied in this inpatient group. This approach showed, for the first time, a significantly improved physical activity and metabolic health on the longer term, compared to treatment as usual (TAU) [14]. This Multidisciplinary Lifestyle enhancing Treatment for Inpatients with SMI (MULTI) was pragmatically implemented within a group of inpatients with the purpose of overall lifestyle change with a focus on decreasing sedentary behaviour, increasing physical activity and improving dietary habits within the context of day-to-day treatment. These findings are very promising for inpatients with SMI and add to the evidence of physical health benefits of lifestyle interventions in people with SMI. More patient-oriented factors, such as the psychological functioning and QoL, are less well studied, although such outcomes are often more relevant for patients' subjective well-being. Where QoL focuses on ones' perceived quality of life in several domains (e.g. physical or psychological), psychosocial functioning includes more clinical factors such as the presence of behavioural problems (e.g. aggressive behaviour), impairments or social problems (e.g. with relationships or activities of daily living). Also in hospitalised patients with SMI, data on the effects of improving lifestyle on these outcomes in hospitalised patients with SMI are scarce [25].

Therefore, in addition to findings in physical health, the present study aimed to analyse changes in perceived psychosocial functioning and QoL after 18 months of MULTI compared to TAU and to explore whether increased physical activity mediated significant changes. 


\section{Methods}

\section{Study design}

This observational cohort study is part of a comprehensive evaluation of MULTI, a treatment method that was implemented pragmatically in February 2014 at three wards for long-term inpatient mental healthcare within a psychiatric hospital of GGz Centraal (The Netherlands). To evaluate changes in psychosocial functioning and QoL 18 months after implementation, we used routine screening data, which were collected yearly in the context of the treatment and compared it to three wards that continued TAU. For baseline, we used the screening data measured prior to implementation of MULTI (August - December 2013), and accelerometer-measured total activity counts as a continuous outcome for sedentary behaviour and physical activity, obtained from our dataset of previous cross-sectional research [20]. For follow-up, data from screening 18 months after implementation (August - December 2015) was used, supplemented by a repeated physical activity measurement. The study protocol was approved by the Medical Ethical Committee of the Isala Academy (case 14.0678) and all subjects gave written informed consent in accordance with the Declaration of Helsinki.

\section{Study population}

The cohort consisted of patients with SMI who were hospitalised for at least one year. Patients were included if they received no other intervention related to lifestyle within 18 months after the start of MULTI and if baseline accelerometer data were available. Patients were excluded for follow-up if they were deceased, moved to other wards or were discharged from the hospital. Included patients dropped out for further analyses if they refused follow-up measurement, were not able to conduct questionnaires, had insufficient accelerometer data or if baseline data on questionnaires were missing.

\section{Randomisation and blinding}

MULTI was already implemented pragmatically at three wards before the start of this study. Therefore, randomisation was not feasible, but we analysed potential differences between groups at baseline and, if significant, corrected for these differences in analyses as potential confounders. The severity of psychosocial functioning was scored by the responsible psychiatrist or nurse practitioner, who could not be blinded either due to their knowledge regarding patients' treatment. QoL screening data were collected by research assistants who were not informed about the treatment condition. However, blinding was not assured due to visible differences in the day-to-day program and changes in weight loss. 


\section{Treatment}

The purpose of MULTI was an overall lifestyle change with a focus on decreasing sedentary behaviour, increasing physical activity and improving dietary habits. The treatment was based on improving day-to-day structure, by starting each day with getting up on time, having three joint meals per day and an active day to day program consisting of sports-related activities (e.g. walking, running, yoga, biking, indoor team sports), workrelated activities (e.g. gardening and working in services such as the copy shop and lunchroom), psychoeducation (e.g. about side effects, dietary habits) and daily living skills training (e.g. making a grocery list, shopping, cooking). Also, existing policies were reviewed critically, such as limiting the use of personal transport within walking distance within the hospital area. To intend sustainable change, the content and intensity of the day to day program was tailored to the particular ward and individual patients by the nurses and specific disciplines (see below), taking heterogeneity in illness severity, capabilities and interests into account. Although the actual frequency, intensity, kind of activities and format (e.g. group or alone) could therefore vary per patient, it was expected that all patients were doing any of the activities in the morning and afternoon, instead of lying in bed or sitting at the ward. A final essential element concerned the participation of the nurses in the day to day program, which contributed to culture change and support of patients. MULTI was based on a 'change from within-principle', developed by current staff (psychiatrists, nurses and team leaders in collaboration with activity coordinators and a dietitian). It was supervised and disseminated per ward by the head practitioner (a psychiatrist) as an innovative treatment method. Nurses received support from the psychiatrists (psycho-education), activity coordinators and the dietitian. The physical activity part was supervised by activity coordinators who completed secondary vocational education in sports and exercise. Adherence to and compliance with the treatment was discussed in the weekly multidisciplinary consultation. If a patient could not get along in the day-to-day program (e.g. getting out of bed or attending selected activities), it was agreed that specific action would be taken to physically activate the particular patient, using extra individual motivational interviewing by their mentor (one of the nurses) or psychiatrist who were trained in this and by consulting an activity coordinator or dietitian if needed.

Patients receiving TAU continued their treatment, which mainly concerned pharmacological treatment and a less structured day program, and did not include any supported lifestyle interventions or adjustments. 


\section{Measurements}

\section{Psychosocial functioning}

Psychosocial functioning was measured by the Dutch version of the Health of the Nation Outcome Scales (HoNOS). The majority of patients were measured by the adult version (HoNOS-12) [26, 27], the specific HoNOS 65+ [28, 29] was used for elderly patients. Both scales consist of 12 items, divided into four subscales: behavioural problems (overactive, aggressive, disruptive or agitated behaviour, non-accidental self-injury, problem drinking or drug taking), impairment (cognitive problems and physical illness or disability problems), symptomatic problems (hallucinations and delusions, depressed mood or other mental and behavioural problems) and social problems (problems with relationships, activities of daily living, living conditions or occupation and activities). All items were scored on a five-point scale measuring the severity of problems from 0 (no problem) to 4 (very severe problem). The Dutch versions were studied in adult [26] and geriatric $[30,31]$ psychiatry, showing fair to excellent reliability (ICC $=0.53-0.86)$, concurrent and construct validity and to be sensitive enough to measure change. Sum scores of the first 11 items and subscales were calculated to use in analyses. We excluded the last item (occupation and activities), because, unlike the adult version, the HoNOS 65+ additionally measured the extent of patients collaboration, which resulted in incomparable results on this item [28].

\section{Quality of life}

To assess QoL, we used the Dutch versions of the EuroQol 5D (EQ-5D) [32] and the domains of the brief World Health Organization Quality of Life Assessment scale (WHOQoLBref) [33]. The EQ-5D is a generic instrument, measuring five dimensions of health (one item each): mobility, self-care, usual activities, pain/discomfort and anxiety/depression, rated from 1 (no problems) to 3 (many problems). We calculated an index score ranging from 0 (worst QoL) to 1 (perfect QoL) using the Dutch value-set based on time-trade-off weightings [34]. The four WHOQoL-Bref domains are measured by 24 items, focusing on ones' perceived physical (7 items), psychological (6 items), social (3 items) and environmental (8 items) QoL. Item scores ranged from 1 to 5 (e.g. from 'very dissatisfied' to 'very satisfied') and were transformed into domain scores ranging from 4 to 20 , according to the WHO guidelines [35]. The WHOQoL-Bref is the most often used QoL-instrument in patients diagnosed with schizophrenia [36]. The EQ-5D was studied in patients with a diagnosis of schizophrenia [37] and the WHOQoL-Bref in both psychiatric patients [38, 39] and patients with a diagnosis schizophrenia specifically [40], showing good reliability (ICC $=0.65-0.85)$ and content and construct validity. 


\section{Physical activity}

To analyse potential mediation by an increase in physical activity, we used scores from accelerometer measurement (ActiGraph GT3X+). Detailed procedures and settings used in the baseline and follow-up measurement were described elsewhere [14, 20]. Accelerometers were worn on the right hip with an elastic strap between two belt loops or, if patients did not have belt loops, in a pouch pinned on the right hip. Wear time of $\geq 6$ hours/day for $\geq 3$ days was used as the criterion for sufficient measurement, and the same timeframe (09.00am till 10.00pm) was used for each dataset to be able to compare individual data. Data were analysed using the ActiGraph software ActiLife 6.8.0 and calculated into average total activity counts per hour (TAC/h) as a continuous and detailed outcome variable, where more counts indicate a higher level of physical activity. The GT3X+ showed a high inter- and intra-instrumental reliability and validity in healthy adults. Inter-instrument reliability in free-living conditions (hip worn) was high for overall activity (ICC $=0.97$ and a $95 \%$ limit of agreement of \pm 81.3 counts per minute for vector magnitude) [41, 42] and moderate-to-vigorous activity (ICC = 0.99) [43]. The GT3X+ showed acceptable agreement between step counts observed in a laboratory setting (ICC $=0.61-0.99)$ and free-living situations $($ ICC $=0.90)[44]$.

\section{Statistical analyses}

Data analyses were performed using SPSS 22.0 and MLwiN 2.22 with a two-tailed significance level of $p<0.05$. Differences in patient and disease characteristics between patients receiving MULTI and TAU were analysed using independent t-test (age, illness severity, years of hospitalisation) and chi-square statistics (sex and diagnosis). Patients of whom a change score for one measurement was missing were excluded from analysis for this particular variable. Continuous variables were examined for normality of distributions, homogeneity of variances and linearity of the relationship with the dependent variable as assumptions for t-tests and linear regression analyses. Variables that were found to be non-linearly related to the dependent variable were added as tertiles in the linear regression analysis, with the first tertile as reference-category. No other assumptions were violated.

Multilevel linear regression was used to evaluate changes in psychosocial functioning and QoL. Possible clustering of data within wards and thereby nursing-teams was taken into account, using a two-level structure with the wards as the first level and the participants as the second. The change scores of the outcome variables were regressed on the treatment variable and adjusted for the baseline value to prevent potential regression to the mean (crude, model 1). Patient and disease characteristics, which significantly differed between patients receiving MULTI and TAU, were added as covariates in models 2 and 3, respectively. Additionally, to take a first step in gaining more insight into the contribution of different elements of MULTI in the total outcome effect, final models of significant changes in psychosocial functioning or QoL were analysed for possible mediation. 
Therefore, we used the product of the coefficient method (Figure 1) within the PROCESS tool in SPSS [45]. Associations were estimated using linear regression. The mediation effect is the product of the a- and b-coefficient (ab, not shown within models) and was considered significant if the bias-corrected and accelerated (BCa) bootstrapped confidence intervals did not include zero.



(c')

Fig. 1. Model summarising how the role of change in average total activity counts per hour (TAC/h) as a potential mediator $(\mathrm{M})$ in the association between treatment condition $(\mathrm{X})$ and change in outcome variables for psychosocial functioning and quality of life $(Y)$ is quantified in mediation analysis. It includes the associations between treatment condition and TAC/h (a), TAC/h and the particular outcome variable (b) and treatment condition on the particular outcome variable (c). Mediation is only possible if (a) and (b) are significant. The coefficient between the latter two, controlling for change in TAC/h, is in parentheses $\left(c^{\prime}\right)$.

\section{Results}

As can be seen in Figure 2, 112 patients were included, and 11 dropped out. Table 1 shows the baseline characteristics of patients receiving MULTI and TAU. On average, patients receiving MULTI were younger ( $\mathrm{M}=-6.52$ years, $95 \% \mathrm{Cl}$ : -10.41 to -2.63 ), had a higher baseline illness severity ( $\mathrm{M}=0.64,95 \% \mathrm{Cl}$ : 0.17 to 1.10$)$ and were more frequently diagnosed with schizophrenia or other psychotic disorders $\left(X^{2}=19.63, p<0.001\right)$, compared to patients receiving TAU. 


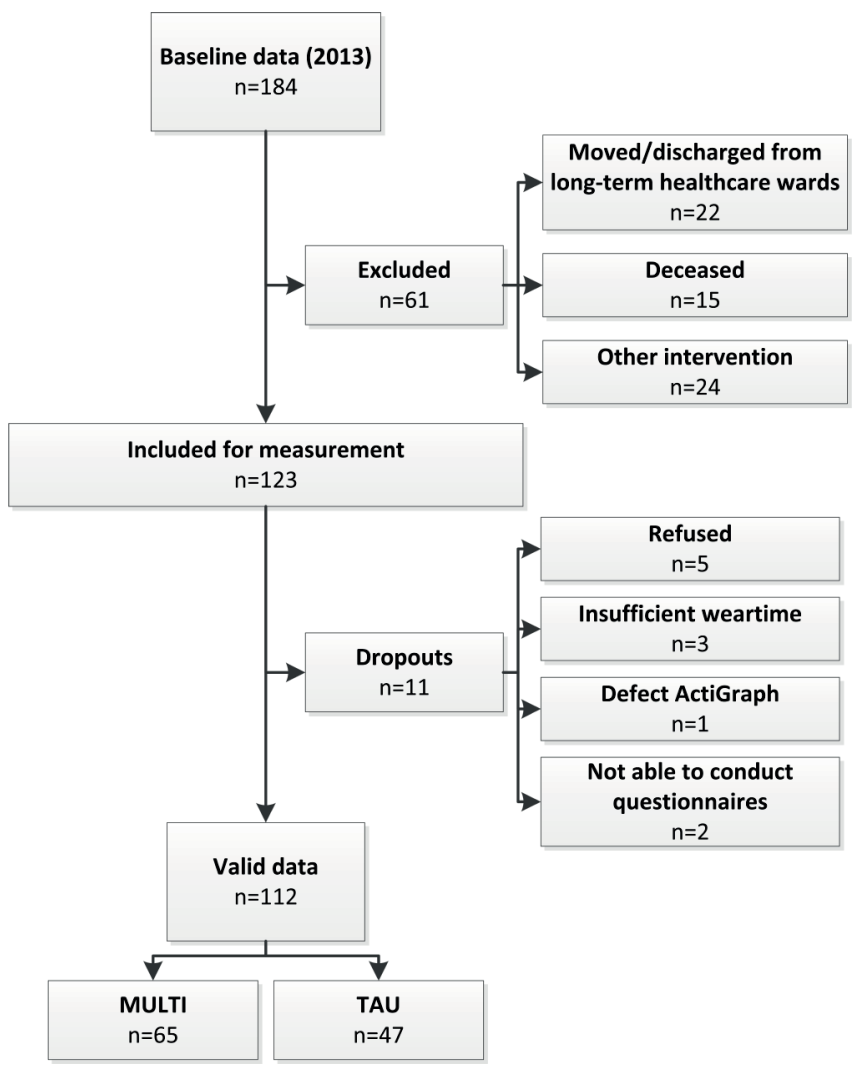

Fig. 2. Flowchart of the study population. MULTI: Multidisciplinary Lifestyle-enhancing Treatment for Inpatients with severe mental illness, TAU: Treatment As Usual. Baseline data reported in Kruisdijk et al., 2017 [20]. 


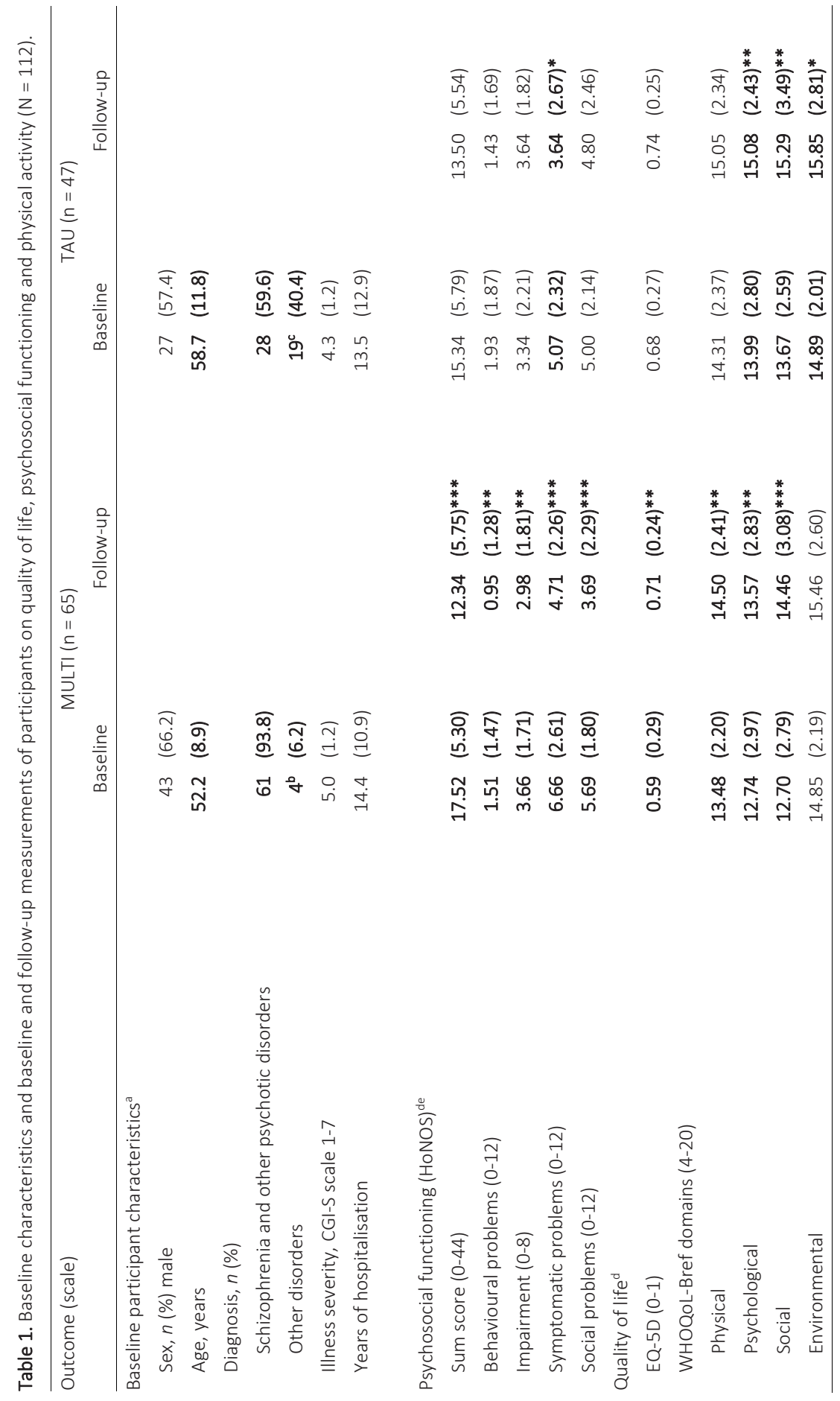


The MULTI study II: psychosocial functioning and quality of life

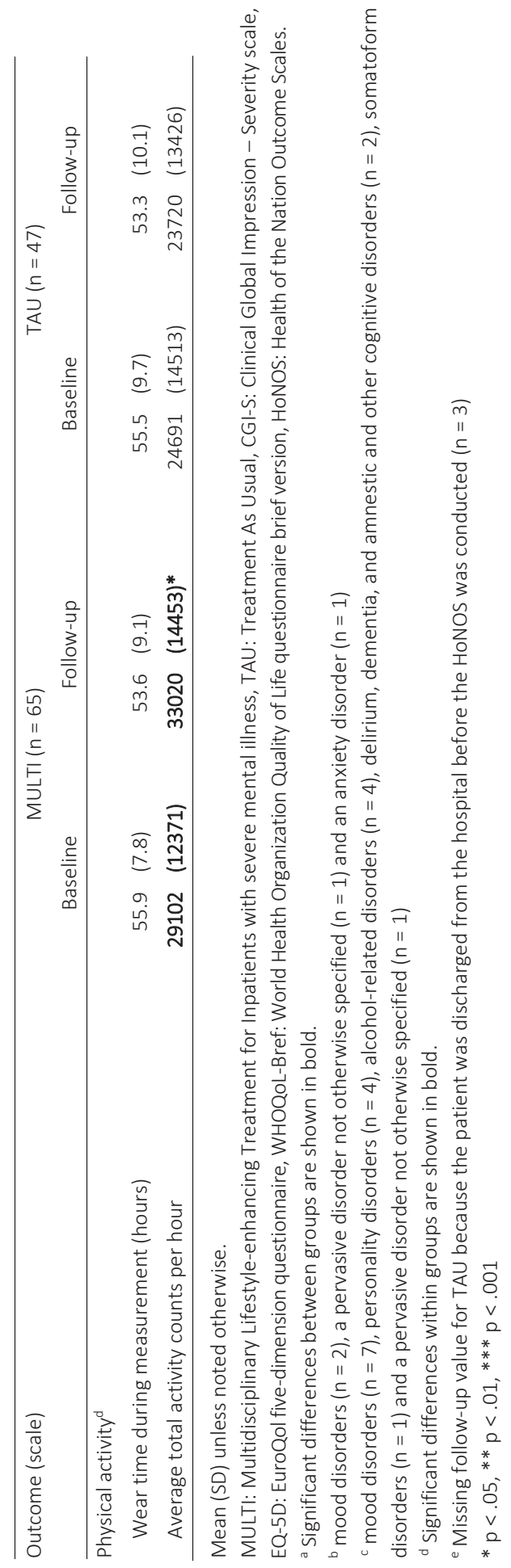




\section{Chapter 5}

\section{Psychosocial functioning}

Three patients who received TAU were excluded from analyses of this outcome as their change score was missing because they were discharged before the HoNOS follow-up was conducted. Within patients receiving MULTI, all mean scores on the severity of psychosocial functioning significantly decreased (Table 1). Both the sum score as well as the subscales showed improvements, while within the group of patients receiving TAU only the means score on symptomatic problems significantly decreased. Table 2 shows that, after correction for baseline measurement, age, diagnosis and baseline illness severity, MULTI significantly decreased total severity of psychosocial functioning, impairment and social problems, compared to TAU. 


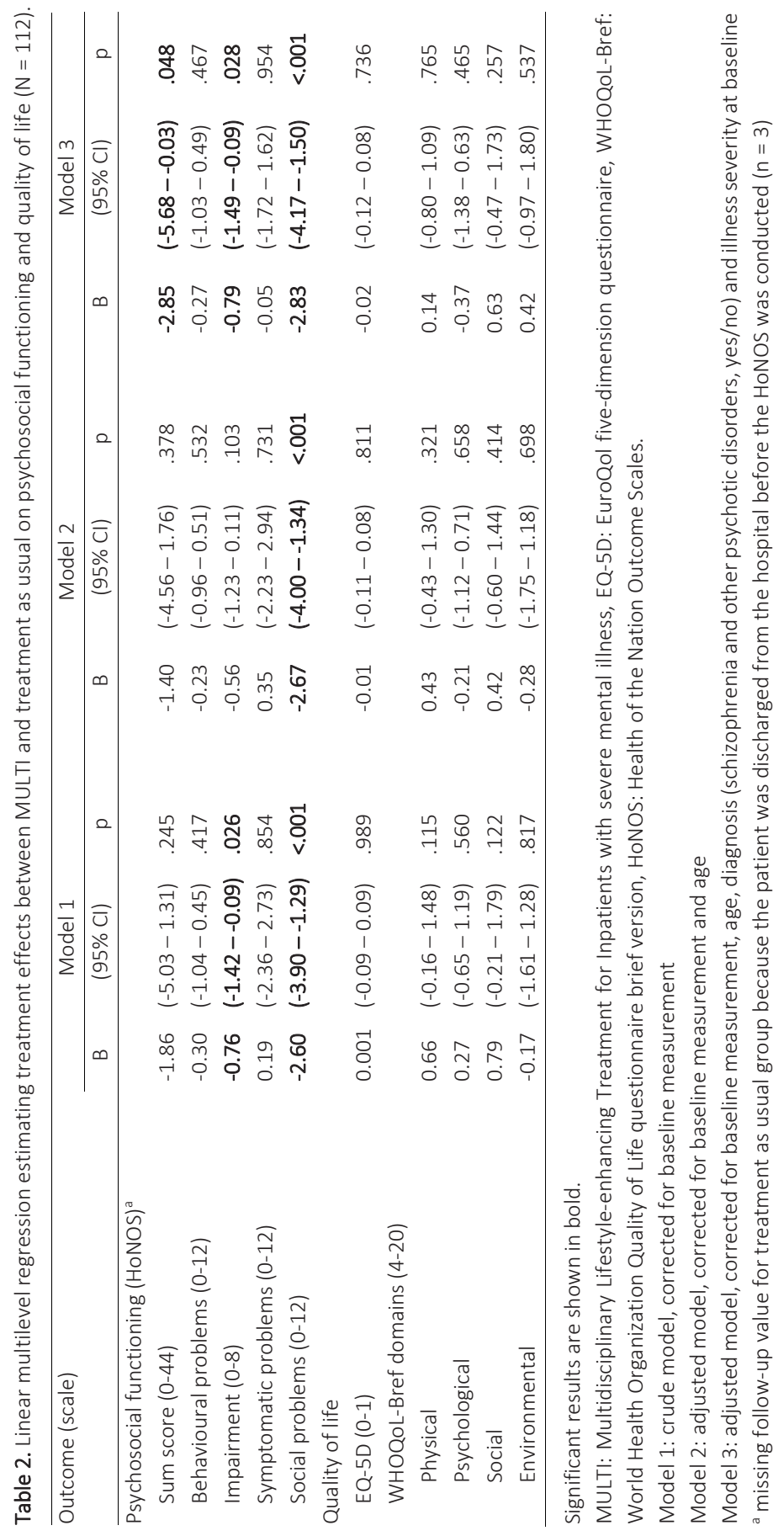




\section{Quality of life}

The linear multilevel regression estimating treatment effects (Table 2) showed no significant differences between MULTI and TAU in any of the three models. This corresponds to an increase in QoL observed in almost all variables in both MULTI and TAU as shown in Table 1, where additionally within-group results are shown to gain more insight. The EQ5D and almost all patients' perceived QoL measures improved within MULTI. Only environmental QoL showed no significant change. Patients receiving TAU showed significantly improved perceived psychological, social and environmental QoL, but no significant changes were found for the EQ-5D score and perceived physical QoL.

\section{Mediation by change in average total activity counts}

Baseline and follow-up accelerometer data are shown in Table 1. Baseline wear time ranged between $32-65$ hours and $23-65$ hours in MULTI and TAU, respectively. At follow-up, these ranged between $23-65$ hours in MULTI and 24-65 hours in TAU. Figure 3 shows the mediation models to check whether significant effects between MULTI and TAU were mediated by increased physical activity. None of the models showed significant associations between change in total activity counts and the relevant outcome (b). In line with these findings, mediation analyses showed that change in total activity counts did not mediate the effect of MULTI on total severity of psychosocial functioning $(a b=-0.28$; 95\% BCa Cl: $-1.24-0.17)$, impairment ( $\mathrm{ab}=-0.003 ; 95 \% \mathrm{BCa} \mathrm{Cl}:-0.19-0.17$ ) and social problems ( $\mathrm{ab}=-0.24 ; 95 \% \mathrm{BCa} \mathrm{Cl}:-0.72-0.008)$.

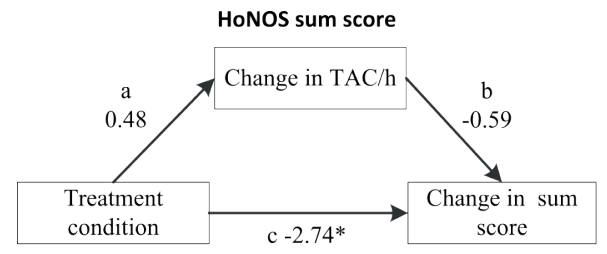

$\left(c^{\prime}-2.46^{*}\right)$



(c'-0.72)

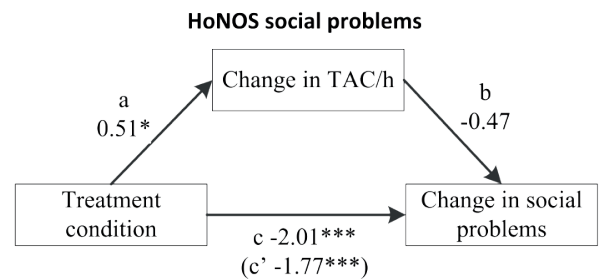

Fig. 3. Standardised regression coefficients for significant treatment effects on the Health of the Nation Outcome Scales (HoNOS) sum score, impairment and social problems, analysed for mediation by a change in average total activity counts per hour (TAC/h). The standardised regression coefficient between treatment condition and the specific measure, controlling for change in $\mathrm{TAC} / \mathrm{h}$, is in parentheses. Models were corrected for baseline measurement, age, diagnosis (schizophrenia/other psychotic disorders, yes/no) and illness severity at baseline. ${ }^{*} p<.05^{* *} p<.01 * * * p<.001$ 


\section{Discussion}

This is the first study that evaluated the changes in psychosocial functioning and QoL on the longer term in inpatients with SMI after an integrated lifestyle approach. It showed that psychosocial functioning sustainably improved in patients receiving MULTI compared to TAU. In addition, QoL improved in patients receiving MULTI. However, changes did not significantly differ from TAU as QoL improved in this group as well.

We observed improvements in overall psychosocial functioning, and notably, a decrease in impairment and social problems compared to TAU. Decreased impairments are plausible in light of the improvements in physical health such as weight and abdominal girth [14]. As the change in physical activity did not mediate the substantial decrease in social problems, the decrease is not just based on an inverse relationship between activity levels and social problems found in previous research [46]. We assume there was an increase in social interaction due to all group elements in MULTI. Findings are however not consistent with a recent RCT in Dutch residential and clinical teams treating patients with SMI, evaluating a combined diet- and exercise lifestyle intervention targeting the obesogenic environment [25]. This study showed no effect on HoNOS scores after three or twelve months follow-up. As the authors notice, this may be due to difficulties with implementation. Also, compared to MULTI, their approach focusing on small changes may have led to changes that were too small to bring about detectable changes in psychosocial functioning [25]. Although measured by other scales, our findings are in line with a positive association between physical activity and global functioning in inpatients with a diagnosis of schizophrenia [47], and indications found for psychosocial benefits of exercise in hospitalized schizophrenia inmates [48] and small samples of patients with first-episode psychosis [49, 50].

The absence of mediation of physical activity in psychosocial functioning and physical health changes [14], indicates that increasing physical activity is not solely the cause of the improvements. We hypothesise that the organisational culture change - in which qualified staff participating in the day-to-day structure and activities played a significant role - is an essential factor, with multiple components complementing physical activity, including attention to dietary habits, psycho-education, personal tailoring and support by peers. This is consistent with recent studies, which advocated the use of such elements [12, 51-54].

The improved QoL in MULTI corresponds to a recent systematic review and metaanalysis on physical activity interventions in mainly outpatients with schizophrenia or related psychotic diagnosis [15] and recent studies evaluating lifestyle interventions in outpatients with SMI $[55,56]$, although they found no improvements in long-term healthcare [55]. Regarding inpatients, findings are in line with a previously found positive association between health-promoting lifestyles and QoL in patients with chronic schizophrenia [57]. The QoL improvement we found did not significantly differ from TAU, because QoL within those patients improved as well. Due to the observational design of this study within a naturalistic setting, we were not able to control for other - non-lifestyle related-changes 
at TAU wards which might have had an effect. Based on clinical practice and consultation with the attending nurses while evaluating the results, it could be that an intervention which took place within the first year of MULTI affected the results on QoL within TAU. During this period, nurses and patients (targeting especially the elderly) worked together making life story books at the majority of TAU wards aiming to increase their QoL. This could be a plausible cause given a positive association between therapeutic relationship and QoL in long-term inpatient psychiatry [58]. Thereby, such an intervention could improve QoL without improving physical health, which is consistent with our previous findings [14], and the fact that we found significant improvements on all but the physical QoL domain. Moreover, improved QoL after life story related work is in line with results of studies targeting older adults with dementia, Down syndrome and intellectual disabilities [59-61].

The main limitations of this study arise from the naturalistic setting, whereby patients were not randomised, and we were not able to control for changes over time, such as the introduction of life story books within TAU. By using multilevel regression correcting for differences between MULTI and TAU, we aimed to minimise bias and obtain robust results. Since this correction included age too, we simultaneously reduced potential bias by the use of the HoNOS 65+ in elderly patients as much as possible, as this version may be more sensitive for problems specific to this population [62]. Nevertheless, bias due to unmeasured potential confounders other than differences between MULTI and TAU may be present. As MULTI was based on long-term inpatient mental healthcare, such an approach may be less feasible for other healthcare settings. However, aforementioned essential elements of MULTI that are supported by literature such as combining multiple components (e.g. instead of physical activity and diet separately), multidisciplinary cooperation and support of peers and qualified staff have the potential to be implemented in other settings, such as sheltered housing or outpatient facilities, as well. Furthermore, with effects on psychosocial functioning and QoL in addition to improvements in physical activity and metabolic health [14], it would be interesting to study interactions between these changes. For example, does improved functioning apply especially to patients who have become more physically healthy? Nevertheless, more data will be needed to have enough power to gain more insight into such questions.

Because of the naturalistic setting and treatment developed within current clinical practice and resources, our data support the generalizability of our findings and feasibility of MULTI, which is very relevant for clinical practice [63]. It supplements the evidence of RCTs on benefits of lifestyle improvements in patients with SMI, which contribute to the need to improve external validity of RCTs such that clinicians and management staff in real-world settings have appropriate evidence in order to be able to make the right clinical decisions [64]. Results are strengthened by a follow-up period of 18 months - as there is a lack of studies evaluating long-term effects [24] - and several methodological aspects. For example, in the multilevel analysis, we corrected for potential differences that are clustered within wards (e.g. the way they work), regression to the mean (e.g. overweight 
patients are more likely to lose weight) and differences in patient- and disease characteristics between MULTI and TAU. Also, we used objective data on physical activity, which significantly improved the reliability of the outcomes compared to self-reports in this population $[65,66]$. By analysing possible mediation effects of total activity counts, we took a first step to gain more insight into the contribution of different elements of MULTI to the observed improvements. Moreover, by including baseline measures in these analyses, our mediation analyses are mathematically identical to a covariance approach, which was the recommended method for mediation analyses $[67,68]$

For MULTI to be implemented widely in inpatient mental healthcare, further research including measurements at other sites is needed. However, current findings provide substantial implications for clinical practice, showing that - in addition to improved physical health [14] - patients' perceived QoL and psychosocial functioning improved after 18 months of MULTI. This is very relevant for hospitalised patients with SMI, as highly prevalent physical health problems and more prolonged illness duration are associated with lower QoL $[19,69]$. These positive changes over the longer term, with a treatment developed within the current clinical practice and resources of inpatients mental healthcare, suggest that sustainable improvement of the health of inpatients with SMI is within our reach. However, an integrated multi-component treatment requires a culture change driven by multidisciplinary cooperation and staff participation, supported at management level. Therefore, identifying the barriers against, and facilitators for, implementation are of great importance for optimisation and broader implementation of MULTI in clinical practice.

In summary, this 18 months follow-up study shows that, in addition to improvement of physical health, an integrated multi-component and multidisciplinary lifestyle enhancing treatment can improve QoL within patients with SMI and can increase psychosocial functioning compared to treatment as usual. We encourage further long-term follow-up studies on patient-oriented outcomes in addition to physical health after lifestyle interventions to better the lives of patients with SMI, which are greatly affected by disproportional metabolic health problems.

\section{Acknowledgements}

The authors would like to acknowledge, with thanks, all patients and mental healthcare professionals of GGz Centraal who have made efforts to collect all the data, which formed the basis of this publication. 


\section{References}

1. Vancampfort D, Stubbs B, Mitchell AJ, De Hert M, Wampers M, Ward PB, Rosenbaum S, Correll CU. Risk of metabolic syndrome and its components in people with schizophrenia and related psychotic disorders, bipolar disorder and major depressive disorder: a systematic review and meta-analysis. World Psychiatry. 2015;14(3):339-347.

2. Stubbs B, Vancampfort D, De Hert M, Mitchell AJ. The prevalence and predictors of type two diabetes mellitus in people with schizophrenia: a systematic review and comparative meta-analysis. Acta Psychiatr Scand. 2015;132(2):144-157.

3. Correll CU, Solmi M, Veronese N, Bortolato B, Rosson S, Santonastaso P, Thapa-Chhetri N, Fornaro M, Gallicchio D, Collantoni E et al. Prevalence, incidence and mortality from cardiovascular disease in patients with pooled and specific severe mental illness: a large-scale meta-analysis of 3,211,768 patients and 113,383,368 controls. World Psychiatry. 2017;16(2):163-180.

4. Laursen TM, Wahlbeck K, Hallgren J, Westman J, Osby U, Alinaghizadeh H, Gissler M, Nordentoft M. Life expectancy and death by diseases of the circulatory system in patients with bipolar disorder or schizophrenia in the Nordic countries. PLoS One. 2013;8(6):e67133.

5. Walker ER, McGee RE, Druss BG. Mortality in Mental Disorders and Global Disease Burden Implications A Systematic Review and Meta-analysis. Jama Psychiatry. 2015;72(4):334-341.

6. Hayes JF, Marston L, Walters K, King MB, Osborn DPJ. Mortality gap for people with bipolar disorder and schizophrenia: UK-based cohort study 2000-2014. Br J Psychiatry. 2017;211(3):175-181.

7. Lee EE, Liu J, Tu X, Palmer BW, Eyler LT, Jeste DV. A widening longevity gap between people with schizophrenia and general population: A literature review and call for action. Schizophr Res. 2017.

8. Piotrowski P, Gondek TM, Krolicka-Deregowska A, Misiak B, Adamowski T, Kiejna A. Causes of mortality in schizophrenia: An updated review of European studies. Psychiatr Danub. 2017;29(2):108-120.

9. Hjorthøj C, Sturup AE, McGrath JJ, Nordentoft M. Years of potential life lost and life expectancy in schizophrenia: a systematic review and meta-analysis. The Lancet Psychiatry. 2017;4(4):295-301.

10. Tanskanen A, Tiihonen J, Taipale H. Mortality in schizophrenia: 30-year nationwide follow-up study. Acta Psychiatr Scand. 2018.

11. Rosenbaum S, Tiedemann A, Sherrington C, Curtis J, Ward PB. Physical activity interventions for people with mental illness: a systematic review and meta-analysis. J Clin Psychiatry. 2014;75(9):964-974.

12. Teasdale SB, Ward PB, Rosenbaum S, Samaras K, Stubbs B. Solving a weighty problem: systematic review and meta-analysis of nutrition interventions in severe mental illness. The British Journal of Psychiatry. 2017;210(2):110-118

13. Vera-Garcia E, Mayoral-Cleries F, Vancampfort D, Stubbs B, Cuesta-Vargas Al. A systematic review of the benefits of physical therapy within a multidisciplinary care approach for people with schizophrenia: An update. Psychiatry Res. 2015;229(3):828-839.

14. Deenik J, Tenback DE, Tak ECPM, Rutters F, Hendriksen IJM, van Harten PN. Changes in physical and psychiatric health after a multidisciplinary lifestyle enhancing treatment for inpatients with severe mental illness: the MULTI study I. Schizophr Res. 2018.

15. Dauwan M, Begemann MJH, Heringa SM, Sommer IE. Exercise improves clinical symptoms, quality of life, global functioning, and depression in schizophrenia: A systematic review and meta-analysis. Schizophr Bull. 2016;42(3):588-599.

16. Mitchell AJ, Vancampfort D, Sweers K, van Winkel R, Yu W, De Hert M. Prevalence of metabolic syndrome and metabolic abnormalities in schizophrenia and related fisorders - A systematic review and metaanalysis. Schizophr Bull. 2013;39(2):306-318.

17. Vancampfort D, Probst M, Scheewe T, De Herdt A, Sweers K, Knapen J, van Winkel R, De Hert M. Relationships between physical fitness, physical activity, smoking and metabolic and mental health parameters in people with schizophrenia. Psychiatry Res. 2013;207(1-2):25-32.

18. Vancampfort D, Firth J, Schuch FB, Rosenbaum S, Mugisha J, Hallgren M, Probst M, Ward PB, Gaughran F, De Hert $\mathrm{M}$ et al. Sedentary behavior and physical activity levels in people with schizophrenia, bipolar 
disorder and major depressive disorder: a global systematic review and meta-analysis. World Psychiatry. 2017;16(3):308-315.

19. Vancampfort D, Guelinckx H, Probst M, Stubbs B, Rosenbaum S, Ward PB, De Hert M. Health-related quality of life and aerobic fitness in people with schizophrenia. Int J Ment Health Nurs. 2015;24(5):394-402.

20. Kruisdijk F, Deenik J, Tenback D, Tak E, Beekman A, van Harten P, Hopman-Rock M, Hendriksen I. Accelerometer-measured sedentary behaviour and physical activity of inpatients with severe mental illness. Psychiatry Res. 2017;254:67-74.

21. Stubbs B, Chen LJ, Chung MS, Ku PW. Physical activity ameliorates the association between sedentary behavior and cardiometabolic risk among inpatients with schizophrenia: A comparison versus controls using accelerometry. Compr Psychiatry. 2017;74:144-150.

22. Stanton R, Happell B. Exercise for mental illness: A systematic review of inpatient studies. Int J Ment Health Nurs. 2014;23(3):232-242.

23. Levitt GA, Shinault K, Patterson S, Otaluka O. Weight Gain in Psychiatric Inpatients: Are Interventions Making a Positive Impact? Prim Care Companion CNS Disord. 2017;19(4):17m02111.

24. Vancampfort D, Stubbs B, Ward PB, Teasdale S, Rosenbaum S. Integrating physical activity as medicine in the care of people with severe mental illness. Aust N Z J Psychiatry. 2015;49(8):681-682.

25. Stiekema APM, Looijmans A, van der Meer L, Bruggeman R, Schoevers RA, Corpeleijn E, Jorg F. Effects of a lifestyle intervention on psychosocial well-being of severe mentally ill residential patients: ELIPS, a cluster randomized controlled pragmatic trial. Schizophr Res. 2018.

26. Mulder CL, Staring ABP, Loos J, Buwalda VJA, Kuijpers D, Sytema S, Wierdsma Al. The Health of the Nation Outcome Scales (HONOS) in Dutch translation as an instrument for Routine Outcome Assessment. Tijdschrift voor Psychiatrie. 2004;46(5):273-284.

27. Wing JK, Beevor AS, Curtis RH, Park SB, Hadden S, Burns A. Health of the Nation Outcome Scales (HoNOS). Research and development. Br J Psychiatry. 1998;172:11-18.

28. Burns A, Beevor A, Lelliott P, Wing J, Blakey A, Orrell M, Mulinga J, Hadden S. Health of the Nation Outcome Scales for elderly people (HoNOS 65+). Glossary for HoNOS 65+ score sheet. The British Journal of Psychiatry. 1999;174(5):435.

29. Staring ABP, Stobbe J, Mulder CL. Nederlandse vertaling van de HoNOS 65+ [Dutch translation of the NoNOS 65+ scale]. 2013.

30. Aartsen MJ, Spitsbaard AK, van Baarsen C, Dhondt ADF, Mascini M, Nefs A, Snoeijers A, van Diest M, Wilting R. Een multicenterstudie naar betrouwbaarheid, validiteit en gevoeligheid voor verandering van de HoNOS65+ binnen de ouderenpsychiatrie. [A multi-centre study of the reliability, validity and sensitivity to change of the HoNOS65+ in psychiatry for older persons]. Tijdschrift voor Psychiatrie. 2010;52(8):543-553.

31. Broersma TW, Sytema S. De Health of the Nation Outcome Scale als effectmaat in de ouderenpsychiatrie [The Health of the Nation Outcome Scales as clinical outcome indicator in elderly psychiatry]. Tijdschr Gerontol Geriatr. 2010;41(1):13-18.

32. EuroQol Group. EQ-5D-3L User Guide. Basic information on how to use the EQ-5D-3L instrument. Rotterdam: EuroQol Group; 2011.

33. de Vries J, van Heck GL. The Dutch version of the WHOQOL-Bref. (In Dutch: De Nederlandse versie van de WHOQOL-Bref). Tilburg: Tilburg University; 1995.

34. Lamers LM, McDonnell J, Stalmeier PFM, Krabbe PFM, Busschbach JJV. The Dutch tariff: Results and arguments for an effective design for national EQ-5D valuation studies. Health Econ. 2006;15(10):1121-1132.

35. WHO. WHOQOL-Bref: Introduction, Administration, Scoring and Generic Version of the Assessment. Field Trial Version. Geneva: World Health Organization; 1996.

36. Karow A, Wittmann L, Schottle D, Schafer I, Lambert M. The assessment of quality of life in clinical practice in patients with schizophrenia. Dialogues Clin Neurosci. 2014;16(2):185-195.

37. Prieto L, Sacristan JA, Hormaechea JA, Casado A, Badia X, Gomez JC. Psychometric validation of a generic health-related quality of life measure (EQ-5D) in a sample of schizophrenic patients. Curr Med Res Opin. 2004;20(6):827-835.

38. Oliveira SE, Carvalho H, Esteves F. Toward an understanding of the quality of life construct: Validity and reliability of the WHOQOL-Bref in a psychiatric sample. Psychiatry Res. 2016;244:37-44. 
39. Trompenaars FJ, Masthoff ED, Van Heck GL, Hodiamont PP, De Vries J. Content validity, construct validity, and reliability of the WHOQOL-Bref in a population of Dutch adult psychiatric outpatients. Qual Life Res. 2005;14(1):151-160.

40. Mas-Expósito L, Amador-Campos JA, Gómez-Benito J, Lalucat-Jo L. The World Health Organization Quality of Life Scale Brief Version: A validation study in patients with schizophrenia. Qual Life Res. 2011;20(7):1079-1089.

41. Ozemek C, Kirschner MM, Wilkerson BS, Byun W, Kaminsky LA. Intermonitor reliability of the GT3X+ accelerometer at hip, wrist and ankle sites during activities of daily living. Physiol Meas. 2014;35(2):129-138.

42. Aadland E, Ylvisaker E. Reliability of the Actigraph GT3X+ Accelerometer in Adults under Free-Living Conditions. PLoS One. 2015;10(8):e0134606.

43. Jarrett H, Fitzgerald L, Routen AC. Interinstrument reliability of the ActiGraph GT3X+ambulatory activity monitor during free-living conditions in adults. Journal of Physical Activity and Health. 2015;12(3):382-387.

44. Lee JA, Williams SM, Brown DD, Laurson KR. Concurrent validation of the Actigraph gt3x+, Polar Active accelerometer, Omron HJ-720 and Yamax Digiwalker SW-701 pedometer step counts in lab-based and free-living settings. J Sports Sci. 2015;33(10):991-1000.

45. PROCESS: A versatile computational tool for observed variable mediation, mod-eration, and conditionalprocess modeling [White paper] [http://www.afhayes.com/public/process2012.pdf]

46. McLeod HJ, Jaques S, Deane FP. Base rates of physical activity in Australians with schizophrenia. Psychiatr Rehabil J. 2009;32(4):269-275.

47. Vancampfort D, Guelinckx H, Probst M, Ward PB, Rosenbaum S, Stubbs B, De Hert M. Aerobic capacity is associated with global functioning in people with schizophrenia. J Ment Health. 2015;24(4):214-218.

48. Loh SY, Abdullah A, Abu Bakar AK, Thambu M, Nik Jaafar NR. Structured Walking and Chronic Institutionalized Schizophrenia Inmates: A pilot RCT Study on Quality of Life. Global journal of health science. 2015;8(1):238-248.

49. Firth J, Carney R, Elliott R, French P, Parker S, McIntyre R, McPhee JS, Yung AR. Exercise as an intervention for first-episode psychosis: a feasibility study. Early intervention in psychiatry. 2016.

50. Firth J, Carney R, French P, Elliott R, Cotter J, Yung AR. Long-term maintenance and effects of exercise in early psychosis. Early intervention in psychiatry. 2016.

51. Long C, Rowell A, Rigg S, Livesey F, McAllister P. What is effective in promoting a healthy lifestyle in secure psychiatric settings? A review of the evidence for an integrated programme that targets modifiable health risk behaviours. The Journal of Forensic Practice. 2016;18(3):204-215.

52. Roberts SH, Bailey JE. Incentives and barriers to lifestyle interventions for people with severe mental illness: a narrative synthesis of quantitative, qualitative and mixed methods studies. J Adv Nurs. 2011;67(4):690-708.

53. Vancampfort D, Rosenbaum S, Schuch F, Ward PB, Richards J, Mugisha J, Probst M, Stubbs B. Cardiorespiratory fitness in severe mental illness: A systematic review and meta-analysis. Sports Med. 2017;47(2):343-352.

54. Ward MC, White DT, Druss BG. A meta-review of lifestyle interventions for cardiovascular risk factors in the general medical population: lessons for individuals with serious mental illness. J Clin Psychiatry. 2015;76(4):e477-486.

55. Hjorth P, Medici CR, Juel A, Madsen NJ, Vandborg K, Munk-Jorgensen P. Improving quality of life and physical health in patients with schizophrenia: A 30-month program carried out in a real-life setting. Int J Soc Psychiatry. 2017;63(4):287-296.

56. Rönngren Y, Bjork A, Audulv A, Enmarker I, Kristiansen L, Haage D. Educational nurse-led lifestyle intervention for persons with mental illness. Int J Ment Health Nurs. 2018;27(3):1022-1031.

57. Lin SP, Liu CY, Yang CY. Relationship Between Lifestyles That Promote Health and Quality of Life in Patients With Chronic Schizophrenia: A Cross-Sectional Study. J Nurs Res. 2017.

58. McCabe R, Röder-Wanner U-U, Hoffmann K, Priebe S. Therapeutic Relationships and Quality of Life: Association of Two Subjective Constructs in Schizophrenia Patients. Int J Soc Psychiatry. 1999;45(4):276-283.

59. Bai X, Ho DW, Fung K, Tang L, He M, Young KW, Ho F, Kwok T. Effectiveness of a life story work program on older adults with intellectual disabilities. Clin Interv Aging. 2014;9:1865-1872. 
60. Crook N, Adams M, Shorten N, Langdon PE. Does the Well-Being of Individuals with Down Syndrome and Dementia Improve When Using Life Story Books and Rummage Boxes? A Randomized Single Case Series Experiment. Journal of applied research in intellectual disabilities : JARID. 2016;29(1):1-10.

61. Subramaniam $P$, Woods B, Whitaker C. Life review and life story books for people with mild to moderate dementia: a randomised controlled trial. Aging \& mental health. 2014;18(3):363-375.

62. Turner S. Are the Health of the Nation Outcome Scales (HoNOS) useful for measuring outcomes in older people's mental health services? Aging \& mental health. 2004;8(5):387-396.

63. Naslund JA, Whiteman KL, McHugo GJ, Aschbrenner KA, Marsch LA, Bartels SJ. Lifestyle interventions for weight loss among overweight and obese adults with serious mental illness: A systematic review and metaanalysis. Gen Hosp Psychiatry. 2017;47:83-102.

64. Kennedy-Martin T, Curtis S, Faries D, Robinson S, Johnston J. A literature review on the representativeness of randomized controlled trial samples and implications for the external validity of trial results. Trials. 2015;16:495.

65. Soundy A, Roskell C, Stubbs B, Vancampfort D. Selection, use and psychometric properties of physical activity measures to assess individuals with severe mental illness: a narrative synthesis. Arch Psychiatr Nurs. 2014;28(2):135-151.

66. Stubbs B, Williams JE, Gaughran F, Craig T. How sedentary are people with psychosis? A systematic review and meta-analysis. Schizophr Res. 2016;171(1-3):103-109.

67. Landau S, Emsley R, Dunn G. Beyond total treatment effects in randomised controlled trials: Baseline measurement of intermediate outcomes needed to reduce confounding in mediation investigations. Clin Trials. 2018;15(3):247-256.

68. Twisk J, Bosman L, Hoekstra T, Rijnhart J, Welten M, Heymans M. Different ways to estimate treatment effects in randomised controlled trials. Contemporary Clinical Trials Communications. 2018;10:80-85.

69. Malhotra N, Kulhara P, Chakrabarti S, Grover S. Lifestyle related factors \& impact of metabolic syndrome on quality of life, level of functioning \& self-esteem in patients with bipolar disorder \& schizophrenia. Indian J Med Res. 2016;143(4):434-442. 



\section{Chapter}

Less medication use in inpatients with severe mental illness receiving a multidisciplinary lifestyle enhancing treatment. The MULTI study III

Deenik, J., Tenback, D.E., van Driel, H.F., Tak, E.C.P.M., Hendriksen, I.J.M., van Harten, P.N.

Frontiers in Psychiatry 2018; 9: 707

doi: 10.3389/fpsyt.2018.00707 


\section{Abstract}

Besides having an unhealthy lifestyle contributing to premature mortality, inpatients with severe mental illness (SMI) use high dosages of medication. Previous research has shown improved health after lifestyle improvements in SMI. In addition, we aimed to retrospectively study whether a multidisciplinary lifestyle enhancing treatment (MULTI) was associated with changes in medication use after 18 months, as compared with patients that continued treatment as usual (TAU) and explored mediation by a change in physical activity. We conducted an observational study within a cohort of inpatients with SMI, who received MULTI ( $N=65)$ or continued TAU $(N=49)$. Data on their somatic and psychotropic medications were collected, converted into defined daily dose (DDD), and analyzed using linear multilevel regression, correcting for baseline value and differences between groups in age, diagnosis, and illness severity. Compared with TAU, the DDD for psychotropic medication significantly decreased with $\mathrm{MULTI}(\mathrm{B}=-0.55, P=0.02)$. Changes in total activity did not mediate this association, suggesting that multiple components of MULTI contributed. Corrected between-group analyses for subgroups of medication were not possible due to lack of power and skewed distributions. Within-group data showed a decreased proportion of users as well as median DDD in both groups for almost all medications. In addition to previously reported health improvements after 18 months of MULTI, we observed a significant decrease in dose of psychotropic medication in MULTI compared to TAU. This first study evaluating a wide range of medications indicates a possible effect of lifestyle improvements on medication use in inpatients with SMI. Findings need to be confirmed in future controlled studies, however. 


\section{Introduction}

In patients with severe mental illness (SMI), a high prevalence of metabolic risk factors (13 ) contribute to their poor cardiovascular health, largely contributing to a reduced life expectancy of at least 7-20 years compared to the general population (4-6). Besides a sedentary lifestyle (7-10), side effects of psychotropic medication (such as weight gain, dyslipidemia, diabetes mellitus and direct and indirect harm to the vascular system) are associated with these cardiovascular health issues (11-14). Polypharmacy, higher dosages, and longer-term use are associated with higher risk for most of these side effects and somatic diseases $(11,12,15)$. A study in people diagnosed with schizophrenia showed that both no exposure as well as high exposure to antipsychotics were associated with higher cardiovascular mortality than either low or moderate exposure (16). Unfortunately, polypharmacy is very prevalent among people with $\operatorname{SMI}(15,17)$ and the dosage of antipsychotic medication has only increased during the last decades for long-term hospitalized patients $(18,19)$. Alongside this psychotropic medication, patients use antihypertensive, lipid-lowering, antihyperglycemic and other additional drugs if cardiovascular health issues (whether or not caused by psychotropic medication) are too severe (20-24).

Nowadays, there is more focus on the lowest effective dose, on the avoidance of inappropriate polypharmacy to minimize the side effect of antipsychotics (25-28), and on supporting a healthy lifestyle (29-32). Despite an increased number of studies showing benefits of lifestyle interventions in people with SMI, there is a lack of evidence to support long-term effectiveness of such interventions in hospitalized patients (33, 34). Moreover, to the best of our knowledge, studies evaluating lifestyle interventions in inpatients did not analyze changes in medication use. Recently, improved physical activity and metabolic health were shown after 18 months in this group of patients receiving a multidisciplinary lifestyle enhancing treatment for inpatients with SMI (MULTI) (35). MULTI was pragmatically implemented in a group of inpatients whose psychotropic medication was already critically reviewed prior to its implementation; hence, dose reduction was not a specific goal. The treatment focused on decreasing sedentary behavior, increasing physical activity, and improving dietary habits in the context of day-to-day treatment.

Because the (side) effects of medications are associated with cardiometabolic health issues, we hypothesized that we might observe changes in medication use after lifestyle changes, in addition to improvements in physical health. Therefore, the present study aimed to retrospectively study whether 18 months of MULTI was associated with changes in medication use, as compared with patients that continued treatment as usual (TAU) and to explore whether changes were mediated by increased physical activity as an essential component of MULTI. 


\section{Materials and methods}

\section{Study design}

This observational cohort study was conducted at wards for long-term inpatient mental healthcare in a psychiatric hospital of GGz Centraal (The Netherlands). The current study is part of a comprehensive evaluation of MULTI, a treatment that was implemented pragmatically in February 2014 in three wards. MULTI was developed because of the identified need to address the comorbidity (e.g. sleep apnea and cardiovascular morbidity) in this population, in part due to a lack of physical activity, obesity, and dietary risks. The implementation of MULTI (described in the next paragraph) was conducted by psychiatrists, nurses and team leaders in collaboration with activity coordinators and a dietitian. During a previous MULTI study (35), data of baseline (Aug.-Dec. 2013) and one follow-up (Aug.Dec. 2015) were collected from 114 patients (65 received MULTI and 49 continued TAU). Data on types and dose of medication were extracted from electronic patient records and compared between patients receiving MULTI and those receiving TAU. Because of the observational nature of this study, whereby MULTI was already implemented pragmatically in three wards before the start of this study, no randomization took place. Therefore, we analyzed potential differences between groups at baseline and, if significant, corrected for these differences in analyses as potential confounders. The study protocol was approved by the Medical Ethical Committee of the Isala Academy (case 14.0678). All subjects gave written informed consent in accordance with the Declaration of Helsinki.

\section{Study population}

The cohort consisted of patients with SMI who had been hospitalized for at least one year. Patients were included in the MULTI study if they had not received any other intervention related to lifestyle within 18 months since the start of MULTI and if baseline accelerometer data was available. Exclusion criterion was a lack of data after 18 months due to being either discharged or deceased. Patients included for follow-up were dropped out for further analyses if they had insufficient accelerometer data (see 2.4.2 below) or refused the repeated accelerometer measurement.

\section{MULTI}

The purpose of MULTI was a holistic lifestyle change with a focus on decreasing sedentary behavior, increasing physical activity, and improving dietary habits. Improving the day-today structure formed the base of the treatment, by starting each day with getting up on time, having three joint meals per day, and an active day program consisting of sportsrelated activities (e.g. walking, running, yoga, biking, indoor team sports), work-related activities (e.g. gardening and helping out with daily jobs), psycho-education (e.g. about side effects, dietary habits), and skills training (e.g. making a grocery list, shopping, 
cooking). Also, existing policies were reviewed critically - e.g. the use of personal transport within walking distance around the hospital area for every patient was reduced to its use for immobile patients and in case of extreme weather only. Because of heterogeneity in illness severity and different capabilities and interests, the content and intensity of the day-to-day program were tailored to the particular ward and individual patients by the nurses and specific disciplines (see below). Therefore, the actual frequency, intensity, kind of activities and format (e.g. group or alone) could vary between patients and wards. However, it was intended that all patients were doing some of the activities in the morning and afternoon, to prevent prolonged periods of lying in bed or sitting at the ward. Also, participation of nurses in the day-to-day program was an essential element, which contributed to the culture change within the institution and in the provision of support to patients. MULTI was based on a "change from within-principle" developed by current staff (psychiatrists, nurses and team leader in collaboration with activity coordinators and a dietitian), working with regular context and resources in day-to-day routine care. It was supervised and disseminated per ward by the head practitioner (a psychiatrist) as an innovative treatment method. Nurses received support from the psychiatrists (psycho-education), activity coordinators, and the dietitian. Adherence to and compliance with the treatment was discussed in the weekly multidisciplinary consultation. If a patient could not get along in the day-to-day program (e.g. getting out of bed or attending selected activities), it was agreed upon that specific action was to be taken to physically activate a particular patient, using extra individual motivational interviewing by their mentor (one of the nurses) or psychiatrist, who were trained in this, and by consulting an activity coordinator or dietitian if needed.

Patients who received TAU continued their treatment, which mainly concerned pharmacological treatment and a less structured day program and did not include any supported lifestyle interventions or adjustments.

\section{Measurements}

\section{Medication}

Medication use was classified by type of medication in the main groups and by converting doses to daily defined doses (DDD) according to the Anatomical Therapeutic Chemical (ATC) Classification System of the World Health Organization (36). Somatic medications included medications for the alimentary tract and metabolism (A), blood and blood-forming organs (B), cardiovascular system (C), and respiratory system (R). Psychotropic medications included the medications for the nervous system (N). Due to the differences in specific purpose, efficacy, and side effects of psycholeptics (N05), we distinguished antipsychotics (N05A) from anxiolytics, hypnotics, and sedatives (N05B \& N05C). Likewise, we distinguished the category antipsychotics into three groups: (i) typical and (ii) atypical antipsychotics (occurring in different subgroups) and (iii) lithium (N05AN). For this study, we only used fixed prescriptions (i.e. not including medication to be given as needed). 
Physical activity

To test for potential mediation by a change in physical activity, we used accelerometer data (ActiGraph GT3X+) that was collected within the MULTI study. Detailed procedures and settings used in the baseline and follow-up measurement were described elsewhere $(9,35)$. Accelerometers were worn on the right hip; wear time of $\geq 6$ hours/day for $\geq 3$ days was used as the criterion for sufficient measurement, and the same timeframe (9:00 am - 10:00 pm) was used for each dataset to be able to compare individual data. These were analyzed using the ActiGraph (ActiGraph Corp., Pensacola FL, USA) software ActiLife 6.8.0 and calculated into average total activity counts per hour (TAC/h) as a continuous and detailed outcome variable, where more counts indicate a higher level of activity. The GT3X+ showed a high inter- and intra-instrumental reliability and validity in healthy adults. Inter-instrument reliability in free-living conditions (hip worn) was high for overall activity (ICC $=0.97$ and a $95 \%$ limit of agreement of \pm 81.3 counts per minute for vector magnitude) $(37,38)$ and moderate-to-vigorous activity (ICC = 0.99) (39). The GT3X+ showed acceptable agreement between step counts observed in a laboratory setting (ICC $=0.61-0.99)$ and free-living situations (ICC $=0.90)(40)$.

\section{Statistical analysis}

Data analyses were performed using SPSS 22.0 and interpreted at a two-tailed significance level of $p<0.05$. Differences in patient and disease characteristics between patients who received MULTI and those receiving TAU were analyzed using independent t-test and chisquare statistics. Continuous variables were examined for linearity, normality, and homogeneity as assumptions for linear analysis by comparing means with medians and analyzing frequency histograms, normality plots, and plots of residuals versus predicted values. If variables were not distributed linearly towards the dependent variables, they were added as tertiles in the analysis, with the first tertile as the reference category. If data was not distributed normally, analyses were performed using non-parametric tests.

Sum scores of changes in DDDs of somatic and psychotropic medications were distributed normally, after excluding two outliers $(z<-3)$ from the DDD of somatic medication. We used linear multilevel regression to evaluate changes in these outcomes between MULTI and TAU, whereby possible clustering of data within wards was taken into account using a two-level structure, with the wards as the first level and the patients as the second. The change scores of the outcome variables were regressed on the treatment variable and adjusted for the baseline value to prevent potential regression to the mean (crude, model 1). We added patient and disease characteristics that significantly differed between patients receiving MULTI and TAU as covariates in models 2 and 3, respectively. We were not able to properly run corrected between-group analyses on subgroups of medication due to skewed distributions and insufficient power for non-parametric between-group analyses. Therefore, we analyzed the change in DDDs within subgroups of medication separately within MULTI and TAU, using Wilcoxon signed-rank tests. 
Additionally, final significant models were analyzed for possible mediation by a change in total activity counts per hour (TAC/h), using the PROCESS tool in SPSS (41) (Figure 1). The mediation effect was calculated as the product of those coefficients (ab, not shown within the model) and was considered significant if the bias-corrected and accelerated ( $\mathrm{BC}$ ) bootstrapped confidence intervals did not include zero.



(c')

Fig. 1. Model summarizing how the role of change in average total activity counts per hour (TAC/h) as a potential mediator $(\mathrm{M})$ in the association between treatment condition $(\mathrm{X})$ and significant change in medication use (Y) is quantified in mediation analysis. It includes the associations between treatment condition and TAC/h (a), $\mathrm{TAC} / \mathrm{h}$ and the particular outcome variable (b) and treatment condition on the particular outcome variable (c). The coefficient between the latter two, controlling for change in TAC/h, is in parentheses ( $\left.c^{\prime}\right)$.

\section{Results}

Table 1 shows the baseline characteristics of patients receiving MULTI and TAU. None of the included 114 patients dropped out. On average, patients receiving MULTI were younger $(M=-6.45$ years, $95 \% \mathrm{Cl}$ : -10.27 to -2.64$)$, had a higher baseline illness severity $(M=0.63,95 \% \mathrm{Cl}: 0.17$ to 1.08$)$ and were more frequently diagnosed with schizophrenia or other psychotic disorders $\left(X^{2}=21.98, p<0.001\right)$ than patients receiving TAU.

Table 1. Baseline characteristics of patients $(N=114)$.

\begin{tabular}{lrlrl}
\hline Outcome (scale) & MULTI $(n=65)$ & \multicolumn{1}{c}{ TAU $(n=49)$} \\
\hline Sex, $n$ (\%) male & 43 & $(66.2)$ & 27 & $(55.1)$ \\
Age, years, mean (SD) & 52.2 & $(8.9)$ & 58.7 & $(11.6)$ \\
Diagnosis, $n$ (\%) & & & & \\
$\quad$ Schizophrenia and other psychotic disorders & $61^{\mathrm{a}}$ & $(93.8)$ & $28^{\mathrm{b}}$ & $(57.1)$ \\
$\quad$ & $4^{\mathrm{c}}$ & $(6.2)$ & $21^{\mathrm{d}}$ & $(42.9)$ \\
$\quad$ Other disorders & 5.0 & $(1.2)$ & 4.3 & $(1.2)$ \\
IIIness severity, CGI-S scale 1-7, mean (SD) & 14.4 & $(10.9)$ & 13.2 & $(12.7)$ \\
Years of hospitalization, mean (SD) & & & &
\end{tabular}

Significant differences between groups are shown in bold.

MULTI, MUltidisciplinary Lifestyle enhancing Treatment for Inpatients with severe mental illness; TAU, Treatment As Usual; CGI-S, Clinical Global Impression - Severity scale.

a other: schizoaffective disorder $(n=4)$ and a psychotic disorder not otherwise specified $(n=1)$

${ }^{b}$ other: schizoaffective disorder $(n=4)$ and a psychotic disorder not otherwise specified $(n=2)$

${ }^{c}$ mood disorders $(n=2)$ : a pervasive disorder not otherwise specified $(n=1)$ and an anxiety disorder $(n=1)$ 


\section{Chapter 6}

${ }^{\mathrm{d}}$ mood disorders $(n=8)$ : personality disorders $(n=4)$, alcohol-related disorders $(n=4)$, somatoform disorders $(n=2)$, delirium, dementia, and amnestic and other cognitive disorders $(n=2)$ and a pervasive disorder not otherwise specified $(n=1)$

\section{Total use of somatic and psychotropic medication}

Table 2 shows the number of patients using $\geq 1$ medicine within the relevant groups at baseline and follow-up, including their median DDD and the result of analyzing dose changes within both groups. In both MULTI and TAU, there were fewer patients using somatic medication after 18 months, and their median DDD significantly decreased. The same was observed in the totals for psychotropic medication. Table 3 shows the linear regression estimating the effect of MULTI on the change in DDD sum scores for both somatic and psychotropic medication. After adjusting for baseline sum scores, age, diagnosis, and baseline illness severity, the association with the change in the dose of psychotropic medication remained significant in favor of MULTI. This association was not mediated by a change in TAC/h, as no indirect effect was found $(a b=0.06,95 \% \mathrm{BCa} \mathrm{Cl}:-0.01$ $-0.26)$. 


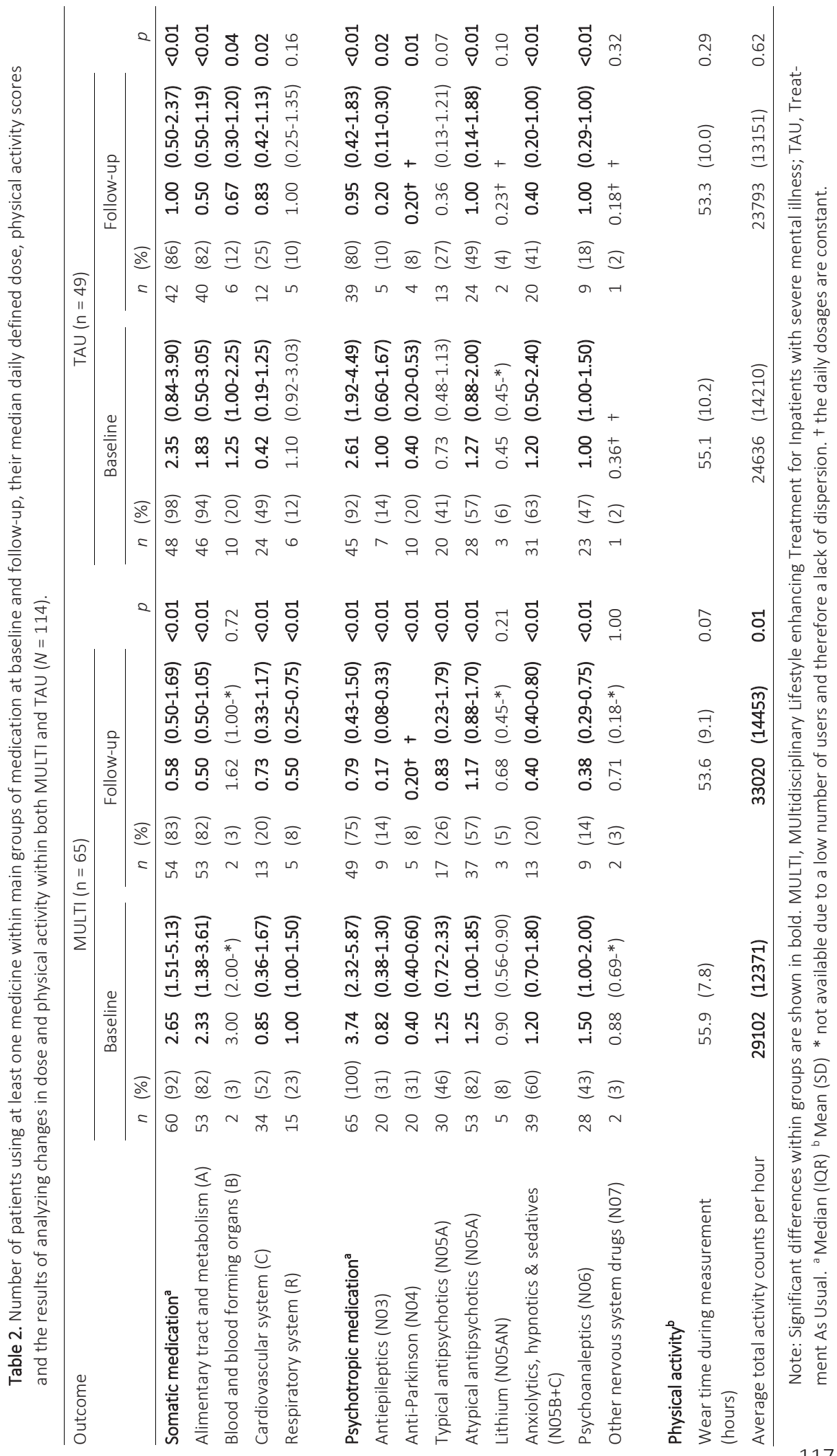


Table 3. Linear regression estimating treatment effects of MULTI compared to treatment as usual on mean daily defined dose $(N=114)$.

\begin{tabular}{llll}
\hline Outcome (ATC code) & B & $(95 \% \mathrm{Cl})$ & $p$ \\
\hline Somatic medications (A, B, C, R) & & & \\
Model 1 & -0.48 & $(-0.90-0.06)$ & 0.025 \\
Model 2 & -0.44 & $(-0.88-0.01)$ & 0.054 \\
Model 3 & -0.38 & $(-0.87-0.11)$ & 0.130 \\
Psychotropic medications (N) & & & \\
Model 1 & -0.47 & $(-0.86-0.07)$ & 0.022 \\
Model 2 & -0.48 & $(-0.90--0.07)$ & 0.023 \\
Model 3 & -0.55 & $(-1.00-0.09)$ & 0.020 \\
\hline
\end{tabular}

Significant results are shown in bold. MULTI, MUltidisciplinary Lifestyle enhancing Treatment for Inpatients with severe mental illness; ATC code, Anatomical Therapeutic Chemical code; A, Alimentary tract and metabolism; B, Blood and blood-forming organs; C, Cardiovascular system; R, Respiratory system; N, Nervous system.

Model 1: crude model, corrected for baseline measurement

Model 2: adjusted model, corrected for baseline measurement and age

Model 3: adjusted model, corrected for baseline measurement, age, diagnosis (schizophrenia and other psychotic disorders, yes/no) and illness severity at baseline

$* n=112$, as two outliers were excluded

\section{Analyses on medication subgroups}

The results of analyses of changes in subgroups of medication are shown in Table 2. For almost all somatic medications, a reduction in the percentage of users was shown in both MULTI and TAU, the largest being in the subgroup regarding the cardiovascular system. The DDD concerning the alimentary tract and metabolism significantly decreased within both groups. For MULTI and TAU this concerned significantly decreased doses of drugs for acid-related disorders (A02; $z=-4.22, p<0.001$ ), constipation (A06; $z=-4.68, p<$ 0.001 ), and diabetes (A10; $z=-2.97, p=0.003$ ). For TAU, decreases in this main group were also reflected in dose reductions in drugs for acid-related disorders (A02; $z=-4.0, p$ $<0.001$ ) and constipation (A06; $z=-4.11, p<0.001$ ), but not for diabetes. Although the median dose of cardiovascular system drugs increased within TAU, the percentage of users decreased. A significant decrease in dose was observed in beta-blocking agents in both MULTI (C07; $z=-4.00, p<0.001)$ and TAU (C07; $z=-3.54, p<0.001)$. Patients receiving MULTI also used a lower dose for disorders of the respiratory system, as shown by a significant decrease of medication for obstructive airway diseases (R03; $z=-2.56, p$ $=0.01$ ), while TAU showed a decreased use of medication of blood and blood-forming organs, as reflected by lower use of antithrombotic agents (B01; $z=-2.06, p=0.04$ ).

For psychotropic medication, a reduction in the percentage of users was shown for almost all subgroups as well, the highest decrease being $40 \%$ in users of anxiolytics, hypnotics, and sedatives within MULTI. Both groups showed significant reductions in dose of medications such as antiepileptics, anti-Parkinson drugs, atypical antipsychotics, 
anxiolytics, hypnotics and sedatives, and psychoanaleptics. In contrast to TAU, MULTI also showed a decrease in the dose of typical antipsychotics.

\section{Discussion}

In the current study we observed a significant dose reduction in psychotropic medications after 18 months of MULTI, compared to TAU. Although the dose reduction in somatic medication was in favor of MULTI too, it was not significant. When these main groups were split into subgroups, there was a lack of power for corrected between-group analyses. However, the first steps in gaining more detailed insight into dose reductions by using within-group analyses showed interesting leads, for example, in the reduction of medication for diabetes and the respiratory system, which is in line with previously reported physical health improvements within MULTI (35). It also showed clearly the remarkable dose reductions in TAU. It is not likely that this is a time effect, as there was no change of policy in the organization regarding the dosage of medication during these 18 months. The reductions might, however, be a disruptive effect caused by a change in medical staff during the 18 months of this study. The psychiatrist responsible for the majority of the patients within TAU retired and was replaced by a younger colleague, who critically reviewed medication policies. Nevertheless, such a critical review had already been done on the wards receiving MULTI prior to its implementation, so dose reduction was not a specific goal within MULTI. Therefore, the significant decrease in the dose of psychotropic medication is even more striking. One explanation could be that this may be caused partly by decreased psychotic symptoms, but earlier results of the MULTI study showed no significant changes in these symptoms, as compared with TAU, after 18 months (35). Another explanation may be that the psychiatrists reduced the dose of medication based on observed improvements in psychosocial functioning in people who received MULTI (42). It is, however, challenging to clarify specific mechanisms with regard to dose reduction, as there are many variables involved (e.g. interactions between different medications; changes in and preferences of the staff; etc.).

Our findings are somewhat in line with the only other study known to us that evaluated medication use after a lifestyle focused program in patients with SMI (43). In that naturalistic study, $\mathrm{H} \varnothing \mathrm{jlund}$ et al. found a decrease in the use of antipsychotics in patients, although they found no specific association between these changes and the degree of participation in the intervention they delivered. However, their reported proportions of patients who used psychotropic co-medication (N categories except for N05) showed little change at follow-up, which is not in line with our observations. Differences may be caused by a different population, as their study was conducted in outpatients with a substantially shorter history of illness, who were relatively young and of whom only a minority used psychotropic co-medication. Also, the absence of a comparison group without lifestyle support makes it difficult to compare results. Indicating decreases in 
medication use after lifestyle improvement is however very relevant for clinical practice. The ideal situation would be to have medication that addresses the symptoms of psychosis with minimal side effects. However, due to a lack of fundamental innovation in psychopharmacology during recent decades, we still have to work with antipsychotics with a range of motor, metabolic, and cognitive side-effects $(28,44)$. Moreover, as there is still an overall favorable benefit-to-risk ratio for the use of antipsychotics (45), addressing lifestyle is of importance to help minimize such side effects. Besides previously reported improvements in physical health (35), current results show that an integrated multidisciplinary approach is associated with a decrease in the dose of medication. Thereby, it potentially reduces (the risk for) those side effects, which are partly dose-dependent (11, 46). Additionally, because many but not all side effects are reversible, it suggests that lifestyle improvements could contribute to the prevention of irreversible effects, e.g. motor side effects. The reductions found are also promising from the patient's point of view, as side effects and negative attitudes towards medication use are associated with nonadherence, distress, and life impact (47-50).

Our explorative mediation analysis showed that the increase in physical activity observed in patients receiving MULTI after 18 months (35) did not mediate the association between MULTI and change in psychotropic medication use in this same period of time. This indicates that the decrease of psychotropic medication was not a result of just increasing physical activity. We hypothesize that, with an organizational culture change as a base, multiple components that complement physical activity contribute to improvements, including focus on dietary habits, psycho-education, personal tailoring, and support by peers and qualified participating staff, in line with recent studies advocating the use of such elements $(29,30,51-53)$. Such a holistic approach, in which patients are encouraged to do any activities instead of none (i.e. decreasing sedentary behavior), may be more feasible and beneficial in the longer term for inpatients with SMI. While previous studies have shown that structured exercise is feasible in those with SMI in general (31), sedentary behavior (as distinct from physical inactivity) is highly prevalent and associated with cardiometabolic risks that are largely independent of time spent in structured exercise $(7,8)$. Thus, controlled trials are needed to examine further the feasibility and effects of interventions targeting sedentary behavior.

Limitations in this study mainly arise from the naturalistic and observational design. In this design, we were not able to randomize patients (e.g. the TAU wards treated fewer patients with psychotic disorders) and control for treatment settings in advance (e.g. the continuity of psychiatrists). In addition, although dose reduction was not a specific goal of MULTI, psychiatrists were not blinded for patients' treatment condition (i.e. receiving MULTI or not), which might have affected observed dose reductions. Although this observational study seems the first indicating a possible effect of lifestyle improvements on medication use in inpatients with SMI, future well-designed trials are needed to study the efficacy of lifestyle changes on medication use. Regarding the participation of patients in MULTI, we have no specific data on (the degree of) their adherence. It was intended that 
all patients were doing some activities in the morning and afternoon, tailored to the particular ward and patients' abilities and interests. However, data on adherence to these individualized day-to-day programs including more detailed data on participation (e.g. frequency and intensity of activities) would make it possible to study the association between the (degree of) adherence and treatment outcomes. Also, our analyses depended on the availability of data within the cohort. Nevertheless, by using multilevel analyses adjusting for differences between MULTI and TAU, we aimed for robust results. However, more data will be needed to have sufficient power for adequate between-group analyses within subgroups of medication, whereby we could gain more detailed insight into specific reductions as indicated by within-group analyses (e.g. drugs for diabetes or obstructive airway diseases). This would provide the opportunity to control for possible differences between groups such as age, which can affect the prescribed dosages of medication (54-56). Furthermore, we used a simple mediation model to explore the influence of a change in physical activity, as an essential element of MULTI, on the association between MULTI and change in medication use. However, the main limitation of this is that by measuring all variables within the mediation analyses nearly simultaneously, we assumed that the association between change in total activity and change in medication use between our pre (T1) and post measurement (T2) would be the same as we would have measured between T2 and a (theoretical) third time point. To study if physical activity mediates associations between lifestyle interventions and medication use, in general, it would be the best to measure physical activity as a middle time-point to study the effect of a change in physical activity over time. Finally, we did not include pro necessitate medication (i.e. to be given as needed) because we cannot specify if and to what extend patients took these medications.

The strength of this study is that it is the first study to report detailed dose-specific data on changes in both somatic and psychotropic medication use in inpatients with SMI after lifestyle changes. Despite the limitations, first steps were taken to analyze associations between lifestyle improvements and medication use in these patients, who are suffering from severe physical health problems and receive high dosages of medication. The naturalistic setting of the study improves the generalizability of the results and meets the need for observational studies to supplement randomized controlled trials in order to improve the external validity, such that clinicians treating patients in real-world settings have relevant evidence on which to base their clinical decisions (57). Regarding the impact of critically reviewing medication use that was most likely observed in TAU, it is a strength in favor of MULTI that medication was already critically reviewed on these wards before its implementation, so dose reduction was not a specific goal within MULTI. This suggests that lifestyle improvement has added value with regard to decreasing the dose of medication in inpatients with SMI. Above all, this strengthens the fact that we compared it with TAU. Otherwise, we would only have observed the improvements in MULTI without any context. Moreover, by analyzing possible mediation by total activity, we took a first step to gaining more insight into the contribution of different elements of MULTI 
to the observed improvements. Finally, by including baseline measures in this analysis, our mediation analysis is mathematically in line with a covariance approach, which was the recommended method for mediation analyses $(58,59)$.

In summary, in addition to previously reported improvements in physical activity and metabolic health after 18 months of MULTI, we observed a significant decrease in dose of psychotropic medication as compared with TAU. We encourage further longitudinal controlled research to gain more insight into the relationship between lifestyle changes and possible dose reductions to improve health outcomes in inpatients with SMI.

\section{Acknowledgements}

The authors would like to acknowledge, with thanks, all patients and staff of GGz Centraal who have made efforts to collect the data on which this study was based.

\section{Funding}

This study was supported by an unrestricted grant from Stichting tot Steun VCVGZ. The authors declare that they have no competing interests.

\section{Author contributions}

JD: obtaining funding, study design, retrieving, processing and analyzing data, drafting the manuscript. DT: study design, supporting retrieving, processing and analyzing data. HvD: retrieving, processing and supporting analyzing data. $\mathrm{IH}$ : supporting analyzing data. DT and PvH: supporting grant applications. All authors critically revised the manuscript and approved the final version.

\section{Availability of data and materials}

Data are available from the corresponding author on reasonable request and with permission of GGz Centraal.

\section{Conflict of interest statement}

The authors declare that the research was conducted in the absence of any commercial or financial relationships that could be construed as a potential conflict of interest. 


\section{References}

1. Vancampfort D, Stubbs B, Mitchell AJ, De Hert M, Wampers M, Ward PB, et al. Risk of metabolic syndrome and its components in people with schizophrenia and related psychotic disorders, bipolar disorder and major depressive disorder: a systematic review and meta-analysis. World Psychiatry (2015) 14:339-47. doi: 10.1002/wps.20252

2. Stubbs B, Vancampfort D, De Hert M, Mitchell AJ. The prevalence and predictors of type two diabetes mellitus in people with schizophrenia: a systematic review and comparative meta-analysis. Acta Psychiatr Scand (2015) 132:144-57. doi: 10.1111/acps.12439

3. Correll CU, Solmi M, Veronese N, Bortolato B, Rosson S, Santonastaso P, et al. Prevalence, incidence and mortality from cardiovascular disease in patients with pooled and specific severe mental illness: a largescale meta-analysis of 3,211,768 patients and 113,383,368 controls. World Psychiatry (2017) 16:163-80. doi: 10.1002/wps.20420

4. Piotrowski P, Gondek TM, Krolicka-Deregowska A, Misiak B, Adamowski T, Kiejna A. Causes of mortality in schizophrenia: An updated review of European studies. Psychiatr Danub (2017) 29:108-20.

5. Hjorthøj C, Sturup AE, McGrath JJ, Nordentoft M. Years of potential life lost and life expectancy in schizophrenia: a systematic review and meta-analysis. The Lancet Psychiatry (2017) 4:295-301. doi: 10.1016/s2215-0366(17)30078-0

6. Tanskanen A, Tiihonen J, Taipale H. Mortality in schizophrenia: 30-year nationwide follow-up study. Acta Psychiatr Scand (2018). doi: 10.1111/acps.12913

7. Biswas A, Oh PI, Faulkner GE, Bajaj RR, Silver MA, Mitchell MS, et al. Sedentary Time and Its Association With Risk for Disease Incidence, Mortality, and Hospitalization in Adults A Systematic Review and Metaanalysis. Ann Intern Med (2015) 162:123-32. doi: 10.7326/m14-1651

8. Brocklebank LA, Falconer CL, Page AS, Perry R, Cooper AR. Accelerometer-measured sedentary time and cardiometabolic biomarkers: A systematic review. Prev Med (2015) 76:92-102. doi: 10.1016/j.ypmed.2015.04.013

9. Kruisdijk F, Deenik J, Tenback D, Tak E, Beekman A, van Harten P, et al. Accelerometer-measured sedentary behaviour and physical activity of inpatients with severe mental illness. Psychiatry Res (2017) 254:67-74. doi: 10.1016/j.psychres.2017.04.035

10. Stubbs B, Firth J, Berry A, Schuch FB, Rosenbaum S, Gaughran F, et al. How much physical activity do people with schizophrenia engage in? A systematic review, comparative meta-analysis and meta-regression. Schizophr Res (2016) 176:431-40. doi: 10.1016/j.schres.2016.05.017

11. Correll CU, Detraux J, De Lepeleire J, De Hert M. Effects of antipsychotics, antidepressants and mood stabilizers on risk for physical diseases in people with schizophrenia, depression and bipolar disorder. World Psychiatry (2015) 14:119-36. doi: 10.1002/wps.20204

12. Kahl KG, Westhoff-Bleck M, Kruger THC. Effects of psychopharmacological treatment with antipsychotic drugs on the vascular system. Vascul Pharmacol (2017). doi: 10.1016/j.vph.2017.09.001

13. Solmi M, Murru A, Pacchiarotti I, Undurraga J, Veronese N, Fornaro M, et al. Safety, tolerability, and risks associated with first- and second-generation antipsychotics: a state-of-the-art clinical review. Ther Clin Risk Manag (2017) 13:757-77. doi: 10.2147/tcrm.s117321

14. Verhaegen AA, Van Gaal LF. Drug-induced obesity and its metabolic consequences: a review with a focus on mechanisms and possible therapeutic options. J Endocrinol Invest (2017) 40:1165-74. doi: 10.1007/s40618-017-0719-6

15. Westaway K, Sluggett JK, Alderman C, Procter N, Roughead E. Prevalence of multiple antipsychotic use and associated adverse effects in Australians with mental illness. International Journal of Evidence-Based Healthcare (2016) 14:104-12. doi: 10.1097/xeb.0000000000000082

16. Torniainen M, Mittendorfer-Rutz E, Tanskanen A, Bjorkenstam C, Suvisaari J, Alexanderson K, et al. Antipsychotic treatment and mortality in schizophrenia. Schizophr Bull (2015) 41:656-63. doi: 10.1093/schbul/sbu164 
17. Brett J, Daniels B, Karanges EA, Buckley NA, Schneider C, Nassir A, et al. Psychotropic polypharmacy in Australia, 2006 to 2015: a descriptive cohort study. Br J Clin Pharmacol (2017) 83:2581-8. doi: 10.1111/bcp.13369

18. Bakker PR, de Groot IW, van Os J, van Harten PN. Long-Stay psychiatric patients: A prospective study revealing persistent Antipsychotic-Induced movement disorder. PLoS One (2011) 6.

19. Mentzel CL, Bakker PR, Van Os J, Drukker M, Matroos GE, Hoek HW, et al. Effect of Antipsychotic Type and Dose Changes on Tardive Dyskinesia and Parkinsonism Severity in Patients With a Serious Mental Illness: The Curacao Extrapyramidal Syndromes Study XII. J Clin Psychiatry (2017) 78:E279-E85. doi: 10.4088/JCP.16m11049

20. Catapano AL, Graham I, De Backer G, Wiklund O, Chapman MJ, Drexel H, et al. 2016 ESC/EAS Guidelines for the Management of Dyslipidaemias. Eur Heart J (2016) 37:2999-3058. doi: 10.1093/eurheartj/ehw272

21. Grundy SM, Cleeman JI, Daniels SR, Donato KA, Eckel RH, Franklin BA, et al. Diagnosis and Management of the Metabolic Syndrome. An American Heart Association/National Heart, Lung, and Blood Institute Scientific Statement (2005) 112:2735-52. doi: 10.1161/circulationaha.105.169404

22. Maayan L, Correll CU. Management of antipsychotic-related weight gain. Expert Rev Neurother (2010) 10:1175-200. doi: 10.1586/ern.10.85

23. Mancia G, Fagard R, Narkiewicz K, Redon J, Zanchetti A, Bohm M, et al. 2013 ESH/ESC Guidelines for the management of arterial hypertension: the Task Force for the management of arterial hypertension of the European Society of Hypertension (ESH) and of the European Society of Cardiology (ESC). J Hypertens (2013) 31:1281-357. doi: 10.1097/01.hjh.0000431740.32696.cc

24. Ryden L, Grant PJ, Anker SD, Berne C, Cosentino F, Danchin N, et al. ESC Guidelines on diabetes, prediabetes, and cardiovascular diseases developed in collaboration with the EASD: the Task Force on diabetes, pre-diabetes, and cardiovascular diseases of the European Society of Cardiology (ESC) and developed in collaboration with the European Association for the Study of Diabetes (EASD). Eur Heart J (2013) 34:3035-87. doi: 10.1093/eurheartj/eht108

25. Barnes TR. Evidence-based guidelines for the pharmacological treatment of schizophrenia: recommendations from the British Association for Psychopharmacology. J Psychopharmacol (2011) 25:567-620. doi: 10.1177/0269881110391123

26. Bhugra D, Howes O. Handbook for Psychiatric Trainees: Royal College of Psychiatrists (2008).

27. Emsley R. On discontinuing treatment in schizophrenia: a clinical conundrum. NPJ Schizophrenia (2017) 3:4. doi: 10.1038/s41537-016-0004-2

28. Lally J, MacCabe JH. Antipsychotic medication in schizophrenia: a review. Br Med Bull (2015) 114:169-79. doi: 10.1093/bmb/ldv017

29. Teasdale SB, Ward PB, Rosenbaum S, Samaras K, Stubbs B. Solving a weighty problem: systematic review and meta-analysis of nutrition interventions in severe mental illness. The British Journal of Psychiatry (2017) 210:110-8. doi: 10.1192/bjp.bp.115.177139

30. Ward MC, White DT, Druss BG. A meta-review of lifestyle interventions for cardiovascular risk factors in the general medical population: lessons for individuals with serious mental illness. J Clin Psychiatry (2015) 76:e477-86. doi: 10.4088/JCP.13r08657

31. Stubbs B, Vancampfort D, Hallgren M, Firth J, Veronese N, Solmi M, et al. EPA guidance on physical activity as a treatment for severe mental illness: a meta-review of the evidence and Position Statement from the European Psychiatric Association (EPA), supported by the International Organization of Physical Therapists in Mental Health (IOPTMH). Eur Psychiatry (2018) 54:124-44. doi: 10.1016/j.eurpsy.2018.07.004

32. Liu NH, Daumit GL, Dua T, Aquila R, Charlson F, Cuijpers $P$, et al. Excess mortality in persons with severe mental disorders: a multilevel intervention framework and priorities for clinical practice, policy and research agendas. World Psychiatry (2017) 16:30-40. doi: 10.1002/wps.20384

33. Levitt GA, Shinault K, Patterson S, Otaluka O. Weight Gain in Psychiatric Inpatients: Are Interventions Making a Positive Impact? Prim Care Companion CNS Disord (2017) 19:17m02111. doi: 10.4088/PCC.17m02111

34. Looijmans A, Stiekema A, Bruggeman R, van der Meer L, Stolk RP, Schoevers RA, et al. Changing the obesogenic environment to improve cardiometabolic health in residential patients with a severe mental 
IIIness: ELIPS, a randomized controlled trial. Br J Psychiatry (2017) 211:296-303. doi: 10.1186/s12888-0140293-9

35. Deenik J, Tenback DE, Tak ECPM, Rutters F, Hendriksen IJM, van Harten PN. Changes in physical and psychiatric health after a multidisciplinary lifestyle enhancing treatment for inpatients with severe mental illness: the MULTI study I. Schizophr Res (2018). doi: 10.1016/j.schres.2018.07.033

36. WHO Collaborating Centre for Drug Statistics Methodology. ATC classification index with DDDs, 2017. Oslo: World Health Organization (2016).

37. Ozemek C, Kirschner MM, Wilkerson BS, Byun W, Kaminsky LA. Intermonitor reliability of the GT3X+accelerometer at hip, wrist and ankle sites during activities of daily living. Physiol Meas (2014) 35:129-38.

38. Aadland E, Ylvisaker E. Reliability of the Actigraph GT3X+Accelerometer in Adults under Free-Living Conditions. PLoS One (2015) 10:e0134606. doi: 10.1371/journal.pone.0134606

39. Jarrett H, Fitzgerald L, Routen AC. Interinstrument reliability of the ActiGraph GT3X+ambulatory activity monitor during free-living conditions in adults. Journal of Physical Activity and Health (2015) 12:382-7. doi: 10.1123/jpah.2013-0070

40. Lee JA, Williams SM, Brown DD, Laurson KR. Concurrent validation of the Actigraph gt3x+, Polar Active accelerometer, Omron HJ-720 and Yamax Digiwalker SW-701 pedometer step counts in lab-based and free-living settings. J Sports Sci (2015) 33:991-1000. doi: 10.1080/02640414.2014.981848

41. Hayes AF. PROCESS: A versatile computational tool for observed variable mediation, mod-eration, and conditionalprocess modeling [White paper] (2012). Available from: http://www.afhayes.com/public/process2012.pdf.

42. Deenik J, Tenback DE, Tak ECPM, Hendriksen IJM, van Harten PN. Improved quality of life and psychosocial functioning in inpatients with severe mental illness receiving a multidisciplinary lifestyle enhancing treatment. The MULTI study II. Mental Health and Physical Activity (2018) 15:145-52. doi: 10.1016/j.mhpa.2018.10.004

43. Højlund M, Elliott AF, Madsen NJ, Viuff AG, Munk-Jørgensen P, Hjorth P. Changes in antipsychotics and other psychotropic drugs during a 30-month lifestyle intervention among outpatients with schizophrenia. Nordic Journal of Psychiatry (2017) 71:598-604. doi: 10.1080/08039488.2017.1365379

44. Dimitrelis K, Shankar R. Pharmacological treatment of schizophrenia - a review of progress. Prog Neurol Psychiatry (2016) 20:28-35. doi: doi:10.1002/pnp.430

45. Correll CU, Rubio JM, Kane JM. What is the risk-benefit ratio of long-term antipsychotic treatment in people with schizophrenia? World Psychiatry (2018) 17:149-60. doi: 10.1002/wps.20516

46. Leucht S, Corves C, Arbter D, Engel RR, Li C, Davis JM. Second-generation versus first-generation antipsychotic drugs for schizophrenia: a meta-analysis. Lancet (2009) 373:31-41. doi: 10.1016/s01406736(08)61764-x

47. Ashoorian D, Davidson R, Rock D, Dragovic M, Clifford R. A clinical communication tool for the assessment of psychotropic medication side effects. Psychiatry Res (2015) 230:643-57. doi: 10.1016/j.psychres. 2015.10.022

48. Velligan DI, Sajatovic M, Hatch A, Kramata P, Docherty JP. Why do psychiatric patients stop antipsychotic medication? A systematic review of reasons for nonadherence to medication in patients with serious mental illness. Patient Prefer Adherence (2017) 11:449-68. doi: 10.2147/ppa.s124658

49. Wykes T, Evans J, Paton C, Barnes TRE, Taylor D, Bentall R, et al. What side effects are problematic for patients prescribed antipsychotic medication? The Maudsley Side Effects (MSE) measure for antipsychotic medication. Psychol Med (2017) 47:2369-78. doi: 10.1017/s0033291717000903

50. Hui CL, Poon VW, Ko WT, Miao HY, Chang WC, Lee EH, et al. Risk factors for antipsychotic medication nonadherence behaviors and attitudes in adult-onset psychosis. Schizophr Res (2016) 174:144-9. doi: 10.1016/j.schres.2016.03.026

51. Long C, Rowell A, Rigg S, Livesey F, McAllister P. What is effective in promoting a healthy lifestyle in secure psychiatric settings? A review of the evidence for an integrated programme that targets modifiable health risk behaviours. The Journal of Forensic Practice (2016) 18:204-15. doi: 10.1108/jfp-12-2015-0055 
52. Roberts SH, Bailey JE. Incentives and barriers to lifestyle interventions for people with severe mental illness: a narrative synthesis of quantitative, qualitative and mixed methods studies. J Adv Nurs (2011) 67:690-708. doi: 10.1111/j.1365-2648.2010.05546.x

53. Vancampfort D, Rosenbaum S, Schuch F, Ward PB, Richards J, Mugisha J, et al. Cardiorespiratory fitness in severe mental illness: A systematic review and meta-analysis. Sports Med (2017) 47:343-52. doi: 10.1007/s40279-016-0574-1

54. Rej S, Beaulieu S, Segal M, Low NC, Mucsi I, Holcroft C, et al. Lithium dosing and serum concentrations across the age spectrum: from early adulthood to the tenth decade of life. Drugs Aging (2014) 31:911-6. doi: 10.1007/s40266-014-0221-1

55. de Mendonca Lima CA, Baumann P, Brawand-Amey M, Brogli C, Jacquet S, Cochard N, et al. Effect of age and gender on citalopram and desmethylcitalopram steady-state plasma concentrations in adults and elderly depressed patients. Prog Neuropsychopharmacol Biol Psychiatry (2005) 29:952-6. doi: 10.1016/j.pnpbp.2005.06.001

56. Beyth RJ, Shorr RI. Principles of drug therapy in older patients: rational drug prescribing. Clin Geriatr Med (2002) 18:577-92.

57. Kennedy-Martin T, Curtis S, Faries D, Robinson S, Johnston J. A literature review on the representativeness of randomized controlled trial samples and implications for the external validity of trial results. Trials (2015) 16:495. doi: 10.1186/s13063-015-1023-4

58. Landau S, Emsley R, Dunn G. Beyond total treatment effects in randomised controlled trials: Baseline measurement of intermediate outcomes needed to reduce confounding in mediation investigations. Clin Trials (2018) 15:247-56. doi: 10.1177/1740774518760300

59. Twisk J, Bosman L, Hoekstra T, Rijnhart J, Welten M, Heymans M. Different ways to estimate treatment effects in randomised controlled trials. Contemporary Clinical Trials Communications (2018) 10:80-5. doi: 10.1016/j.conctc. 2018.03 .008 


\section{Chapter}



\section{Implementation barriers and facilitators of an integrated multidisciplinary lifestyle enhancing treatment for inpatients with severe mental illness. The MULTI study IV}




\section{Abstract}

\section{Background:}

Despite the established efficacy of lifestyle interventions in improving the poor health outcomes for people with severe mental illness (SMI), routine implementation remains ad hoc. Recently, a multidisciplinary lifestyle enhancing treatment for inpatients with SMI (MULTI) was implemented as part of routine care at a long-term inpatient facility in the Netherlands, resulting in significant health improvements after 18 months. The current study aimed to identify barriers and facilitators of its implementation.

\section{Methods:}

Determinants associated with implementation of MULTI, related to the innovation, the users (patients, the healthcare professionals (HCPs)), and the organisational context, were assessed at the three wards that delivered MULTI. The evidence-based Measurement Instrument for Determinants of Innovations was used to assess determinants (29 items), each measured through a 5-point Likert scale and additional open-ended questions. We considered determinants to which $\geq 20 \%$ of the HCPs or patients responded negatively ("totally disagree/disagree", score $<3$ ) as barriers and to which $\geq 80 \%$ of HCPs or patients responded positively ("agree/totally agree", score $>3$ ) as facilitators. We included responses to open-ended questions if the topic was mentioned by $\geq 2$ HCPs or patients. In total 50 HCPs (online questionnaire) and 46 patients (semi-structured interview) were invited to participate in the study.

\section{Results:}

Participating HCPs ( $n=42$ ) mentioned organisational factors as the strongest barriers (e.g. organisational changes and financial resources). Patients $(n=33)$ mentioned the complexity of participating in MULTI as the main barrier, which could partly be due to organisational factors (e.g. lack of time for nurses to improve tailoring). The implementation was facilitated by positive attitudes of HCPs and patients towards MULTI, including their own role in it. Open responses of HCPs and patients showed strong commitment, collaboration and ownership towards MULTI.

\section{Conclusions:}

This is the first study analysing the implementation of a pragmatic lifestyle intervention targeting SMI inpatients in routine clinical care. Positive attitudes of both HCPS and patients towards such an approach facilitated the implementation of MULTI. Strategies addressing organisational barriers are needed to further improve and maintain MULTI and its beneficial effects, to succeed in achieving positive health-related outcomes in inpatients with SMI. 


\section{Background}

It is well established that the implementation of lifestyle interventions in people with severe mental illness (SMI), such as psychotic disorders, in psychiatry is a major challenge. The urgency to improve physical health is stressed by the substantially reduced life expectancy of 7-20 years compared to the general population [1-3]. This is largely caused by poor cardiovascular health [2, 4-7], in which modifiable lifestyle factors such as lack of physical activity [8-12] and poor nutrition [13] play a major role. A substantial body of evidence supports the efficacy of interventions addressing the impact of such factors on cardiometabolic health, aerobic capacity, global functioning, psychiatric symptoms, quality of life and cognitive functioning in patients with SMI [14-21]. Although these studies were vital to show that lifestyle interventions work (i.e. efficacy), there is a need for more research studying how patients with SMI can include such changes in their day-to-day lives (i.e. effectiveness) [22]. Currently, the evidence to support the long-term sustainability of lifestyle interventions for patients with SMI is limited [18, 23, 24]. Therefore, improving the physical health of people with SMI should not be considered as a gap in knowledge but rather as an implementation gap [25]. The challenge of implementing lifestyle interventions in patients with SMI was well illustrated in a pilot study, where patients were offered free access to fitness facilities, and $90 \%$ of the patients dropped out after six months [26]. Also, in a recent trial in SMI inpatients [27, 28], no long-term effects of a lifestyle intervention were found, and the authors hypothesized that implementation problems (partly) contributed to the null finding. Even more examples of negative findings in clinical practice likely exist, however failed implementation studies are less likely to be published [29].

Understanding implementation barriers and facilitators can contribute to the interpretation of the results of interventions and to devise strategies to enhance integration of research findings into routine clinical care [30]. They manifest themselves on levels of the intervention, the individual (patient), provider (healthcare professionals; HCPs), organisation, and community/system [31], although the latter two largely overlap in inpatient facilities. A previous study showed that the perceived benefits which may motivate patients with SMI to be physically active (such as mood improvement, stress reduction and improvement in physical health) were found to be contrary to perceived barriers (e.g. low mood and motivation, physical comorbidities, stress and side effects of medication) [32]. Thereby, HCPs reported a lack of motivation in patients as the main obstacle to increasing physical activity [33-36]. Perceived barriers by HCPs were related to lack of time, support or training, competing work demands and organisational issues, e.g. prioritisation and lack of management support [36-38]. However, studies evaluating the implementation of lifestyle interventions in 'real-world' settings are scarce and so far little has changed in day-to-day routine care for patients with SMI [39]. Moreover, previous research has mainly focused on the individual perspective (both patients and HCPs), 
whereas there is a need for insight into (modifiable) barriers and facilitators at the organisational/environmental level as well [40].

Recently, a multidisciplinary lifestyle enhancing treatment for inpatients with SMI (MULTI) was introduced in the Netherlands. A team of psychiatrists, nurses, activity coordinators, team leaders and a dietitian implemented MULTI within daily treatment with the purpose of achieving overall lifestyle change, focusing on decreasing sedentary behaviour, increasing physical activity and improving dietary habits. Through such an approach, MULTI aligns with the recommendations of recent studies that a multidisciplinary and holistic approach, supported by peers and qualified HCPs, personalisation/tailoring, the use of multiple components and an organisational culture change [15, 36, 41-51] should be addressed. After 18 months, we conducted a pragmatic evaluation and observed significant improvements in physical activity, metabolic health and psychosocial functioning $[52,53]$ and a decreased use of psychotropic medication (unpublished data) compared to usual treatment. Increased quality of life [53] and decreased use of somatic medication (unpublished data) were also observed within MULTI. This was the first study to demonstrate such comprehensive long-term improvements in the inpatient population. The lack of improvements in physical activity and metabolic health in the treatment as usual group during these 18 months reinforces the need for systemic change within routine clinical care [52].

Nonetheless, within the inpatient setting - in which there is a weak evidence base $[21,44,54]$ - the main challenge after studying the effectiveness of interventions targeting lifestyle lies in the implementation and maintenance of lifestyle interventions. To determine whether MULTI can reduce the implementation gap, we aimed to identify barriers and facilitators that influence the implementation of MULTI. The results will enable us to better interpret previously studied outcomes of MULTI and devise strategies for future implementation of lifestyle interventions for this vulnerable population.

\section{Methods}

\section{Design and procedure}

In this study, we took different levels of implementation into account: the innovation itself, the users and the organisation, according to the framework as proposed by Fleuren et al. [55] based on pooled analysis of studies and a Delphi study among - and consultation of - implementation experts. This study was conducted at three long-stay wards ( $\geq 1$ year) within a psychiatric hospital of GGz Centraal (the Netherlands). This implementation study is part of the MULTI-study [52]. MULTI was developed because of the identified need to address the comorbidity (e.g. sleep apnoea and cardiovascular morbidity) in this population, in part due to a lack of physical activity, obesity and unhealthy eating habits. The implementation of MULTI (described in the next paragraph) was conducted by 
psychiatrists, nurses and team leaders in collaboration with activity coordinators and a dietitian. After finishing data collection for evaluation of health outcomes 18 months after the start of MULTI (February 2014) as described elsewhere $[52,53]$, patients $(N=65)$ and HCPS $(N=56)$ involved in MULTI were invited to participate in the present study. Patients were excluded if they did not understand the content of MULTI, in consultation with their attending psychiatrist and HCPs were excluded if they did not actively work with MULTI.

All 50 eligible HCPs (psychiatrists, nurses, activity coordinators, team leaders and a dietitian) were invited by email to participate. They completed an online questionnaire using an unique link, to answer an online survey assessing barriers and facilitators of implementing MULTI. Three reminder e-mails were sent at two-week intervals to all nonresponders. To evaluate MULTI among patients, a trained research assistant conducted semi-structured interviews. The Medical Ethical Committee of the Isala Academy approved the protocol (case 14.0678). All subjects gave (digital) written informed consent in accordance with the Declaration of Helsinki.

\section{MULTI}

The purpose of MULTI was a holistic lifestyle change with a focus on decreasing sedentary behaviour, increasing physical activity and improving dietary habits among long-term inpatients with SMI. The treatment method was based on improving day-to-day structure, by starting each day with getting up on time, having three joint meals per day and participation in an active day program. The latter consisted of sports-related activities (e.g. walking, running, yoga, biking, indoor team sports), work-related activities (e.g. gardening and working in services within the hospital), psycho-education (e.g. about side effects of medication, dietary habits) and daily living skills training (e.g. shopping, cooking). Additionally, existing policies were critically reviewed and adjusted if necessary (e.g. limiting the use of personal transport by patients for trips within walking distance around the hospital area). Based on heterogeneity in patients' illness severity, capabilities and interests, the content and intensity of the day-to-day program was tailored to the particular ward and individual patients to establish sustainable change. Therefore, the actual frequency, intensity, kind of activities and format (e.g. group or alone) could vary between patients and wards. However, it was intended that all patients were doing some of the activities in the morning and afternoon, to prevent prolonged periods lying in bed or sitting at the ward. Also, the participation of nurses in the day-to-day program was an essential element, which contributed to the culture change within the institution and in provision of support to patients.

MULTI was based on a 'change from within' principle, meaning that it was developed by current staff using current resources within routine clinical care. It was supervised and disseminated per ward by the head practitioner (a psychiatrist) as an innovative treatment method. Multidisciplinary work sessions led to detailed plans of the day-to-day 
programs which were shared by and between the different teams and discussed, thus leading to maximum participation and engagement needed to achieve culture change. Staff received support by the psychiatrists (psycho-education), activity coordinators and the dietitian. Adherence to and compliance with the treatment was discussed in the weekly multidisciplinary consultation. If a patient could not sufficiently participate in the day-to-day program (e.g. had problems getting out of bed or had low attendance during the selected activities), it was agreed to provide extra support, using motivational counselling by their mentor (one of the nurses) or psychiatrist and by consulting an activity coordinator or dietitian if needed.

\section{Measures}

To analyse the implementation of MULTI, we used the evidence-based Measurement Instrument for Determinants of Innovations (MIDI) [55, 56]. It was primarily designed to determine barriers and facilitators of implementation, to choose appropriate implementation strategies. In this study, it was used while running MULTI to learn from the experiences for future implementation and better interpretation of health outcome results. The MIDI comprises of four subscales, measuring determinants for implementation of the intervention itself ( 7 items), the user (11 items), the organisation (10 items) and the sociopolitical context ( 1 item). Although in the original development of MIDI the user was seen as the main provider of the innovation (the HCPs), we considered the patients as users as well, due to their significant role in MULTI. The 29 items are scored using a five-point scale (totally disagree - totally agree). In accordance with the MIDI instruction guide [57] and based on input from clinical practice and testing the content and usability of the questionnaire with two HCPs, we made some adjustments to tailor the questionnaire to MULTI and its context. To gain more detailed insight into the determinants of both HCPs and patients, we split personal benefits/disadvantages (item 8) into two separate items. To measure personal benefits and disadvantages and potential organisational changes affecting implementation, we included predefined answers based on the feedback of the HCPs who tested the questionnaire. For outcome expectations (both importance and probability), social support, subjective norm (both normative beliefs and motivation to comply) and self-efficacy, we included predefined answers based on the design of MULTI, supplemented by answers based on feedback while testing the questionnaire. Lastly, we did not assess the subscale 'socio-political context', as we assumed legislation and regulations to be the same at all wards of our hospital [55]. Table S1 (see Additional file 1) includes the final questionnaire used to assess the determinants in the HCPs. For patients, we limited the number of items of this questionnaire to those that were relevant from patients' perspective, to increase feasibility and prevent unnecessary burden. Therefore, we excluded procedural clarity (item 1), correctness (item 2), self-efficacy (item 17) and knowledge (item 18), as (evidence for) the description and use of MULTI was focused on HCPs as its main 'implementers'. Also, the subscale regarding determinants of the 
organisation was excluded, as patients are not involved in the organisational structure and regulations. The aforementioned predefined answers were reduced as well and tailored to relevant topics from the patients' perspective, based on consultation with patients and nurses and pilot testing in two interviews. In Table S2 (see Additional file 2) the final questionnaire used to assess determinants in patients is shown. In addition, both HCPs and patients were asked to mention the barriers and facilitators that they experienced which were not specifically addressed in MIDI, using open-ended questions. The internal consistency of the final questionnaire was fair to excellent for HCPs (intervention subscale: $\alpha=.84$; user subscale: $\alpha=.93$; organisation subscale: $\alpha=.74)$. In patients, this was poor for the intervention subscale $(\alpha=.48$ ) and good for the user subscale $(\alpha=.86)$.

\section{Statistical analysis}

We used the Statistical Package for the Social Sciences (SPSS) version 23.0 for all analyses. Independent-samples t-tests and chi-square test were used to analyse potential differences between participating patients and non-participants (excluded/dropout) in gender, age, diagnosis and illness severity at the start of implementation. Such analyses were not possible for HCPs, as only HCPs that completed the questionnaire provided consent to participate.

For the evaluation of the MIDI questionnaire items, we used means and standard deviations for each determinant, as well as the score per subscale, after recoding negatively stated items. Consistent with recent studies $[58,59]$ and in consultation with Dr. Fleuren (developer MIDI), we decided that items to which $\geq 20 \%$ of the HCPs and patients responded negatively (corresponding to "totally disagree/disagree", score <3) were considered barriers and those to which $\geq 80 \%$ of HCPs and patients responded positively (corresponding "agree/totally agree", score >3) were considered facilitators in the implementation of MULTI. Due to differences between scale ranges, the item descriptive norm (item 15, scored 1-7) and awareness of the content of the treatment (item 19, scored 14 ) were excluded in calculating mean subscale scores. To identify barriers and facilitators, descriptive norm was categorised as negative (score 1-3), neutral (score 4) and positive (score 5-7) and awareness of the content of the treatment as negative (score 1-2) or positive (score 3-4). To code the open-ended questions with regard to barriers and facilitators we used an inductive approach to determine topics and included the topics if mentioned by at least two HCPs or patients. 


\section{Results}

Of the 50 eligible HCPs, 42 (84\%) completed the questionnaire (see Figure 1). All disciplines involved were represented. Activity coordinators covered both HCPs that focused on physical activity $(n=2)$ as well as other lifestyle training ( $n=3$, e.g. cooking). Compared to patients who were excluded $(n=19)$ or dropped out $(n=13)$, patients who completed the questionnaire ( $n=33$ ) were younger $(M=-4.90,95 \% \mathrm{Cl}=-9.19$ to -0.61$)$, had lower illness severity $(M=-1.08,95 \% \mathrm{Cl}=-1.62$ to -0.53$)$ and were hospitalised for fewer years $(M=-5.55,95 \% \mathrm{Cl}=-10.81$ to -0.28$)$. Participating patients were mainly diagnosed with schizophrenia or related psychotic disorders (see Table 1).
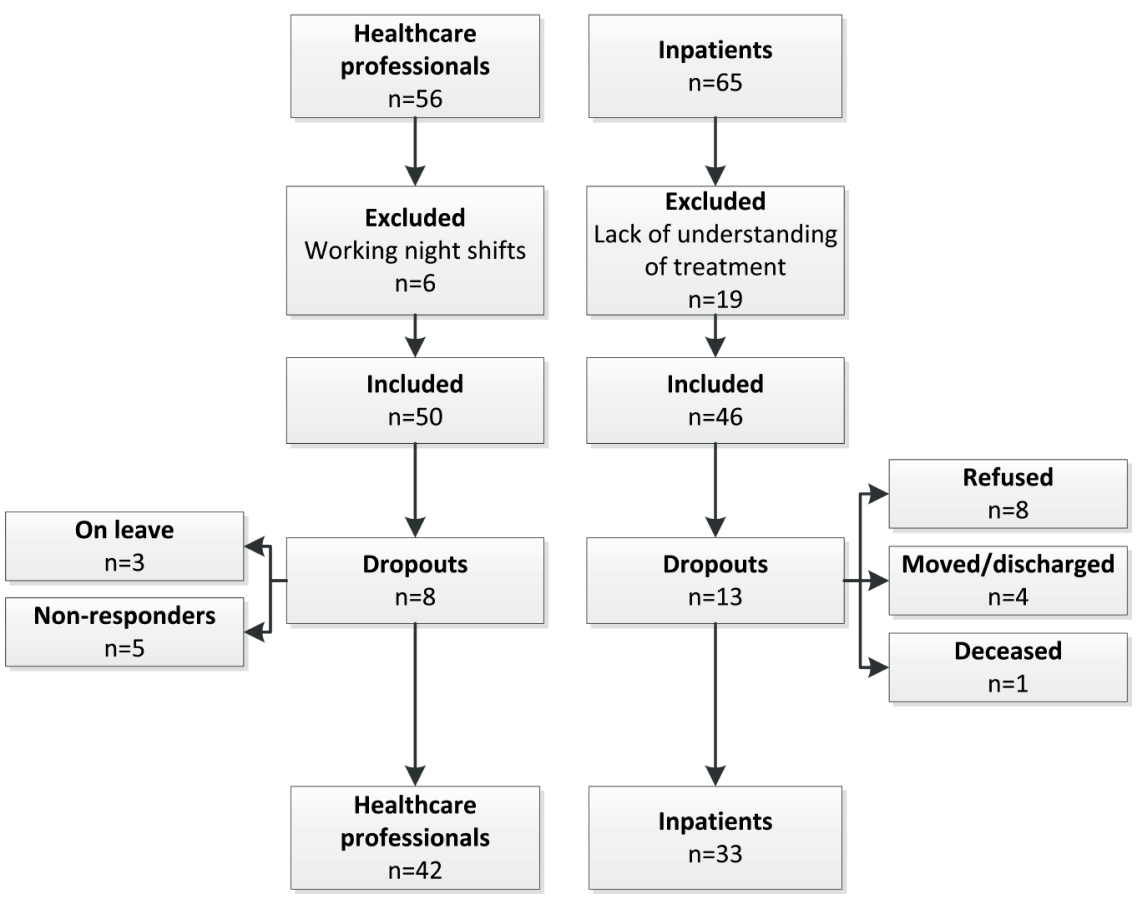

Fig. 1. Flowchart of participants 
Table 1. Characteristics of patients and healthcare professionals (HCPs)

\begin{tabular}{|c|c|c|}
\hline Outcome (scale) & $\operatorname{HCPs}(N=42)$ & Patients $(N=33)$ \\
\hline Sex, $n(\%)$ female & $29(69.0)$ & $11(33.3)$ \\
\hline Age, years, mean (SD) & $44.3(12.7)$ & $51.7(8.7)$ \\
\hline \multicolumn{3}{|l|}{ Patients' illness characteristics } \\
\hline Diagnosis schizophrenia or other psychotic disorder, $n(\%)$ & & $30(90.9)$ \\
\hline Non-psychotic disorder, $n(\%)$ & & $3^{a}(9.1)$ \\
\hline IIIness severity, CGI-S scale $1-7$, mean (SD) & & $4.4(1.1)$ \\
\hline Years of hospitalisation, mean (SD) & & $11.6(9.4)$ \\
\hline \multicolumn{3}{|l|}{ HCPs disciplines, $n(\%)$} \\
\hline Nurse & $26(61.9)$ & \\
\hline Nurse trainee & $4 \quad(9.5)$ & \\
\hline Nurse practitioner & $1(2.4)$ & \\
\hline Team leader & $3(7.1)$ & \\
\hline Psychiatrist & $2(4.8)$ & \\
\hline Activity coordinator & 5 (11.9) & \\
\hline Dietitian & $1(2.4)$ & \\
\hline
\end{tabular}

Note. CGI-S: Clinical Global Impression - Severity scale.

a mood disorder $(n=1)$, a pervasive disorder not otherwise specified $(n=1)$ and an anxiety disorder $(n=1)$

\section{Barriers}

As shown in Table 2, HCPs only identified the completeness of MULTI (whether it provides all the information and materials needed to work with it properly) as a barrier regarding the intervention itself ( $21 \%$ responded negatively). Patients identified complexity (complicated to participate in MULTI; 67\% responded negatively) and relevance (30\% responded negatively) as barriers.

Of the determinants of the HCPs themselves, personal disadvantages were identified as a barrier (24\% responded negatively), mainly regarding the time needed to get patients involved in their day-to-day program, which was endorsed by all who responded negatively. Among patients, personal benefits and disadvantages were barriers (27\% and 30\% respectively responded negatively), mostly by disagreeing with the statements / feel more actively involved in my treatment (24\%), there is a better atmosphere at the ward and I feel better (both 21\%) and agree that participating in MULTI takes a lot of time and energy (both 30\%). Outcome expectations were identified as a barrier (24\% responded negatively), whereby patients especially disagreed with expecting more fun and a brighter future (21\%) and less psychiatric problems and more contact with other people (both 24\%). Finally, slightly more than half of the patients reported not to be aware of the content of MULTI.

Determinants of the organisation were scored low by HCPs $(M=2.8, S D=0.5)$. Except for access to information about the use of MULTI, all determinants of the organisation 
were identified as a barrier, with the largest proportions of negative response by HCPs to organisational changes (88\%) and financial resources (74\%).

Information derived from open-ended questions is shown in Table 3. The topics mentioned most often as barriers by HCPs, were the lack of time for personal development within MULTI (21\%), the decrease of support by allied health professionals (20\%) and the fact that it takes significant energy to get everyone involved (17\%). Patients' perceived barriers were mixed, with the lack of time to choose their own activities within the group approach most often cited (24\%).

\section{Facilitators}

Overall, both HCPs and patients responded positively towards determinants of MULTI (M $=3.9, S D=0.6$ and $M=3.9, S D=0.7$, respectively). HCPs responded that the activities required to apply MULTI as intended were clear (95\%), not too complicated (88\%) and that MULTI was based on factually correct knowledge (91\%). For patients, MULTI provided sufficient information about the different possibilities for regular physical activity and healthy nutrition (completeness; 97\% responded positively) and outcomes were clearly observable (e.g. effects of MULTI were visible; $82 \%$ responded positively).

Also, for determinants of themselves, both HCPs and patients responded positively overall $(M=3.9, S D=0.4$ and $M=3.8, S D=0.6$, respectively). The vast majority of the determinants of HCPs themselves facilitated the implementation of MULTI. Regarding personal benefits, many HCPs agreed on the statements that with MULTI work is more fun (79\%), work is more efficient due to more structure and moments with the group (71\%), there was an improved relationship with patients (60\%) and there was less turmoil and incidents at the ward (55\%). Almost all HCPs (98\%) agreed on the importance and expectation that MULTI contributed to the intended outcomes (Table S1, see Additional file 1), felt responsible (task perception; 93\%), and were positive about subjective norms (98\%) and knowledge (83\%). They all felt themselves able to put described activities into practice (self-efficacy) and were aware of the content of the treatment. Patients agreed that it is part of their treatment to improve lifestyle (task perception; 82\%) and were satisfied with MULTI (client satisfaction; 88\%) and nurse cooperation (91\%). They responded positively to the availability of adequate assistance within MULTI (social support; 85\%), with the most positive response for support by nurses (97\%), activity coordinators and dietitian (both 76\%) and the least by peers (36\%). Determinants of the organisation showed no facilitators.

Additional information derived out of open-ended questions (Table 3) revealed that the activities were the largest facilitator, as endorsed by $52 \%$ of patients. 


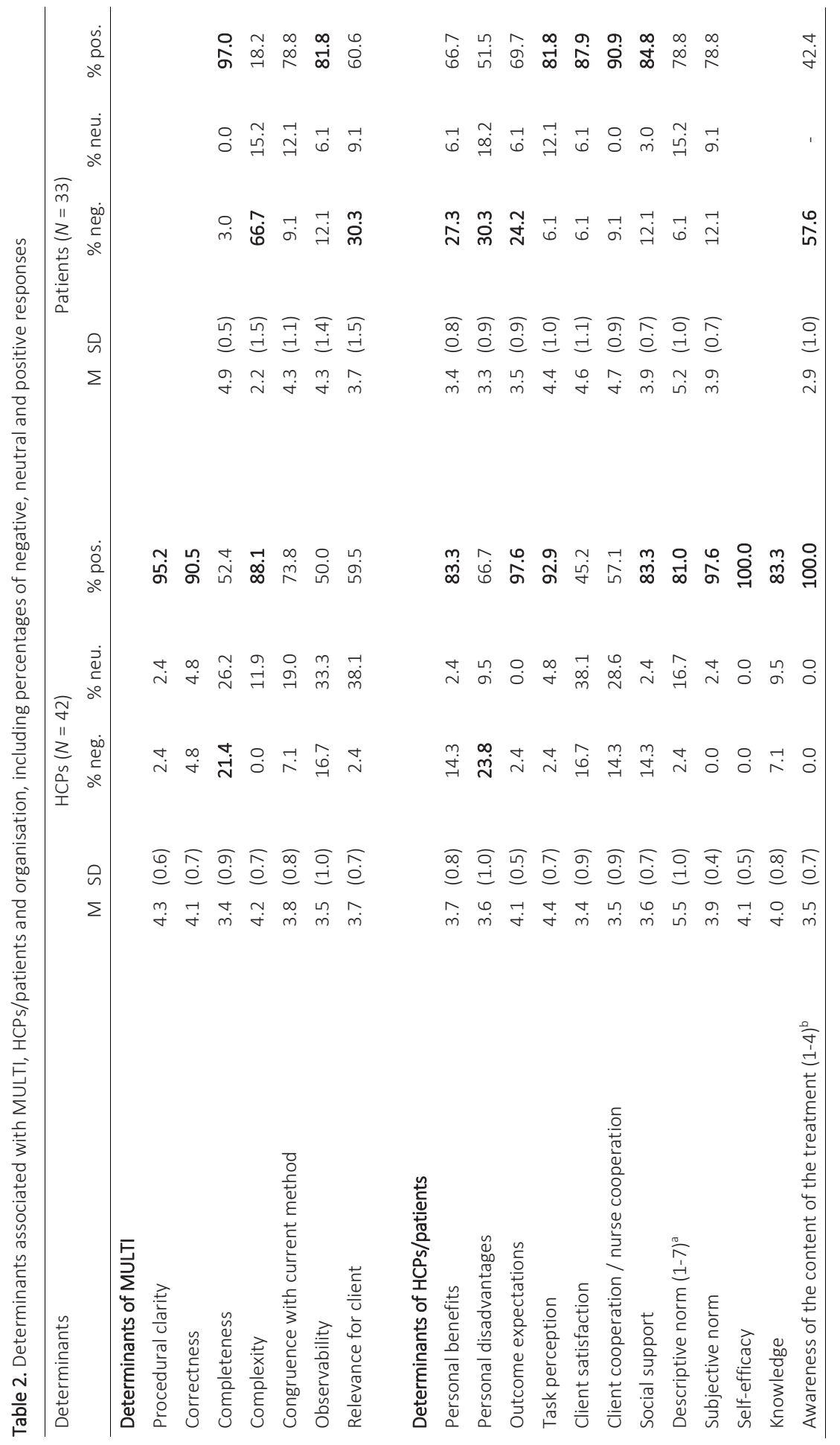


Chapter 7

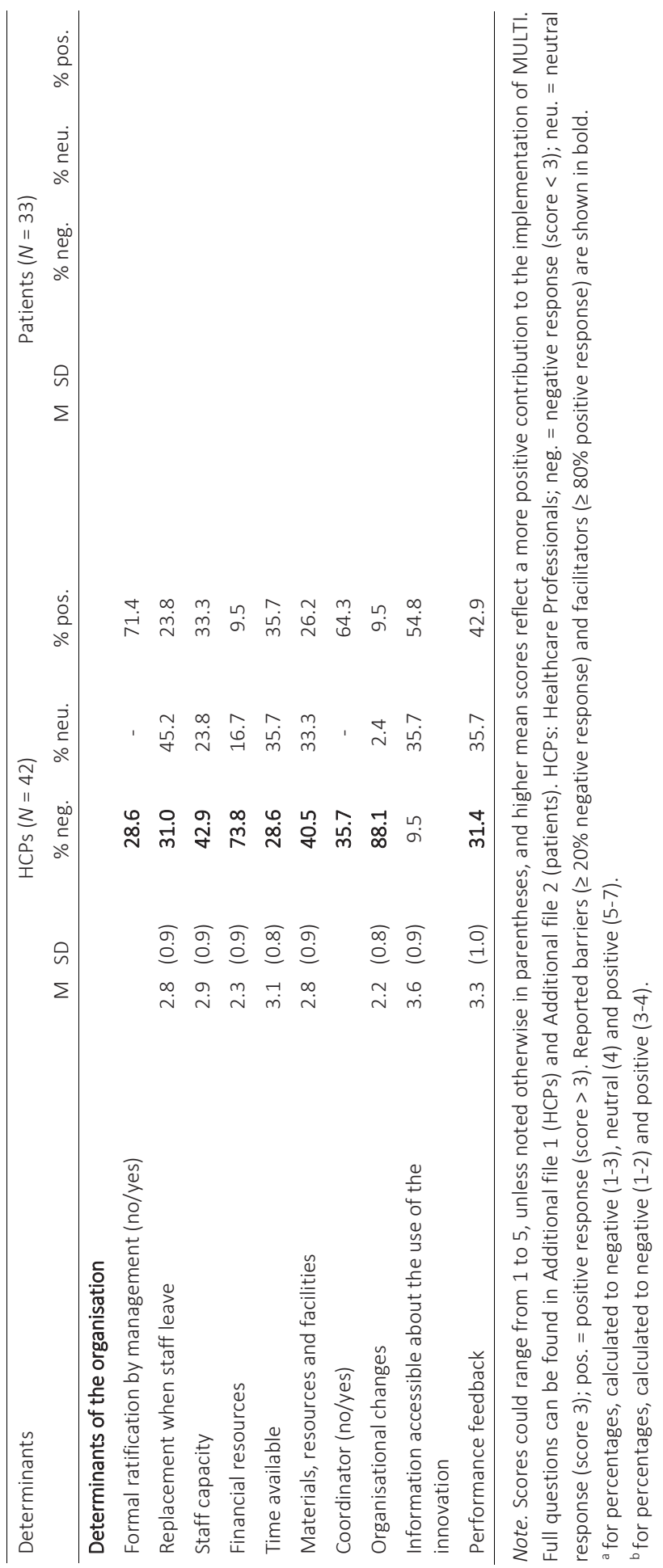


The MULTI study IV: barriers and facilitators of implementation

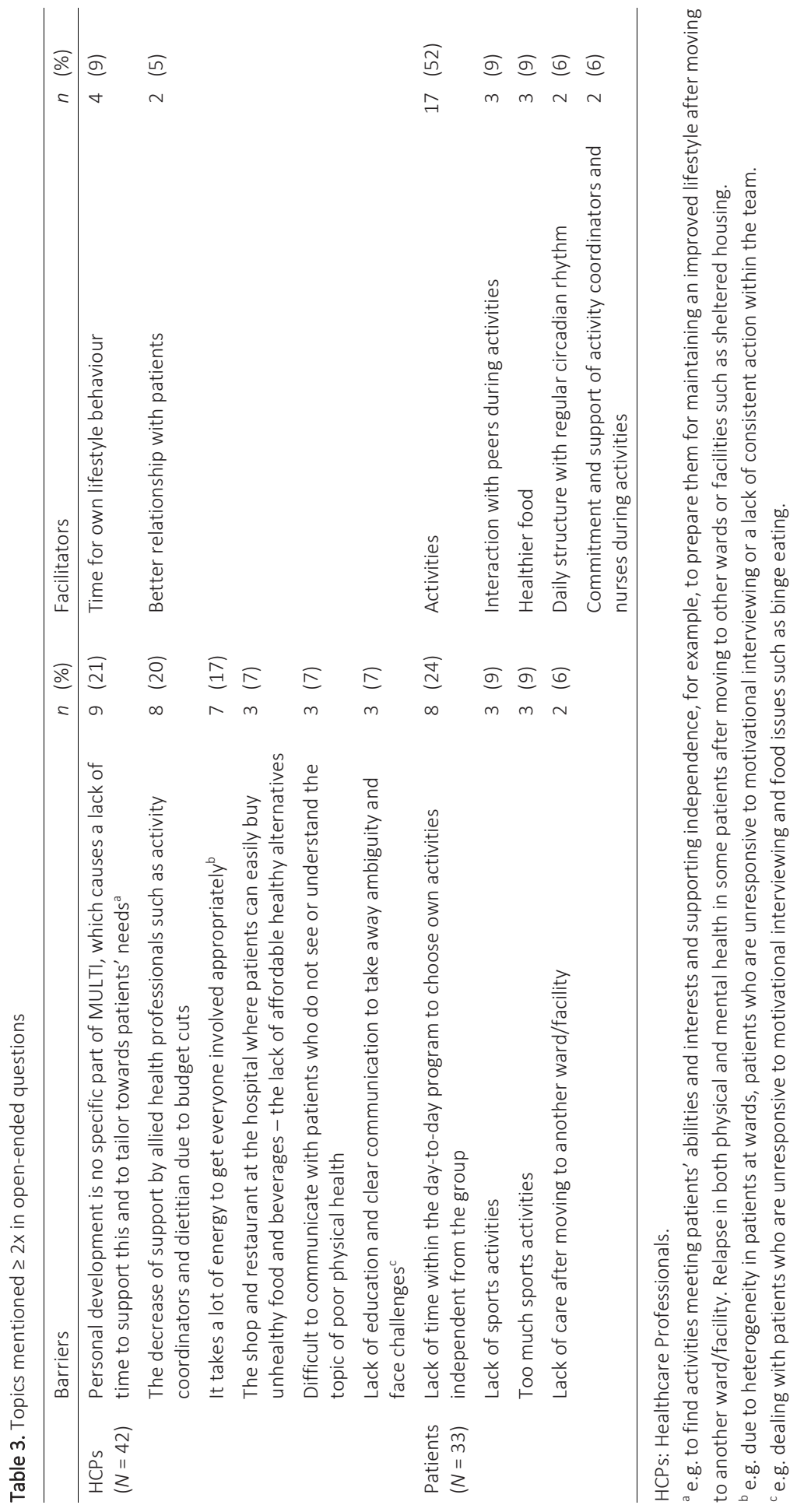




\section{Discussion}

This is the first study analysing the implementation of a pragmatic lifestyle intervention targeting inpatients with SMI in routine clinical care, including perspectives of both HCPS and patients, as well as the environmental context. In the implementation of MULTI, almost all organisational factors were identified as barriers by HCPs. The strongest barrier in patients was the complexity of participating in MULTI. Many determinants related to MULTI and the HCPs/patients themselves were reviewed as facilitators, reflecting positive attitudes towards such a multidisciplinary integrated approach and their role in it.

\section{Barriers}

Results show that it was complicated for patients to participate in MULTI (complexity). They identified a lack of time within the day-to-day program to choose their own activities, for instance. The results indicate mixed experiences with the day-to-day program as there were positive responses as well regarding barriers such as personal benefits and disadvantages and outcome expectations. This seems to correspond to the lack of time to spend on personal development and tailoring mentioned by HCPs and the time and energy it takes to get patients engaged. Those findings are in line with the previously found contradiction between perceived benefits and barriers in patients with SMI [32], and that it is more difficult to implement lifestyle focused interventions in this population due to challenges they face. These include negative symptoms (e.g. blunted affect, lack of initiative and apathy), cognitive deficits (e.g. memory and attention) [45, 60-63] and low literacy rates [64]. As it is likely that both HCPs and patients were more confronted with those challenges, this may have contributed to perceived barriers towards MULTI and themselves, including the lack of awareness of specific content of MULTI. In line with these results, recent studies suggest that there is both a need to invest more time and emphasis to overcome those challenges by HCPs [65], as well as a need to tailor interventions to address patients' needs and provide individually meaningful and suitable opportunities to be physically active, which may increase autonomous motivation for those activities [36, 45-47, 51, 66].

However, HCPs mainly reported organisational barriers, such as organisational changes, lack of resources (e.g. financially, replacement and capacity of staff, materials and time), education and decreased support from allied health professionals, which seems to hinder them from making the investment in time and emphasis to overcome aforementioned challenges. Previous studies reported such issues as factors that can negatively impact the support of lifestyle-related behaviour by mental health nurses [36, $67,68]$. Although the 'change from within' approach using current staff and resources seemed to be good from the start (overall sustained ownership and commitment), cuts in general budgets and staffing within the hospital during this period most likely affected MULTI. The reported ambiguity and lack of consistent action within the team seem to 
correspond with the lack of coordination from the organisation (ambiguity about a coordinator, formal ratification by management, easy access to unhealthy food and beverages within the hospital and lack of performance feedback). A previous study also reported that a lack of coordination and support from management can be a major barrier to successful implementation [38]. Formal ratification by leaders in mental healthcare organisations and identifying a champion who promotes the implementation process are essential $[56,69]$. Nevertheless, the fact that we did not find any facilitators in the organisational context may be a result of the 'bottom-up' approach. In this implementation at limited scale within a large mental healthcare organisation - MULTI was developed and carried out at team level without significant involvement of higher management. Therefore, it makes sense that most improvements are needed in organisational determinants, which could contribute to improving tailoring.

\section{Facilitators}

In general, both HCPs and patients were committed towards the design of MULTI as a multicomponent, integrated treatment method, which was emphasised by the response to the open-ended questions. Both agreed that improving lifestyle should be a part of treatment and felt supported by the multidisciplinary team. This confirms the success of a multidisciplinary approach and social support as essential elements in improving lifestyle $[16,43-46,48,70-73]$. Patients felt especially supported by nurses. Apart from the fact that nurses constitute the largest group of the multidisciplinary team, who have a wellestablished relationship with patients and regular face-to-face contact [74], this is in line with the design of MULTI whereby nurses participated in activities. Combined with interaction with peers as a facilitator, which has been mentioned by some patients in openended questions, and HCPs indicating less turmoil and incidents and improved relationships with patients, this has led to improved social functioning as a result of MULTI [53]. Moreover, our findings seem to confirm previous studies that it is more likely that the lifestyle of patients improves when HCPs are engaged in a healthy lifestyle themselves [65, $70,75,76]$. The positive response of HCPs towards personal benefits (e.g. work is more fun and better for their lifestyle) and outcome expectations - contrary to patients - may contribute to this engagement. This is consistent with the suggestion that mental health nurses may be more optimistic about physical activity participation than patients [72]. In addition, participation of HCPs could have a positive 'side-effect' as it potentially addresses their high percentage of sedentary behaviour as well [8]. 


\section{Limitations and strengths}

The results of this study should be considered in light of several limitations. Firstly, excluded patients could have experienced other barriers and facilitators towards participating in lifestyle interventions as they were older and had a higher illness severity. However, including patients with SMI in self-reports or semi-structured interviews remains challenging, given the aforementioned psychopathology and cognitive deficits [45, 60-63]. For future research, with more participants, it would be clinically relevant to study whether patient and disease characteristics predict specific barriers and facilitators. Secondly, in respect to the MIDI questionnaire, the internal consistency for MULTI determinants was lower in patients' than in HCPs. This may be due to the fact that the questionnaire was not designed for this population and that we excluded several items because they were less relevant for patients. In addition, the cut-offs to qualify determinants as barriers (20\%) or facilitators (80\%) are yet still a rule of thumb and reduced the variable to a dichotomous one. Therefore, it must be noted that items that did not qualify as a barrier or facilitator could still have had a significant influence on the implementation of MULTI.

A strength of this study is that it includes both the HCPS and the patients' perspective. To the best of our knowledge, it is the first study analysing the implementation of a lifestyle enhancing intervention in routine clinical care for SMI inpatients. It adds to the limited literature on implementation-related factors, which aim to better understand and eventually close the gap in translating evidence-based interventions into practice. Regarding measurements, social desirability was prevented as much as possible by assessing MIDI anonymously online in HCPs and by working with an independent research assistant to conduct all patient interviews. Furthermore, the MULTI study was conducted in a naturalistic setting (e.g. including all patients and staff without selecting on health status or motivation). This makes it highly relevant for clinical practice, as despite the methodological limitations of the observational design compared to randomised controlled trials, the latter are unlikely to represent both the population (HCPs and patients) as well as organisational factors (e.g. resourcing) under real-world conditions [25]. The response of HCPs was high (75\%), which increases the generalizability. This study answers the call for more research to identify and manage barriers and facilitators of implementing lifestyle-related interventions and to understand how these interventions can be delivered successfully in real-world settings, including associated issues within daily mental healthcare [40]. Moreover, it completes a comprehensive evaluation of MULTI, because analyses of the implementation can be used to better interpret the positive changes in health $[52,53]$ and medication use (unpublished data) as found in previous studies.

\section{Implications for clinical practice: directions to address barriers}

In clinical practice, HCPs often may be too pessimistic about the ability of people with SMI to embrace health behaviour change, the capabilities of HCPs and the feasibility of change $[25,77]$. Our results show that MULTI was feasible in interrupting the general 
status quo of poor health in inpatients, leading to improvements in a variety of health outcomes $[52,53]$. Findings show that not only HCPs but also patients are positive towards such an integrated, multidisciplinary, and structured approach, including their own role in it. This emphasises the importance that perceived barriers by management or HCPs should not limit access to the benefits of lifestyle interventions for people living with SMI [77]. We believe that this commitment is largely the result of ownership and multidisciplinary collaboration, whereby HCPs themselves developed a day-to-day program within the clinical context of their wards.

To further improve and disseminate MULTI, action is needed. Recently, a guide was developed to increase the likelihood of successful implementation and scale-up of physical activity interventions in real-world settings and can be used in other areas of public health prevention as well [31]. It describes four iterative steps to 1) characterize the parameters of the implementation setting, 2) identify and engage key stakeholders across multiple levels within the delivery system(s), 3) identify contextual barriers and facilitators to implementation, and 4) address potential barriers to effective implementation. The current study primarily focused on the third step, after step one and two have been part of developing and implementing MULTI. However, reviewing step one and two to address the multiple organisational barriers is needed for further improvement and scaleup of MULTI. This comprises reviewing the key stakeholders (e.g. engaging higher management in addition to the current team) and characterizing implementation setting parameters together. The latter includes the identification of individual or organisational champions and questions like how HCPs can be engaged, trained and supported, how associated costs and resources will be sustainably funded and how implementation processes will be integrated into organisational policies and job descriptions [31]. Together with conveying a vision that inspires HCPs, addressing those topics gives further direction for future work. This is relevant as when it comes to discussions about (dealing with) the availability of particular food and beverages for patients within the hospital, as reported by HCPs. Reviewing these steps will give input to address many organisational barriers found (step 4) and creates a great foundation for further improvement. In the context of education and support, allied health professionals such as activity coordinators and dieticians are essential [46]. They are specialised in addressing specific challenges in physical activity and nutrition, can support mental health staff and contribute to education. Also, setting up community or university partnerships could potentially help with upskilling and enhancing the capabilities of new HCPs [46, 78]. In line with this, knowledge about lifestyle as a topic in mental healthcare must be a part of the curriculum for nurses and other related disciplines.

If such improvements in organisational context can be made, it is expected this would enhance a more unambiguous approach and facilitate HCPs and patients in improving individual tailoring. For this, patients could be more involved in designing the day-to-day program to better target activities towards their abilities, interests and needs, which potentially increases intrinsic motivation. In counselling and informing patients (e.g. psycho 
education or designing the day-to-day program), tailoring could be improved by taking cognitive challenges faced by people with SMI into account. To enhance retention and comprehension, the use of simplified language and visual materials should be preferred, as well as the use of techniques such as lesson repetition, reading aloud and educational games $[45,79]$. Adressing those barriers in implementation and tailoring would largely improve the continuation and further implementation of MULTI, as other determinants are positive. Nevertheless, to confirm current findings and to explore whether the aforementioned suggested improvements are effective, the implementation of MULTI should be studied in different contexts, using the current results and lessons learned. Also, although we know there were little additional costs given the 'change from within' approach, there is a need for cost-effectiveness analysis regarding lifestyle interventions $[24,76]$. This would especially be of value in the context of considering investments to address barriers.

\section{Conclusions}

To the best of our knowledge, this is the first study analysing the implementation of a lifestyle enhancing treatment within routine clinical care for inpatients with SMI. Findings show important barriers related to organisational factors. Many facilitators related to MULTI and the HCPs/patients themselves reflected positive attitudes towards such a multidisciplinary integrated approach and their own role in it, having driven the implementation of MULTI. Organisational strategies are needed to further improve and maintain MULTI, including increased management involvement. To confirm and complement current findings, we encourage further implementation and pragmatic research regarding optimal delivery of lifestyle interventions as an integrated component of daily life at inpatient wards.

\section{Additional files}

Additional file 1: Table S1. Questions used to measure each determinant in healthcare professionals, number of questions and ranges. (DOCX $27 \mathrm{~kb}$ )

Additional file 2: Table S2. Questions used to measure each determinant in patients, number of questions and ranges. (DOCX $23 \mathrm{~kb}$ ) 


\section{List of abbreviations}

SMI

MULTI

HCPS

MIDI severe mental illness

multidisciplinary lifestyle enhancing treatment

healthcare professionals

measurement instrument for determinants of innovations

\section{Declarations}

\section{Ethics approval and consent to participate}

The study protocol was approved by the Medical Ethical Committee of the Isala Academy (case 14.0678). All subjects gave written informed consent in accordance with the Declaration of Helsinki.

\section{Consent for publication}

Not applicable

\section{Availability of data and material}

The data that support the findings of this study are not publicly available, because that is inconsistent with the informed consent. However, data are available from the corresponding author on reasonable request and with permission of GGz Centraal.

\section{Competing interests}

The authors declare that they have no competing interests.

\section{Funding}

Stichting tot Steun VCVGZ supported this study by an unrestricted grant. The funder had no role in the study design, data collection and analysis, decision to publish or preparation of the manuscript.

\section{Authors contributions}

JD obtained funding, designed the study and the questions specific to clinical practice, collected and analysed the data and drafted the manuscript. ET, DT, OBH and IH contributed to designing the study, questions and data analysis. DT and PH contributed to the grant applications. All authors contributed to the data interpretation, critically revised the manuscript and approved the final version. 


\section{Acknowledgements}

The authors would like to acknowledge, with thanks, all patients and mental healthcare professionals of GGz Centraal who have made efforts to participate in this study. Furthermore, we would like to thank Stichting tot Steun VCVGZ for their financial support.

\section{References}

1. Hjorthøj C, Sturup AE, McGrath JJ, Nordentoft M. Years of potential life lost and life expectancy in schizophrenia: a systematic review and meta-analysis. The Lancet Psychiatry. 2017;4(4):295-301.

2. Piotrowski P, Gondek TM, Krolicka-Deregowska A, Misiak B, Adamowski T, Kiejna A. Causes of mortality in schizophrenia: An updated review of European studies. Psychiatr Danub. 2017;29(2):108-120.

3. Tanskanen A, Tiihonen J, Taipale H. Mortality in schizophrenia: 30-year nationwide follow-up study. Acta Psychiatr Scand. 2018.

4. Laursen TM, Wahlbeck K, Hallgren J, Westman J, Osby U, Alinaghizadeh H, Gissler M, Nordentoft M. Life expectancy and death by diseases of the circulatory system in patients with bipolar disorder or schizophrenia in the Nordic countries. PLoS One. 2013;8(6):e67133.

5. Walker ER, McGee RE, Druss BG. Mortality in Mental Disorders and Global Disease Burden Implications A Systematic Review and Meta-analysis. Jama Psychiatry. 2015;72(4):334-341.

6. Hayes JF, Marston L, Walters K, King MB, Osborn DPJ. Mortality gap for people with bipolar disorder and schizophrenia: UK-based cohort study 2000-2014. Br J Psychiatry. 2017;211(3):175-181.

7. Lee EE, Liu J, Tu X, Palmer BW, Eyler LT, Jeste DV. A widening longevity gap between people with schizophrenia and general population: A literature review and call for action. Schizophr Res. 2017.

8. Kruisdijk F, Deenik J, Tenback D, Tak E, Beekman A, van Harten P, Hopman-Rock M, Hendriksen I. Accelerometer-measured sedentary behaviour and physical activity of inpatients with severe mental illness. Psychiatry Res. 2017;254:67-74.

9. Stubbs B, Chen LJ, Chung MS, Ku PW. Physical activity ameliorates the association between sedentary behavior and cardiometabolic risk among inpatients with schizophrenia: A comparison versus controls using accelerometry. Compr Psychiatry. 2017;74:144-150.

10. Stubbs B, Firth J, Berry A, Schuch FB, Rosenbaum S, Gaughran F, Veronesse N, Williams J, Craig T, Yung AR et al. How much physical activity do people with schizophrenia engage in? A systematic review, comparative meta-analysis and meta-regression. Schizophr Res. 2016;176(2-3):431-440.

11. Stubbs B, Williams JE, Gaughran F, Craig T. How sedentary are people with psychosis? A systematic review and meta-analysis. Schizophr Res. 2016;171(1-3):103-109.

12. Vancampfort D, Probst M, Scheewe T, De Herdt A, Sweers K, Knapen J, van Winkel R, De Hert M. Relationships between physical fitness, physical activity, smoking and metabolic and mental health parameters in people with schizophrenia. Psychiatry Res. 2013;207(1-2):25-32.

13. Teasdale SB, Samaras K, Wade T, Jarman R, Ward PB. A review of the nutritional challenges experienced by people living with severe mental illness: a role for dietitians in addressing physical health gaps. J Hum Nutr Diet. 2017;30(5):545-553.

14. Rosenbaum S, Tiedemann A, Sherrington C, Curtis J, Ward PB. Physical activity interventions for people with mental illness: a systematic review and meta-analysis. J Clin Psychiatry. 2014;75(9):964-974.

15. Teasdale SB, Ward PB, Rosenbaum S, Samaras K, Stubbs B. Solving a weighty problem: systematic review and meta-analysis of nutrition interventions in severe mental illness. The British Journal of Psychiatry. 2017;210(2):110-118

16. Vera-Garcia E, Mayoral-Cleries F, Vancampfort D, Stubbs B, Cuesta-Vargas Al. A systematic review of the benefits of physical therapy within a multidisciplinary care approach for people with schizophrenia: An update. Psychiatry Res. 2015;229(3):828-839. 
17. Dauwan M, Begemann MJH, Heringa SM, Sommer IE. Exercise improves clinical symptoms, quality of life, global functioning, and depression in schizophrenia: A systematic review and meta-analysis. Schizophr Bull. 2016;42(3):588-599.

18. Naslund JA, Whiteman KL, McHugo GJ, Aschbrenner KA, Marsch LA, Bartels SJ. Lifestyle interventions for weight loss among overweight and obese adults with serious mental illness: A systematic review and metaanalysis. Gen Hosp Psychiatry. 2017;47:83-102.

19. Firth J, Cotter J, Elliott R, French P, Yung AR. A systematic review and meta-analysis of exercise interventions in schizophrenia patients. Psychol Med. 2015;45(7):1343-1361.

20. Firth J, Stubbs B, Rosenbaum S, Vancampfort D, Malchow B, Schuch F, Elliott R, Nuechterlein KH, Yung AR. Aerobic Exercise Improves Cognitive Functioning in People With Schizophrenia: A Systematic Review and Meta-Analysis. Schizophr Bull. 2017;43(3):546-556.

21. Stanton R, Happell B. Exercise for mental illness: A systematic review of inpatient studies. Int J Ment Health Nurs. 2014;23(3):232-242.

22. Vancampfort D, Stubbs B, Ward PB, Teasdale S, Rosenbaum S. Why moving more should be promoted for severe mental illness. The lancet Psychiatry. 2015;2(4):295.

23. Jakobsen AS, Speyer H, Norgaard HCB, Karlsen M, Birk M, Hjorthoj C, Mors O, Krogh J, Gluud C, Pisinger C et al. Effect of lifestyle coaching versus care coordination versus treatment as usual in people with severe mental illness and overweight: Two-years follow-up of the randomized CHANGE trial. PLoS One. 2017;12(10):e0185881

24. Stubbs B, Vancampfort D, Hallgren M, Firth J, Veronese N, Solmi M, Brand S, Cordes J, Malchow B, Gerber $M$ et al. EPA guidance on physical activity as a treatment for severe mental illness: a meta-review of the evidence and Position Statement from the European Psychiatric Association (EPA), supported by the International Organization of Physical Therapists in Mental Health (IOPTMH). Eur Psychiatry. 2018;54:124144.

25. Bartels SJ. Can behavioral health organizations change health behaviors? The STRIDE study and lifestyle interventions for obesity in serious mental illness. Am J Psychiatry. 2015;172(1):9-11.

26. Archie S, Wilson JH, Osborne S, Hobbs H, McNiven J. Pilot Study: Access to Fitness Facility and Exercise Levels in Olanzapine-Treated Patients. Canadian Journal of Psychiatry. 2003;48(9):628-632.

27. Looijmans A, Stiekema A, Bruggeman R, van der Meer L, Stolk RP, Schoevers RA, Jörg F, Corpeleijn E. Changing the obesogenic environment to improve cardiometabolic health in residential patients with a severe mental IIIness: ELIPS, a randomized controlled trial. Br J Psychiatry. 2017;211(5):296-303.

28. Stiekema APM, Looijmans A, van der Meer L, Bruggeman R, Schoevers RA, Corpeleijn E, Jorg F. Effects of a lifestyle intervention on psychosocial well-being of severe mentally ill residential patients: ELIPS, a cluster randomized controlled pragmatic trial. Schizophr Res. 2018.

29. Mlinarić A, Horvat M, Šupak Smolčić V. Dealing with the positive publication bias: Why you should really publish your negative results. Biochemia medica. 2017;27(3):030201-030201.

30. Glasgow RE, Emmons KM. How can we increase translation of research into practice? Types of evidence needed. Annu Rev Public Health. 2007;28:413-433.

31. Koorts H, Eakin E, Estabrooks P, Timperio A, Salmon J, Bauman A. Implementation and scale up of population physical activity interventions for clinical and community settings: the PRACTIS guide. Int J Behav Nutr Phys Act. 2018;15(1):51.

32. Firth J, Rosenbaum S, Stubbs B, Gorczynski P, Yung AR, Vancampfort D. Motivating factors and barriers towards exercise in severe mental illness: a systematic review and meta-analysis. Psychol Med. 2016:1-13.

33. Happell B, Platania-Phung C, Scott D. Survey of Australian mental health nurses on physical activity promotion. International Journal of Mental Health Promotion. 2013;15(3):148-161.

34. Leutwyler H, Hubbard EM, Jeste DV, Vinogradov S. "We're not just sitting on the periphery": a staff perspective of physical activity in older adults with schizophrenia. Gerontologist. 2013;53(3):474-483.

35. Robson D, Haddad M, Gray R, Gournay K. Mental health nursing and physical health care: a cross-sectional study of nurses' attitudes, practice, and perceived training needs for the physical health care of people with severe mental illness. Int J Ment Health Nurs. 2013;22(5):409-417. 
36. Stanton R, Happell B, Reaburn P. Investigating the exercise-prescription practices of nurses working in inpatient mental health settings. Int J Ment Health Nurs. 2015;24(2):112-120.

37. Chen M-D, I J-H, Pellegrini CA, Tang T-C, Kuo C-C. A qualitative exploration of facilitators and barriers to physical activity participation in people with severe mental illness in Taiwan. Mental Health and Physical Activity. 2017;13:100-107.

38. Bartels S, Brunette M, Aschbrenner K, Daumit G. Implementation of a system-wide health promotion intervention to reduce early mortality in high risk adults with serious mental illness and obesity. Implementation Science. 2015;10(1):A15.

39. Stewart R. Mental disorders and mortality: so many publications, so little change. Acta Psychiatr Scand. 2015;132(5):410-411.

40. Liu NH, Daumit GL, Dua T, Aquila R, Charlson F, Cuijpers P, Druss B, Dudek K, Freeman M, Fujii C et al. Excess mortality in persons with severe mental disorders: a multilevel intervention framework and priorities for clinical practice, policy and research agendas. World Psychiatry. 2017;16(1):30-40.

41. Bonfioli E, Berti L, Goss C, Muraro F, Burti L. Health promotion lifestyle interventions for weight management in psychosis: a systematic review and meta-analysis of randomised controlled trials. BMC Psychiatry. 2012;12(1):1-12.

42. Long $C$, Rowell A, Rigg S, Livesey F, McAllister $P$. What is effective in promoting a healthy lifestyle in secure psychiatric settings? A review of the evidence for an integrated programme that targets modifiable health risk behaviours. The Journal of Forensic Practice. 2016;18(3):204-215.

43. Vancampfort D, Rosenbaum S, Schuch F, Ward PB, Richards J, Mugisha J, Probst M, Stubbs B. Cardiorespiratory fitness in severe mental illness: A systematic review and meta-analysis. Sports Med. 2017;47(2):343-352.

44. Vancampfort D, Stubbs B, Ward PB, Teasdale S, Rosenbaum S. Integrating physical activity as medicine in the care of people with severe mental illness. Aust N Z J Psychiatry. 2015;49(8):681-682.

45. Ward MC, White DT, Druss BG. A meta-review of lifestyle interventions for cardiovascular risk factors in the general medical population: lessons for individuals with serious mental illness. J Clin Psychiatry. 2015;76(4):e477-486.

46. Lederman O, Suetani S, Stanton R, Chapman J, Korman N, Rosenbaum S, Ward PB, Siskind D. Embedding exercise interventions as routine mental health care: implementation strategies in residential, inpatient and community settings. Australasian psychiatry : bulletin of Royal Australian and New Zealand College of Psychiatrists. 2017;25(5):451-455.

47. Hargreaves J, Lucock M, Rodriguez A. From inactivity to becoming physically active: The experiences of behaviour change in people with serious mental illness. Mental Health and Physical Activity. 2017;13:83-93.

48. Arbour-Nicitopoulos KP, Duncan MJ, Remington G, Cairney J, Faulkner GE. The Utility of the Health Action Process Approach Model for Predicting Physical Activity Intentions and Behavior in Schizophrenia. Front Psychiatry. 2017;8:135

49. Fibbins H, Ward PB, Watkins A, Curtis J, Rosenbaum S. Improving the health of mental health staff through exercise interventions: a systematic review. J Ment Health. 2018;27(2):184-191.

50. Ringen PA, Faerden A, Antonsen B, Falk RS, Mamen A, Rognli EB, Solberg DK, Andreassen OA, Martinsen EW. Cardiometabolic risk factors, physical activity and psychiatric status in patients in long-term psychiatric inpatient departments. Nordic journal of psychiatry. 2018:1-7.

51. Lundstrom S, Ahlstrom BH, Jormfeldt H, Eriksson H, Skarsater I. The Meaning of the Lived Experience of Lifestyle Changes for People with Severe Mental Illness. Issues Ment Health Nurs. 2017;38(9):717-725.

52. Deenik J, Tenback DE, Tak ECPM, Rutters F, Hendriksen IJM, van Harten PN. Changes in physical and psychiatric health after a multidisciplinary lifestyle enhancing treatment for inpatients with severe mental illness: the MULTI study I. Schizophr Res. 2018.

53. Deenik J, Tenback DE, Tak ECPM, Hendriksen IJM, van Harten PN. Improved quality of life and psychosocial functioning in inpatients with severe mental illness receiving a multidisciplinary lifestyle enhancing treatment. The MULTI study II. Mental Health and Physical Activity. 2018;15:145-152.

54. Levitt GA, Shinault K, Patterson S, Otaluka O. Weight Gain in Psychiatric Inpatients: Are Interventions Making a Positive Impact? Prim Care Companion CNS Disord. 2017;19(4):17m02111. 
55. Fleuren MAH, Paulussen TGWM, Van Dommelen P, Van Buuren S. Towards a measurement instrument for determinants of innovations. Int J Qual Health Care. 2014;26(5):501-510.

56. Fleuren MAH, Wiefferink K, Paulussen TGWM. Determinants of innovation within health care organizations: literature review and Delphi study. Int J Qual Health Care. 2004;16(2):107-123.

57. Fleuren MAH, Paulussen TGWM, Van Dommelen P, Van Buuren S. Measurement Instrument for Determinants of Innovations (MIDI). Leiden: TNO; 2014.

58. Verberne LM, Kars MC, Schepers SA, Schouten-van Meeteren AYN, Grootenhuis MA, van Delden JJM. Barriers and facilitators to the implementation of a paediatric palliative care team. BMC Palliat Care. 2018;17:23.

59. Schepers SA, Sint Nicolaas SM, Haverman L, Wensing M, Schouten van Meeteren AYN, Veening MA, Caron HN, Hoogerbrugge PM, Kaspers GJL, Verhaak CM et al. Real-world implementation of electronic patientreported outcomes in outpatient pediatric cancer care. Psychooncology. 2017;26(7):951-959.

60. Vancampfort D, De Hert M, Stubbs B, Ward PB, Rosenbaum S, Soundy A, Probst M. Negative symptoms are associated with lower autonomous motivation towards physical activity in people with schizophrenia. Compr Psychiatry. 2015;56:128-132.

61. Harvey PD, Rosenthal JB. Cognitive and functional deficits in people with schizophrenia: Evidence for accelerated or exaggerated aging? Schizophr Res. 2018;196:14-21.

62. Aleman A, Hijman R, De Haan EHF, Kahn RS. Memory impairment in schizophrenia: A meta-analysis. Am J Psychiatry. 1999;156(9):1358-1366.

63. Fioravanti M, Bianchi V, Cinti ME. Cognitive deficits in schizophrenia: an updated metanalysis of the scientific evidence. BMC Psychiatry. 2012;12:64

64. Clausen W, Watanabe-Galloway S, Bill Baerentzen M, Britigan DH. Health Literacy Among People with Serious Mental IIIness. Community Ment Health J. 2016;52(4):399-405.

65. Way K, Kannis-Dymand L, Lastella M, Lovell GP. Mental health practitioners' reported barriers to prescription of exercise for mental health consumers. Mental Health and Physical Activity. 2018;14:52-60.

66. Farholm A, Sorensen M, Halvari H. Motivational factors associated with physical activity and quality of life in people with severe mental illness. Scand J Caring Sci. 2017;31(4):914-921.

67. Happell B, Scott D, Nankivell J, Platania-Phung C. Screening physical health? Yes! But...: nurses' views on physical health screening in mental health care. J Clin Nurs. 2013;22(15-16):2286-2297.

68. Happell B, Scott D, Platania-Phung C, Nankivell J. Nurses' views on physical activity for people with serious mental illness. Mental Health and Physical Activity. 2012;5(1):4-12.

69. Damschroder $\amalg$, Aron DC, Keith RE, Kirsh SR, Alexander JA, Lowery JC. Fostering implementation of health services research findings into practice: a consolidated framework for advancing implementation science. Implementation Science. 2009;4(1):50.

70. Hutchison SL, Terhorst L, Murtaugh S, Gross S, Kogan JN, Shaffer SL. Effectiveness of a Staff Promoted Wellness Program to Improve Health in Residents of a Mental Health Long-Term Care Facility. Issues Ment Health Nurs. 2016;37(4):257-264.

71. Aschbrenner KA, Mueser KT, Bartels SJ, Pratt SI. Perceived social support for diet and exercise among persons with serious mental illness enrolled in a healthy lifestyle intervention. Psychiatr Rehabil J. 2013;36(2):65-71.

72. Stanton R, Reaburn P, Happell B. Barriers to exercise prescription and participation in people with mental illness: the perspectives of nurses working in mental health. J Psychiatr Ment Health Nurs. 2015;22(6):440448.

73. Knight M, Bolton P, Kopeski L. Providing Physical Care to Persons With Serious Mental IIIness: Attitudes, Confidence, Barriers and Psychological Empowerment. Arch Psychiatr Nurs. 2017;31(5):447-453.

74. Happell B, Platania-Phung C, Scott D. Placing physical activity in mental health care: a leadership role for mental health nurses. Int J Ment Health Nurs. 2011;20(5):310-318.

75. Fie S, Norman IJ, While AE. The relationship between physicians' and nurses' personal physical activity habits and their health-promotion practice: A systematic review. Health Educ J. 2013;72(1):102-119. 
76. Rosenbaum S, Tiedemann A, Stanton R, Parker A, Waterreus A, Curtis J, Ward PB. Implementing evidencebased physical activity interventions for people with mental illness: an Australian perspective. Australasian psychiatry : bulletin of Royal Australian and New Zealand College of Psychiatrists. 2016;24(1):49-54.

77. Ward PB, Firth J, Rosenbaum S, Samaras K, Stubbs B, Curtis J. Lifestyle interventions to reduce premature mortality in schizophrenia. The lancet Psychiatry. 2017;4(7):e14.

78. Teasdale SB, Latimer G, Byron A, Schuldt V, Pizzinga J, Plain J, Buttenshaw K, Forsyth A, Parker E, Soh N. Expanding collaborative care: integrating the role of dietitians and nutrition interventions in services for people with mental illness. Australasian psychiatry : bulletin of Royal Australian and New Zealand College of Psychiatrists. 2018;26(1):47-49.

79. Cabassa L, Ezell JM, Lewis-Fernández R. Lifestyle interventions for adults with serious mental illness: A systematic literature review. Psychiatr Serv. 2010;61(8):774-782. 
The MULTI study IV: barriers and facilitators of implementation

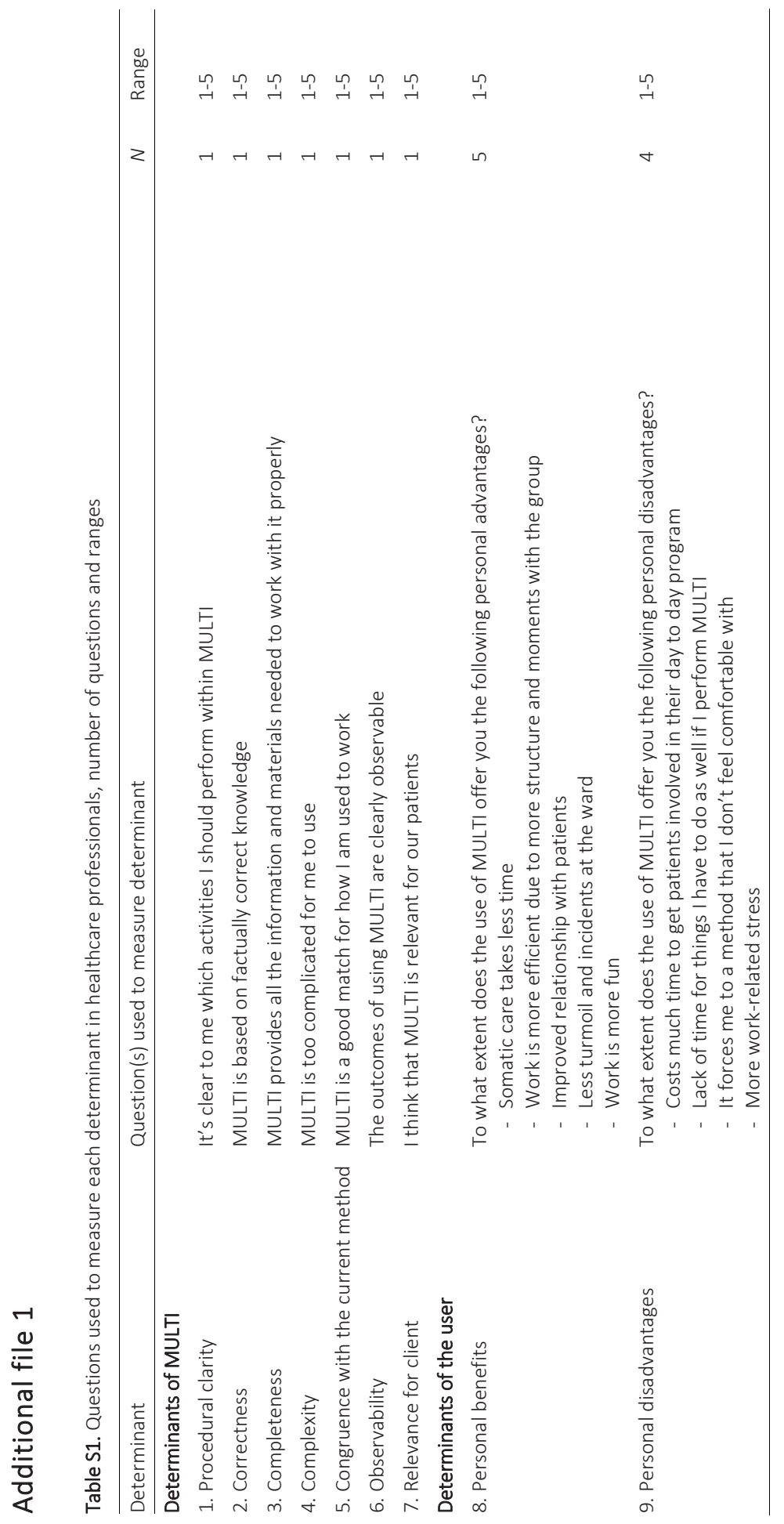


Chapter 7

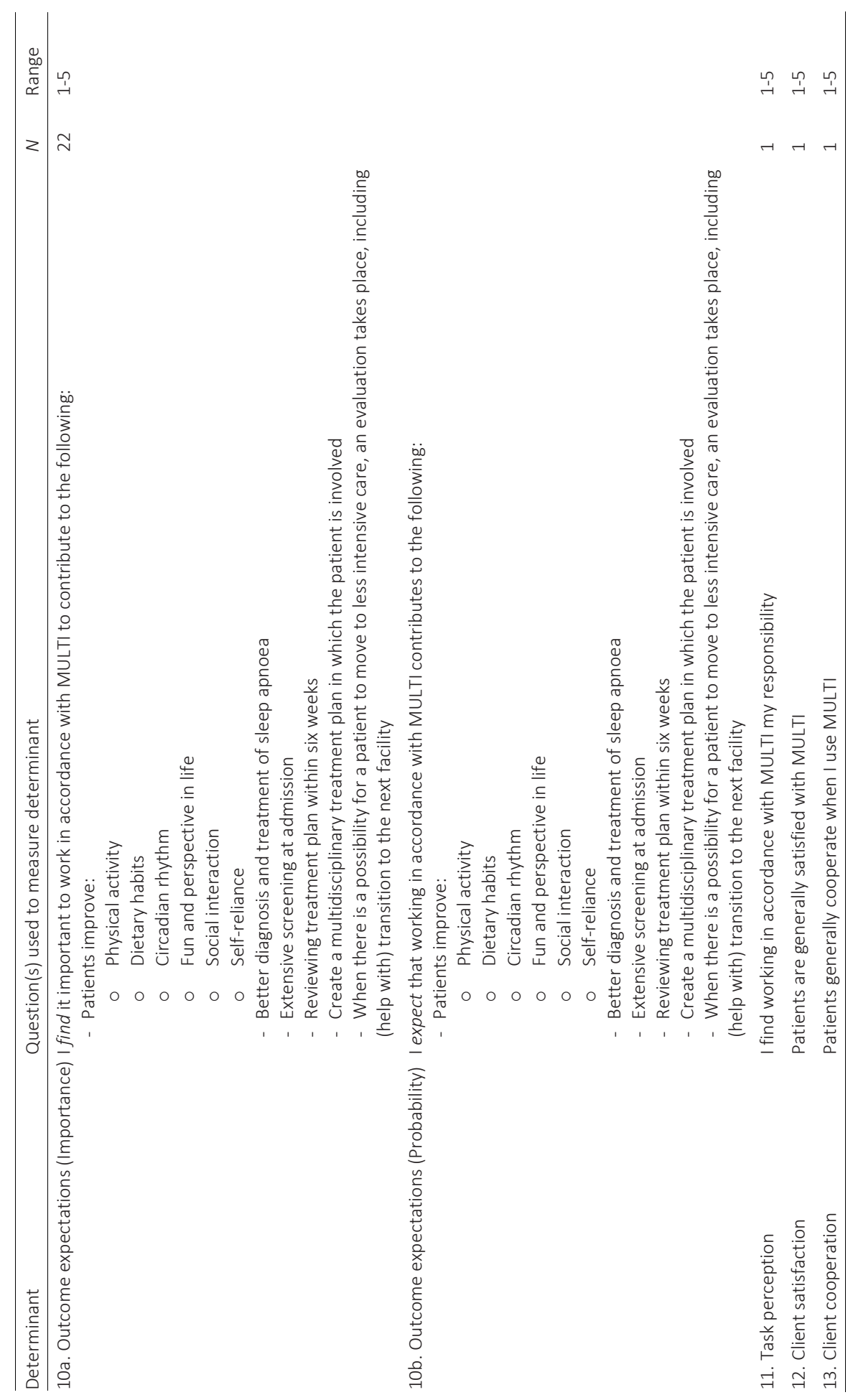


The MULTI study IV: barriers and facilitators of implementation

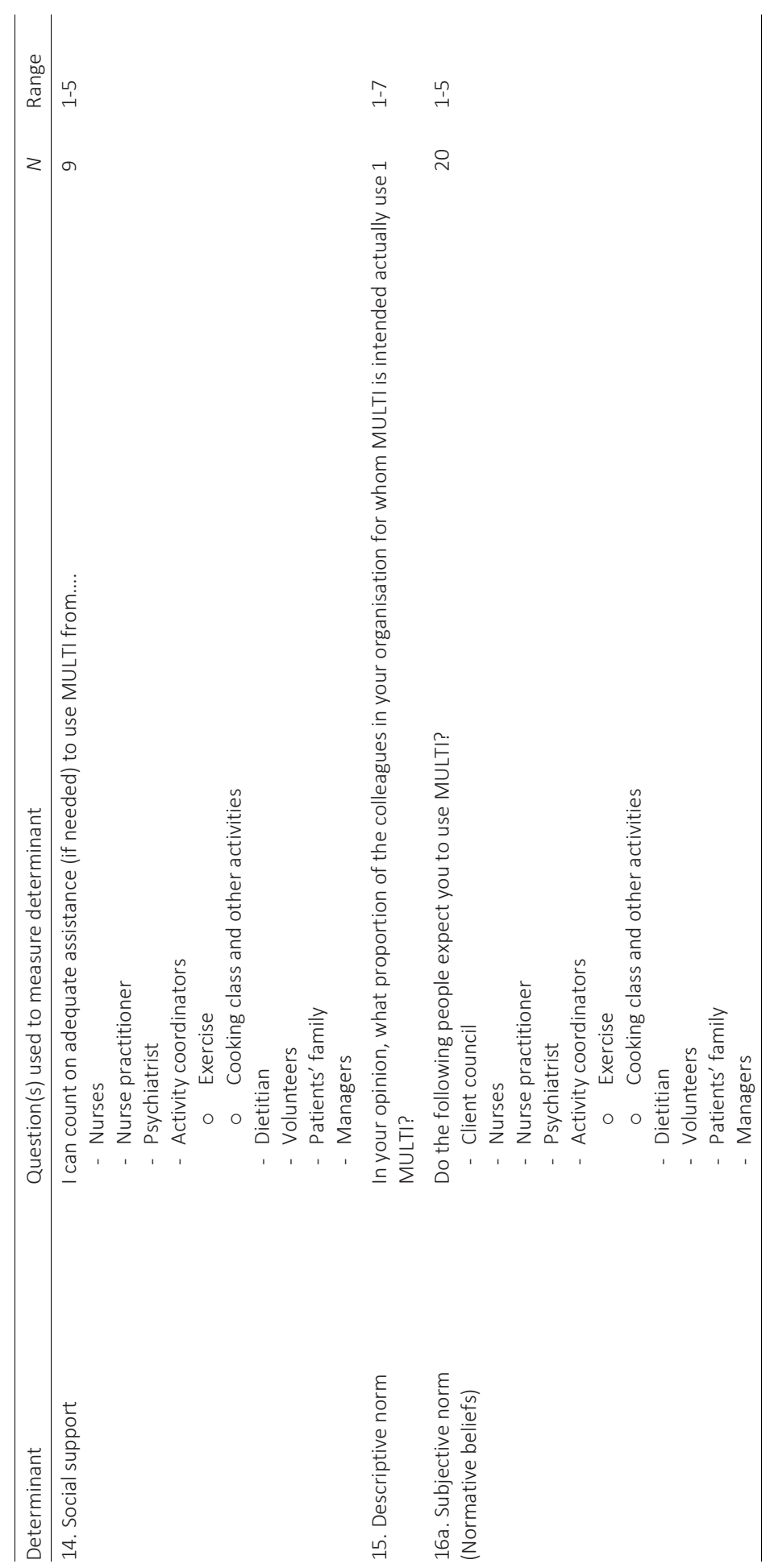


Chapter 7

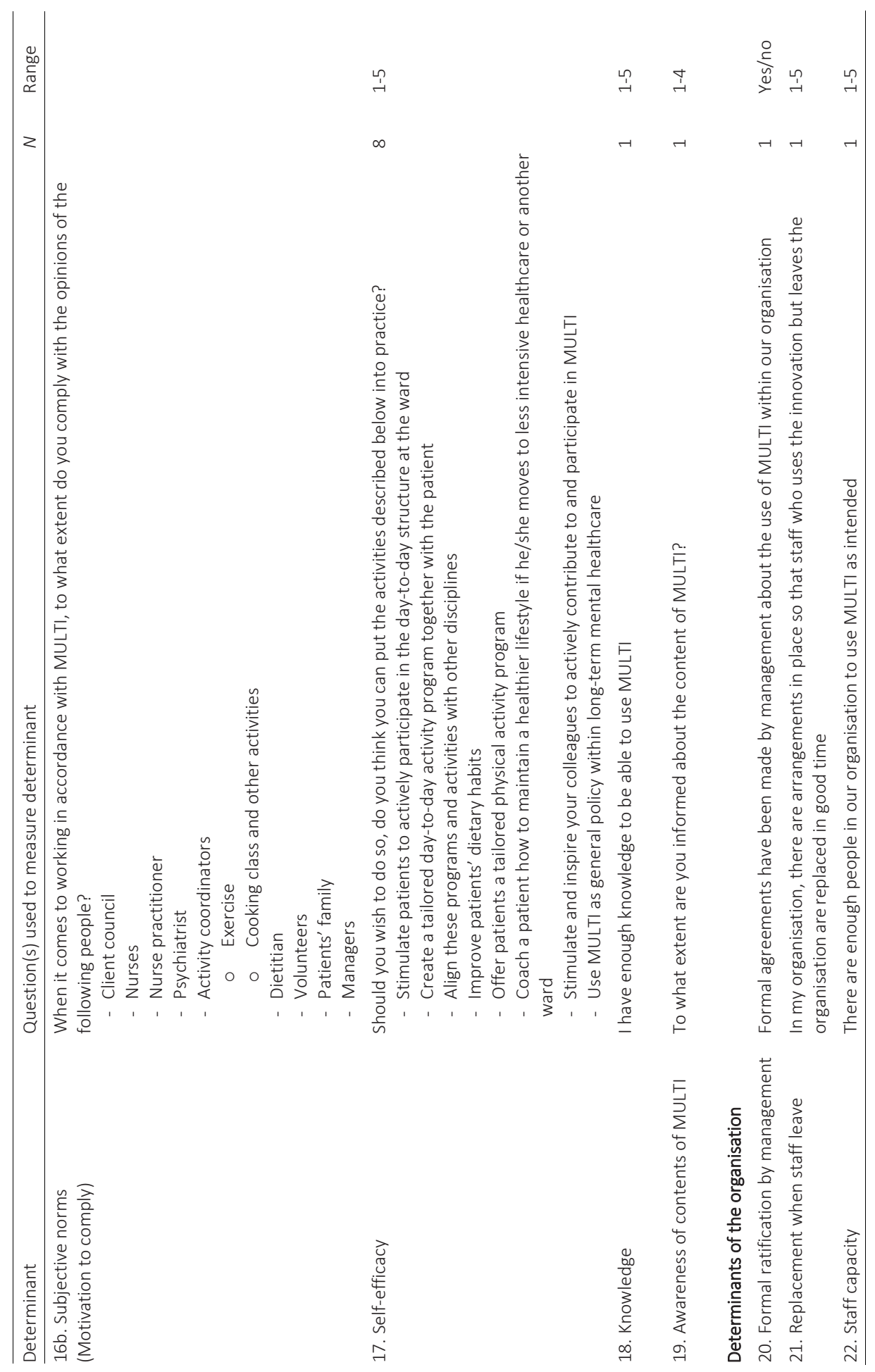


The MULTI study IV: barriers and facilitators of implementation

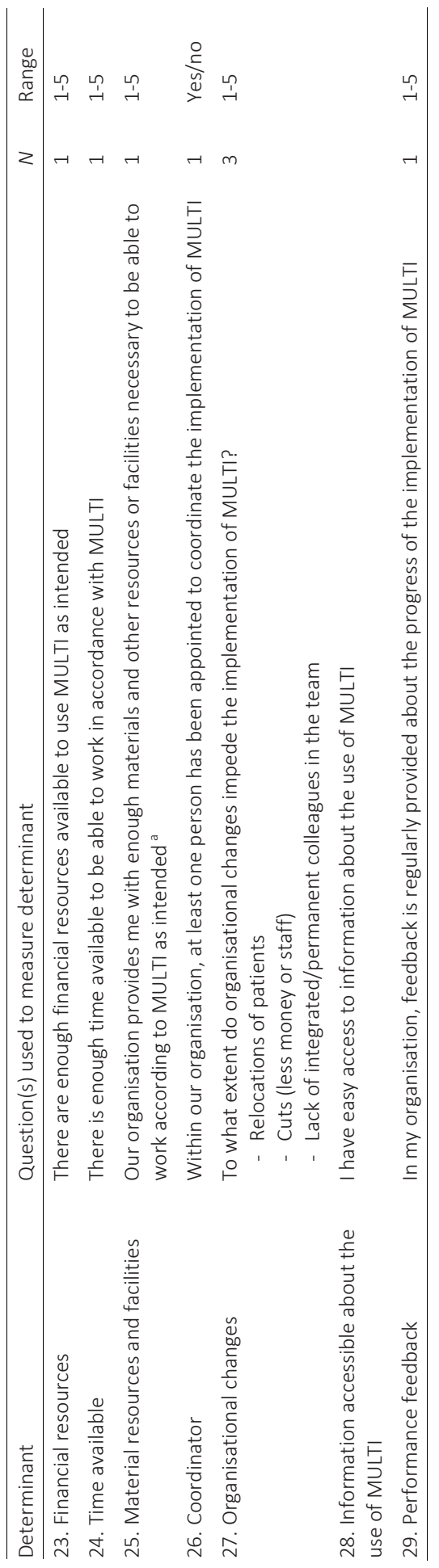




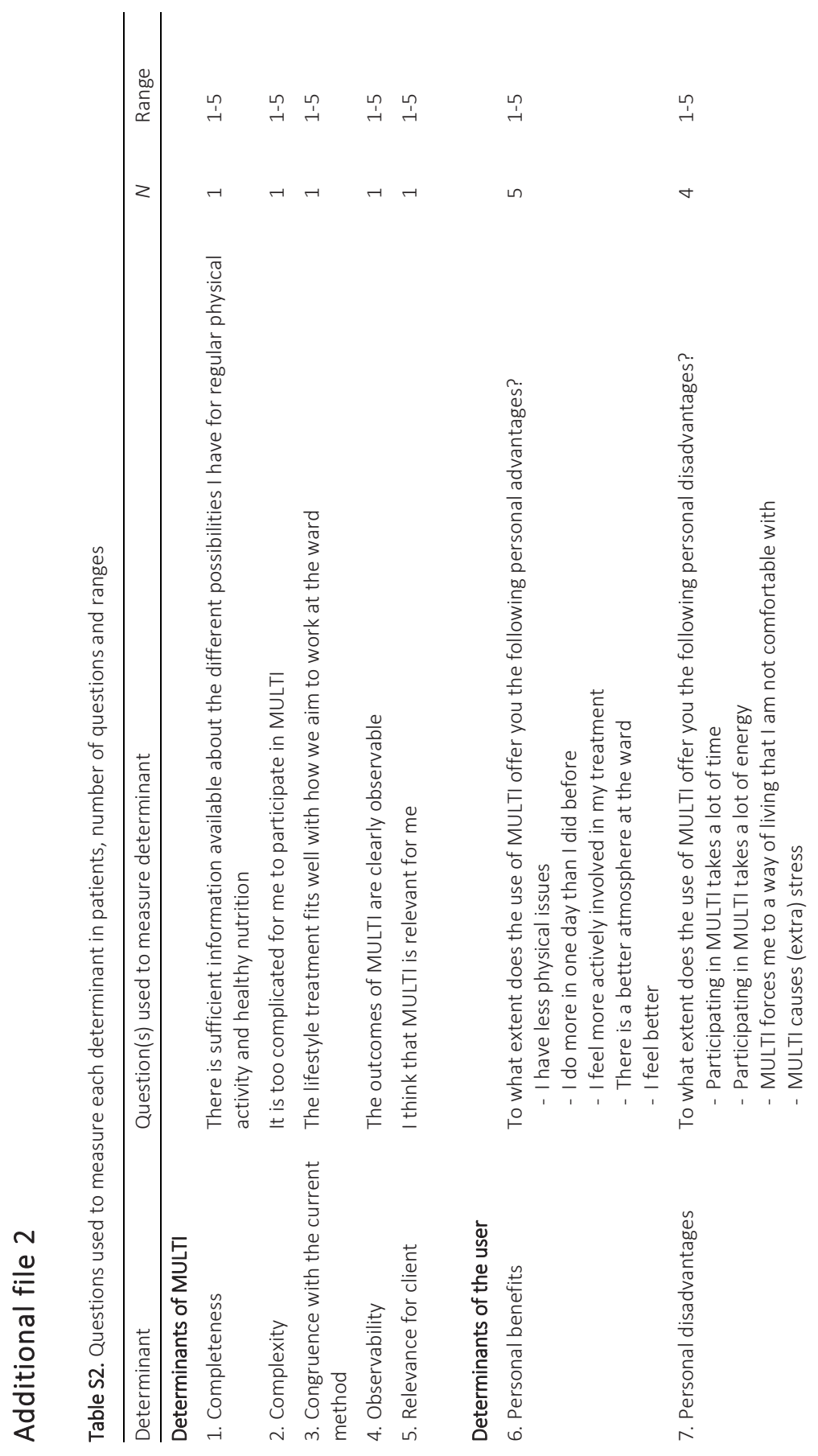


$\wedge$
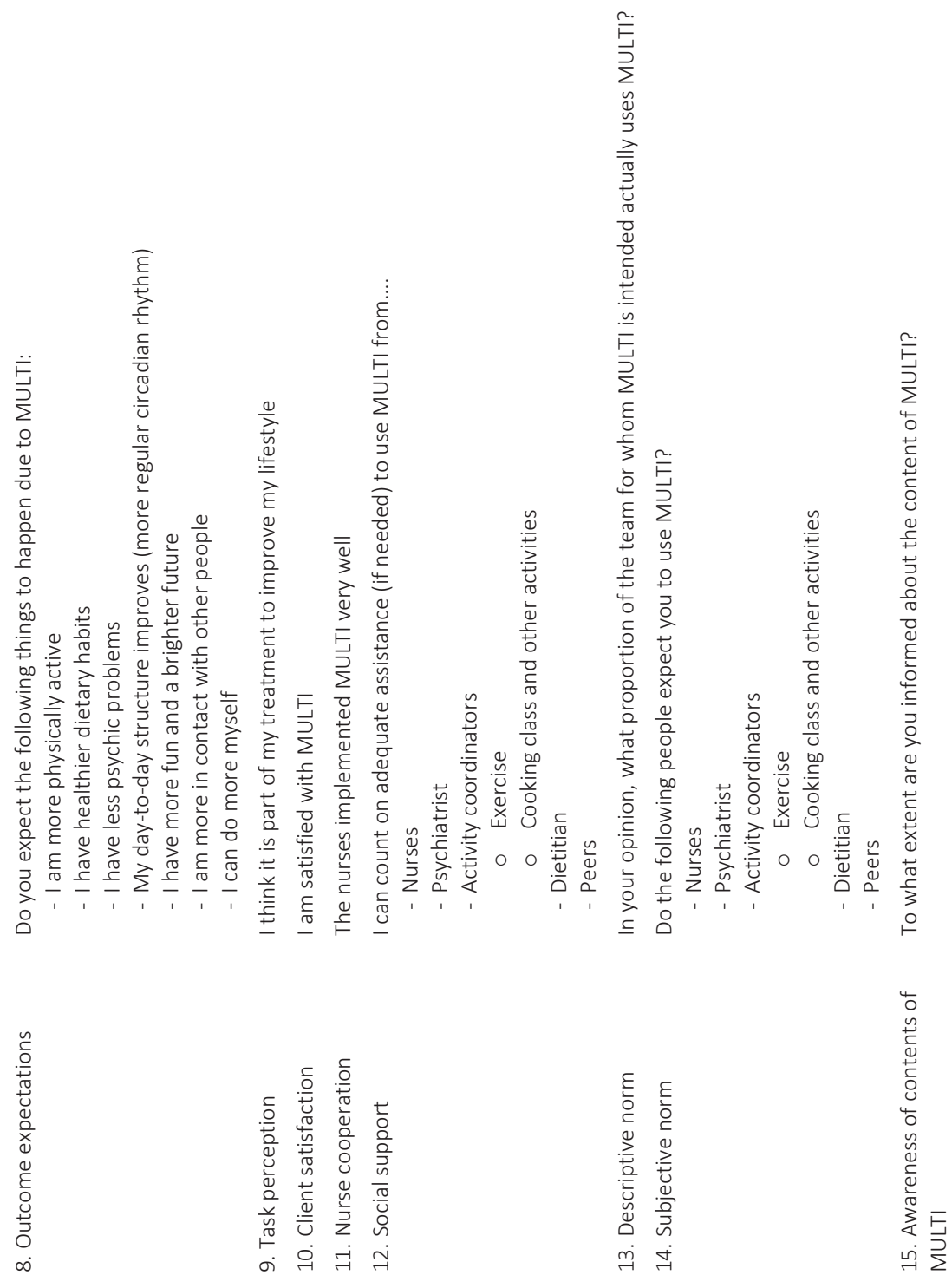


\section{It would not be surprising if future academic generations wonder why it has taken us so long to take action, but that is for others to judge.}

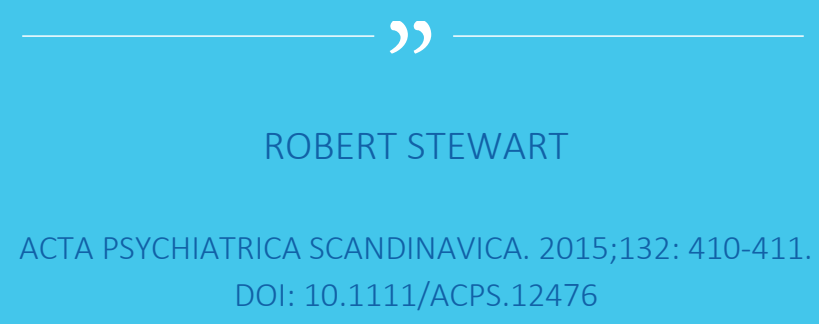




\section{Chapter}

\section{From impact factors to real impact: translating evidence on lifestyle interventions into routine mental healthcare}

Deenik, J., Czosnek, L., Teasdale, S.B., Stubbs, B., Firth, J., Schuch, F.B., Tenback, D.E., van Harten, P.N., Tak, E.C.P.M., Lederman, O., Ward, P.B., Hendriksen, I.J.M., Vancampfort, D., Rosenbaum, S. 

People with severe mental illness (SMI) experience a reduced life expectancy up to 20 years compared to the general population, predominantly due to poor physical health [15]. Modifiable cardiometabolic risk factors, such as physical inactivity, a sedentary lifestyle, smoking, and dietary risks contribute significantly to these negative health outcomes [6-10]. Interventions that address these risk factors are increasingly recognized as important components of treatment for this vulnerable population. For example, many systematic reviews and meta-analyses have demonstrated the efficacy of physical activity interventions on cardiometabolic health, psychiatric symptoms, quality of life and global and cognitive functioning in people with SMI, with the most efficacious interventions executed at higher levels of intensity and delivered by qualified exercise professionals (e.g. exercise physiologists, physiotherapists) [11, 12].

In 2016, the Society of Behavioral Medicine (SBM), together with the American College of Sports Medicine (ACSM), called for the expansion of US health plan coverage for exercise programming for people with SMI [13]. This was in response to the limited availability of such programs in routine care and the considerable evidence demonstrating the efficacy of 'lifestyle interventions' i.e. programs which aim to promote an active and healthy lifestyle. Despite the increasing number of publications and policies aiming to address the reduced life expectancy of people with SMI, there remains little change in routine clinical practice [14]. The overwhelming majority of evidence to date has focused on the efficacy of lifestyle interventions, using randomized controlled trials (RCTs) to answer the question 'does it work?' [15]. While essential, such studies have limited external validity, frequently involving individuals who are already looking to change their health behaviors and who are often less severely unwell [16]. Further, efficacy studies are typically performed under ideal conditions, that are unlikely to reflect typical resourcing of interventions under real-world conditions. Therefore, positive findings from RCTs cannot automatically translate into routine clinical care.

Thus, if efficacy is shown, studies evaluating the effectiveness of interventions in realworld settings can help to understand how to 'make a program work' in routine clinical practice, as outlined in the model of Brown et al. [15] (Fig. 1). Such studies will help answer the question as to how patients with SMI can include lifestyle changes in their daily lives in real-world settings [17-19], which is also relevant in light of the limited evidence regarding the maintenance and long-term health benefits of lifestyle interventions [11, 19, 20].

Implementing and then sustaining (i.e. integration within an organization) evidencebased interventions within routine clinical care is a complex process. Specific characteristics of real-world clinical settings and multilevel barriers for successful implementation are two key challenges in this [21, 22]. In addition to factors at the individual level (e.g. patients and healthcare professionals) [23-25], environmental (e.g. community/system and policy influences) and organizational level factors (i.e. ensuring adequate resourcing, organizational culture) are crucial, although less frequently studied [13, 17, 21, 22, 26]. A better understanding of implementation-related factors can reveal why interventions 
may or may not work in a 'real-world' context and how they can be sustained over the longer term, which would support efforts to embed these services in routine clinical practice. Such factors are relevant for healthcare professionals and people living with SMI, in addition to policymakers and other key stakeholders, to ensure the long-term impact of investments in lifestyle interventions [22, 27, 28].

Implementation science, i.e. studying methods to promote the systematic uptake of evidence-based interventions into practice and policy, is designed to address such difficulties. In addition to more effectiveness studies, we advocate for more implementation research to further close the gap between research and practice in lifestyle interventions for people with SMI. Such studies should assess measures of acceptability, adoption, fidelity, implementation costs, and sustainability in addition to clinical markers [29] (Fig. 1). A practical guide to support this type of research is PRACTIS (PRACTical planning for Implementation and Scale-up). PRACTIS was introduced as a step-by-step approach to implementing physical activity interventions in real-world settings and can be applied to other areas of public health prevention [21]. It describes four iterative steps. The first step focuses on the characterization of the parameters of the implementation setting, such as the size of the target population, how implementers will be engaged, trained and supported and the identification of champions. It also includes how associated costs and resources will be sustainably funded and alignment with and integration into organizational missions, policies and job descriptions. The second step includes identifying and engaging key stakeholders across multiple levels within the implementation setting. The third and fourth step focus on the identification of contextual barriers and facilitators to implementation and addressing potential barriers. PRACTIS supports implementation efforts by outlining "a structure for researchers and stakeholders, with varying levels of implementation experience and expertise, to navigate the complex considerations and decision-making processes involved in translating evidence-based interventions into practice" [21]. It should be recognized that these steps are not a fixed linear process, as uncertainty and unpredictability (e.g. organizational changes) are inherent to real-world settings [30]. Although effectiveness and implementation studies are typically considered to be separate research designs, they can be combined to expedite the translation of research findings into routine practice [31]. Furthermore, there is a need for support implementation research through appropriate funding schemes as well as encouraging and promoting the publication of implementation-based findings in addition to efficacy studies from traditional RCTs. In addition to a call for more effectiveness studies conducted in real-world settings, concurrently studying the implementation and systematic uptake of effective interventions in practice and policy is an essential step to drive this field forward. We should ensure that the implementation of such interventions does not become the 'elephant in the room'. The challenge of implementation is widely recognized and we need more than efficacy studies to address this. It is time to focus on how we can implement and deliver interventions in routine clinical practice, in order to achieve long-term change and improve the health status of people with SMI. 


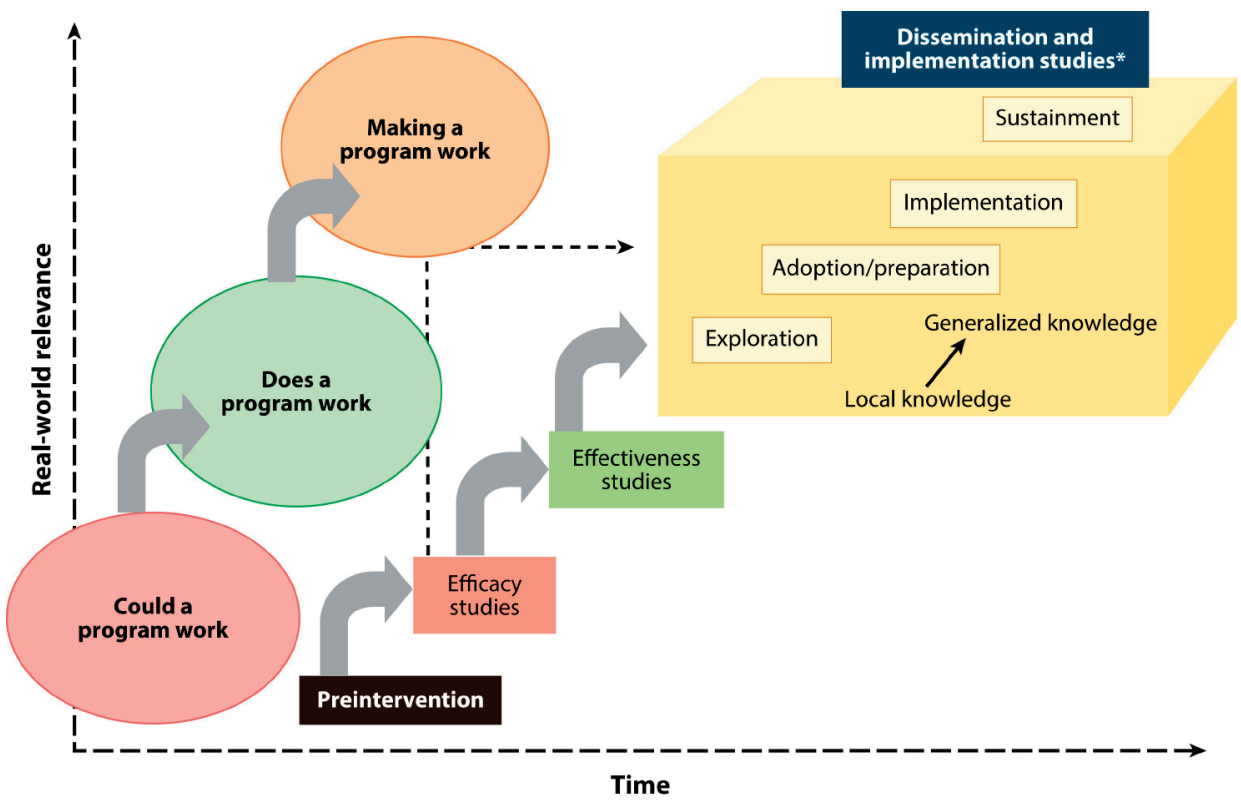

*These dissemination and implementation stages include systematic monitoring, evaluation, and adaptation as required.

Fig. 1. The traditional translational pipeline from preintervention, efficacy, effectiveness, to dissemination and implementation studies. Adapted from Brown et al. [15]. 


\section{References}

1. Hjorthøj C, Sturup AE, McGrath JJ, Nordentoft M. Years of potential life lost and life expectancy in schizophrenia: a systematic review and meta-analysis. The Lancet Psychiatry. 2017;4(4):295-301.

2. Piotrowski P, Gondek TM, Krolicka-Deregowska A, Misiak B, Adamowski T, Kiejna A. Causes of mortality in schizophrenia: An updated review of European studies. Psychiatr Danub. 2017;29(2):108-120.

3. Tanskanen A, Tiihonen J, Taipale H. Mortality in schizophrenia: 30-year nationwide follow-up study. Acta Psychiatr Scand. 2018.

4. Walker ER, McGee RE, Druss BG. Mortality in Mental Disorders and Global Disease Burden Implications A Systematic Review and Meta-analysis. Jama Psychiatry. 2015;72(4):334-341.

5. Correll CU, Solmi M, Veronese N, Bortolato B, Rosson S, Santonastaso P, Thapa-Chhetri N, Fornaro M, Gallicchio D, Collantoni E et al. Prevalence, incidence and mortality from cardiovascular disease in patients with pooled and specific severe mental illness: a large-scale meta-analysis of 3,211,768 patients and 113,383,368 controls. World Psychiatry. 2017;16(2):163-180.

6. de Leon J, Diaz FJ. A meta-analysis of worldwide studies demonstrates an association between schizophrenia and tobacco smoking behaviors. Schizophr Res. 2005;76(2-3):135-157.

7. Stubbs B, Chen LJ, Chung MS, Ku PW. Physical activity ameliorates the association between sedentary behavior and cardiometabolic risk among inpatients with schizophrenia: A comparison versus controls using accelerometry. Compr Psychiatry. 2017;74:144-150.

8. Vancampfort D, Probst M, Scheewe T, De Herdt A, Sweers K, Knapen J, van Winkel R, De Hert M. Relationships between physical fitness, physical activity, smoking and metabolic and mental health parameters in people with schizophrenia. Psychiatry Res. 2013;207(1-2):25-32.

9. Firth J, Stubbs B, Teasdale SB, Ward PB, Veronese N, Shivappa N, Hebert JR, Berk M, Yung AR, Sarris J. Diet as a hot topic in psychiatry: a population-scale study of nutritional intake and inflammatory potential in severe mental illness. World Psychiatry. 2018;17(3):365-367.

10. Teasdale SB, Ward PB, Samaras K, Firth J, Stubbs B, Tripodi E, Burrows TL. Dietary intake of people with severe mental illness: systematic review and meta-analysis. Br J Psychiatry. 2019:1-9.

11. Stubbs B, Vancampfort D, Hallgren M, Firth J, Veronese N, Solmi M, Brand S, Cordes J, Malchow B, Gerber $M$ et al. EPA guidance on physical activity as a treatment for severe mental illness: a meta-review of the evidence and Position Statement from the European Psychiatric Association (EPA), supported by the International Organization of Physical Therapists in Mental Health (IOPTMH). Eur Psychiatry. 2018;54:124144.

12. Czosnek L, Lederman O, Cormie P, Zopf E, Stubbs B, Rosenbaum S. Health benefits, safety and cost of physical activity interventions for mental health conditions: A meta-review to inform translation efforts. Mental Health and Physical Activity. in press.

13. Pratt SI, Jerome GJ, Schneider KL, Craft LL, Buman MP, Stoutenberg M, Daumit GL, Bartels SJ, Goodrich DE. Increasing US health plan coverage for exercise programming in community mental health settings for people with serious mental illness: a position statement from the Society of Behavior Medicine and the American College of Sports Medicine. Transl Behav Med. 2016;6(3):478-481.

14. Stewart R. Mental disorders and mortality: so many publications, so little change. Acta Psychiatr Scand. 2015;132(5):410-411.

15. Brown CH, Curran G, Palinkas LA, Aarons GA, Wells KB, Jones L, Collins LM, Duan N, Mittman BS, Wallace A et al. An Overview of Research and Evaluation Designs for Dissemination and Implementation. Annu Rev Public Health. 2017;38:1-22.

16. Bartels SJ. Can behavioral health organizations change health behaviors? The STRIDE study and lifestyle interventions for obesity in serious mental illness. Am J Psychiatry. 2015;172(1):9-11.

17. Liu NH, Daumit GL, Dua T, Aquila R, Charlson F, Cuijpers P, Druss B, Dudek K, Freeman M, Fujii C et al. Excess mortality in persons with severe mental disorders: a multilevel intervention framework and priorities for clinical practice, policy and research agendas. World Psychiatry. 2017;16(1):30-40. 
18. Vancampfort D, Stubbs B, Ward PB, Teasdale S, Rosenbaum S. Why moving more should be promoted for severe mental illness. The lancet Psychiatry. 2015;2(4):295.

19. Naslund JA, Whiteman KL, McHugo GJ, Aschbrenner KA, Marsch LA, Bartels SJ. Lifestyle interventions for weight loss among overweight and obese adults with serious mental illness: A systematic review and metaanalysis. Gen Hosp Psychiatry. 2017;47:83-102.

20. Jakobsen AS, Speyer H, Norgaard HCB, Karlsen M, Birk M, Hjorthoj C, Mors O, Krogh J, Gluud C, Pisinger C et al. Effect of lifestyle coaching versus care coordination versus treatment as usual in people with severe mental illness and overweight: Two-years follow-up of the randomized CHANGE trial. PLoS One. 2017;12(10):e0185881.

21. Koorts H, Eakin E, Estabrooks P, Timperio A, Salmon J, Bauman A. Implementation and scale up of population physical activity interventions for clinical and community settings: the PRACTIS guide. Int J Behav Nutr Phys Act. 2018;15(1):51.

22. Lennox L, Maher L, Reed J. Navigating the sustainability landscape: a systematic review of sustainability approaches in healthcare. Implementation Science. 2018;13(1):27.

23. Firth J, Rosenbaum S, Stubbs B, Gorczynski P, Yung AR, Vancampfort D. Motivating factors and barriers towards exercise in severe mental illness: a systematic review and meta-analysis. Psychol Med. 2016:113.

24. Robson D, Haddad M, Gray R, Gournay K. Mental health nursing and physical health care: a cross-sectional study of nurses' attitudes, practice, and perceived training needs for the physical health care of people with severe mental illness. Int J Ment Health Nurs. 2013;22(5):409-417.

25. Stanton R, Happell B, Reaburn P. Investigating the exercise-prescription practices of nurses working in inpatient mental health settings. Int J Ment Health Nurs. 2015;24(2):112-120.

26. Bartels S, Brunette M, Aschbrenner K, Daumit G. Implementation of a system-wide health promotion intervention to reduce early mortality in high risk adults with serious mental illness and obesity. Implementation Science. 2015;10(1):A15.

27. Wiltsey-Stirman S, Kimberly J, Cook N, Calloway A, Castro F, Charns M. The sustainability of new programs and innovations: a review of the empirical literature and recommendations for future research. Implement Science. 2012;7:17.

28. Chambers DA, Glasgow RE, Stange KC. The dynamic sustainability framework: addressing the paradox of sustainment amid ongoing change. Implement Sci. 2013;8:117.

29. Proctor E, Silmere H, Raghavan R, Hovmand P, Aarons G, Bunger A, Griffey R, Hensley M. Outcomes for implementation research: conceptual distinctions, measurement challenges, and research agenda. Adm Policy Ment Health. 2011;38(2):65-76.

30. Braithwaite J, Churruca K, Long JC, Ellis LA, Herkes J. When complexity science meets implementation science: a theoretical and empirical analysis of systems change. BMC Med. 2018;16(1):63.

31. Curran GM, Bauer M, Mittman B, Pyne JM, Stetler C. Effectiveness-implementation hybrid designs: combining elements of clinical effectiveness and implementation research to enhance public health impact. Med Care. 2012;50(3):217-226. 

Chapter

Summary and general discussion 

There is an urgent need to improve the health of patients with severe mental illness (SMI) [1-9]. This is reflected in the fact that $69 \%$ of the patients with SMI included in our study met the criteria for metabolic syndrome at the start of the research. Modifiable lifestyle factors, such as physical activity and dietary habits, play a significant role in improving the health status of patients with SMI [10-14]. Although many studies have demonstrated the beneficial effects of lifestyle interventions on both physical and mental health [15-23], there is currently a gap in the evidence when it comes to inpatients hospitalised for an extended period of time due to the severity of their illness. However, hospitalised patients with SMI, in particular, evince an alarmingly deteriorated health status [10, 24-26] and their premature mortality risk is the highest among patients with SMI [4]. Their health is likely worse than that of outpatients, due to the negative associations between duration of illness and physical activity, physical health, and quality of life [13, 27-29]. Also, the hospital setting itself has been considered "obesogenic" and a cause of inactivity [24, 30]. So far, several efforts within studies and daily clinical practice have not yielded any sustainable change, and little is known about any effective method to tackle this morbidity and mortality hazard [31, 32].

In addition to a gap in the evidence concerning effective interventions for inpatients, there is also a so-called gap in implementation when it comes to lifestyle interventions for patients with SMI, in general [33]. Despite the increase in evidence-based mainly on outpatient settings-supporting the efficacy of lifestyle interventions in SMI in the last decade, there is limited evidence to support its maintenance and long-term health benefits and little has changed in routine clinical care [19, 23, 34, 35]. Therefore, there is a need for more insight into successful strategies to implement lifestyle-related interventions in real-world settings [6, 36-39]. This thesis aims to address both gaps-in evidence and in implementation-in changing lifestyle to improve the health status of inpatients with SMI.

\section{Evidence}

To address the first gap, we explored the levels of total activity, sedentary behaviour and physical activity in inpatients with SMI. In order to explore the mechanisms behind their levels of activity, we analysed its association with quality of life, attitude, and self-efficacy towards physical activity. After an integrated lifestyle-enhancing treatment was implemented, we evaluated changes in physical activity, physical health, psychotic symptoms, quality of life, psychosocial functioning, and medication use.

Objective measurement showed that inpatients with SMI spent a higher proportion (84\%) of their waking time in sedentary behaviour and were less physically active than people without SMI (76\%) (chapter 2). This finding was in line with previous findings for mainly outpatients $[11,12]$. These accelerometric data, which are the first in this patient group measured on a larger scale in Europe, enabled us to look in more detail along the spectrum of sedentary behaviour and physical activity, including at the relationships with 
other relevant health outcome measures (chapter 3). Being less sedentary and more physically active showed a positive relationship with quality of life. The non-linearity of this relationship suggested that being involved in some physical activity instead of doing nothing would be the most beneficial for the quality of life. We found no association with scores on attitude and self-efficacy towards physical activity. This confirmed observations made in clinical practice, whereby only focusing on attitude and self-efficacy did not result in increased physical activity, suggesting the need for a more integrated approach to guiding patients towards healthier lifestyles.

The multidisciplinary lifestyle-enhancing treatment for inpatients with SMI (MULTI), evaluated in this thesis, is just such a supportive, integrated approach. MULTI was shown to be able to improve physical health compared to treatment as usual after 18 months. Analyses showed positive changes in physical activity and cardiometabolic risk factors, consistent with findings in studies focussing mainly on outpatients (chapter 4) [14, 15, 17 , $19,20]$. As to the central issue of why patients with SMI die up to 20 years earlier, physical health has generally been the most evaluated outcome in lifestyle intervention studies in this population. Therefore, the improvements in physical activity and cardiometabolic health were actually what we hypothesised. Those findings are new for inpatients with $\mathrm{SMI}$ in the longer term. Moreover, we showed that these outcomes did not improve at all or even deteriorated under treatment as usual. This indicates that continuing the current usual treatment is not an option if we want to improve the physical health of patients with SMI. Aside from physical health, we found no improvements in psychotic symptoms (chapter 4). This result corresponds with the results of previous studies on inpatients, which suggest that these patients - with a higher and more prolonged severity of illness than outpatients - are less likely to improve on these outcomes [40-42]. Outcomes such as quality of life and psychosocial functioning and use of medication are much less studied, although they are often relevant to patients' subjective well-being. Improvements in quality of life (chapter 5) were shown previously in outpatients [15, 18], but improvements in psychosocial functioning (chapter 5 ) have never been reported in the literature. Most similar were those studies - mainly on outpatients - that found positive effects on global functioning $[18,20]$. Also, a decrease in the use of medications was shown for the first time (chapter 6 ). In addition to quality of life and psychosocial functioning, this decrease is also an important outcome from the patients' perspective, as side effects of medications and negative attitudes towards medication use, are associated with nonadherence, distress and are negatively impacting one's quality of life [4346]. To our knowledge, only one study has evaluated the use of antipsychotics specifically after a lifestyle programme. In this study, which included outpatients and no treatmentas-usual group or another control condition, a small decrease in the daily dose of antipsychotics was found [47]. As described in the introduction, interactions between certain specific factors (e.g. lifestyle and medication) contribute to the downward spiral in the physical health status of patients with SMI. Findings about medication use suggest that 
such factors can interact positively and interrupt or even reverse the spiral by improving lifestyle.

Remarkably, the only other studies evaluating lifestyle interventions in a population quite similar to ours found almost no significant health benefits. The most similar studies, done by Looijmans et al. [31] and Stiekema et al. [42] evaluated a combined diet-andexercise lifestyle interventions in a pragmatic randomised controlled trial, targeting the obesogenic environment in residential and long-term clinical care teams for inpatients with SMI. In this intervention, lifestyle coaches created a tailored lifestyle plan for the mental healthcare teams and guided its implementation. No effects on physical health outcomes [31] and psychosocial functioning [42] were found after twelve months. They reported that this might be due to their unidimensional focus on environmental factors and difficulties with implementation after three months, at which time the teams began to be guided less frequently by the lifestyle coaches. This finding is in contrast to the integrated design of MULTI, which includes multiple components and has the added feature that all the healthcare professionals (HCPs) were involved in and responsible for the program and implementation from the beginning. Another study concerned an observational evaluation of an intervention based on motivational techniques in long-stay wards for patients with SMI [41]. They found no improvements in physical activity or physical health after six months, except for an improvement in triglyceride levels. The lack of a control condition, no correction for disease characteristics, and the low number of participants in this study by Ringen et al. [41] hinders comparison of results. For example, in our study, we also observed a decrease in triglyceride levels in the group receiving MULTI (chapter 4), but this result was non-significant after comparing it to usual care and controlling for disease characteristics. Ringen et al. [41] concluded that the lack of changes found may suggest that their intervention was too weak or non-targeted.

Based on the results of these studies and their conclusions, we believe that MULTI's integrated, holistic design-including multiple components, personalisation/tailoring, support by peers and qualified HCPs, and an organisational culture change-is key to our positive findings. We hypothesise that this design contributed to ownership and thus to uptake in clinical practice. This interpretation is supported by several recent studies that advocated the use of these elements for successful lifestyle change [16, 25, 36, 48-56]. Altogether, MULTI is the first treatment that has combined these factors in an integrated approach within routine clinical care that showed a variety of sustainable health improvements in inpatients with SMI.

\section{Implementation}

We aimed to address the implementation gap by studying the implementation of MULTI. Implementation of lifestyle interventions in real-world settings is a challenge in inpatients with mental illnesses. Although there is much evidence published regarding its beneficial 
effects on both physical and mental health [15, 57-63], there is yet little change in the health status of patients with SMI in clinical practice [35]. As outlined in chapter 8 , the majority of studies that contributed to the increase in evidence on lifestyle interventions in patients with SMI in the last decade focused on the efficacy ("Could and does a program work?" - as in, for example, increasing physical activity). However, proving efficacy does not guarantee successful implementation of interventions in daily clinical practice. and there is a need for a shift towards the question of how to make a program work (i.e. effectiveness, see Figure 1, p. 163) [6, 36-39]. The MULTI study adds to this by evaluating a treatment integrated within daily routine care. Also, we aimed to study the barriers to and facilitators of its actual implementation. There have been some studies that indicated essential factors for successful lifestyle change in patients with SMI, such as a multidisciplinary holistic approach, support by peers and qualified HCPs, personalisation/tailoring, and the use of multiple components (e.g. nutrition and psycho-education in addition to physical activity) $[16,25,36,48-56]$. However, the challenge is how to implement a combination of those factors in clinical practice.

This challenge was also reflected in the barriers to the implementation of MULTI mentioned both by HCPs and patients alike (chapter 7). We found that within this multidisciplinary supportive-group approach, there was a need for more tailoring towards patients' abilities, interests, and needs. Addressing this topic is relevant, as tailoring improves the meaningfulness and suitability of activities for patients and thereby their autonomous motivation, which was suggested to enhance sustainable engagement [51-53, 56, 64]. Nevertheless, organisational barriers played a central role and affected nurses' opportunities to tailor activities, as well (e.g. lack of time, staff, and management support). Such issues are known to be factors that can impact negatively the support of lifestyle-related behaviour by mental health nurses $[56,65,66]$. The development and implementation of MULTI at a team level contributed to ownership, commitment, and collaboration. However, the organisational barriers we found are most likely in line with this bottom-up approach, as there was no significant involvement of higher management. These barriers can be addressed using an implementation framework such as PRACTIS (PRACTical planning for Implementation and Scale-up) [67], as outlined in chapter 8. According to this framework, key stakeholders should be reviewed (e.g. engaging higher management in attrition to the current team) and essential factors should be reconsidered in the implementation of MULTI (e.g. training and support for HCPs and sustainable funding). Paying attention to both of these items will provide input with which to address many of the organisational barriers found and creates an excellent foundation for further improvement (chapter 7).

Nevertheless, this study showed the positive response of both HCPs and patients towards this integrated, multidisciplinary, structured approach and their roles in it, which facilitated the implementation of MULTI. The participation of HCPs was an essential element, which is in accordance with previous studies that stressed the value of engagement [68-71]. Together, the findings add to the sparse evidence in terms of analysing factors 
related to actual implementation in clinical practice for patients with SMI, in general. MULTI combines several factors found to be significant in the literature. The study of barriers and facilitators is exceptional, as studies involving the perspectives of both HCPs and patients are rare. More specifically, findings fill a gap in the evidence when it comes to inpatient settings. They confirm the feasibility of MULTI and provide concrete suggestions for further improvement.

\section{Methodological issues}

To date, the majority of studies that have focused on the efficacy of lifestyle interventions have used a randomised controlled trial design. Our design was different. During the execution of MULTI, we evaluated both its effectiveness and implementation using an observational design, including wards that continued treatment as usual as a comparison. As a result, we were not able to randomise patients to MULTI or usual care. In addition, we were limited in controlling changes in clinical practice over time, which could influence the outcomes. Consider, for example, the introduction of life-story books (aimed at improving quality of life) (chapter 5), the replacement of a psychiatrist who revised medication prescriptions at the wards receiving treatment as usual (chapter 6), and budget cuts that limited the deployments of allied health professionals (chapter 7). Also, we were limited to isolating the contribution of each element to the improvements we found, such as physical activity, attention to dietary habits, or the participation of HCPs. We addressed these challenges in our analyses in order to obtain results that were as robust as possible. In the multilevel analysis, we corrected for potential differences that were clustered within wards (e.g. the way they work), regression to the mean (e.g. overweight patients are more likely to lose weight), and differences in patient and/or disease characteristics between MULTI and usual care. The correction for baseline values which we used in all analyses was recommended for evaluating treatments [72], as well as mediation analyses [73]. With the latter, we took the first step to gain more insight into the contributions of different elements of MULTI to the observed improvements.

The observational controlled design was also a major strength and served an important purpose in terms of external validity. Although typical efficacy studies are essential for answering the question "Does it work?" (e.g. increasing physical activity), they have limited external validity in terms of supporting effectiveness in routine clinical care (i.e. how to "make it work") [74]. For example, such studies are highly likely to recruit participants selectively who are already in an advanced stage of motivation and readiness to change and are not representative of the typical inpatient [33]. These trials are usually performed under ideal, controlled conditions, which are unlikely to reflect the usual level of resourcing for interventions in daily practice. These factors restrict large-scale implementation due to less generalizable results [19, 23, 34]. We evaluated an implemented lifestyle-enhancing treatment that combined elements important to change. We conducted this evaluation 
despite current clinical practice and resource challenges, such as daily issues on the wards, staff turnover, and budget cuts, making it highly relevant for clinical practice. Thus, where randomised controlled trials have strength in showing efficacy, our design has a much better external validity. Moreover, our approach was shown to be feasible in daily routine inpatient care in terms of improving various health outcomes. Therefore, the current study fills a gap in both the evidence and in clinical practice and meets the widespread call for a shift towards effectiveness studies in real-world clinical practice [6, 36-39]. Thereby, it contributes to improving methods for external validity in order to create appropriate evidence which supports decision-making for clinicians and management staff in real-world settings [75].

Apart from the design, there are some considerations concerning measuring outcomes in inpatients with SMI, which resulted mainly from the limited research that has been done on this population. For instance, there were no questionnaires regarding attitude and self-efficacy available at the time of our cross-sectional research that were validated in patients with SMI (chapter 3). Moreover, self-report questionnaires can be challenging in this population, in general. Reliability and validity are affected by factors such as illness severity, negative symptoms, and cognitive deficits [51, 76, 77]. Therefore, for questionnaires, using methods such as semi-structured interviews supported by an independent research assistant worked best in terms of including patients and collecting valid data. In this context, the use of accelerometers to measure sedentary behaviour and physical activity is a strength in our studies as well. For this, we developed short elastic belts and pouches to secure the accelerometer to each patient's right hip, instead of using the long belts around the entire waist generally used. With this, we aimed to avoid discomfort, improve ease of use for both patients and nurses (e.g. with regard to toilet visits and changing clothes), and thereby increased our chances of obtaining successful measurements. Despite challenges in the comparability of data due to a lack of international consensus on data collection and processing, the use of accelerometry significantly improved reliability, validity, and the detail of data on sedentary behaviour, physical activity, and studied relationships, compared to often-used self-reports [12, 78, 79].

\section{Implications}

In the last decade, there has been a significant increase in studies addressing the topic of physical health and lifestyle in patients with SMI. Previous studies focused mainly on outpatients and efficacy. In this thesis, we went further and focused on the actual "How to make a program work" and studied its implementation in inpatients with SMI, whose health status as a group is generally worse than that of outpatients. It fills a gap in both evidence and implementation for inpatients with SMI, who were largely understudied. Thereby, the MULTI study is the first of its kind evaluating such an integrated approach 
in the longer term in a real-world setting. This raises the question: What do these findings mean for inpatient daily clinical practice?

To start with, the inpatient setting is characterised by high levels of sedentary behaviour, lack of physical activity, poor physical health (not improving under care as usual), including frequent use of a diversity of medications in often high dosage-all of which emphasise the urgency for change. We hypothesised (and showed) that a multidisciplinary integrated approach within current clinical practice could lead to much needed positive changes in a variety of health outcomes in inpatients with SMI. These findings, therefore, address the pessimism about the ability of patients with SMI to embrace healthbehaviour changes and the feasibility of improving their health status [33, 80]. It emphasises that therapeutic nihilism (e.g. "It is not possible to improve their physical health") should not limit access to the benefits of lifestyle interventions for patients with SMI [37]. The improvements found were largely a result of collaboration between different disciplines within the current organisational structure. This is in line with previous indications that the challenge to improving the health of patients with SMI is more a challenge to caregivers (i.e. HCPs and organisations), rather than to the patients themselves [81].

Based on a bottom-up, "change from within" principle, the positive outcomes of MULTI suggest that a sustainable solution towards a healthier lifestyle is already at our fingertips. HCPs and patients are ready and willing to participate in this change, which can be further improved and maintained if they are supported and facilitated by cultural changes at a management level. This "thinking inside the box" (i.e. thinking and making changes in the current context of routine clinical care) requires collaboration between all disciplines involved in making changes in physical activity and nutrition. Apart from actively participating HCPs, patients, and allied health professionals, this collaboration network should also include support facilities, such as the kitchen who delivers meals, shops where patients can buy food and beverages, and passenger transport around the hospital area. The strength of the bottom-up approach is that each discipline can give input based on its expertise, whereby allied health professionals and the aforementioned facilities can support HCPs in the wards. By including patients' input in the supported decision-making with the HCPs (e.g. in choosing activities), personalisation is achieved. This contributes to ownership and commitment of everyone's share within the treatment. Based on our findings, we recommend using the available expertise within the organisation as much as possible and integrating the activities into the daily lives of the patients. Conditions in which initiators are not going to be involved long-term in the organisational structure (e.g. lifestyle coaches from outside the organisation) are highly likely to result in a lack of integration and commitment in routine clinical care, thus undermining proper implementation. Instead, clear goals can be set when HCPs are in the lead-supported by management, allied health professionals, and facilities within the hospital-in order to develop an appropriate way to achieve them. For example, MULTI has several essential elements to distinguish: a day-to-day structure, more physical activity (both sport- and work-related and daily living activity), attention to dietary habits, psycho-education, daily living 
skills training, and active participation of HCPs. Every ward includes these elements in a new day-to-day program. The HCPs are the leaders in filling in these elements, which are tailored to particular wards (both in terms of facilities and the population) and individual patients (both abilities and interests). Although the elements addressed are the same, the actual day-to-day program-including frequency, intensity, kind of activities, and format (e.g. group or alone)-could vary per ward and patient. As it is tailored, it can be expected that all patients are doing some of the activities in the morning and afternoon in order to prevent prolonged periods of lying in bed or sitting on the ward. In such an approach, teams can learn from each other by sharing and discussing challenges and strategies in addressing their goals.

Ethical considerations play an essential role in this culture change. It brings us back to the question of what we think is ethical, responsible, and appropriate healthcare for patients with SMI. Although everyone would probably agree that nobody recovers while lying in bed all day long, this remains a difficult question to answer and translate into clinical practice. Apart from the aforementioned possible pessimism and therapeutic nihilism [37, 82], the question can be about specific topics, which could result in ambiguity and therefore inconsistent behaviour within teams. Do we allow patients to lie in bed all day long? What will you do if a patient does not want to get out of bed? Do we tolerate patients buying bottles of soda at the hospital or eating "fast food" on the ward? Can you make a lifestyle-related decision for a patient as an HCP for his/her own good? Do we tolerate HCPs themselves eating "fast food" on the ward during night shifts? Many questions like these have to do with balancing patients' autonomy and freedom of choice versus delivering proper healthcare. For example, regarding food, day-to-day issues, such as friction with patient autonomy and the battle over what one can eat, were raised previously among inpatients with SMI [32]. In the context of forensic units, this was discussed as the dilemma of whether the duty of care to a patient could be outweighed by the patient's free choice to make their own decisions, even though this could be harmful to his/her future physical health [48]. On the other hand, each patient has a "right to health" -including the patient with mental illness who lacks the capacity to prevent contracting metabolic syndrome. In this context, a ward without a supporting program regarding physical health could be deemed neglectful according to law [48]. Therefore, the hospital should provide the opportunities (physical and organisational) whereby healthy behavioural choices are promoted as much as possible. As part of this, it is helpful to form and express a vision of challenging topics in daily routine practice, such as those mentioned above. Involving both HCPs and patients in this kind of decision-making throughout the change process can prevent inconsistencies and tensions which could undermine the proper implementation of lifestyle interventions [83].

Although the studies in this thesis included a cohort of inpatients with SMI who were hospitalised for an extended period, the findings largely fit the population of inpatients with SMI, in general. As this thesis focuses on the hospitalised setting and what we offer there, findings could be translated to a shorter stay, as well. The MULTI study shows that 
the hospital can be an important place in which to offer structured support to improve one's lifestyle in order to improve several health outcomes. Thereby, it could play a significant role in improving the recovery of patients who are hospitalised and, in turn, this may result in a shorter stay in the hospital. In this context, since SMI, in particular, starts at an early age [84] and somatic comorbidities are associated with more frequent rehospitalisations [85] such an approach can provide lifelong improvements and prevent the major health issues that are seen currently in patients with a long history of SMI.

\section{Further directions}

The results of this thesis call for adjustments in the current treatment and living conditions of inpatients with SMI. Real change in clinical practice will not be achieved by increasing the number of studies performed using the prevailing study designs. There is a substantial body of evidence supporting the efficacy of physical activity and lifestyle improvement in patients with SMI. However, there is, as yet, a systemic failure in implementation. Therefore, there is a need for studies focusing on effectiveness (how to make a program work in routine clinical care) and implementation in order to enhance the translation to daily clinical practice.

Regarding MULTI, the most important question for further directions is whether an optimised version of this approach can be implemented and sustained at other inpatient facilities, with the same or even better results. Findings can then be used for broader implementation in inpatient mental healthcare. It would be worthwhile to increase the number of participants in such a study. A larger sample allows studying changes in medication in more detail, for example. A large sample would also provide the opportunity to control for patient and disease characteristics, such as age, which can affect the prescribed dosage of medication [86-88]. Further analysis of changes in the use of medications is particularly relevant, as this portion of the study has not yet been well studied in patients with SMI, in general. However, it remains challenging to design methodologically strong studies that include the "real-world" daily routine care. Since patients on wards generally live in groups, it can be difficult to randomise patients on an individual level, for instance. Moreover, with the increasing awareness and popularity of lifestyle changes as a topic, in general, and the evidence of its efficacy, it can be challenging to create control groups, both for practical and ethical reasons. Therefore, an interrupted time series design could be an alternative design for future studies, whereby multiple measurements before and after the implementation of an intervention are used to study its effectiveness [89]. Previous findings indicate that the interrupted time series design can provide effect estimates that are concordant with the results of a randomised controlled trial [90].

Furthermore, the content of MULTI should be considered in connection with smoking cessation, which is yet another important factor in the poor health status of patients with SMI. Patients with SMI have higher frequencies of heavy smoking and higher nicotine 
dependence than the general population [91], contributing significantly to their reduced life expectancy [91]. As part of an unhealthy lifestyle, smoking is historically and culturally embedded profoundly within inpatient mental health settings [92]. Within clinical practice, many HCPs report barriers to and show negative attitudes towards smoking cessation interventions [93]. This culture and its attendant barriers may have also contributed to the fact that smoking was not a specific topic in MULTI. However, the feasibility of smoking reduction was shown in both outpatients and inpatients with SMI [94, 95], despite negative preconceptions and stereotypes. Because of the substantial health benefits, it is advisable to include smoking cessation interventions in the MULTI approach, as well.

There are also some recommendations for the field of lifestyle interventions in patients with SMI, in general. Firstly, to complement the increasing body of evidence for clinical practice, cost-effectiveness analyses are of value to translation and implementation efforts of lifestyle interventions within mental healthcare $[39,69]$. Such knowledge can be essential for organisations and health insurance companies and may improve the sustainability of interventions as part of routine clinical practice. Although it is not expected that integrated interventions have high costs, there is currently a lack of evidence to substantiate this [23]. Secondly, in addition to patient-focused interventions, there is increasing attention on educating HCPs on how they can contribute to behavioural change in patients and their role in it. These interventions can focus on HCPs' own lifestyle behaviours, as well, which could address the high level of sedentary behaviour we found in our HCPs (chapter 2), for instance. Up to now, findings are optimistic and highlight the potential for such interventions to be a key component in achieving culture change, which may support improving overall health outcomes in patients with SMI [55]. Thirdly, in addition to more intervention studies conducted in real-world settings, involving implementation science is an essential step in terms of driving this field forward (chapter 8). Implementation science is defined as studying methods to promote the systematic uptake of evidence-based interventions into practice and policy to improve health [96]. Such studies could contribute to understanding how the developed interventions can be delivered successfully as part of routine care, including addressing associated issues within these settings. To convert evidence into practice, it can be helpful to identify different steps in the research, according to the model of Brown et al. (Figure 1, p. 163) [74]. However, it must be recognised that identifying these steps is not a linear process. Unpredictability and uncertainty are normal characteristics of systems, including multiple forces, variables, and influences during a change process [97]. With regard to lifestyle interventions, the aforementioned PRACTIS framework can support in the stepwise translation of the evidence into practice, including by supplying practical examples [67]. In line with involving implementation science, there is a need to facilitate more such research, for example, through appropriate funding schemes and by journals encouraging publication of implementation-based findings instead of primarily evidence obtained in research settings, such as randomised controlled trials. 
All these recommendations contribute to improving further implementation of proper, integrated, lifestyle-enhancing interventions in inpatient settings. In the meantime, there is no reason to await further action. In the inpatient settings, everything we need in order to start a positive change is already within our reach. This thesis showed that it is feasible to positively change the status quo in inpatients with SMI and improve their health status by thinking and acting inside this box, just in a different way.

\section{6}

If you are looking for him, you might come back right after lunch, when everybody is here. Or check the day-to-day programme at the wall. He went to his activities after breakfast.

99

A NURSE DURING FOLLOW-UP MEASUREMENTS 


\section{References}

1. Correll CU, Solmi M, Veronese N, Bortolato B, Rosson S, Santonastaso P, Thapa-Chhetri N, Fornaro M, Gallicchio D, Collantoni E et al. Prevalence, incidence and mortality from cardiovascular disease in patients with pooled and specific severe mental illness: a large-scale meta-analysis of 3,211,768 patients and 113,383,368 controls. World Psychiatry. 2017;16(2):163-180.

2. Hjorthøj C, Sturup AE, McGrath JJ, Nordentoft M. Years of potential life lost and life expectancy in schizophrenia: a systematic review and meta-analysis. The Lancet Psychiatry. 2017;4(4):295-301.

3. Hoang U, Goldacre MJ, Stewart R. Avoidable mortality in people with schizophrenia or bipolar disorder in England. Acta Psychiatr Scand. 2013;127(3):195-201.

4. John A, McGregor J, Jones I, Lee SC, Walters JTR, Owen MJ, O'Donovan M, DelPozo-Banos M, Berridge D, Lloyd K. Premature mortality among people with severe mental illness - New evidence from linked primary care data. Schizophr Res. 2018;199:154-162.

5. Laursen TM, Wahlbeck K, Hallgren J, Westman J, Osby U, Alinaghizadeh H, Gissler M, Nordentoft M. Life expectancy and death by diseases of the circulatory system in patients with bipolar disorder or schizophrenia in the Nordic countries. PLoS One. 2013;8(6):e67133.

6. Liu NH, Daumit GL, Dua T, Aquila R, Charlson F, Cuijpers P, Druss B, Dudek K, Freeman M, Fujii C et al. Excess mortality in persons with severe mental disorders: a multilevel intervention framework and priorities for clinical practice, policy and research agendas. World Psychiatry. 2017;16(1):30-40.

7. Piotrowski P, Gondek TM, Krolicka-Deregowska A, Misiak B, Adamowski T, Kiejna A. Causes of mortality in schizophrenia: An updated review of European studies. Psychiatr Danub. 2017;29(2):108-120.

8. Tanskanen A, Tiihonen J, Taipale H. Mortality in schizophrenia: 30-year nationwide follow-up study. Acta Psychiatr Scand. 2018.

9. Walker ER, McGee RE, Druss BG. Mortality in Mental Disorders and Global Disease Burden Implications A Systematic Review and Meta-analysis. Jama Psychiatry. 2015;72(4):334-341.

10. Stubbs B, Chen LJ, Chung MS, Ku PW. Physical activity ameliorates the association between sedentary behavior and cardiometabolic risk among inpatients with schizophrenia: A comparison versus controls using accelerometry. Compr Psychiatry. 2017;74:144-150.

11. Stubbs B, Firth J, Berry A, Schuch FB, Rosenbaum S, Gaughran F, Veronesse N, Williams J, Craig T, Yung AR et al. How much physical activity do people with schizophrenia engage in? A systematic review, comparative meta-analysis and meta-regression. Schizophr Res. 2016;176(2-3):431-440.

12. Stubbs B, Williams JE, Gaughran F, Craig T. How sedentary are people with psychosis? A systematic review and meta-analysis. Schizophr Res. 2016;171(1-3):103-109.

13. Vancampfort D, Probst M, Scheewe T, De Herdt A, Sweers K, Knapen J, van Winkel R, De Hert M. Relationships between physical fitness, physical activity, smoking and metabolic and mental health parameters in people with schizophrenia. Psychiatry Res. 2013;207(1-2):25-32.

14. Teasdale SB, Samaras K, Wade T, Jarman R, Ward PB. A review of the nutritional challenges experienced by people living with severe mental illness: a role for dietitians in addressing physical health gaps. J Hum Nutr Diet. 2017;30(5):545-553.

15. Rosenbaum S, Tiedemann A, Sherrington C, Curtis J, Ward PB. Physical activity interventions for people with mental illness: a systematic review and meta-analysis. J Clin Psychiatry. 2014;75(9):964-974.

16. Teasdale SB, Ward PB, Rosenbaum S, Samaras K, Stubbs B. Solving a weighty problem: systematic review and meta-analysis of nutrition interventions in severe mental illness. The British Journal of Psychiatry. 2017;210(2):110-118

17. Vera-Garcia E, Mayoral-Cleries F, Vancampfort D, Stubbs B, Cuesta-Vargas Al. A systematic review of the benefits of physical therapy within a multidisciplinary care approach for people with schizophrenia: An update. Psychiatry Res. 2015;229(3):828-839.

18. Dauwan M, Begemann MJH, Heringa SM, Sommer IE. Exercise improves clinical symptoms, quality of life, global functioning, and depression in schizophrenia: A systematic review and meta-analysis. Schizophr Bull. 2016;42(3):588-599. 
19. Naslund JA, Whiteman KL, McHugo GJ, Aschbrenner KA, Marsch LA, Bartels SJ. Lifestyle interventions for weight loss among overweight and obese adults with serious mental illness: A systematic review and metaanalysis. Gen Hosp Psychiatry. 2017;47:83-102.

20. Firth J, Cotter J, Elliott R, French P, Yung AR. A systematic review and meta-analysis of exercise interventions in schizophrenia patients. Psychol Med. 2015;45(7):1343-1361.

21. Firth J, Stubbs B, Rosenbaum S, Vancampfort D, Malchow B, Schuch F, Elliott R, Nuechterlein KH, Yung AR. Aerobic Exercise Improves Cognitive Functioning in People With Schizophrenia: A Systematic Review and Meta-Analysis. Schizophr Bull. 2017;43(3):546-556.

22. Stanton R, Happell B. Exercise for mental illness: A systematic review of inpatient studies. Int J Ment Health Nurs. 2014;23(3):232-242.

23. Stubbs B, Vancampfort D, Hallgren M, Firth J, Veronese N, Solmi M, Brand S, Cordes J, Malchow B, Gerber $M$ et al. EPA guidance on physical activity as a treatment for severe mental illness: a meta-review of the evidence and Position Statement from the European Psychiatric Association (EPA), supported by the International Organization of Physical Therapists in Mental Health (IOPTMH). Eur Psychiatry. 2018;54:124144.

24. Ringen PA, Engh JA, Birkenaes AB, Dieset I, Andreassen OA. Increased mortality in schizophrenia due to cardiovascular disease - a non-systematic review of epidemiology, possible causes, and interventions. Frontiers in psychiatry. 2014;5:137-137.

25. Ringen PA, Faerden A, Antonsen B, Falk RS, Mamen A, Rognli EB, Solberg DK, Andreassen OA, Martinsen EW. Cardiometabolic risk factors, physical activity and psychiatric status in patients in long-term psychiatric inpatient departments. Nordic journal of psychiatry. 2018:1-7.

26. Tenback DE, Van Kessel F, Jessurun J, Pijl YJ, Heerdink ER, Van Harten PN. Risk factors for inactivity in patients in long-term care with severe mental illness. Tijdschrift voor Psychiatrie. 2013;55(2):83-91.

27. Mitchell AJ, Vancampfort D, Sweers K, van Winkel R, Yu W, De Hert M. Prevalence of metabolic syndrome and metabolic abnormalities in schizophrenia and related fisorders - A systematic review and meta-analysis. Schizophr Bull. 2013;39(2):306-318.

28. Vancampfort D, Firth J, Schuch FB, Rosenbaum S, Mugisha J, Hallgren M, Probst M, Ward PB, Gaughran F, De Hert $\mathrm{M}$ et al. Sedentary behavior and physical activity levels in people with schizophrenia, bipolar disorder and major depressive disorder: a global systematic review and meta-analysis. World Psychiatry. 2017;16(3):308-315.

29. Vancampfort D, Guelinckx H, Probst M, Stubbs B, Rosenbaum S, Ward PB, De Hert M. Health-related quality of life and aerobic fitness in people with schizophrenia. Int J Ment Health Nurs. 2015;24(5):394-402.

30. Faulkner GE, Gorczynski PF, Cohn TA. Psychiatric illness and obesity: recognizing the "obesogenic" nature of an inpatient psychiatric setting. Psychiatr Serv. 2009;60(4):538-541.

31. Looijmans A, Stiekema A, Bruggeman R, van der Meer L, Stolk RP, Schoevers RA, Jörg F, Corpeleijn E. Changing the obesogenic environment to improve cardiometabolic health in residential patients with a severe mental IIIness: ELIPS, a randomized controlled trial. Br J Psychiatry. 2017;211(5):296-303.

32. Levitt GA, Shinault K, Patterson S, Otaluka O. Weight Gain in Psychiatric Inpatients: Are Interventions Making a Positive Impact? Prim Care Companion CNS Disord. 2017;19(4):17m02111.

33. Bartels SJ. Can behavioral health organizations change health behaviors? The STRIDE study and lifestyle interventions for obesity in serious mental illness. Am J Psychiatry. 2015;172(1):9-11.

34. Jakobsen AS, Speyer H, Norgaard HCB, Karlsen M, Birk M, Hjorthoj C, Mors O, Krogh J, Gluud C, Pisinger C et al. Effect of lifestyle coaching versus care coordination versus treatment as usual in people with severe mental illness and overweight: Two-years follow-up of the randomized CHANGE trial. PLoS One. 2017;12(10):e0185881.

35. Stewart R. Mental disorders and mortality: so many publications, so little change. Acta Psychiatr Scand. 2015;132(5):410-411.

36. Vancampfort D, Stubbs B, Ward PB, Teasdale S, Rosenbaum S. Why moving more should be promoted for severe mental illness. The lancet Psychiatry. 2015;2(4):295.

37. Ward PB, Firth J, Rosenbaum S, Samaras K, Stubbs B, Curtis J. Lifestyle interventions to reduce premature mortality in schizophrenia. The lancet Psychiatry. 2017;4(7):e14. 
38. Rebar AL, Taylor A. Physical activity and mental health; it is more than just a prescription. Mental Health and Physical Activity. 2017;13:77-82.

39. Czosnek L, Lederman O, Cormie P, Zopf E, Stubbs B, Rosenbaum S. Health benefits, safety and cost of physical activity interventions for mental health conditions: A meta-review to inform translation efforts. Mental Health and Physical Activity. in press.

40. Heggelund J, Nilsberg GE, Hoff J, Morken G, Helgerud J. Effects of high aerobic intensity training in patients with schizophrenia: a controlled trial. Nordic journal of psychiatry. 2011;65(4):269-275.

41. Ringen PA, Falk RS, Antonsen B, Faerden A, Mamen A, Rognli EB, Solberg DK, Martinsen EW, Andreassen $\mathrm{OA}$. Using motivational techniques to reduce cardiometabolic risk factors in long term psychiatric inpatients: a naturalistic interventional study. BMC Psychiatry. 2018;18(1):255.

42. Stiekema APM, Looijmans A, van der Meer L, Bruggeman R, Schoevers RA, Corpeleijn E, Jorg F. Effects of a lifestyle intervention on psychosocial well-being of severe mentally ill residential patients: ELIPS, a cluster randomized controlled pragmatic trial. Schizophr Res. 2018.

43. Ashoorian D, Davidson R, Rock D, Dragovic M, Clifford R. A clinical communication tool for the assessment of psychotropic medication side effects. Psychiatry Res. 2015;230(2):643-657.

44. Velligan DI, Sajatovic M, Hatch A, Kramata P, Docherty JP. Why do psychiatric patients stop antipsychotic medication? A systematic review of reasons for nonadherence to medication in patients with serious mental illness. Patient preference and adherence. 2017;11:449-468.

45. Wykes T, Evans J, Paton C, Barnes TRE, Taylor D, Bentall R, Dalton B, Ruffell T, Rose D, Vitoratou S. What side effects are problematic for patients prescribed antipsychotic medication? The Maudsley Side Effects (MSE) measure for antipsychotic medication. Psychol Med. 2017;47(13):2369-2378.

46. Hui CL, Poon VW, Ko WT, Miao HY, Chang WC, Lee EH, Chan SK, Lin J, Chen EY. Risk factors for antipsychotic medication non-adherence behaviors and attitudes in adult-onset psychosis. Schizophr Res. 2016;174(13):144-149.

47. Højlund M, Elliott AF, Madsen NJ, Viuff AG, Munk-Jørgensen P, Hjorth P. Changes in antipsychotics and other psychotropic drugs during a 30-month lifestyle intervention among outpatients with schizophrenia. Nordic journal of psychiatry. 2017;71(8):598-604.

48. Long C, Rowell A, Rigg S, Livesey F, McAllister P. What is effective in promoting a healthy lifestyle in secure psychiatric settings? A review of the evidence for an integrated programme that targets modifiable health risk behaviours. The Journal of Forensic Practice. 2016;18(3):204-215.

49. Vancampfort D, Rosenbaum S, Schuch F, Ward PB, Richards J, Mugisha J, Probst M, Stubbs B. Cardiorespiratory fitness in severe mental illness: A systematic review and meta-analysis. Sports Med. 2017;47(2):343352.

50. Vancampfort D, Stubbs B, Ward PB, Teasdale S, Rosenbaum S. Integrating physical activity as medicine in the care of people with severe mental illness. Aust N Z J Psychiatry. 2015;49(8):681-682.

51. Ward MC, White DT, Druss BG. A meta-review of lifestyle interventions for cardiovascular risk factors in the general medical population: lessons for individuals with serious mental illness. J Clin Psychiatry. 2015;76(4):e477-486.

52. Lederman O, Suetani S, Stanton R, Chapman J, Korman N, Rosenbaum S, Ward PB, Siskind D. Embedding exercise interventions as routine mental health care: implementation strategies in residential, inpatient and community settings. Australasian psychiatry : bulletin of Royal Australian and New Zealand College of Psychiatrists. 2017;25(5):451-455.

53. Hargreaves J, Lucock M, Rodriguez A. From inactivity to becoming physically active: The experiences of behaviour change in people with serious mental illness. Mental Health and Physical Activity. 2017;13:83-93.

54. Arbour-Nicitopoulos KP, Duncan MJ, Remington G, Cairney J, Faulkner GE. The Utility of the Health Action Process Approach Model for Predicting Physical Activity Intentions and Behavior in Schizophrenia. Front Psychiatry. 2017;8:135.

55. Fibbins H, Ward PB, Watkins A, Curtis J, Rosenbaum S. Improving the health of mental health staff through exercise interventions: a systematic review. J Ment Health. 2018;27(2):184-191.

56. Stanton R, Happell B, Reaburn P. Investigating the exercise-prescription practices of nurses working in inpatient mental health settings. Int J Ment Health Nurs. 2015;24(2):112-120. 
57. Bauer IE, Galvez JF, Hamilton JE, Balanza-Martinez V, Zunta-Soares GB, Soares JC, Meyer TD. Lifestyle interventions targeting dietary habits and exercise in bipolar disorder: A systematic review. J Psychiatr Res. 2016;74:1-7.

58. Gordon BR, McDowell CP, Lyons M, Herring MP. The Effects of Resistance Exercise Training on Anxiety: A Meta-Analysis and Meta-Regression Analysis of Randomized Controlled Trials. Sports Med. 2017;47(12):2521-2532.

59. Vancampfort D, Hallgren M, Firth J, Rosenbaum S, Schuch FB, Mugisha J, Probst M, Van Damme T, Carvalho AF, Stubbs B. Physical activity and suicidal ideation: A systematic review and meta-analysis. J Affect Disord. 2018;225:438-448.

60. Rosenbaum S, Vancampfort D, Steel Z, Newby J, Ward PB, Stubbs B. Physical activity in the treatment of Posttraumatic stress disorder: A systematic review and meta-analysis. Psychiatry Res. 2015;230(2):130-136.

61. Stubbs B, Rosenbaum S, Vancampfort D, Ward PB, Schuch FB. Exercise improves cardiorespiratory fitness in people with depression: A meta-analysis of randomized control trials. J Affect Disord. 2016;190:249-253.

62. Schuch FB, Vancampfort D, Firth J, Rosenbaum S, Ward PB, Silva ES, Hallgren M, Ponce De Leon A, Dunn AL, Deslandes AC et al. Physical Activity and Incident Depression: A Meta-Analysis of Prospective Cohort Studies. Am J Psychiatry. 2018;175(7):631-648.

63. Teasdale SB, Ward PB, Rosenbaum S, Watkins A, Curtis J, Kalucy M, Samaras K. A nutrition intervention is effective in improving dietary components linked to cardiometabolic risk in youth with first-episode psychosis. Br J Nutr. 2016;115(11):1987-1993.

64. Farholm A, Sorensen M, Halvari H. Motivational factors associated with physical activity and quality of life in people with severe mental illness. Scand J Caring Sci. 2017;31(4):914-921.

65. Happell B, Scott D, Nankivell J, Platania-Phung C. Screening physical health? Yes! But...: nurses' views on physical health screening in mental health care. J Clin Nurs. 2013;22(15-16):2286-2297.

66. Happell B, Scott D, Platania-Phung C, Nankivell J. Nurses' views on physical activity for people with serious mental illness. Mental Health and Physical Activity. 2012;5(1):4-12.

67. Koorts H, Eakin E, Estabrooks P, Timperio A, Salmon J, Bauman A. Implementation and scale up of population physical activity interventions for clinical and community settings: the PRACTIS guide. Int J Behav Nutr Phys Act. 2018;15(1):51.

68. Fie S, Norman IJ, While AE. The relationship between physicians' and nurses' personal physical activity habits and their health-promotion practice: A systematic review. Health Educ J. 2013;72(1):102-119.

69. Rosenbaum S, Tiedemann A, Stanton R, Parker A, Waterreus A, Curtis J, Ward PB. Implementing evidencebased physical activity interventions for people with mental illness: an Australian perspective. Australasian psychiatry : bulletin of Royal Australian and New Zealand College of Psychiatrists. 2016;24(1):49-54.

70. Way K, Kannis-Dymand L, Lastella M, Lovell GP. Mental health practitioners' reported barriers to prescription of exercise for mental health consumers. Mental Health and Physical Activity. 2018;14:52-60.

71. Hutchison SL, Terhorst L, Murtaugh S, Gross S, Kogan JN, Shaffer SL. Effectiveness of a Staff Promoted Wellness Program to Improve Health in Residents of a Mental Health Long-Term Care Facility. Issues Ment Health Nurs. 2016;37(4):257-264.

72. Twisk J, Bosman L, Hoekstra T, Rijnhart J, Welten M, Heymans M. Different ways to estimate treatment effects in randomised controlled trials. Contemporary Clinical Trials Communications. 2018;10:80-85.

73. Landau S, Emsley R, Dunn G. Beyond total treatment effects in randomised controlled trials: Baseline measurement of intermediate outcomes needed to reduce confounding in mediation investigations. Clin Trials. 2018;15(3):247-256.

74. Brown CH, Curran G, Palinkas LA, Aarons GA, Wells KB, Jones L, Collins LM, Duan N, Mittman BS, Wallace A et al. An Overview of Research and Evaluation Designs for Dissemination and Implementation. Annu Rev Public Health. 2017;38:1-22.

75. Kennedy-Martin T, Curtis S, Faries D, Robinson S, Johnston J. A literature review on the representativeness of randomized controlled trial samples and implications for the external validity of trial results. Trials. 2015;16:495. 
76. Vancampfort D, De Hert M, Stubbs B, Ward PB, Rosenbaum S, Soundy A, Probst M. Negative symptoms are associated with lower autonomous motivation towards physical activity in people with schizophrenia. Compr Psychiatry. 2015;56:128-132.

77. Harvey PD, Rosenthal JB. Cognitive and functional deficits in people with schizophrenia: Evidence for accelerated or exaggerated aging? Schizophr Res. 2018;196:14-21.

78. Soundy A, Roskell C, Stubbs B, Vancampfort D. Selection, use and psychometric properties of physical activity measures to assess individuals with severe mental illness: a narrative synthesis. Arch Psychiatr Nurs. 2014;28(2):135-151.

79. Firth J, Stubbs B, Vancampfort D, Schuch FB, Rosenbaum S, Ward PB, Firth JA, Sarris J, Yung AR. The Validity and Value of Self-reported Physical Activity and Accelerometry in People With Schizophrenia: A Population-Scale Study of the UK Biobank. Schizophr Bull. 2017.

80. De Hert M, Cohen D, Bobes J, Cetkovich-Bakmas M, Leucht S, Ndetei DM, Newcomer JW, Uwakwe R, Asai I, Möller $\mathrm{H}$ et al. Physical illness in patients with severe mental disorders. II. Barriers to care, monitoring and treatment guidelines, plus recommendations at the system and individual level. World Psychiatry. 2011;10.

81. Thornicroft G. Physical health disparities and mental illness: the scandal of premature mortality. Br J Psychiatry. 2011;199(6):441-442.

82. Bartels S, Brunette M, Aschbrenner K, Daumit G. Implementation of a system-wide health promotion intervention to reduce early mortality in high risk adults with serious mental illness and obesity. Implementation Science. 2015;10(1):A15.

83. Johnson M, Day M, Moholkar R, Gilluley P, Goyder E. Tackling obesity in mental health secure units: a mixed method synthesis of available evidence. BJPsych Open. 2018;4(4):294-301.

84. Kessler RC, Amminger GP, Aguilar-Gaxiola S, Alonso J, Lee S, Ustun TB. Age of onset of mental disorders: a review of recent literature. Current opinion in psychiatry. 2007;20(4):359-364.

85. Filipcic I, Simunovic Filipcic I, Ivezic E, Matic K, Tunjic Vukadinovic N, Vuk Pisk S, Bodor D, Bajic Z, Jakovljevic M, Sartorius N. Chronic physical illnesses in patients with schizophrenia spectrum disorders are independently associated with higher rates of psychiatric rehospitalization; a cross-sectional study in Croatia. Eur Psychiatry. 2017;43:73-80.

86. Rej S, Beaulieu S, Segal M, Low NC, Mucsi I, Holcroft C, Shulman K, Looper KJ. Lithium dosing and serum concentrations across the age spectrum: from early adulthood to the tenth decade of life. Drugs Aging. 2014;31(12):911-916.

87. de Mendonca Lima CA, Baumann P, Brawand-Amey M, Brogli C, Jacquet S, Cochard N, Powell-Golay K, Eap $\mathrm{CB}$. Effect of age and gender on citalopram and desmethylcitalopram steady-state plasma concentrations in adults and elderly depressed patients. Prog Neuropsychopharmacol Biol Psychiatry. 2005;29(6):952956.

88. Beyth RJ, Shorr RI. Principles of drug therapy in older patients: rational drug prescribing. Clin Geriatr Med. 2002;18(3):577-592.

89. Bernal JL, Cummins S, Gasparrini A. Interrupted time series regression for the evaluation of public health interventions: a tutorial. Int J Epidemiol. 2017;46(1):348-355.

90. Fretheim A, Soumerai SB, Zhang F, Oxman AD, Ross-Degnan D. Interrupted time-series analysis yielded an effect estimate concordant with the cluster-randomized controlled trial result. J Clin Epidemiol. 2013;66(8):883-887.

91. de Leon J, Diaz FJ. A meta-analysis of worldwide studies demonstrates an association between schizophrenia and tobacco smoking behaviors. Schizophr Res. 2005;76(2-3):135-157.

92. Lawn SJ. Systemic barriers to quitting smoking among institutionalised public mental health service populations: a comparison of two Australian sites. Int J Soc Psychiatry. 2004;50(3):204-215.

93. Sheals K, Tombor I, McNeill A, Shahab L. A mixed-method systematic review and meta-analysis of mental health professionals' attitudes toward smoking and smoking cessation among people with mental illnesses. Addiction. 2016;111(9):1536-1553. 
94. Michopoulos I, Rizos E, Gournellis R, Karvouni A, Kotsioumpa I, Douzenis A. Smoking reduction in psychiatric inpatients is feasible: results from a 12-month prospective study. Annals of General Psychiatry. 2015;14(1):4.

95. Peckham E, Brabyn S, Cook L, Tew G, Gilbody S. Smoking cessation in severe mental ill health: what works? an updated systematic review and meta-analysis. BMC Psychiatry. 2017;17(1):252.

96. Foy R, Sales A, Wensing M, Aarons GA, Flottorp S, Kent B, Michie S, O'Connor D, Rogers A, Sevdalis N et al. Implementation science: a reappraisal of our journal mission and scope. Implement Sci. 2015;10:51.

97. Braithwaite J, Churruca K, Long JC, Ellis LA, Herkes J. When complexity science meets implementation science: a theoretical and empirical analysis of systems change. BMC Med. 2018;16(1):63. 

Nederlandse samenvatting /

Dutch summary 



\section{Inleiding}

Mensen met een ernstige psychiatrische aandoening (EPA) hebben naast geestelijke gezondheidsproblemen ook een slechte lichamelijke gezondheid. Zij leven tot 20 jaar korter dan de algemene bevolking. Lichamelijke aandoeningen, vooral hart- en vaatziekten, zijn de belangrijkste oorzaak van deze kortere levensverwachting. Risicofactoren hiervoor, zoals overgewicht, hoge bloeddruk en verstoorde cholesterol- en suikerwaardes in het bloed, zijn geclusterd in het zogenoemde metabool syndroom (hoofdstuk 1). Het metabool syndroom komt bij mensen met EPA veel voor. Van de mensen in ons onderzoek had bijvoorbeeld 69\% het metabool syndroom; twee keer zoveel dan in de algemene bevolking. Dit wordt veroorzaakt door verschillende factoren die met elkaar interacteren waaronder genetische en biologische kwetsbaarheid, slechtere lichamelijke gezondheidszorg (bijv. onderdiagnostiek en -behandeling), (in)directe bijwerkingen van medicatie (bijv. gewichtstoename, bewegingsstoornissen, veranderende subjectieve voedingsbehoefte) en een ongezonde leefstijl met veel roken, weinig beweging en ongezonde eetgewoonten. Binnen deze factoren speelt een ongezonde leefstijl een grote rol in de slechtere gezondheid van mensen met EPA, maar heeft wellicht het grootste potentieel om hierin verbetering aan te brengen. De laatste jaren is er een toename in onderzoek naar interventies om de leefstijl - en daarmee de gezondheidstoestand - van mensen met EPA te verbeteren. Uit dit onderzoek blijkt dat beweeg- en dieet interventies zowel lichamelijke als geestelijke gezondheid kunnen verbeteren. Veel van deze onderzoeken hebben zich gericht op de ambulante zorg en er is nog weinig bekend over leefstijl(verandering) in de klinieken. Het bovengenoemd risico op voortijdig overlijden is echter groter bij mensen die langdurig opgenomen zijn in een kliniek. Hun gezondheid is hoogstwaarschijnlijk slechter dan dat van mensen in ambulante zorg, door negatieve relaties tussen ziekteduur en fysieke activiteit, lichamelijke gezondheid en kwaliteit van leven. Bovendien hebben de meeste onderzoeken de effecten gemeten op relatief korte termijn ( $\leq 6$ maanden) en is er weinig bekend over de effectiviteit van leefstijlinterventies op de langere termijn voor mensen met EPA. Daarnaast heeft voorgaand onderzoek zich vooral gericht op de werkzaamheid van bijvoorbeeld meer beweging op lichamelijke en geestelijke gezondheid, en niet zozeer op hoe dit geïmplementeerd en volgehouden kan worden in de dagelijkse praktijk. Dit draagt bij aan de kloof tussen onderzoek en de praktijk. Nu er steeds meer werkzame leefstijlinterventies komen in de geestelijke gezondheidszorg (ggz), is het belangrijk om onderzoek te doen naar belemmerende en bevorderende factoren bij het implementeren hiervan. Het gebrek aan kennis ten aanzien van (de implementatie van) verandering van leefstijl in de langdurige klinische zorg was dan ook de aanleiding voor het starten van dit proefschrift. Het proefschrift start met onderzoek naar sedentair gedrag (zitten/liggen zonder te slapen) en de mate van beweging bij mensen met EPA in de langdurige klinische zorg. Vervolgens worden de resultaten van het invoeren van een multidisciplinaire leefstijl-bevorderende behandelmethode beschreven, evenals, de 
factoren die van invloed zijn bij de implementatie hiervan in de dagelijkse behandeling, en wat we hieruit kunnen leren voor de zorg voor mensen met EPA.

\section{Sedentair gedrag en mate van beweging bij mensen met EPA}

In hoofdstuk 2 beschrijven we het zit- en beweeggedrag van langdurig opgenomen patienten met EPA. Hoewel sedentair gedrag (zitten/liggen zonder te slapen) een onafhankelijke risicofactor is voor hart- en vaatziekten, zijn er weinig betrouwbare gegevens over het zitgedrag in deze populatie. In deze eerste grootschalige studie, waarbij met beweegmeters het zit- en beweeggedrag objectief werd gemeten, lieten we zien dat patiënten ( $N=184$ ) gemiddeld $84 \%$ van de tijd dat zij wakker waren $(50 \mathrm{~min} / \mathrm{u}$ ) sedentair doorbrachten en weinig bewogen. Hun totale activiteit was significant lager dan bij een referentiegroep van medewerkers ( $N=54)$, die echter nog $76 \%$ van hun tijd sedentair doorbrachten. Van de patiënt- en ziektekenmerken bleek leeftijd de enige voorspeller voor de mate van beweging, waarbij een hogere leeftijd samenhing met minder beweging. Ook vonden we dat patiënten die meer bewogen een hogere kwaliteit van leven hadden (hoofdstuk 3), met name bij patiënten die licht intensief bewogen, ten opzichte van de patiënten die zeer sedentair waren. Dit geeft aan dat de belangrijkste winst wellicht ligt in het activeren van de groep patiënten die zeer sedentair is (van weinig naar iets meer komen). Opmerkelijk was de bevinding dat de mate waarin patiënten een positieve attitude hadden ten aanzien van beweging of zich in staat voelden om te gaan bewegen, geen verband hield met de objectief gemeten hoeveelheid beweging. Dit lijkt de ervaring in de praktijk te bevestigen, waarbij enkel attitude verhogen (bijv. het belang van gezonde leefstijl uitleggen en verbaal motiveren) en het faciliteren (bijv. hometrainer op de afdeling zetten) tot weinig gedragsverandering heeft geleid. De resultaten suggereren de behoefte aan een meer geïntegreerde en ondersteunende aanpak om patiënten met EPA in de context van langdurige zorg in beweging te krijgen.

\section{De MULTI-studie}

De MULTI-studie evalueert een multidisciplinaire leefstijl bevorderende behandeling voor opgenomen patiënten met EPA (MUltidisciplinary Lifestyle enhancing Treatment for Inpatients with severe mental illness). Een team van verpleegkundigen/begeleiders, psychiaters, teamleiders, activiteitenbegeleiders en een diëtist implementeerden MULTI met als doel de leefstijl te verbeteren. In deze aanpak, geïmplementeerd binnen de bestaande context van de zorg (inside the box) is specifieke aandacht voor het verminderen van ziten liggedrag, meer bewegen en het verbeteren van eetgewoonten. Hierin staat algehele activering centraal, met als basis een duidelijke dagstructuur: op tijd opstaan, zoveel mogelijk gezamenlijke maaltijden en een actief dagprogramma afgestemd op mogelijkheden 
en interesses van de patiënt. Het dagprogramma bestaat uit minder sedentair gedrag, meer beweging, aandacht voor voeding, psycho-educatie en vaardigheidstraining. De invulling van het programma is opgebouwd door het begeleidende team, dat zelf actief mee doet. Na anderhalf jaar zijn veranderingen in de gezondheid geobserveerd van zowel patiënten die MULTI volgden als patiënten die de gebruikelijke behandeling continueerden. Tevens zijn belemmerende en bevorderende factoren ten aanzien van de implementatie van MULTI in kaart gebracht.

We hebben kunnen aantonen dat patiënten die MULTI volgden na anderhalf jaar significant meer waren gaan bewegen en een afname hadden van gewicht, buikomvang en bloeddruk (bovendruk), vergeleken met de patiënten die de gebruikelijke behandeling kregen (hoofdstuk 4). Het feit dat de lichamelijke gezondheid bij de gebruikelijke behandeling in deze periode niet verbeterde of zelfs verslechterde, bevestigt de status quo ten aanzien van lichamelijke gezondheid bij patiënten met EPA. Dit vormt een duidelijk signaal voor de klinische praktijk dat er verandering nodig (en mogelijk) is om verbetering te bereiken. We vonden echter geen verandering in psychotische symptomen (hoofdstuk 4). Naast positieve veranderingen in lichamelijke gezondheid vonden we ook verbeteringen in psychosociaal functioneren en kwaliteit van leven, welke wellicht relevanter zijn voor de patiënten zelf (hoofdstuk 5). De analyse van medicatiegebruik liet tevens een significante afname zien van voorgeschreven dosis psychotrope medicatie vergeleken met de gebruikelijke behandeling (hoofdstuk 6). Dit geeft een eerste indicatie voor een mogelijk effect van leefstijlverbeteringen op medicatiegebruik bij patiënten met EPA. Om enige uitspraak te kunnen doen over de effectiviteit van de verschillende elementen waaruit MULTI bestaat, analyseerden we in hoeverre bovengenoemde effecten verklaard konden worden door enkel de toename van de hoeveelheid beweging. Dit was bij geen van de resultaten het geval (hoofdstukken 4-6), wat suggereert dat meerdere elementen van MULTI hebben bijgedragen aan de positieve veranderingen. Het onderzoek naar de implementatie van MULTI laat zien dat zowel patiënten als medewerkers behoefte hadden aan meer tijd en mogelijkheden om het dagprogramma toe te spitsen op iemands capaciteiten, doelen, wensen en interesses (hoofdstuk 7). Dit sluit aan bij de grootste belemmeringen die de behandelteams noemden in relatie tot factoren ten aanzien van de organisatie, zoals te weinig tijd, beperkte bezetting of te weinig ondersteuning vanuit het management. De implementatie werd bevorderd door een positieve houding van zowel medewerkers als patiënten ten aanzien van zo'n geïntegreerde aanpak, en hun eigen rol daarin.

\section{Discussie}

Naast het samenvatten van de resultaten, bediscussiëren we deze ook in hoofdstuk 9. De uitkomsten van het onderzoek in dit proefschrift zijn klinisch relevant en vernieuwend voor opgenomen patiënten met EPA en dragen bij aan de evidentie rondom de 
implementatie van leefstijlverandering in de dagelijkse behandeling van deze doelgroep. Met een objectieve beweegmeting kon een betrouwbaar en gedetailleerd beeld verkregen worden van (verandering in) het zitgedrag, de mate van beweging en relaties met relevante factoren. De MULTI-studie is het eerste onderzoek dat op de langere termijn positieve veranderingen laat zien in de gezondheidstoestand en het medicatiegebruik van mensen met EPA in de klinische zorg. Het laat vooral zien dat binnen de huidige kaders van de psychiatrie verbetering bereikt kan worden in de leefstijl en gezondheid van mensen met EPA. Samen met de bevinding dat de gevonden verbeteringen niet enkel verklaard worden door meer bewegen, geloven we dat de positieve verandering in belangrijke mate te danken is aan de integrale aanpak, ingevuld door het behandelend en begeleidend team. In deze multidisciplinaire samenwerking zijn het gebruik van meerdere activiteiten (bijv. aandacht voor voeding en psycho-educatie in aanvulling op meer beweging), toespitsen op interesses en mogelijkheden van de doelgroep en groepsbenadering met deelname van het team, belangrijke elementen. We veronderstellen dat deze aanpak heeft bijgedragen aan eigenaarschap en daarmee implementatie in de dagelijkse behandeling. Dit wordt gesteund door recente studies die pleiten voor het opnemen van deze elementen als essentiële factoren voor succesvolle leefstijlverandering in de psychiatrie.

\section{Methodologische overwegingen}

Het observationele design van de MULTI-studie heeft zowel positieve als negatieve consequenties. Aan de ene kant is dit design gevoeliger voor veranderingen in de dagelijkse praktijk vergeleken met het veel gebruikte gerandomiseerde gecontroleerde onderzoek (RCT), dat als gouden standaard gezien wordt voor effectonderzoek. In een RCT-design worden patiënten gerandomiseerd en de omstandigheden het liefst zo stabiel mogelijk gehouden, zodat het effect dat gemeten wordt zo zuiver mogelijk toegeschreven kan worden aan de interventie. In ons onderzoek zijn de resultaten ten aanzien van kwaliteit van leven (hoofdstuk 5) en medicatiegebruik (hoofdstuk 6) in de referentiegroep die de gebruikelijke behandeling kreeg echter mogelijk beïnvloed door respectievelijk de invoering van levensverhaal-boeken en de vervanging van de psychiater op deze afdelingen. Het is in een observationeel design tevens lastiger om specifiek het effect van afzonderlijke elementen van MULTI te meten. We hebben in de analyses zoveel mogelijk rekening gehouden met deze beperkingen, door bijvoorbeeld te corrigeren voor verschillen tussen de groepen (MULTI en gebruikelijke behandeling) en specifiek het aandeel van de toename in beweging te analyseren (mediatie). Het observationele design is tegelijkertijd een groot pluspunt van de MULTI-studie. Een RCT-design heeft als nadeel dat de onderzochte interventies niet altijd extrapoleerbaar zijn vanwege de selectiebias en de gecontroleerde omstandigheden die niet altijd overeenkomen met de dagelijkse praktijk. De uitkomsten van een observationeel onderzoek zijn beter generaliseerbaar. Door het observationele design weerspiegelt het de patiënten, medewerkers en middelen in de 
dagelijkse praktijk van de langdurige zorg, inclusief de uitdagingen. Daarmee sluit het onderzoek aan bij de behoefte aan meer onderzoek in de context van de dagelijkse behandeling.

\section{Suggesties voor vervolgstappen in praktijk en onderzoek}

Met een aanpak binnen de huidige kaders van de zorg voor mensen met EPA, suggereren de positieve uitkomsten dat een duurzame oplossing voor een gezondere leefstijl binnen handbereik is. Een belangrijke vervolgstap is om op basis van de uitkomsten van dit proefschrift de aanpak te verbeteren. De ontwikkeling en invulling van MULTI op teamniveau heeft bijgedragen aan eigenaarschap, betrokkenheid en samenwerking. Factoren vanuit de organisatie die verbeterd kunnen worden zijn het betrekken van alle lagen inclusief hoger management in aanvulling op het huidige team, het garanderen van noodzakelijke voorwaarden in de implementatie van MULTI zoals training en ondersteuning van zorgprofessionals en duurzame financiering, en het vormgeven en uitspreken van een eenduidige visie. Dit inside the box denken, zoals de titel van het proefschrift luidt, vereist samenwerking tussen alle disciplines die betrokken zijn bij de behandeling om specifieke aanpassingen in beweging en voeding te realiseren. Los van actief deelnemende teams en patiënten omvat dit ook samenwerking met ondersteunende diensten, zoals maaltijdverzorging en inkoop, faciliteiten voor het stimuleren van beweging, gezond eten en drinken, en persoonsvervoer op en rondom het terrein. De kracht van de aanpak is dat iedere discipline vanuit eigen expertise input kan geven, waarbij (para)medici, activiteitenbegeleiders en bovengenoemde disciplines de zorgprofessionals en patiënten op de afdeling kunnen ondersteunen. Door de input van patiënten mee te nemen in besluitvorming (bijv. het activiteitenaanbod bepalen), kan de interventie nog meer gepersonaliseerd worden, wat hun betrokkenheid en intrinsieke motivatie verder kan vergroten. Daarbij staat niet langer de vraag centraal of er aan een gezondere leefstijl gewerkt gaat worden, maar hoe. In het toewerken naar een eenduidige visie en gezamenlijke besluitvorming, is het ook aan te raden in gesprek te gaan over dagelijkse uitdagingen. Hoewel iedereen het erover eens zal zijn dat niemand herstelt van hele dagen grotendeels op bed liggen, is de invulling van 'goede zorg' niet altijd makkelijk te beantwoorden en te vertalen naar de dagelijkse behandeling. Ethische overwegingen, zoals de balans tussen de autonomie en keuzevrijheid van patiënten versus de ziekte-ernst en verantwoorde zorg, komen namelijk al snel aan bod bij leefstijlveranderingen. Een methode zoals het moreel beraad zou hierbij kunnen ondersteunen. Tot slot is het vanwege aanzienlijke voordelen voor de gezondheid aan te raden om ook 'stoppen met roken' interventies op te nemen in de MULTI-aanpak. Hiervoor zijn al diverse effectieve methoden beschikbaar.

Met betrekking tot vervolgonderzoek is de belangrijkste vraag na dit proefschrift of MULTI elders geïmplementeerd kan worden en of dit tot een vergelijkbare verbetering in gezondheid kan leiden. Een dergelijk onderzoek is belangrijk voor verdere opschaling van de aanpak binnen psychiatrische ziekenhuizen. In hoofdstuk 8 benadrukken we de 
noodzaak van het betrekken van implementatiewetenschap om beter inzicht te krijgen in het integreren van leefstijlinterventies in de behandeling van mensen met EPA. Hierbij is het van belang om niet alleen de opzet van de interventie zelf en het perspectief van patiënt of hulpverlener te betrekken, maar ook factoren ten aanzien van de omgeving en/of organisatie waarin een interventie geïmplementeerd wordt. Dit speelt een grote rol bij het dichten van de kloof tussen effectief bevonden interventies en duurzame implementatie en borging ervan in de dagelijkse praktijk. Daarnaast zijn er een aantal specifieke onderwerpen die relevant zijn voor de praktijk en verder onderzoek behoeven, zoals de relatie tussen leefstijlveranderingen en medicatiegebruik, de kosteneffectiviteit van leefstijlinterventies en de effectiviteit van leefstijlinterventies die zich richten op het gedrag van zorgprofessionals om de gezondheid van patiënten te verbeteren.

Al deze suggesties dragen bij aan de verbetering van verdere implementatie van geïntegreerde, leefstijl bevorderende interventies in de kliniek. In de tussentijd is er geen reden om verdere actie af te wachten. Binnen de kliniek is alles binnen handbereik om een positieve verandering in gang te zetten. Dit proefschrift laat zien dat het mogelijk is om de veronderstelde status quo bij mensen met EPA in de kliniek te veranderen en hun gezondheidstoestand te verbeteren, door op een andere manier te denken en te handelen binnen de huidige kaders. 
Valorisation 



\section{Relevance}

This chapter describes how the research in this thesis can be translated into societal and possibly economic value. By exploring, implementing, and evaluating the topic in the context of daily routine care, the findings become generalisable in terms of day-to-day inpatient mental healthcare, as described in the discussion (chapter 9). The relevance of changing the lifestyle of inpatients with severe mental illness (SMI) to improve their health status has already been extensively described in previous chapters. The health status of patients with SMI is characterized by a significantly reduced life expectancy (up to 20 years), primarily due to physical illness [1-5], in which an unhealthy lifestyle plays a substantial role [6-10]. The studied Multidisciplinary Lifestyle-enhancing Treatment for Inpatients with SMI (MULTI) proved its direct value in daily routine care. The finding that especially physical health outcomes did not improve in the "treatment as usual" group within a year and a half (chapter 4) reflects the status quo in inpatient facilities and demonstrates the need for change. In line with previous studies [11-13], this thesis demonstrates that the benefits of changing one's lifestyle go beyond physical health alone and can also improve such outcomes as psychosocial functioning and quality of life (chapter 5), which may be even more relevant to patients than mere physical health. The results of the implementation study (chapter 7) provide input for further improvement and implementation of MULTI; hence they contribute to its valorisation, both in the mental healthcare organisation itself (GGz Centraal, the Netherlands) and (inter)nationally.

Depending on the data sources and definition of patients with SMI, it is estimated that there are between 185,359 (2012 data) [14] and 221,360 (2016 data) [15] adults ( $\geq 18$ years old) with SMI in the Netherlands. Based on the latter, 48,060 (22\%) of them do not live on their own and stay in sheltered housing or inpatient facilities due to the severity of their illness [15]. Besides their poorer mental health, their risk of premature death is the highest of all patients with SMI [16] and their overall health status is likely worse than that of outpatients due to the negative associations between duration of illness and physical activity, physical health, and quality of life $[8,17-19]$. Although this $22 \%$ is a minority within SMI patients, they represent the majority (64\%) of all healthcare costs in this group in the Netherlands [15]. This is inherent to illness severity, for which we want to offer appropriate healthcare. However, this thesis shows that it is possible to improve the health of inpatients with SMI through lifestyle changes, thereby addressing the pessimism about the feasibility of achieving positive change in the health status of people with SMI $[20,21]$. The findings of the MULTI study suggest an overall effect in which not only improvements in physical health were shown, but also in psychosocial functioning, quality of life, and even first indications regarding a decrease in medication use. Structured support to improve one's lifestyle could play a significant role in improving the recovery of inpatients with SMI. In addition to a decrease in costs related to healthcare issues (e.g. for physical illness or medication use), this may result in a decrease in the need for care (e.g. lower intensity or even shorter stays) in inpatient mental healthcare. This would, of 
course, be relevant for the patients themselves, but could have an economic impact as well. Since SMI starts at an early age [22] and somatic comorbidities are associated with more frequent rehospitalisations [23], such an approach could provide lifelong improvements and might help to prevent some of the major health issues that are currently seen in patients with a long history of SMI. Therefore, an integrated lifestyle-enhancing treatment could have both societal and economic value in the longer term.

\section{More than inpatient facilities}

Since the challenge of addressing premature death and implementing and maintaining effective lifestyle interventions applies to the population of patients with SMI as a whole, the relevance of this thesis is not limited to inpatient facilities. Culture change, day-today structure, peer support, and the participation of healthcare professionals are also increasingly understood as essential elements in effective lifestyle interventions in outpatient settings [24-33]. With MULTI, including corresponding elements, we conjecture that this integrated, multi-component approach was key to our positive findings, as described in chapter 9. We expect that such elements are as crucial in outpatient as in inpatient settings and that the experiences and findings of designing and implementing MULTI can be used in outpatient settings as well. However, the specific implementation needs to be applied to the community setting (e.g. collaborating with dietitians, general practitioners, and exercise professionals outside the mental healthcare organization and supporting patients more remotely). For example, a recent study in outpatients with firstepisode psychosis - who often start to use antipsychotics - evaluated a lifestyle intervention that included several of the aforementioned elements. In this study, an intervention including both exercise and cooking classes, as well as peer support and participation of healthcare professionals, was shown to significantly prevent weight gain compared to treatment as usual $[34,35]$.

\section{Target groups}

The findings are first of all relevant for all healthcare professionals in mental healthcare working with people with SMI as well as for the patients themselves. The thesis stresses the need for collaboration between different disciplines and their individual role in such a multidisciplinary integrated approach and the importance to discuss challenges together to take further steps towards improving the health status of patients with SMI. As the organizational and environmental context was shown to be essential in the implementation and maintenance of such a treatment approach, the outcomes are relevant for managers and policymakers as well. 


\section{Activities and products}

The ultimate goal of this thesis is to benefit daily routine care. Therefore, we perform and create several activities and products to apply the findings to healthcare professionals (in training), to patients and their relatives, and to managers and policy makers, in an understandable way. Since the research was conducted directly in daily routine care, the dissemination was already started. As described in chapter 8, the primary challenge to benefit routine care is to translate the current (and future) evidence into practice. Thus, these activities and products aim to contribute to awareness, knowledge, and discussion of challenges in daily routine care, culture change, and eventually real impact in daily routine care.

\section{Presentations, workshops, and discussion groups}

Table 1 summarises the meetings where the research for this thesis was and will be presented (already accepted or invited). The presentations, workshops, and discussion groups at congresses and symposia aim to share and discuss the findings with fellow researchers and healthcare professionals, patients, their relatives, and managers and policymakers, both nationally and internationally. The symposium of GGz Centraal (Thinking Inside the Box) was organised to share the final outcomes of this thesis specifically, including talks by patients themselves, of which a summarizing video can be found at www.ggzcentraal.nl/leefstijlonderzoek. Currently, we are planning to organise a congress focused on the implementation of a healthier lifestyle in routine mental healthcare for the beginning of 2020. Apart from congresses and symposia, meetings mainly focused on discussing the application of the findings in other mental healthcare organisations and sharing information with patients and their relatives (e.g. Ypsilon Psysalon meetings devoted to this topic). Furthermore, the topic and specific findings of this thesis were shared and discussed in multiple multidisciplinary teams, with patients and peer support workers, in both inpatient and outpatient facilities, within the organisation where this research was conducted (GGz Centraal). Just as in the meetings with other mental healthcare organisations, suggestions were discussed on how these teams could start changing the patients' lifestyle within those facilities to improve their health status. Such presentations, workshops, and discussion groups will continue in the coming years. 
Table 1. Meetings at which (preliminary) findings of this thesis were presented and discussed with healthcare professionals, patients, their relatives, researchers, managers, policy makers, and students

\begin{tabular}{|c|c|c|c|}
\hline Context & Where & Year & Regarding \\
\hline \multicolumn{4}{|l|}{ Congresses/symposia } \\
\hline Meander Medical Centre & Amersfoort, NL & 2014 & Chapters 1-3† \\
\hline Resilience+ & Amersfoort, NL & 2014 & Chapter $2+$ \\
\hline Dutch Association for Psychiatry (NVvP) & Maastricht, NL & 2015 & Chapters $1-3+\neq *$ \\
\hline GGz Centraal - Lifestyle & Amersfoort, NL & 2015 & Chapters $1-3 \ddagger$ \\
\hline $\begin{array}{l}\text { School for Mental Health and Neuroscience, } \\
\text { Maastricht University }\end{array}$ & Maastricht, NL & 2015 & Chapter $3^{+}$ \\
\hline GGz Centraal - Psychotic Disorders & Amersfoort, NL & 2015 & Chapters $1-3 \ddagger$ \\
\hline $\begin{array}{l}\text { German Association for Psychiatry and } \\
\text { Psychotherapy (DGPPN) }\end{array}$ & Berlin, DE & 2015 & Chapter $2 \ddagger$ \\
\hline Dutch Association for Psychiatry (NVvP) & Maastricht, NL & 2016 & Chapter $4 \dagger \neq$ \\
\hline $\begin{array}{l}\text { Schizophrenia International Research Society } \\
\text { (SIRS) }\end{array}$ & Florence, IT & 2016 & Chapter $4^{\dagger}$ \\
\hline $\begin{array}{l}\text { Phrenos Centre of Expertise for Severe Mental } \\
\text { Illness }\end{array}$ & Zwolle, NL & 2016 & Chapters $4-5^{+*}$ \\
\hline Meander Medical Centre & Amersfoort, NL & 2017 & Chapters 4-6‡ \\
\hline Dutch Association for Psychiatry (NVvP) & Maastricht, NL & 2017 & Chapters 4-7†‡ \\
\hline GGz Centraal - 'Thinking Inside the Box' & Amersfoort, NL & 2017 & Chapters 1-7‡§ \\
\hline GGz Centraal - Severe Mental Illness & Amersfoort, NL & 2017 & Chapters 4-7 $\ddagger^{*}$ \\
\hline European Health Psychology Society (EHPS) & Padua, IT & 2017 & Chapters 4, 5, 7†‡ \\
\hline $\begin{array}{l}\text { European Scientific Association on Schizophrenia } \\
\text { and Other Psychoses (ESAS) }\end{array}$ & Berlin, DE & 2017 & Chapters $4-5+\ddagger$ \\
\hline $\begin{array}{l}\text { European Network for Mental Health Service } \\
\text { Evaluation (ENMESH) }\end{array}$ & Groningen, NL & 2017 & Chapters 4, 5, 7†‡ \\
\hline $\begin{array}{l}\text { Phrenos Centre of Expertise for Severe Mental } \\
\text { Illness }\end{array}$ & Zwolle, NL & 2017 & Chapters 4-6‡ \\
\hline $\begin{array}{l}\text { School for Mental Health and Neuroscience, } \\
\text { Maastricht University }\end{array}$ & Maastricht, NL & 2017 & Chapters $4-5+$ \\
\hline World Psychiatry Association & Melbourne, AUS & 2018 & Chapters 4-6†‡ \\
\hline Dutch Association for Psychiatry (NVvP) & Maastricht, NL & 2018 & Chapters 6-7† \\
\hline $\begin{array}{l}\text { Schizophrenia International Research Society } \\
\text { (SIRS) }\end{array}$ & Florence, IT & 2018 & Chapters $4-5+$ \\
\hline $\begin{array}{l}\text { Altrecht, Parnassia Group, Inholland, and } \\
\text { University Medical Centre Utrecht - Physical } \\
\text { Health \& Lifestyle in Mental Healthcare }\end{array}$ & Ede, NL & 2018 & $\begin{array}{l}\text { Lifestyle interventions in } \\
\text { mental healthcare (incl. } \\
\text { chapters 1-9) } \ddagger\end{array}$ \\
\hline $\begin{array}{l}\text { Phrenos Centre of Expertise for Severe Mental } \\
\text { Illness }\end{array}$ & Zwolle, NL & 2018 & Chapters $1-9 \ddagger * *$ \\
\hline Society of Behavioral Medicine (SBM) & Washington, US & 2019 & Chapters 7-8 $\ddagger$ \\
\hline Dutch Association for Psychiatry (NVvP) & Maastricht, NL & 2019 & Chapters 1-9†‡ \\
\hline \multicolumn{4}{|c|}{ Other meetings for mental healthcare organisations, patients and their relatives } \\
\hline GGZ Eindhoven & Eindhoven, $\mathrm{NL}$ & 2016 & Chapters $1-4 \ddagger$ \\
\hline Lister & Utrecht, NL & 2017 & Chapters $1-5 \ddagger$ \\
\hline Ypsilon Psysalon & Harderwijk, NL & 2017 & Chapters 1-5 \\
\hline
\end{tabular}




\begin{tabular}{|c|c|c|c|}
\hline Context & Where & Year & Regarding \\
\hline Centrum '45 & Oegstgeest, NL & 2017 & Chapters 1-5 $\ddagger$ \\
\hline Altrecht & Zeist, NL & 2018 & Chapters 1-7 $\ddagger$ \\
\hline $\begin{array}{l}\text { South Eastern Sydney Local Health District / } \\
\text { University of New South Wales }\end{array}$ & Sydney, AUS & 2018 & Chapters $1-7 \ddagger$ \\
\hline Ypsilon Psysalon & Lelystad, NL & 2018 & Chapters 1-7 \\
\hline GGZ Friesland & Leeuwarden, NL & 2018 & Chapters 1-7 \\
\hline Lentis & Zuidlaren, NL & 2018 & Chapters 1-8 $\ddagger$ \\
\hline Lister & Utrecht, NL & 2018 & Chapters 1-8 $\ddagger$ \\
\hline $\begin{array}{l}\text { Phrenos Centre of Expertise for Severe Mental } \\
\text { Illness, GGNet, Parnassia Group, Lister }\end{array}$ & Utrecht, NL & 2018 & $\begin{array}{l}\text { Physical health in mental } \\
\text { healthcare (incl. chapter 1-9) }\end{array}$ \\
\hline \multicolumn{4}{|l|}{ Lectures at universities } \\
\hline University of Twente - Health Psychology & Enschede, NL & 2015 & Chapters $1-3 \ddagger$ \\
\hline University of Twente - Health Psychology & Enschede, NL & 2016 & Chapters $1-4 \ddagger$ \\
\hline $\begin{array}{l}\text { VU Amsterdam - Human Movement Sciences / } \\
\text { Psychomotor Therapy }\end{array}$ & Amsterdam, NL & 2017 & $\begin{array}{l}\text { Psychomotor therapy in } \\
\text { psychotic disorders (incl. } \\
\text { chapters } 1-6) \ddagger\end{array}$ \\
\hline $\begin{array}{l}\text { VU Amsterdam - EpidM / Epidemiology and } \\
\text { Biostatistics }\end{array}$ & Amsterdam & 2017 & Chapters 1-4 $\ddagger$ \\
\hline $\begin{array}{l}\text { University of Applied Sciences Utrecht - Nursing } \\
\text { Mental health course three times a year }\end{array}$ & Amersfoort, NL & 2017 & $\begin{array}{l}\text { Lifestyle in mental healthcare } \\
\text { (incl. chapters } 1-7) \ddagger\end{array}$ \\
\hline University of Padua - Biomedical Sciences & Padua, IT & 2018 & $\begin{array}{l}\text { Physical activity research \& } \\
\text { evaluation in mental } \\
\text { healthcare (incl. chapter 8) }\end{array}$ \\
\hline $\begin{array}{l}\text { VU Amsterdam - Human Movement Sciences / } \\
\text { Psychomotor Therapy }\end{array}$ & Amsterdam, NL & 2018 & $\begin{array}{l}\text { Psychomotor therapy in } \\
\text { psychotic disorders (incl. } \\
\text { chapters } 1-6) \ddagger\end{array}$ \\
\hline $\begin{array}{l}\text { University of Applied Sciences Utrecht - Nursing } \\
\text { Mental health course three times a year }\end{array}$ & Amersfoort, NL & 2018 & $\begin{array}{l}\text { Lifestyle in mental healthcare } \\
\text { (incl. chapters 1-7) } \neq\end{array}$ \\
\hline
\end{tabular}

† Poster; ‡ presentation/workshop/discussion group; § own initiative; *(poster) award; **young talent lecture.

\section{Education}

As can be seen in Table 1, the content of this thesis has been part of lectures for students as well, at various universities. For some courses (e.g. Human Movement Sciences / Psychomotor Therapy and the Nursing course on mental health) these lectures have become part of the annual curriculum. In the coming years, we aim to strengthen and expand collaborations with several universities. Also, the content of this thesis was included in the chapter on psychotic disorders of a new psychomotor therapy handbook, of which the author of this thesis is listed as a co-author (see Table 2). All of this will contribute to the knowledge and skills of future mental healthcare professionals to implement attention to patients' lifestyle into daily routine care. In addition, we aim to develop an educational program for current mental healthcare professionals to improve knowledge about the benefits of lifestyle changes in mental healthcare and to discuss and address challenges in the implementation of such changes in daily routine care. 
Furthermore, the results of this thesis (specifically, questions for future research as discussed in the discussion sections) serve as input for various bachelor's and master's theses (e.g. in pharmacology, clinical psychology, psychomotor therapy, sports science, and nurse practitioner). On average, three students a year were involved in different stages of their training on topics related to lifestyle at GGz Centraal in the last four years. Such collaborations are a considerable return on investment for mental healthcare organisations and can be implemented in many organisations in the Netherlands. We aim to maintain and hopefully expand this training in the coming years, which is supported by different universities (e.g. the master's program in Psychomotor Therapy at Windesheim University for Applied Science). This contributes to further understanding and improvement of changing lifestyle to improve the health status of patients with SMI and will likely lead to future PhD students on this topic.

Table 2. Non-scientific publications

\begin{tabular}{|c|c|c|c|}
\hline Title & Platform & Year & Regarding \\
\hline $\begin{array}{l}\text { Bewegen doet leven [Getting active } \\
\text { makes you feel alive) }\end{array}$ & $\begin{array}{l}\text { MEDEzeggenschaps } \\
\text { Magazine [Landelijk } \\
\text { Steunpunt } \\
\text { Medezeggenschap] }\end{array}$ & 2015 & $\begin{array}{l}\text { Chapters } 1-3 \text { and first experiences } \\
\text { with MULTI }\end{array}$ \\
\hline $\begin{array}{l}\text { Physical activity and quality of life in } \\
\text { inpatients with severe mental illness }\end{array}$ & YouTube & 2015 & $\begin{array}{l}\text { Chapters 1-3 [poster award video } \\
\text { for the Dutch Association for } \\
\text { Psychiatry (NVvP)] }\end{array}$ \\
\hline $\begin{array}{l}\text { GGz Centraal symposium 'Thinking } \\
\text { inside the box' }\end{array}$ & YouTube & 2017 & Chapters 1-7 \\
\hline $\begin{array}{l}\text { Beweegtuin voor mensen met een } \\
\text { ernstige psychiatrische aandoening } \\
\text { (Exercise garden for people with } \\
\text { severe mental illness) }\end{array}$ & Psychosenet Blog & 2018 & $\begin{array}{l}\text { Outdoor exercise facilities for } \\
\text { people with severe mental illness at } \\
\text { GGz Centraal (incl. chapters 1-5) }\end{array}$ \\
\hline $\begin{array}{l}\text { Improving health, step by step: } \\
\text { physical activity for severe mental } \\
\text { illness in the Netherlands }\end{array}$ & $\begin{array}{l}\text { British Journal of Sports } \\
\text { Medicine Blog }\end{array}$ & 2018 & $\begin{array}{l}\text { Outdoor exercise facilities for } \\
\text { people with severe mental illness at } \\
\text { GGz Centraal (incl. chapters 1-5) }\end{array}$ \\
\hline Een ware omslag! (A true change!) & Ypsilon Nieuws & 2018 & Chapters 1-7 \\
\hline $\begin{array}{l}\text { Chapter "Psychotic disorders" for } \\
\text { new handbook on psychomotor } \\
\text { therapy }\end{array}$ & Book chapter (co-author) & 2019 & $\begin{array}{l}\text { Psychomotor therapy for people } \\
\text { with psychotic disorders (incl. } \\
\text { chapters 1-7) }\end{array}$ \\
\hline Thinking inside the box & YouTube & 2019 & $\begin{array}{l}\text { Chapters 1-9 [animated video } \\
\text { summarizing this thesis] }\end{array}$ \\
\hline
\end{tabular}

\section{Non-scientific publications}

Apart from writing Dutch scientific overview articles to enhance the dissemination of knowledge more nationally, the findings and topic in general are disseminated in nonscientific publications as well. As can be seen in Table 2, some interviews and blogs in both Dutch and English have already been published. We are planning to write more after this thesis is published. Hence, we aim to disseminate the topic and findings further and discuss challenges in an understandable way for daily routine mental healthcare. 


\section{Visualisation and digital media}

To support its application to daily routine mental healthcare, we also translated the content of this thesis into digital media format. Two videos that were published on YouTube summarized chapters of this thesis, and we are planning to create an animation video about this thesis in 2019. Such videos are embedded on the webpage for the scientific research on lifestyle of GGz Centraal (www.ggzcentraal.nl/leefstijlonderzoek). We also created an infographic to summarize the findings, in both Dutch and English. The latter is published at the back of this thesis. The infographic is accompanied by several stickers in Dutch (see Figure 1) to stimulate people regarding essential elements of MULTI and lifestyle interventions in general, such as "getting active together with nurses" and "celebrating small successes." In the context of follow-up actions (described further in the "Follow-up Implementation" and "Policy" paragraphs) we also created a logo (see Figure 1). All this material was published in the form of posters, flyers, stickers, and a banner and were-and will be-handed out on wards and at meetings. The infographic and separate elements are used in all communication on this thesis and are-and will be-published digitally, for example on the GGz Centraal website (www.ggzcentraal.nl/leefstijl) and on social media. At these platforms, we publish all relevant information on the findings of this thesis and the topic in general. Especially social media (e.g. Linkedln and Twitter) offer an easy and quick way to disseminate and discuss findings and specific challenges in clinical practice with healthcare professionals, patients, and their relatives. For example, LinkedIn works very well to interact with healthcare professionals in the Netherlands, and we work with both Dutch and English Twitter accounts.

To share research findings specifically for researchers, we use ResearchGate, on which we aim to publish all relevant research information publicly, apart from making all scientific research papers open access. Moreover, in addition to hard copies, this thesis will be published as an app as well for use on smartphones and tablets, to enhance access and thereby the dissemination of findings. 


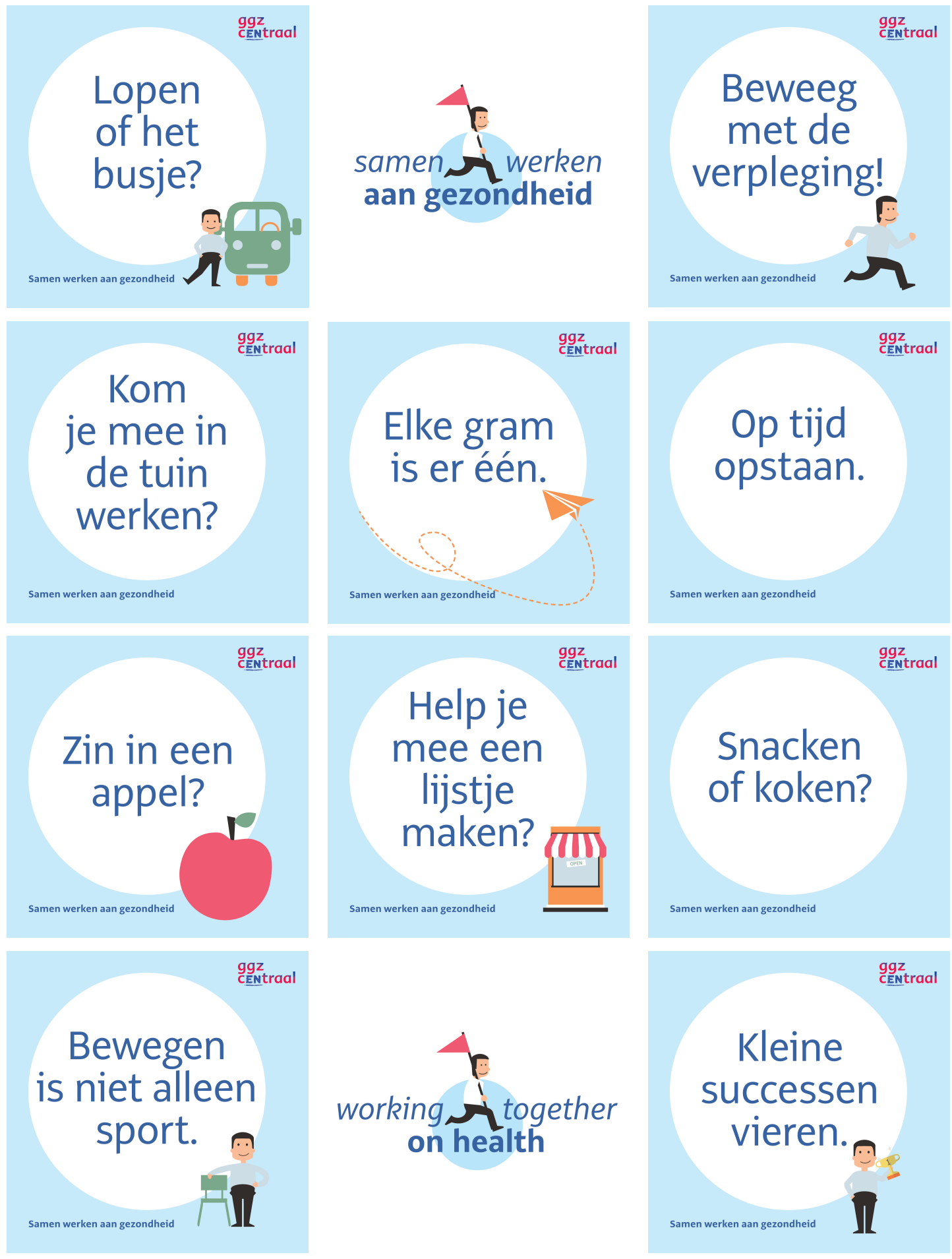

Fig. 1. Stickers and logo (in both Dutch and English) designed to support further dissemination and implementation of (knowledge on) lifestyle changes of people with severe mental illness in daily routine care. 


\section{Follow-up implementation}

Based on the findings of the current thesis and with the help of a grant from Stichting Zorgondersteuningsfonds, we were able to start a follow-up project on MULTI at another GGz Centraal location. This project aims to evaluate whether such an approach can be implemented and reproduced elsewhere, as suggested in chapter 7 . With this project, we will gain further knowledge on the effectiveness and scale-up of MULTI. Findings can help us to understand how this can be done and what is needed to further inform other inpatient facilities (inter)nationally.

\section{Policy}

The findings of this thesis can serve as management input as well, especially when it comes to the relevance of the topic of improving the lifestyle of people with SMI and what is needed to change current inpatient mental healthcare to improve their health status. For example, this thesis already gave input on the policy within the mental healthcare organization where the research was conducted. The findings of the research included in this thesis, the recommendations, and the related discussion were presented for the management team of GGz Centraal (13,467 people in healthcare and 2,654 employees). Together with previous attention and effort on this topic within the organization [36], this thesis substantially contributed to the decision of the management team to mark "somatic health promotion" as one of the three partial specialties in which the organization would like to take a national pioneering role in the coming years. As a result of this, the author of this thesis was invited to organise brainstorming sessions with stakeholders within the organisation to create an action plan. Hence, a delegation of managers, a patient council, a nursing council, allied health professionals, and peer support workers were involved. This plan, firstly focusing on all (partial) inpatient facilities and stimulating outpatient facilities simultaneously, has recently been accepted by the management team, with the first concrete actions to be taken in 2019. As part of this, the human resource department will review policies and start initiatives to foster a healthier lifestyle among the employees as well. In line with this, a meeting was organised involving the board, management team, patient council, family council, nursing council, and the works council to discuss smoking policies within the organisation, aiming to become a "smoking-free" hospital within the next few years.

More nationally, the findings and experiences of such policy actions are shared and discussed with managers and policymakers of other mental healthcare organisations as well, as mentioned above in the paragraph on presentations, workshops, and discussion groups. By doing this, we aim to disseminate knowledge further and enhance its translation into meaningful changes in routine mental healthcare. As mentioned in this thesis, collaboration on this topic is a core part of achieving this change. Therefore, in addition to previous meetings by managers and policymakers, we aim to strengthen the network of experts in the field in the Netherlands in the coming years. Part of this is leading a 
national network on physical health within mental healthcare for people with SMI, to which the author of this thesis was invited. It is part of an action platform called Herstel voor ledereen (Recovery for Everyone) initiated by the boards of mental healthcare organisations (so far) in the Netherlands, which aim to create and share specific action plans to improve the health status and recovery of people with SMI.

\section{(Inter)national collaboration in applied research}

In addition to a collaboration between mental healthcare organisations, we aim to collaborate with other universities as well to drive the field forward by sharing and creating new knowledge and translating the evidence of applied research into daily routine mental healthcare. In the Netherlands, we increasingly work together with other parties that conduct research on this topic, such as the University of Groningen, University Medical Centre Utrecht, VU Amsterdam, and Windesheim University for Applied Science [e.g. 32, 37-42]. The collaboration is carried out internationally, as well. For example, in 2018 the author of this thesis visited international colleagues in Australia (University of New South Wales / South Eastern Sydney Local Health District) and the United Kingdom (Kings College London), which formed the basis for international collaboration that is reflected in chapter 8.

These collaborations will be strengthened and expanded in the coming years, which will contribute to state-of-the-art knowledge on changing lifestyle in mental healthcare including the translation of evidence into practical input for day-to-day treatment.

\section{Innovation}

The primary aim of the activities and products described above is to contribute to awareness, knowledge, and discussion of challenges in daily routine care, culture change, and eventually real impact on daily routine care. Although there has been an increase in scientific evidence on the efficacy of lifestyle interventions in mental healthcare in the past decade, little has changed [43]. The implementation and maintenance of such interventions are challenging, as described in chapters 7 and 8 . This thesis contributes to the evidence on inpatient facilities, shows the benefits of a multidisciplinary integrated treatment approach for the long term for the first time in SMI inpatients, and provides leads on what works (and does not) in implementing this. The activities and products that are created and planned, aiming to disseminate knowledge of this thesis and the topic in general, are innovative in the way that they contribute to closing the current gap between the evidence and daily routine care. 


\section{Schedule and implementation}

The majority of activities to valorise this thesis and topic in general are already ongoing or planned, and we aim to continue and expand those activities as described. With an increased awareness of the topic in recent years, future presentations, workshops, discussion groups, education, and non-scientific publications will increasingly focus on the implementation of interventions in daily routine care, including related challenges. By the follow-up implementation and scale-up of this topic at GGz Centraal, we will gain more knowledge on this, which will contribute to scientific evidence on effectiveness and implementation and improvements in routine clinical practice (inter)nationally in the coming years. Together with the outcomes of the current thesis, this will most likely lead to opportunities for new PhD research on this topic. To drive this field forward, collaborations with other mental healthcare organisations and universities (inter)nationally offer opportunities, to scale up awareness, knowledge, implementation, and thereby change in routine clinical practice. We conjecture that the costs of this mainly include an investment in the process of changing the way we work within mental healthcare and that this most likely will result in saving costs in the longer term, as described in the second paragraph of this chapter. Inherent to this, the most significant risk is a lack of such a longterm vision, including organisational changes and budget cuts with a lack of priority for this topic. However, this risk seems to have become smaller, witness the rise of "lifestyle science" in healthcare in general and the greater awareness of this topic in mental healthcare as well (e.g. priority within mental healthcare organisations and a "somatic health" taskforce by the Dutch association of psychiatry). 


\section{References}

1. Correll CU, Solmi M, Veronese N, Bortolato B, Rosson S, Santonastaso P, Thapa-Chhetri N, Fornaro M, Gallicchio D, Collantoni E et al. Prevalence, incidence and mortality from cardiovascular disease in patients with pooled and specific severe mental illness: a large-scale meta-analysis of 3,211,768 patients and 113,383,368 controls. World Psychiatry. 2017;16(2):163-180.

2. Walker ER, McGee RE, Druss BG. Mortality in Mental Disorders and Global Disease Burden Implications A Systematic Review and Meta-analysis. Jama Psychiatry. 2015;72(4):334-341.

3. Piotrowski P, Gondek TM, Krolicka-Deregowska A, Misiak B, Adamowski T, Kiejna A. Causes of mortality in schizophrenia: An updated review of European studies. Psychiatr Danub. 2017;29(2):108-120.

4. Laursen TM, Wahlbeck K, Hallgren J, Westman J, Osby U, Alinaghizadeh H, Gissler M, Nordentoft M. Life expectancy and death by diseases of the circulatory system in patients with bipolar disorder or schizophrenia in the Nordic countries. PLoS One. 2013;8(6):e67133.

5. Tanskanen A, Tiihonen J, Taipale H. Mortality in schizophrenia: 30-year nationwide follow-up study. Acta Psychiatr Scand. 2018.

6. Stubbs B, Chen LJ, Chung MS, Ku PW. Physical activity ameliorates the association between sedentary behavior and cardiometabolic risk among inpatients with schizophrenia: A comparison versus controls using accelerometry. Compr Psychiatry. 2017;74:144-150.

7. Stubbs B, Williams JE, Gaughran F, Craig T. How sedentary are people with psychosis? A systematic review and meta-analysis. Schizophr Res. 2016;171(1-3):103-109.

8. Vancampfort D, Probst M, Scheewe T, De Herdt A, Sweers K, Knapen J, van Winkel R, De Hert M. Relationships between physical fitness, physical activity, smoking and metabolic and mental health parameters in people with schizophrenia. Psychiatry Res. 2013;207(1-2):25-32.

9. Teasdale SB, Samaras K, Wade T, Jarman R, Ward PB. A review of the nutritional challenges experienced by people living with severe mental illness: a role for dietitians in addressing physical health gaps. J Hum Nutr Diet. 2017;30(5):545-553.

10. Heald A, Pendlebury J, Anderson S, Narayan V, Guy M, Gibson M, Haddad P, Livingston M. Lifestyle factors and the metabolic syndrome in Schizophrenia: a cross-sectional study. Annals of General Psychiatry. 2017;16:12

11. Dauwan M, Begemann MJH, Heringa SM, Sommer IE. Exercise improves clinical symptoms, quality of life, global functioning, and depression in schizophrenia: A systematic review and meta-analysis. Schizophr Bull. 2016;42(3):588-599.

12. Firth J, Cotter J, Elliott R, French P, Yung AR. A systematic review and meta-analysis of exercise interventions in schizophrenia patients. Psychol Med. 2015;45(7):1343-1361.

13. Rosenbaum S, Tiedemann A, Sherrington C, Curtis J, Ward PB. Physical activity interventions for people with mental illness: a systematic review and meta-analysis. J Clin Psychiatry. 2014;75(9):964-974.

14. Delespaul PH. Consensus over de definitie van mensen met een ernstige psychische aandoening (EPA) en hun aantal in Nederland. Tijdschrift voor Psychiatrie. 2013;55(6):427-438.

15. Vektis. GGZ Plus - Monitor EPA GGZ: Cijfers EPA 2016. Zeist: Vektis; 2018.

16. John A, McGregor J, Jones I, Lee SC, Walters JTR, Owen MJ, O'Donovan M, DelPozo-Banos M, Berridge D, Lloyd K. Premature mortality among people with severe mental illness - New evidence from linked primary care data. Schizophr Res. 2018;199:154-162.

17. Mitchell AJ, Vancampfort D, Sweers K, van Winkel R, Yu W, De Hert M. Prevalence of metabolic syndrome and metabolic abnormalities in schizophrenia and related fisorders - A systematic review and meta-analysis. Schizophr Bull. 2013;39(2):306-318.

18. Vancampfort D, Firth J, Schuch FB, Rosenbaum S, Mugisha J, Hallgren M, Probst M, Ward PB, Gaughran F, De Hert $\mathrm{M}$ et al. Sedentary behavior and physical activity levels in people with schizophrenia, bipolar disorder and major depressive disorder: a global systematic review and meta-analysis. World Psychiatry. 2017;16(3):308-315. 
19. Vancampfort D, Guelinckx H, Probst M, Stubbs B, Rosenbaum S, Ward PB, De Hert M. Health-related quality of life and aerobic fitness in people with schizophrenia. Int J Ment Health Nurs. 2015;24(5):394-402.

20. Bartels SJ. Can behavioral health organizations change health behaviors? The STRIDE study and lifestyle interventions for obesity in serious mental illness. Am J Psychiatry. 2015;172(1):9-11.

21. De Hert M, Cohen D, Bobes J, Cetkovich-Bakmas M, Leucht S, Ndetei DM, Newcomer JW, Uwakwe R, Asai I, Möller $\mathrm{H}$ et al. Physical illness in patients with severe mental disorders. II. Barriers to care, monitoring and treatment guidelines, plus recommendations at the system and individual level. World Psychiatry. 2011;10.

22. Kessler RC, Amminger GP, Aguilar-Gaxiola S, Alonso J, Lee S, Ustun TB. Age of onset of mental disorders: a review of recent literature. Current opinion in psychiatry. 2007;20(4):359-364.

23. Filipcic I, Simunovic Filipcic I, Ivezic E, Matic K, Tunjic Vukadinovic N, Vuk Pisk S, Bodor D, Bajic Z, Jakovljevic M, Sartorius N. Chronic physical illnesses in patients with schizophrenia spectrum disorders are independently associated with higher rates of psychiatric rehospitalization; a cross-sectional study in Croatia. Eur Psychiatry. 2017;43:73-80.

24. Teasdale SB, Ward PB, Rosenbaum S, Samaras K, Stubbs B. Solving a weighty problem: systematic review and meta-analysis of nutrition interventions in severe mental illness. The British Journal of Psychiatry. 2017;210(2):110-118

25. Vancampfort D, Rosenbaum S, Schuch F, Ward PB, Richards J, Mugisha J, Probst M, Stubbs B. Cardiorespiratory fitness in severe mental illness: A systematic review and meta-analysis. Sports Med. 2017;47(2):343352.

26. Vancampfort D, Stubbs B, Ward PB, Teasdale S, Rosenbaum S. Integrating physical activity as medicine in the care of people with severe mental illness. Aust N Z J Psychiatry. 2015;49(8):681-682.

27. Lederman O, Suetani S, Stanton R, Chapman J, Korman N, Rosenbaum S, Ward PB, Siskind D. Embedding exercise interventions as routine mental health care: implementation strategies in residential, inpatient and community settings. Australasian psychiatry : bulletin of Royal Australian and New Zealand College of Psychiatrists. 2017;25(5):451-455.

28. Hargreaves J, Lucock M, Rodriguez A. From inactivity to becoming physically active: The experiences of behaviour change in people with serious mental illness. Mental Health and Physical Activity. 2017;13:8393.

29. Arbour-Nicitopoulos KP, Duncan MJ, Remington G, Cairney J, Faulkner GE. The Utility of the Health Action Process Approach Model for Predicting Physical Activity Intentions and Behavior in Schizophrenia. Front Psychiatry. 2017;8:135.

30. Fibbins H, Ward PB, Watkins A, Curtis J, Rosenbaum S. Improving the health of mental health staff through exercise interventions: a systematic review. J Ment Health. 2018;27(2):184-191.

31. Vancampfort D, Stubbs B, Ward PB, Teasdale S, Rosenbaum S. Why moving more should be promoted for severe mental illness. The lancet Psychiatry. 2015;2(4):295.

32. Looijmans A: Lifestyle interventions in patients with a severe mental illness: Addressing self-management and living environment to improve health. Groningen: University of Groningen; 2018.

33. Speyer H, Christian Brix Norgaard H, Birk M, Karlsen M, Storch Jakobsen A, Pedersen K, Hjorthoj C, Pisinger C, Gluud C, Mors O et al. The CHANGE trial: no superiority of lifestyle coaching plus care coordination plus treatment as usual compared to treatment as usual alone in reducing risk of cardiovascular disease in adults with schizophrenia spectrum disorders and abdominal obesity. World Psychiatry. 2016;15(2):155165.

34. Curtis J, Watkins A, Rosenbaum S, Teasdale S, Kalucy M, Samaras K, Ward PB. Evaluating an individualized lifestyle and life skills intervention to prevent antipsychotic-induced weight gain in first-episode psychosis. Early intervention in psychiatry. 2016;10(3):267-276.

35. Curtis J, Watkins A, Teasdale S, Lederman O, Kalucy M, Lappin J, Samaras K, Rosenbaum S, Ward PB. 2year follow-up: Still keeping the body in mind. Aust N Z J Psychiatry. 2018;52(6):602-603.

36. Tenback DE, Van Kessel F, Jessurun J, Pijl YJ, Heerdink ER, Van Harten PN. Risk factors for inactivity in patients in long-term care with severe mental illness. Tijdschrift voor Psychiatrie. 2013;55(2):83-91. 
37. Looijmans A, Stiekema A, Bruggeman R, van der Meer L, Stolk RP, Schoevers RA, Jörg F, Corpeleijn E. Changing the obesogenic environment to improve cardiometabolic health in residential patients with a severe mental IIIness: ELIPS, a randomized controlled trial. Br J Psychiatry. 2017;211(5):296-303.

38. Scheewe TW, Backx FJG, Takken T, Jörg F, van Strater ACP, Kroes AG, Kahn RS, Cahn W. Exercise therapy improves mental and physical health in schizophrenia: A randomised controlled trial. Acta Psychiatr Scand. 2012.

39. Stiekema APM, Looijmans A, van der Meer L, Bruggeman R, Schoevers RA, Corpeleijn E, Jorg F. Effects of a lifestyle intervention on psychosocial well-being of severe mentally ill residential patients: ELIPS, a cluster randomized controlled pragmatic trial. Schizophr Res. 2018.

40. Van Meijel B, Van Hamersveld S, Van Gool R, Van Der Bijl J, Van Harten P. Effects and feasibility of the "traffic light method for somatic screening and lifestyle" in patients with severe mental illness: A pilot study. Perspect Psychiatr Care. 2014.

41. van Peursum M, van Gool R, van Hamersveld S, Meijburg R, van Peperstraten $H$, Oolders $H$, van Meijel B. Leefstijlinterventies in de GGz: Een zorg voor verpleegkundigen. Nurse Academy GGz. 2013;4:22-26.

42. van der Stouwe ECD, van Busschbach JT, de Vries B, Cahn W, Aleman A, Pijnenborg GHM. Neural correlates of exercise training in individuals with schizophrenia and in healthy individuals: A systematic review. Neurolmage Clinical. 2018;19:287-301.

43. Stewart R. Mental disorders and mortality: so many publications, so little change. Acta Psychiatr Scand. 2015;132(5):410-411. 
Dankwoord / Acknowledgements 
Lukraak mailtjes sturen naar ggz-instellingen met de vraag naar de mogelijkheden om voor mijn masterthese-onderzoek een bijdrage te leveren op het gebied van sport/bewegen in de psychiatrie; daar begon het mee. Dat er zes jaar later een proefschrift zou liggen had ik nooit gedacht. Ik werd uitgenodigd bij GGz Centraal voor een oriënterend gesprek bij Diederik Tenback. Hij zette het praktijkprobleem met alle uitdagingen, verwoede pogingen tot verandering en het gebrek aan onderzoek uiteen en ik was vrijwel direct geïnteresseerd. Zoals ik later nog vaker ervoer aan de andere kant van de tafel, kon je bij Diederik na een 'oriënterend gesprek' de kamer uit lopen met een stageplek op zak als beide partijen direct positief waren. Deze pragmatische werkwijze heb ik altijd fijn gevonden en ik ben ervan overtuigd dat dit sterk heeft bijgedragen aan alle positieve ontwikkelingen op de afdelingen die zouden volgen.

Diederik, jouw passie en drive om de zorg voor deze verwaarloosde groep mensen te verbeteren, hier meer onderzoek naar te doen en je kennis en aanpak hierin, heeft voor mij vanaf het begin heel aanstekelijk en inspirerend gewerkt. Dat heeft er mede voor gezorgd dat de ambitie om van zoveel mogelijk mensen voor het eerst objectief de hoeveelheid beweging te meten al snel een vlucht nam en resulteerde in een afstudeertraject van een jaar in plaats van zes maanden. Vanaf dat moment ben jij wellicht de eerste geweest die dit promotietraject had voorzien. Ik heb veel van je geleerd en heb onder andere veel (plezier) gehad aan de momenten waarop we even goed konden sparren over aanpak en analyse. De balans tussen goed onderzoek en haalbaarheid en toepasbaarheid in de dagelijkse praktijk vormde daarin altijd de uitdaging. Je hebt me altijd gestimuleerd om groter te durven denken, wat sterk heeft bijgedragen aan dit promotietraject en alle verdere stappen die inmiddels genomen zijn.

Bij die eerste meting begon ook de samenwerking met Ingrid Hendriksen en Erwin Tak, die vanuit TNO al ervaring hadden met objectieve beweegmetingen en -interventies. Ingrid, jouw kritische blik heeft vanaf het eerste moment ongelooflijk geholpen om de kwaliteit van het onderzoek te verbeteren. Ik weet nog goed hoe we bij de eerste meting aan het puzzelen waren wat de juiste draagwijze, instellingen en drempelwaarden zouden zijn voor de ActiGraph-meting. Dit was voor deze doelgroep zeer vernieuwend en het is altijd de kunst geweest om te midden van de onvermijdelijke methodologische haken en ogen de beste keuzes te maken. Ook in jouw feedback op alle stukken kon ik er altijd zeker van zijn dat je geen detail over het hoofd zag, wat sterk heeft bijgedragen aan de kwaliteit van mijn schrijven en daarmee alles wat in dit boekje staat (hoewel lange zinnen zoals deze hardnekkig uit mijn vingers blijven komen).

Erwin, met al jouw meedenken en feedback op dit proefschrift ben je van 'adviseur' eigenlijk een schaduw-copromotor geworden. Vanaf de start van mijn masterthese heb je meegedacht in de opzet van het onderzoek en de toepasbaarheid van de resultaten. Je invalshoek vanuit de psychologie en ervaring en kennis ten aanzien van (het onderzoeken van) implementatie zijn van grote waarde geweest en hebben verfrissend gewerkt. Dit geldt voor alle studies die we gedaan hebben, maar in het bijzonder de opzet van het onderzoek naar de implementatie van MULTI en de analyse en interpretatie van 
deze data. Dit is daarmee ook van grote waarde geweest voor het vervolg van MULTI op andere locaties.

Gedurende mijn masterthese heb ik nooit de ambitie gehad om te promoveren. Toen bleek dat je ook kon promoveren in de dagelijkse behandelpraktijk, was ik echter om: het was dé manier om dit onderzoek voort te zetten. Vele subsidieaanvragen en afwijzingen verder kwam eind april 2015 het verlossende woord van Stichting tot Steun VCVGZ. Mijn dank hiervoor is groot: zonder jullie financiële steun had dit nooit kunnen starten.

Vanaf dat moment werden Diederik en Ingrid mijn copromotoren en Peter van Harten mijn promotor. Peter, je hebt de plannen voor dit promotietraject vanaf het begin gesteund en je hebt je er vlak na de start hard voor gemaakt dat ik de masteropleiding epidemiologie mocht gaan volgen. Daar ben ik je erg dankbaar voor. Dit heeft sterk bijgedragen aan mijn eigen ontwikkeling en daarmee de kwaliteit van vrijwel iedere analyse in dit proefschrift. Ook jouw passie voor de langdurige zorg en vergeten uitdagingen hierin hebben aanstekelijk gewerkt. Je overstijgende denken en kritische blik hebben me scherp gehouden en hebben de stukken beter gemaakt. Na verschillende veranderingen in de organisatie is onze samenwerking intensiever geworden. Ik heb altijd veel plezier beleefd aan de supervisiegesprekken, waar het bespreken van promotie-gerelateerde zaken soms zelfs in de knel kwam door uitstapjes naar vrije gedachten over nieuwe gadgets en innovaties. Ik heb ook bewondering voor hoe je met je visie en kritische maar steunende en verbindende houding de onderzoeksafdeling hebt opgebouwd en mensen daarin sterker maakt. Dat jij het als een vanzelfsprekendheid bracht dat ik het coördinatorschap van de onderzoekslijn van Diederik zou overnemen, was voor mij een groot compliment.

Ik ben jullie als 'promotiegroep' erg dankbaar. Gedurende de afgelopen jaren is er veel veranderd en we hebben wel eens gegrapt dat ik aan het einde van dit traject de enige zou zijn die nog op dezelfde plek zou zitten. De beweegredenen en keuzes van jullie in deze veranderingen reflecteren mijns inziens kenmerken van jullie waar ik veel aan heb gehad: vooruitstrevend, pragmatisch maar kritisch, bevlogen, opbouwend, oog voor het grotere plaatje, wetenschappelijke kennis praktisch toepassen en niet bang om andere wegen dan die van de minste weerstand in te slaan om dat te bereiken. Het heeft mij erg geholpen en verrijkt om zulke mensen om mij heen te hebben gedurende dit traject.

Dit proefschrift was ook niet mogelijk geweest zonder de hulp van vele anderen. Allereerst alle patiënten die hebben meegewerkt. Vanaf het begin leer en geniet ik er steeds weer van om met jullie samen te werken. Los van jullie inhoudelijke bijdrage heeft jullie feedback ten aanzien van de metingen het onderzoek ook kunnen verbeteren. Daarbij natuurlijk alle teamleiders, behandelaren, begeleiders en verpleegkundigen die zich de afgelopen jaren hebben ingezet om de metingen mede mogelijk te maken en hierin hebben meegedacht. Ik ben me er altijd bewust van geweest dat dit het nodige van jullie vroeg naast de reguliere werkzaamheden (met name de beweegmeters werden beroemd en berucht). Het is mij overduidelijk geworden hoe jullie met ziel en zaligheid werken aan de beste zorg voor de mensen, met de middelen die jullie hebben. Ik heb met veel plezier 
samengewerkt en jullie bijdrage in het onderzoek is van grote waarde geweest voor de toepasbaarheid op de afdelingen. De samenwerking met de poli bijwerkingen (o.a. Els, Ada, John en Rien) en stagiairs (Imtiaaz, Andrea, Nina, Frouwke, Renée, Carlijn en Nathalie) is bij het doen van de metingen onmisbaar geweest. Ik ben jullie erg dankbaar.

Alle coauteurs wil ik ontzettend bedanken in het meedenken en -schrijven om het onderzoek zo goed mogelijk op papier te krijgen: Frank Kruisdijk, Aartjan Beekman, Marijke Hopman-Rock, Annemarie Braakman-Jansen, Erik Taal, Femke Rutters, Harold van Driel, Olivier Blanson Henkemans en Simon Rosenbaum. Jullie hebben hier veel tijd in gestoken en zonder jullie waren het niet zulke mooie stukken geworden. De invalshoeken vanuit jullie verschillende expertises en ervaring hebben mij veel geleerd en hebben de stukken verscherpt en verbeterd. Frank, naast het meeschrijven was jouw steun tijdens de eerste beweegmeting helpend: het was zomervakantie en veel collega's waren op vakantie. Toen halverwege veel patiënten bleken te gaan verhuizen en de strakke planning in de soep dreigde te lopen, wist je me gerust te stellen dat zulke dingen gebeuren in de ggz en dat het allemaal wel goed zou komen. Harold, jouw bijdrage in dit proefschrift ligt grotendeels buiten je co-auteurschap. Samen met Bram en Arno ben je van onschatbare waarde geweest met het bij elkaar krijgen, het samen uitpluizen en in orde krijgen van data uit de systemen. Wetenschappelijk onderzoek doen in een setting die daar niet primair voor ingericht is blijft een uitdaging. Ten aanzien van de data-analyse wil ik ook de docenten van EpidM bedanken, die tijdens de cursussen van de master epidemiologie altijd bereid waren mee te denken met mijn analysen. In het bijzonder Jos Twisk, die ik ook nog na het behalen van de master gerust mocht mailen voor een complexe vraag, waar dan altijd een nuchter en helpend antwoord op kwam. Chantal, Marc en Stef, als medestudenten en collega-promovendi in de master heb ik ook veel gehad aan het onderling sparren, lachen of ons hart luchten over analysen en (frustrerende) studie- en promotie-gerelateerde zaken.

Also, I would like to acknowledge Simon Rosenbaum, Philip Ward, Davy Vancampfort, Joseph Firth, Brendon Stubbs and Felipe Schuch. Isaac Newton once said: "If I have seen further it is by standing on the shoulders of giants". This may sound like a grandiose metaphor to you. However, you are without a doubt among the leading researchers who have built the great evidence base we currently have on physical activity / lifestyle interventions in mental healthcare, on which new PhD candidates can build on (and look further). At least, this is applicable to me, as I have learned a lot from the work you have done and it has significantly contributed to this thesis. Therefore, I am grateful for having the chance to work with you since the last year of my PhD. I would also like to acknowledge Louise Czosnek, Scott Teasdale and Oscar Lederman. As co-PhD candidates, I learned a lot from your work and your expertise. The open and collaborative attitude of you all is reflected in the fact that this thesis includes a chapter to which you contributed, less than a year after we met. I would like to thank Simon and Phil in particular, as this all started with a visit to Sydney where you showed me around. The programme you arranged for 
me and your hospitality during that week - and a week later at the WPA Congress in Melbourne - ensured that I learned a lot and had a memorable experience.

Het zijn echter niet alleen de mensen die inhoudelijk hebben bijgedragen aan het proefschrift die er veel tijd in hebben zitten. Graag bedank ik ook Philippe Delespaul, Stef Kremers, Maarten Bak, Wiepke Cahn en Lieuwe de Haan, die als beoordelingscommissie de tijd hebben genomen om al het geschreven werk kritisch te lezen en te beoordelen.

Daarnaast hebben ook andere collega's onmisbare steun en inspiratie gegeven. Allereerst Yvonne, Hildegard, Karolien, Anne, Anouk, Elisa, Elise en Jonathan: jullie zijn de drijvende kracht (geweest) achter allerlei 'regelzaken'. Rondom en gedurende onderzoeksstage, werkervaringscontract, subsidieverstrekkers en promotietraject heb ik altijd op jullie kunnen rekenen als ik ergens niet uit kwam. Ook Charlie, Thierry, Mushde, Anne en Anne als mede-promovendi: hoewel we veel zelfstandig aan onze projecten werk(t)en heb ik er altijd plezier aan gehad om samen te presenteren op congressen en te sparren over alles wat bij promoveren komt kijken. Barbara, Henny en Yvette, het samenwerken met jullie in de wetenschappelijke onderzoekscommissie geeft ook inspiratie. Ik heb veel respect voor alle mooie projecten die jullie neerzetten binnen de organisatie. Kwalitatief goed wetenschappelijk onderzoek doen binnen een ggz-instelling kent uitdagingen en is niet vanzelfsprekend, maar is erg waardevol voor de dagelijkse praktijk. Ik ben dan ook blij om met jullie allemaal te mogen werken. In deze context wil ik ook graag de raad van bestuur van GGz Centraal van de afgelopen jaren bedanken (Thea Heeren, Albert van Esterik en Arjan Theil) voor jullie steun voor (de voortzetting van) het leefstijlonderzoek.

In het kader van dit vervolgtraject ben ik ook veel dank verschuldigd aan twee andere mensen. Frank (Zaadnoordijk) en Katinka, jullie zijn bijgesprongen om de organisatie van het vervolgproject te ondersteunen toen door veranderingen binnen GGz Centraal dit project in de knel kwam en de werkdruk enorm toenam. Daarmee hebben jullie mij geweldig geholpen om dit proefschrift goed af te kunnen ronden en daar ben ik jullie eeuwig dankbaar voor.

Met deze afronding in zicht had ik ook voor ogen om de resultaten van het onderzoek zo begrijpelijk mogelijk terug te koppelen aan alle betrokkenen en geïnteresseerden. Klaske, Ans, Angelique, Eva, Arjan, Hanneke, Ingrid, Larissa en Annemiek: heel erg bedankt voor jullie meedenken en ondersteuning bij deze vertaling naar teksten, website, infographic en andere media en materialen. Wat is het mooi geworden!

Juist doordat al het onderzoek in dit proefschrift zich jarenlang heeft afgespeeld in de dagelijkse praktijk, is het onmogelijk om iedereen te noemen. In aanvulling op de al genoemde mensen wil ik daarom alle andere collega's binnen en buiten GGz Centraal (begeleiders, managers, (para)medici, behandelaren, mede-promovendi en -onderzoekers, cliëntenraden, etc.) bedanken die meer of minder betrokken en al dan niet bewust tot inspiratie zijn geweest. 
Verder prijs ik mij gelukkig met een hoop mooie en lieve mensen om mij heen, want hoewel dat met name later in een promotietraject soms niet zo lijkt, bestaat het leven uit meer dan alleen onderzoek/werk. Ten eerste, jongens, wil ik jullie bedanken. Jullie betrokkenheid en het soms al dan niet bewust doorbreken van mijn drukte heeft geholpen het werk soms even los te laten en te ontspannen. Dat we elkaar zo lang en goed kennen, ondanks dat we hele andere richtingen in gegaan zijn, vind ik veel waard.

Lieve (schoon)familie: dank voor jullie steun en interesse, al moet het soms hebben geleken alsof het leven uit niets anders bestond dan subsidies, deadlines, schrijven, analyseren en presenteren. In het bijzonder pap en mam; zonder jullie onvoorwaardelijke steun - al bijna 30 jaar - had dit niet zo goed kunnen lukken. Wouter en Bram, ik vind dat we een mooie drie-eenheid zijn en dat dat jullie mijn paranimfen (willen) zijn, zegt genoeg.

Tot slot diegene voor wie mijn dank het moeilijkst te beschrijven is. Lieverd, hoe lang we al in alles op elkaar kunnen vertrouwen, des te meer beloftes heb ik in mijn gedrevenheid afgelopen jaren gebroken. In een vrij weekend (de momenten dat het meer dan drie dagen waren zijn schaars), vrije dag, avond of vrij uur, liep 'nog even dit' of 'nog even dat' doen vrijwel altijd uit op het verdampen van tenminste een groot deel van die vrije tijd. Het is een geruststellende gedachte dat dit op een gegeven moment enkel mezelf nog tegen viel; jij wist al hoe laat het was. Je hebt me altijd gesteund en de ruimte gegeven, zonder het te laten me scherp te houden als dat nodig was. Met je liefde en steun heb je een onmisbaar aandeel in mijn leven en dus ook in dit proefschrift. Ik hoop te mogen te genieten van nog vele jaren met jou. 


\section{Curriculum vitae}

Jeroen Deenik was born on February 14, 1990, in Eindhoven, the Netherlands. He obtained his bachelor's degree in Psychomotor Therapy in 2011 at the Hogeschool van Arnhem en Nijmegen in Nijmegen. Via a premaster's program in psychology, he studied Health Psychology at the University of Twente in Enschede. He fulfilled his master's thesis at GGz Centraal, a mental healthcare organisation in the middle of the Netherlands. In the research for this degree, he measured levels of sedentary behaviour and physical activity at long-stay


wards for people with severe mental illness and explored associations with related psychological factors. In 2014, he graduated with his master's degree in Health Psychology.

Intrigued by the subject and motivated to achieve change, Jeroen decided to stay at GGz Centraal for further research on physical activity and lifestyle in the inpatient facilities. In a work experience placement, he wrote grant applications and prepared for the continuation of his research. After obtaining funding from Stichting tot Steun VGVGZ in May 2015, he got the chance to do so and joined the Psychiatry and Neuropsychology department of the Faculty of Health, Medicine and Life Sciences at Maastricht University as an external PhD candidate. As such, he was employed at GGz Centraal under the supervision of Prof. dr. Peter van Harten. Following his previous work studying how to activate people with severe mental illness, he evaluated a multidisciplinary lifestyle enhancing treatment for patients with severe mental illness (MULTI). During his PhD, he studied Epidemiology at the Vrije Universiteit in Amsterdam and finished this master in 2017. In the same year, he started further research towards the integrated multidisciplinary lifestyle enhancing treatment in patients living in the hospital and sheltered housing facilities within another region of GGz Centraal with the support of Stichting Zorgondersteuningsfonds. Since 2018, Jeroen has been employed as a researcher and coordinator of the "psychotic disorders" research line at GGz Centraal. In addition, since September 2018, he has been employed as a lecturer as well at the Master of Psychomotor Therapy at Hogeschool Windesheim in Zwolle, where he supervises students during their theses. Jeroen is also a guest teacher in different courses on the healthcare professions, teaching students about physical activity and lifestyle in mental healthcare. He expects to finish his PhD in spring of 2019. 


\section{$C$}

Toen ik de verhalen van deze afdelingen hoorde dacht ik dat het vast allemaal hele goede patiënten waren, maar toen ik er kwam werken zag ik dat het precies dezelfde doelgroep was als waar ik eerder mee werkte, en dat verandering dus écht mogelijk was!

EEN BEHANDELAAR

))

\section{C6}

Waar we eerder naar zochten, en wat we toen nog niet konden vinden, was een antwoord op hoe we het aan moesten pakken; wat we moesten doen. En wat volgens mij het gouden recept is gebleken, is samen doen.

EEN PSYCHIATER

3)

\section{C6}

In het begin was het erg afzien, maar na een maand of twee maanden begon het allemaal wel wat beter te gaan, en kon ik goed meedoen met de anderen.

EEN PATIËNT

$$
\text { )) }
$$

C6

Voorheen lag ik de hele dag in bed. Elke dag heb ik eigenlijk geen zin om zo vroeg op te staan, maar na afloop ben ik toch blij dat ik het heb gedaan.

EEN PATIËNT

\section{)}

\section{C6}

Het is belangrijk om naast het strakke programma ook aandacht te hebben voor hoe mensen daar zelf dingen in willen en kunnen.

39

EEN BEGELEIDER/VERPLEEGKUNDIGE

Ik had beloofd om mee te gaan lopen en had mijn sportschoenen al mee, maar het regende en het was vies weer; misschien een volgende keer. Maar ze kwamen naar mijn kamer, spraken me erop aan ("kom op, wij gaan ook allemaal!") en namen me mee. 


\section{CC}

Ja ik ben gewoon veel gelukkiger geworden - en nu

nog een beetje meer van m'n buikie af!

$3)$

EEN PATIËNT

\section{6}

Verpleging begeleidt mee, sport mee, doet eigenlijk alles mee. En ik weet de discussie nog: ja maar als er iemand achter blijft op de afdeling moet er ook verpleging achterblijven op de afdeling. En toen werd er gezegd: ja maar er blijft niemand achter op de afdeling. Je gaat het gewoon samen doen.

EEN PSYCHIATER

\section{))}

\section{C6}

Op de leefstijl ben ik van 150 naar $90 \mathrm{~kg}$ gegaan. Na de leefstijl ben ik verhuisd naar beschermd wonen. Ik heb geprobeerd vanuit daar te fitnessen, maar dat was lastig. Ik mis de nazorg en een vervolg. Al kom je maar $1 x$ in de week met mensen bij elkaar om te bewegen, dat kan al helpen.

EEN PATIËNT

\section{))}

\section{CC}

Na samen te sporten gaat het tijdens de lunch niet over 'ohja, ze zat langs de kant...' of 'ik voel me knap psychotisch en ik moet daar wat aan doen...', nee: 'tof hè, we hebben gewonnen!'. Je hebt het over de dingen die je samen gedaan hebt.

\section{))}

EEN BEGELEIDER/VERPLEEGKUNDIGE

\section{CS}

Ik ben nu 15 jaar werkzaam binnen de organisatie, maar sinds we hier mee bezig zijn heb ik echt het gevoel dat ik doe waarvoor ik opgeleid ben.

\section{C}

Ik vind de leefstijlgroep een verademing voor de maatschappij eigenlijk. 


\section{Working together on health}

\section{the patient}

people with severe mental illness in

long-term

mental healthcare
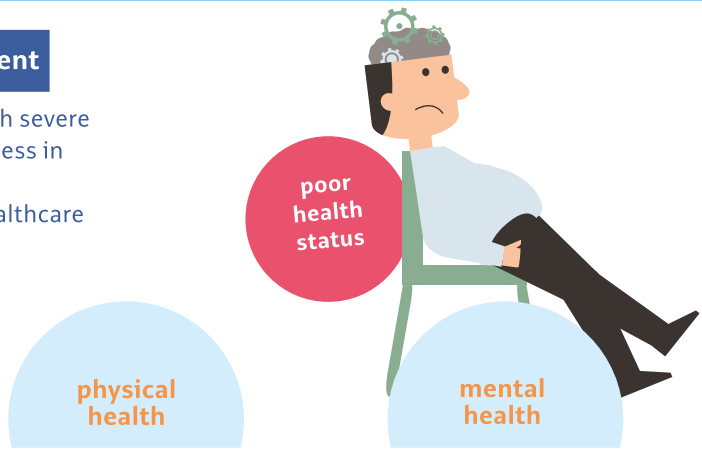

$\mathrm{kg}$ physical health status is alarming

$\dagger$ up to 20 years shorter life expectancy

Iack of physical activity

W. cardiovascular disease

A diabetes

psychosocial functioning

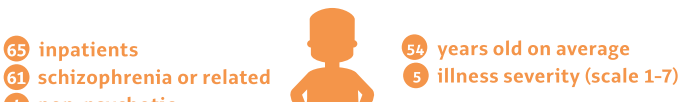

\section{the team}

psychiatrist team leader activity coordinators mental health nurses 4 non-psychotic dietitians
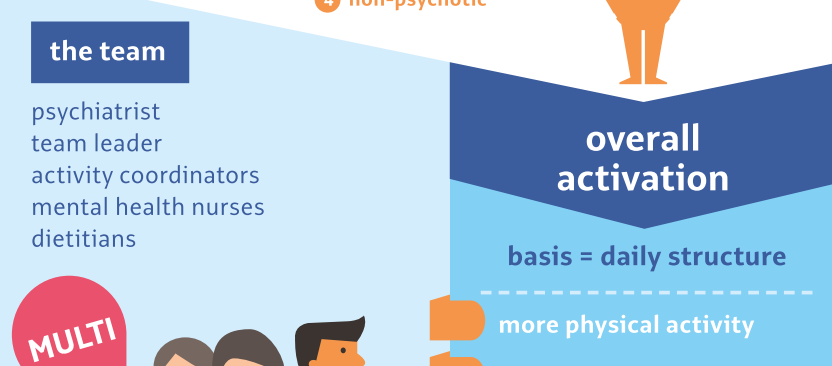

basis = daily structure

more physical activity

work-related activities

psychoeducation

attention to dietary habits

skills training

participation of the team

physical



improvements - less use of medication mental

- more satisfied with

physical health

- feeling better

- better prospects

\section{increase in quality of life}

sustainable behavioural change

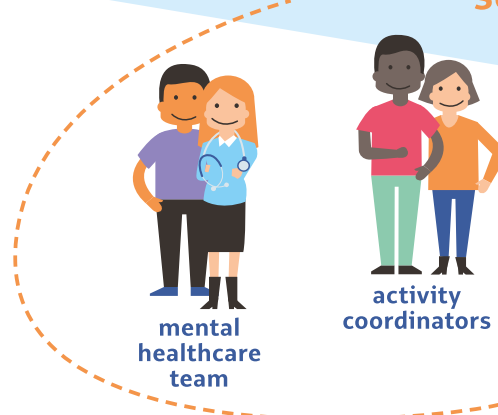

ก
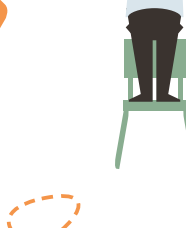

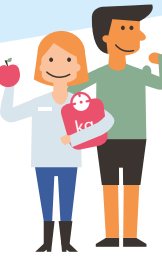

allied health professionals getting up on time

joint meals

active day program

functioning

- more energy

- social support

- contact

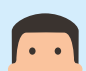

tailored 